Neuronal correlates of repetitive whisker stimulation in the Neuregulin 1 mouse model of schizophrenia 
Copyright: Claudia Barz, Aachen, 2014

Cover design: Claudia Barz

Production: Publishing house of the Research Centre Jülich

ISBN: 978-3-00-046275-7 


\title{
Neuronal correlates of repetitive whisker stimulation in the Neuregulin 1 mouse model of schizophrenia
}

\author{
Dissertation \\ to obtain the degree of Doctor at Maastricht University, \\ on the authority of the Rector Magnificus, Prof.dr. L.L.G Soete \\ in accordance with the decision of the Board of Deans, \\ to be defended in public \\ on Monday, 30 June 2014, at 12.00 hours
}

by

Claudia Susanne Barz 


\section{Supervisors:}

Prof. Dr. Dirk Feldmeyer, Institute of Neuroscience and Medicine, INM-2, Research Centre Jülich, and Dept of Psychiatry, Psychotherapy and Psychosomatics, RWTH Aachen University

Prof. Dr. Peter De Weerd, Dept of Cognitive Neuroscience, Maastricht University

\section{Assessment Committee:}

Prof. Dr. Bernadette Jansma, dean of the Faculty of Psychology and Neuroscience, Maastricht University (chair)

Prof. Dr. Rainer Goebel, Dept of Cognitive Neuroscience, Maastricht University

Prof. Dr. Ute Habel, Dept of Psychiatry, Psychotherapy and Psychosomatics, RWTH Aachen University

Dr. Florent Haiss, associate professor, Interdisciplinary Center for Clinical Research, RWTH Aachen University

Dr. Jos Prickaerts, associate professor, Dept of Psychiatry and Neuropychology, Maastricht University

Dr. Mark Roberts, associate professor, Dept of Biophysics, Nijmegen University, and Dept of Cognitive Neuroscience, Maastricht University

The research has been conducted in collaboration with Ted Abel (Dept of Biology, University of Pennsylvania, Philadelphia), Diego Contreras (Dept of Neuroscience, University of Pennsylvania, Philadelphia) and Thomas Bessaih (CNRS, Université Pierre et Marie Curie, Paris). The work has been supported by the IRTG 1328 Schizophrenia and Autism of the German Research Foundation (Deutsche Forschungsgemeinschaft, DFG; C. Barz), the Barrel Cortex Function (BaCoFun) research group of the DFG (D. Feldmeyer), the Helmholtz association (D. Feldmeyer), NIH grants MH064045 (T. Abel) and P50-MH096891 (T. Abel and R. Gur, PI), and NWO VICl grant 453-04-002 (P. De Weerd). 
To my mother 



\section{Contents}

Preface The study of the healthy and the schizophrenic brain - A historic perspective

1. Introductory remarks

2. The view of the brain from Antiquity to the Middle Ages

3. The Scientific Revolution and the discovery of animal electricity

4. The neuron doctrine of the 19th century

5. The 20th century: Understanding synaptic transmission and brain waves

6. Brain anatomy and function in the 20th century

7. Modern definitions of psychiatric diseases: The concept of schizophrenia

8. The 1950s until today: Psychopharmacology and molecular genetics

9. Perspectives on advancing schizophrenia research REFERENCES

1. Study rationale: Unraveling the cellular basis of schizophrenia 23

2. Defining schizophrenia: Overview of cognitive and sensory dysfunctions 24

3. Neuronal underpinnings of cognitive and sensory abnormalities 26

3.1 Neuronal mechanisms of cognitive deficits 26

3.2 Neuronal mechanisms of sensory deficits in schizophrenia 29

3.2.1 Structural changes $\quad 29$

3.2.2 Functional changes $\quad 30$

3.2.3 Neurophysiological changes 31

3.2.3.1 Neurophysiological deficits in the auditory domain 32

3.2.3.2 Neurophysiological deficits in the visual domain 34

3.2.3.3 Neurophysiological deficits in the somatosensory domain $\quad 36$

3.2.4 Neurochemical changes $\quad 37$

$\begin{array}{ll}3.2 .5 \text { Neuropathological changes } & 38\end{array}$

4. The role of sensory dysfunctions in schizophrenia-related cognitive impairments $\quad 39$

4.1 Various effects of sensory processing deficits on cognitive functioning $\quad 39$

4.2 Mechanisms of disturbed interaction between low-level and high-level brain areas 40

5. Mouse models offer a tool to study the cellular basis of schizophreniarelated dysfunctions

$5.1 N R G 1$ as a schizophrenia susceptibility gene $\quad 42$

5.2 NRG1 signaling $\quad 44$

5.3 NRG1 expression patterns $\quad 45$

5.4 Functional significance of NRG1 46

5.5 NRG1 mouse mutants 47

6. Somatosensation in mice as a model system for studying schizophrenia-
related sensory deficits

6.1 The whisker-to-barrel system $\quad 49$

6.2 Rodent whisking-related behavior and barrel cortex responses $\quad 50$

7. Study aim: Characterizing sensory responses in the NRG1 schizophrenia
model

REFERENCES

$\begin{array}{ll}\text { Chapter II Methods } & 72\end{array}$

1. Animals $\quad 72$

2. Preparation $\quad 72$ 
3. Electrophysiology 73

4. Stimulation

5. Analysis $\quad 75$

5.1 Firing rates and signal-to-noise ratio $\quad 76$

5.2 Adaptation of firing rates $\quad 77$

$\begin{array}{ll}5.3 \text { Response precision } & 77\end{array}$

$\begin{array}{ll}5.4 \text { Inclusion criteria } & 78\end{array}$

5.5 Local field potentials $\quad 78$

6. Histology $\quad 79$

$\begin{array}{ll}\text { REFERENCES } & 79\end{array}$

Chapter III Barrel cortex responses to frequency-modulated whisker stimulation in mice $\quad 80$

$\begin{array}{lr}\text { 1. Abstract } & 80\end{array}$

2. Introduction $\quad 80$

3. Methods $\quad 81$

4. Results $\quad 83$

4.1 Responses to low frequency $(1-15 \mathrm{~Hz})$ stimulation 83

4.1.1 Firing rate 83

4.1.2 Adaptation $\quad 83$

4.1.3 Temporal precision $\quad 87$

4.2 Responses to high-frequency $(10-70 \mathrm{~Hz})$ stimulation $\quad 89$

4.2.1 Firing rate $\quad 89$

$\begin{array}{ll}\text { 4.2.2 Temporal precision } & 91\end{array}$

4.2.3 Gamma oscillations $\quad 94$

5. Discussion $\quad 95$

5.1 Low-frequency band-pass effects in firing rate and precision 96

5.2 Temporal modulation of low-frequency band-pass effects 98

5.3 Precise firing and monotonically increasing rates at $20-70 \mathrm{~Hz} \quad 99$

5.4 Induced gamma oscillations during $70 \mathrm{~Hz}$ stimulation 99

$\begin{array}{lr}\text { REFERENCES } & 100\end{array}$

Chapter IV Altered resonance properties of somatosensory responses in the NRG1 mouse model of schizophrenia $\quad 103$

$\begin{array}{ll}\text { 1. Abstract } & 103\end{array}$

2. Introduction 103

3. Methods 105

4. Results 106

4.1 Aberrant firing rates during baseline and stimulation conditions in
NRG1 mice

4.2 NRG1 responses show abnormal adaptation and facilitation patterns $\quad 110$

4.3 Temporal fidelity of neuronal responses is reduced in NRG1 mutants 113

4.4 NRG1 mice show normal barrel cortex patterning 118

5. Discussion $\quad 119$

5.1 Whisking behavior and frequency tuning of barrel cortex responses $\quad 120$

5.2 Neuronal circuit abnormalities in schizophrenia and in the NRG1
mouse model

$\begin{array}{ll}\text { REFERENCES } & 126\end{array}$

Chapter V Neural deficits during somatosensory stimulation at gamma frequencies in NRG1-deficient mice 135

1. Abstract 135

2. Introduction $\quad 135$

3. Methods 137 
4. Results

4.1 Abnormal firing patterns during stimulation and baseline conditions in NRG1 mutants

4.2 Reduced signal-to-noise ratio and gain in NRG1 mutant mice 141

4.3 Temporal fidelity of neuronal firing 143

4.4 Reduced gamma oscillations in NRG1 mutants $\quad 147$

4.4.1 Induced gamma during high frequency $(50-70 \mathrm{~Hz})$ stimulation $\quad 147$

4.4.2 Steady-state gamma oscillations during $20-40 \mathrm{~Hz}$ stimulation 151

5. Discussion 152

5.1 Firing rates 152

5.2 Temporal precision of neuronal firing 153

5.3 Gamma oscillations 154

5.4 Relevance of findings in NRG1 mice to schizophrenia research in humans 155

5.5 Possible anesthesia effects 158

REFERENCES 159

$\begin{array}{ll}\text { Chapter VI Discussion and future directions } & 167\end{array}$

1. Microcircuit abnormalities and their effects on sensory processing in NRG1 $\begin{array}{ll}\text { mutant mice } & 167\end{array}$

1.1 Columnar connectivity in the barrel cortex 167

1.2 Putative NRG1-ErbB4 expression sites in the barrel column 168

1.3 Effects of defective synaptic signaling on the excitatory-inhibitory balance in NRG1 mutants 169

1.4 Possible contribution of synaptic dysfunctions at the thalamic level $\quad 170$

1.5 Consequences of altered excitatory-inhibitory signaling in NRG1 mutants, and relation with other schizophrenia models 170

1.5.1 Elevated baseline firing $\quad 170$

1.5.2 Increased neuronal responsiveness to sensory stimulation $\quad 172$

1.5.3 Reduced spiking signal-to-noise ratio and neuronal gain 173

1.5.4 Impaired phase locking of spikes $\quad 173$

1.5.5 Decreased stimulus-related gamma oscillations 174

1.5.6 Baseline gamma oscillations $\quad 176$

1.6 Stimulation frequency-dependent deficits in NRG1 mice $\quad 177$

1.7 Relevance to findings in schizophrenic patients 178

2. Future research directions 181

REFERENCES 182

$\begin{array}{ll}\text { Samenvatting } & 188\end{array}$

List of abbreviations $\quad 190$

$\begin{array}{ll}\text { Acknowledgements } & 192\end{array}$

$\begin{array}{ll}\text { Curriculum vitae } & 193\end{array}$ 



\section{Preface}

\section{The study of the healthy and the schizophrenic brain - A historic perspective}

\section{Introductory remarks}

The understanding of normal and abnormal brain processes is closely linked to the historical setting, in particular to the currently available techniques for investigation, as well as the culture and prevalent ideas. The definition of mental illness, specifically schizophrenia, has changed over time, and the understanding of brain structure and function has been advanced by methodological and technological inventions. This section provides an overview of the historical context in which various concepts and neuroscientific sub-disciplines developed that are relevant to the work presented in this thesis.

\section{The view of the brain from Antiquity to the Middle Ages}

The quest for understanding brain processes, in health as well as disease, has a long history and can be traced back at least to the philosopher-scientists of classical antiquity. Aristotle believed that the purpose of the brain was to cool the body, and that the heart was the center of emotion and cognition. This belief was widespread among ancient cultures, including the Egyptian, Mesopotamian, Babylonian and Indian. Among the pre-Socratic philosophers and scientists, Alcmaeon of Croton was the first to perform anatomical dissections and to identify the brain as the site of sensation and intelligence (Gross, 1995). The Greek physician Galen of Pergamon also believed in the brain as the seat of cognition, and suggested that sensation and movement were related to 'psychic pneuma' or 'animal spirits' passing through nerves (Glynn, 1999; Quin, 1994). When the circulation of the pneuma was obstructed in the brain, mental illness would ensue, Galen argued (Gross, 2009). Brain dissections and lesions, case studies and observations were viewed as important tools in understanding the healthy as well as the diseased brain, and most scientists around the middle of the fifth century rejected supposedly supernatural origins of diseases (Gross, 1995).

Galen's theory of the brain remained in place until the Middle Ages. The view of the brain was only extended by the localization of brain functions in the ventricles: Sensation in the anterior ventricle, cognition in the middle ventricle, and memory in the posterior ventricle (Gross, 2009). In medieval Europe, superstition and myth were widespread, and disorders of the mind were 
attributed to demons that had to be excorcized. Mental illness was thought to be cured by the surgical removal of the 'stone of folly' or 'stone of madness', as depicted in the painting by the Flemish artist Hieronymous Bosch during early Renaissance. The procedure whereby a piece of bone is removed from the skull is known as trephining and has been advocated for treating mental illness until the 18th century (Gross, 1999).

\section{The Scientific Revolution and the discovery of animal electricity}

Following the 'dark' Middle Ages, Europe underwent the Scientific Revolution and enlightenment. The 16th and 17th centuries were characterized by an unprecedented surge in scientific discoveries and advancements. With the publication of Andreas Vesalius' book "On the Fabric of the Human Body" in 1543, the foundation was laid for the systematic anatomical study of the human body (Gross, 2009). The results from detailed dissection experiments prompted an increasing number of scientists to question Galen's anatomical and functional description of the ventricular system (Finger, 2001). In 1664, the English physician Thomas Willis published "The Anatomy of the Brain", in which he identified new functional subdivisions of the brain (O'Connor, 2003). Willis assigned memory to the cerebral gyri, sensation and movement to the striatum, and the control of vital functions to the cerebellum (which was thought to include parts of the brainstem; Finger, 2001). Yet, in 1669, Nicolaus Steno concluded: "The brain, the masterpiece of creation, is almost unknown to us." What was missing were optical techniques to investigate the brain at a more detailed level. In following up on the work of Robert Hooke, Antonie van Leeuwenhoek made significant improvements to existing microscopes that allowed him to study cells and, for the first time in 1717, observe nerve fibers or 'axons' (Bentivoglio, 1996).

The notion that nerves conduct electricity was coined by Luigi Galvani in 1791 (Piccolino, 1998). Galvani observed that he could induce contractions in a frog muscle preparation by using external sources of electricity (like an electrostatic machine or atmospheric electricity) and, most surprisingly, by bringing the muscle in contact with a cut nerve end (Gross, 2009). The discovery of animal electricity inspired Alessandro Volta to build the first electric battery in 1799. Volta did not believe in animal electricity, arguing that it was in fact due to currents generated by two dissimilar metals (Piccolino, 2000). Galvani's nephew, Giovanni Aldini, used Volta's battery as a constant source of electricity to stimulate or reanimate animals and even recently deceased humans (Parent, 2004). The powers of electricity impressed scientists and physicians alike, and there was speculation that electrical nerve stimulation could be employed to treat mental illness, which was explained in terms of an electrical breakdown in the brain (Beaudreau and Finger, 2006; Finger, 2001; Finger and 
Zaromb, 2006). Taken together, these developments provided the foundation for modern electrotherapy, used to treat schizophrenia and other mental disorders.

\section{The neuron doctrine of the 19th century}

In the early 19th century, new histological methods for tissue fixation, embedding, cutting, and staining were developed that allowed researchers to gain an increasingly detailed understanding of the brain (Amos, 2000; Finger, 2001). Scientists discovered that all plants and organisms consisted of single cells, but it was unclear whether the same principle applied to the nervous system. Between 1836 and 1839, the first nerve cells were described by several anatomists: Christian Gottfried Ehrenberg, Gabriel Valentin, Jan Evangelista Purkinje and Theodor Schwann. By the middle of the 19th century, researchers also revealed that nervous cells possessed dendrites and axons (Finger, 2001), and that electrical currents generated in the axon produced a so-called 'action potential' (Schuetze, 1983). However, the relationship between axons and dendrites remained elusive, and there was an ongoing debate about the structure of the nervous system: Does it consist of individual units or do neighboring elements form a single reticulum? The decisive step towards solving this fundamental problem was Camillo Golgi's invention of the silver impregnation technique, with which a small fraction of nerve cells could be stained and thus their morphology clearly visualized. While Golgi thought what he observed was a single network of cells, Santiago Ramón y Cajal described nerve cells as individual entities that are not contiguous but separated from one another (Glickstein, 2006). With this groundbreaking discovery, Ramón y Cajal became the father of the neuron doctrine - the theory that the nervous system is composed of single cells, i.e. 'neurons'. In the 1890s, Ramón y Cajal extended his theory to suggest that signals are transmitted with a directionality across the neuron: Impulses are propagated from the dendrites and soma of the neuron, along the axon, and towards the axon terminals. Furthermore, he proposed that neurons integrate and transmit signals by contact, thus forming circuits and pathways. These contacts were coined 'synapses' by the English neurophysiologist Charles Sherrington. With Ramón y Cajal's neuron doctrine, the foundation was set for investigating neurological processes in the healthy and diseased brain (Felipe-Oroquieta, 2009; Shepherd, 2009).

\section{The 20th century: Understanding synaptic transmission and brain waves}

Around the turn of the 20th century, two lines of research prompted significant advancements in studying electrical brain activity. The first advance was an improved understanding of signal transmission at the synapse. At the time, signals were thought to be only transmitted electrically from one cell to another. The German physiologist Emile du Bois-Reymond had already theorized in 
1877 that chemical substances were involved in the signal transduction between nerve fibers and muscles, but experimental proof of his hypothesis was lacking (Lopez-Munoz and Alamo, 2009; Piccolino, 1998). In 1904, Thomas Renton Elliott and John Newport Langley suggested that the chemical substance released when an action potential arrived at the synapse was adrenaline. Only in the 1920s and 30s, a series of experiments carried out by Otto Loewi and Henry Hallett Dale confirmed the theory of chemical transmission through acetylcholine, acting as a neurohormone and neurotransmitter, in the peripheral nervous system (Lopez-Munoz and Alamo, 2009; Todman, 2008).

Subsequently, the understanding of signal transmission was significantly improved by the introduction of the glass micropipette in the late 1930s and the electron microscope in the 1950s. Alan Hodgkin and Andrew Huxley succeeded in performing the first intracellular recording of an action potential (Hausser, 2000; Hodgkin and Huxley, 1939). Follow-up experiments in the 1950s on the squid giant axon led Hodgkin and Huxley, together with their collaborator Bernard Katz, to propose the 'ionic hypothesis' of the action potential (Hodgkin et al., 1949; Hodgkin and Huxley, $1952 a, b, c)$. They suggested that the axonal membrane is permeable to sodium and potassium ions, and that a change in membrane potential upon depolarization of the neuron would lead to a flux of ions according to their electrochemical gradients (Berlucchi, 2010). Two years later, John Carew Eccles demonstrated the principle of chemical transmission in the central nervous system, and revealed that every neuron releases the same [set of] neurotransmitter[s] at all of its synaptic sites (Burke, 2006; Eccles et al., 1954; Strata and Harvey, 1999). Based on a series of experiments in the 1950s and 60s, Bernard Katz and colleagues proposed that neurotransmitters are stored in synaptic vesicles, which fuse with the membrane upon depolarization of the neuron and upon the influx of calcium through synaptic membrane channels (Sakmann, 2007). The measurement of electric activity at single ion channels has been made possible by the development of the patch clamp recording technique by Erwin Neher and Bert Sakmann in the 1970 and 80s (Neher and Sakmann, 1976; Sakmann and Neher, 1984). The properties and distribution of membrane channels at the axon, the synapse, the soma and the dendrites of the neuron have been found to influence the propagation of postsynaptic potentials and action potentials (Baranauskas, 2007; Johnston et al., 1996; Nusser, 2009; Sasaki, 2013). The characterization of ionic channels remains an active field of research until today.

The second important line of research focusing on electrical brain activity has emerged from the pioneering work of Richard Caton and Vladimir Pravdich-Neminsky. Caton is credited for the first electrocorticogram recorded from the exposed surface of animal brains in 1875, and Neminsky obtained the first electroencephalogram (EEG) from the animal skull in 1913 (Niedermeyer and da Silva, 2005; Pravdich-Neminsky, 1913). These developments paved the way for the seminal work of 
Hans Berger, who succeeded in recording the first EEG from the human skull in the 1920s (Ahmed and Cash, 2013; Millett, 2001). Berger, in his personal quest to find the physiological basis of telepathy, investigated electrical brain activity in healthy subjects and in patients with brain damage (Berger, 1933; Millett, 2001). He described oscillatory electrical activity in the alpha $(8-12 \mathrm{~Hz})$ and beta $(14-30 \mathrm{~Hz})$ ranges and its modulation by cognitive tasks, states of vigilance, drugs and disease (Ahmed and Cash, 2013; Berger, 1933; Millett, 2001). The discovery of 'brain waves' or 'rhythms' was first met with skepticism, and only gained acceptance when confirmed by Edgar Douglas Adrian in 1934 (Adrian, 1934; Hodgkin, 1979) and Herbert Jasper in 1935 (Goldensohn, 1998; Jasper and Carmichael, 1935). Subsequently, EEG studies in humans showed that brain oscillations occur at a wide range of frequencies: in the delta $(0.5-3 \mathrm{~Hz})$, theta $(4-7 \mathrm{~Hz})$, and gamma ranges $(35-48 \mathrm{~Hz}$; Ahmed and Cash, 2013; Holland, 2003; Jasper and Andrews, 1938). Adrian correctly hypothesized already in 1936 that the origin of these oscillations lies in the synchronous activity of large cell populations in the brain (Adrian, 1936; Ahmed and Cash, 2013). Later research by Eccles and others revealed that the EEG signals recorded at the scalp, as well as the corresponding field potentials recorded inside the brain, emerge from the postsynaptic activity of a neuronal population and are not directly related to the firing of action potentials (Eccles, 1951; Li and Jasper, 1953).

\section{Brain anatomy and function in the 20th century}

The development of novel cell staining techniques by Karl Weigert and Franz Nissl around the turn of the century opened up a new path to investigating the anatomy of the brain. Following up on the pioneering work by Rudolf Berlin, Korbinian Brodmann used stainings of human brain slices to reveal variations in cell types and cell densities across the six cortical layers. Brodmann proposed a parcellation of the cortex into 52 distinct areas based on the cytoarchitectonic characteristics of the brain tissue. Complementing Brodmann's findings, Oskar and Cecile Vogt studied the organization of nerve fibers in the brain and identified 200 distinct areas based on myeloarchitectonic differences. The three researchers hypothesized that morphological differences between the brain regions suggested functional specialization (Loukas et al., 2011; Mountcastle, 1995; Nieuwenhuys, 2013).

The 'one area, one function' hypothesis was put to the test by electrophysiological studies in the 1930s, which laid the foundation for the field of cortical mapping (Mountcastle, 1995). Electrical responses to sensory stimulation were measured in humans as EEG-recorded evoked potentials and in animals as voltage changes derived from microelectrode recordings. The analysis of neural activity in the primary sensory areas revealed that cytoarchitectonically homogenous maps may contain several functional maps (Mountcastle, 1995). Wade Marshall, Clinton Woolsey, and Philip Bard were the first to describe the functional subdivisions of the primary somatosensory cortex in monkeys and 
cats, showing that tactile stimulation of various body parts resulted in reproducible activation of defined cortical regions (Marshall et al., 1937). This ordered representation of sensory inputs in the cortex is known as 'somatotopy'.

In 1957, Vernon Mountcastle showed that neurons with overlapping representations of a body part are localized in close proximity, spanning layers II-VI in the cat primary somatosensory cortex. Mountcastle suggested that this 'cortical column' represented the elementary unit of cortical organization (Mountcastle, 1957). Indeed, cortical columns have been described in all sensory and motor areas, including the primary visual cortex as demonstrated by the landmark studies in monkeys by David Hubel and Torsten Wiesel (Hubel and Wiesel, 1968, 1969). Apart from confirming Mountcastle's finding of a vertical organization, Hubel and Wiesel also found a functional organization at the horizontal level, where cells with similar properties tended to be localized within the same cortical layer (Hubel and Wiesel, 1968).

\section{Modern definitions of psychiatric diseases: The concept of schizophrenia}

Thomas Willis had already recognized in the 17th century that mental disorders have their origin in dysfunctions of the nervous system, and is hence considered the father of neurology (Feindel, 1962). One of the earliest classification schemes for mental diseases has been postulated by Phillppe Pinel at the beginning of the 18th century, thus providing the foundation for modern psychiatry (Riese, 1951). Pinel also published the first comprehensive description of 'insanity', or schizophrenia-like symptoms, in his "Memoir on Madness" in 1794 (Adityanjee et al., 1999; Weiner, 1992).

The concept of schizophrenia, as we know it today, emerged from the work of Emil Kraepelin and Paul Eugen Bleuler. Kraepelin popularized the term 'dementia praecox' in the 1890s to describe a deterioration of cognition and emotion in patients, and a "loss of inner unity" (Andreasen, 1997; Hoenig, 1983). In 1911, Bleuler introduced the term 'schizophrenia' (split mind) to indicate that patients typically suffered from fragmented thinking, and not just from dementia (Hoenig, 1983). Bleuler also differentiated between 'primary' and 'secondary' symptoms of schizophrenia, which roughly correspond to today's notion of negative and positive symptoms associated with schizophrenia, respectively. Primary symptoms referred to the loss of cognitive and emotional functions (e.g. continuity of thoughts, attention, volition, empathy), while secondary symptoms described abnormal beliefs (delusions) and perceptions (hallucinations; Andreasen, 1997; Tandon, 2012). The underlying causes of schizophrenia were unknown at the time, but the introduction of the human EEG by Berger paved the way to investigating possible disease mechanisms in the brain. Early EEG studies in patients revealed abnormal oscillations in the delta and alpha ranges and at higher frequencies (Davis and Davis, 1939; Hoagland et al., 1937; Jasper et al., 1939). However, no 
clear-cut markers could be identified due to the large variability of EEG patterns across patients as well as control subjects (Jasper et al., 1939). The challenge of finding robust markers that can unequivocally distinguish schizophrenia from other disorders (and even normal brain function) basically persists until today (Javitt et al., 2008; Keshavan et al., 2008; Weickert et al., 2013).

\section{The 1950s until today: Psychopharmacology and molecular genetics}

A major advance in treating schizophrenia and other mental disorders was achieved in the 1950s with the introduction of antipsychotic drugs, or 'neuroleptics'. Chlorprozamine was the first antipsychotic available on prescription in 1952, mainly targeted at schizophrenia patients (Ban, 2004; Delay and Deniker, 1952). By the end of the 1950s, the pharmaceutical industry had developed at least 12 different neuroleptics (Ban, 2006). Another scientific advancement around the time of the drug discovery was the identification of neurotransmitters acting on the central nervous system, including acetylcholine, dopamine, gamma-aminobutyric acid (GABA), norepineephrine, serotonin and substance $P$ (Ban, 2006). The next logical step was to test whether neuroleptics could exert their therapeutic effect through changes in neurotransmission. Investigations in the newly developing field of neuropharmacology were made possible by the invention of the spectrophotofluorometer - a device for detecting changes in the concentration of chemicals involved in signal transmission (Ban, 2004). Using this method, Arvid Carlsson proposed in 1963 that antipsychotic drugs acted through blocking dopaminergic synaptic transmission (Carlsson and Lindqvist, 1963). This hypothesis was confirmed by Phillip Seeman and colleagues who revealed that antipsychotics inhibited dopamine receptors (Bennett, 1998; Seeman et al., 1975). These findings constituted the basis of the chemical imbalance theory of mental disorders, most prominently exemplified by the dopamine hypothesis of schizophrenia. Later on, scientists also discovered aberrant concentrations of other neurotransmitters, including acetylcholine, serotonin, GABA and glutamate, which might also contribute to the neuropathophysiology of schizophrenia (Carlsson et al., 2001). Even today, antipsychotic drugs that target the neurotransmitter systems remain the preferred available treatment option for mental diseases (Ban, 2006). While positive symptoms can be controlled relatively well with neuroleptics, negative symptoms often prove to be treatment resistant (Tandon et al., 2009). Therefore, current research focuses on illuminating the link between schizophrenia symptoms and functional brain changes in order to devise better treatment strategies for patients (Keshavan et al., 2011; Keshavan et al., 2008).

With the advent of molecular genetics, researchers acquired a whole new set of tools for investigating brain function and dysfunction in both humans and animals. Starting with the discovery of the structure of the DNA by James Watson and Francis Crick in 1953 (Crick and Watson, 1953), the 
field of molecular neuroscience advanced rapidly. Rudolf Jaenisch and Beatrice Mintz created the first genetically manipulated or 'transgenic' mouse in 1974 (Jaenisch and Mintz, 1974). In the 1980s and 90s, methodological advancements facilitated efforts to decipher the entire human genome, known as the Human Genome Project (Olson, 1993). Around the same time, genetic linkage and association studies sought to identify genes in humans that are related to an increased risk for schizophrenia (McInnes and Freimer, 1995). Moreover, mice with certain genetic alterations were found to display endophenotypes of schizophrenia (i.e. behaviors similar to those seen in schizophrenic patients), and were starting to be considered as a valuable model for schizophrenia (Lijam et al., 1997; McInnes et al., 1998). Since then, more than 500 schizophrenia candidate genes have been identified (Giusti-Rodriguez and Sullivan, 2013; Sun et al., 2008). One of the most frequently implied genes is Neuregulin 1 (NRG1; Greenwood et al., 2012; Li et al., 2006; Stefansson et al., 2004; Sun et al., 2008). Mice with a genetic disruption of NRG1 exhibit various endophenotypes of schizophrenia, including decreased social interest and impaired executive functioning, as well as deficits in locomotion and working memory (Lu et al., 2011).

\section{Perspectives on advancing schizophrenia research}

In current and future research, the central goal is to understand how genetic alterations change the function of neural circuits and thus give rise to schizophrenia-related endophenotypes and symptoms (Keshavan et al., 2008). Studying the relationship between genes, brain function and behavior requires the combination of various techniques and approaches. These include subdisciplines from the whole spectrum of clinical and fundamental neuroscience, including cellular, molecular, cognitive and behavioral neuroscience as well as genetics. Historically, each discipline largely evolved on its own. However, a combination of approaches is required for understanding the brain in general, and brain diseases in particular. The collaborative effort of different disciplines will be vital for advancing the knowledge about the disease mechanisms, for identifying robust biomarkers, and for improving treatment options for patients.

In an attempt to gain insight into the cellular mechanisms of the pathophysiology of schizophrenia, this thesis combines genetic, electrophysiological and histological methods. The work shows that neuronal responses to sensory stimulation are profoundly disturbed in the NRG1 mouse model of schizophrenia, both at the level of neuronal firing rates as well as oscillatory gamma activity. It is proposed that these functional alterations may be related to a variety of sensory disturbances commonly observed in schizophrenia. 


\section{REFERENCES}

Adityanjee, Aderibigbe, Y.A., Theodoridis, D., and Vieweg, V.R. (1999). Dementia praecox to schizophrenia: the first 100 years. Psychiatry Clin Neurosci 53, 437-448.

Adrian, E.D. (1934). Electrical activity of the nervous system. Archives of neurology and psychiatry $32,1125$.

Adrian, E.D. (1936). The electrical activity of the cortex: (Section of Neurology). Proc R Soc Med 29, 197-200.

Ahmed, O.J., and Cash, S.S. (2013). Finding synchrony in the desynchronized EEG: the history and interpretation of gamma rhythms. Front Integr Neurosci 7, 00058.

Amos, B. (2000). Lessons from the history of light microscopy. Nat Cell Biol 2, E151-152.

Andreasen, N.C. (1997). The evolving concept of schizophrenia: from Kraepelin to the present and future. Schizophr Res 28, 105-109.

Ban, T.A. (2004). Neuropsychopharmacology and the genetics of schizophrenia: a history of the diagnosis of schizophrenia. Prog Neuropsychopharmacol Biol Psychiatry 28, 753-762.

Ban, T.A. (2006). A history of the Collegium Internationale Neuro-Psychopharmacologicum (19572004). Prog Neuropsychopharmacol Biol Psychiatry 30, 599-616.

Baranauskas, G. (2007). Ionic channel function in action potential generation: current perspective. Mol Neurobiol 35, 129-150.

Beaudreau, S.A., and Finger, S. (2006). Medical electricity and madness in the 18th century: the legacies of Benjamin Franklin and Jan Ingenhousz. Perspect Biol Med 49, 330-345.

Bennett, M.R. (1998). Monoaminergic synapses and schizophrenia: 45 years of neuroleptics. J Psychopharmacol (Oxf) 12, 289-304.

Bentivoglio, M. (1996). 1896-1996: the centennial of the axon. Brain Res Bull 41, 319-325.

Berger, H. (1933). Über das Elektrenkephalogramm des Menschen. Eur Arch Psychiatry Clin Neurosci 98, 231-254.

Berlucchi, G. (2010). Chapter 13: the contributions of neurophysiology to clinical neurology an exercise in contemporary history. Handb Clin Neurol 95, 169-188.

Burke, R.E. (2006). John Eccles' pioneering role in understanding central synaptic transmission. Prog Neurobiol 78, 173-188.

Carlsson, A., and Lindqvist, M. (1963). Effect of chlorpromazine or haloperidol on formation of 3-methoxytyramine and normetanephrine in mouse brain. Acta Pharmacol Toxicol (Copenh) 20, 140-144.

Carlsson, A., Waters, N., Holm-Waters, S., Tedroff, J., Nilsson, M., and Carlsson, M.L. (2001). Interactions between monoamines, glutamate, and GABA in schizophrenia: new evidence. Annu Rev Pharmacol Toxicol 41, 237-260.

Crick, F., and Watson, J. (1953). Molecular structure of nucleic acids. Nature 171, 737-738.

Davis, P.A., and Davis, H. (1939). The electroencephalograms of psychotic patients. Am J Psychiatry 95, 1007-1025.

Delay, J., and Deniker, P. (1952). Le traitement des psychoses par une méthode neurolytique dérivée de I'hibernothérapie. Congrès des Médecins Aliénistes et Neurologistes de France Luxembourg, 497-502.

Eccles, J.C. (1951). Interpretation of action potentials evoked in the cerebral cortex. Electroencephalogr Clin Neurophysiol 3, 449-464.

Eccles, J.C., Fatt, P., and Koketsu, K. (1954). Cholinergic and inhibitory synapses in a pathway from motor-axon collaterals to motoneurones. J Physiol 126, 524-562.

Feindel, W. (1962). Thomas Willis (1621-1675) - the founder of neurology. Can Med Assoc J 87, 289296.

Felipe-Oroquieta, D. (2009). Cajal's place in the history of neuroscience. In Encyclopedia of Neuroscience, R.S. Editor-in-Chief: Larry, ed. (Oxford: Academic Press), 497-507.

Finger, S. (2001). Origins of neuroscience: a history of explorations into brain function (Oxford University Press, USA). 
Finger, S., and Zaromb, F. (2006). Benjamin Franklin and shock-induced amnesia. Am Psychol 61, 240-248.

Giusti-Rodriguez, P., and Sullivan, P.F. (2013). The genomics of schizophrenia: update and implications. J Clin Invest 123, 4557-4563.

Glickstein, M. (2006). Golgi and Cajal: the neuron doctrine and the 100th anniversary of the 1906 Nobel Prize. Curr Biol 16, R147-151.

Glynn, I. (1999). Two millennia of animal spirits. Nature 402, 353.

Goldensohn, E.S. (1998). Animal electricity from Bologna to Boston. Electroencephalogr Clin Neurophysiol 106, 94-100.

Greenwood, T.A., Light, G.A., Swerdlow, N.R., Radant, A.D., and Braff, D.L. (2012). Association analysis of 94 candidate genes and schizophrenia-related endophenotypes. PLoS One 7, 13.

Gross, C.G. (1995). Aristotle on the brain. The Neuroscientist 1, 245-250.

Gross, C.G. (1999). 'Psychosurgery' in renaissance art. Trends Neurosci 22, 429-431.

Gross, C.G. (2009). History of neuroscience: early neuroscience. In Encyclopedia of Neuroscience, R.S. Editor-in-Chief: Larry, ed. (Oxford: Academic Press), 1167-1171.

Hausser, M. (2000). The Hodgkin-Huxley theory of the action potential. Nat Neurosci 3 Suppl, 1165.

Hoagland, H., Cameron, D.E., and Rubin, M.A. (1937). The electroencephalogram of schizophrenics during insulin treatments: the delta index as a clinical measure. Am J Psychiatry 94, 183-208.

Hodgkin, A. (1979). Edgar Douglas Adrian, Baron Adrian of Cambridge. 30 November 1889-4 August 1977. Biographical Memoirs of Fellows of the Royal Society 25, 1-73.

Hodgkin, A., Huxley, A., and Katz, B. (1949). Ionic currents underlying activity in the giant axon of the squid. Arch Sci Physiol (Paris) 3, 129-150.

Hodgkin, A.L., and Huxley, A.F. (1939). Action potentials recorded from inside a nerve fibre. Nature $144,710-711$.

Hodgkin, A.L., and Huxley, A.F. (1952a). The components of membrane conductance in the giant axon of Loligo. J Physiol 116, 473-496.

Hodgkin, A.L., and Huxley, A.F. (1952b). Currents carried by sodium and potassium ions through the membrane of the giant axon of Loligo. J Physiol 116, 449-472.

Hodgkin, A.L., and Huxley, A.F. (1952c). A quantitative description of membrane current and its application to conduction and excitation in nerve. J Physiol 117, 500-544.

Hoenig, J. (1983). The concept of schizophrenia. Kraepelin-Bleuler-Schneider. Br J Psychiatry 142, 547-556.

Holland, O. (2003). Exploration and high adventure: the legacy of Grey Walter. Philos Trans A Math Phys Eng Sci 361, 2085-2121.

Hubel, D.H., and Wiesel, T.N. (1968). Receptive fields and functional architecture of monkey striate cortex. J Physiol 195, 215-243.

Hubel, D.H., and Wiesel, T.N. (1969). Anatomical demonstration of columns in the monkey striate cortex. Nature 221, 747-750.

Jaenisch, R., and Mintz, B. (1974). Simian virus 40 DNA sequences in DNA of healthy adult mice derived from preimplantation blastocysts injected with viral DNA. Proc Natl Acad Sci U S A 71, 1250-1254.

Jasper, H.H., and Andrews, H.L. (1938). Electroencephalography. III. Normal differentiation of occipital and precentral regions in man. Archives of Neurology \& Psychiatry 39, 96-115.

Jasper, H.H., and Carmichael, L. (1935). Electrical potentials from the intact human brain. Science 81, 51-53.

Jasper, H.H., Fitzpatrick, C.P., and Solomon, P. (1939). Analogies and opposites in schizophrenia and epilepsy. Am J Psychiat 95, 835-838i.

Javitt, D.C., Spencer, K.M., Thaker, G.K., Winterer, G., and Hajos, M. (2008). Neurophysiological biomarkers for drug development in schizophrenia. Nat Rev Drug Discov 7, 68-83.

Johnston, D., Magee, J.C., Colbert, C.M., and Cristie, B.R. (1996). Active properties of neuronal dendrites. Annu Rev Neurosci 19, 165-186. 
Keshavan, M.S., Nasrallah, H.A., and Tandon, R. (2011). Schizophrenia, "just the facts" 6. Moving ahead with the schizophrenia concept: from the elephant to the mouse. Schizophr Res 127, 3-13.

Keshavan, M.S., Tandon, R., Boutros, N.N., and Nasrallah, H.A. (2008). Schizophrenia, "just the facts": what we know in 2008: Part 3: neurobiology. Schizophr Res 106, 89-107.

Li, C.-L., and Jasper, H. (1953). Microelectrode studies of the electrical activity of the cerebral cortex in the cat. J Physiol 121, 117-140.

Li, D., Collier, D.A., and He, L. (2006). Meta-analysis shows strong positive association of the neuregulin 1 (NRG1) gene with schizophrenia. Hum Mol Genet 15, 1995-2002.

Lijam, N., Paylor, R., McDonald, M.P., Crawley, J.N., Deng, C.X., Herrup, K., Stevens, K.E., Maccaferri, G., McBain, C.J., Sussman, D.J., et al. (1997). Social interaction and sensorimotor gating abnormalities in mice lacking Dvl1. Cell 90, 895-905.

Lopez-Munoz, F., and Alamo, C. (2009). Historical evolution of the neurotransmission concept. J Neural Transm 116, 515-533.

Loukas, M., Pennell, C., Groat, C., Tubbs, R.S., and Cohen-Gadol, A.A. (2011). Korbinian Brodmann (1868-1918) and his contributions to mapping the cerebral cortex. Neurosurgery 68, 6-11.

Lu, Y., Yin, D.-M., Xiong, W.-C., and Mei, L. (2011). Modeling schizophrenia in Neuregulin 1 and ErbB4 mutant mice. In Animal Models of Schizophrenia and Related Disorders (Springer), 261-277.

Marshall, W.H., Woolsey, C.N., and Bard, P. (1937). Cortical representation of tactile sensibility as indicated by cortical potentials. Science $85,388-390$.

McInnes, L.A., and Freimer, N.B. (1995). Mapping genes for psychiatric disorders and behavioral traits. Curr Opin Genet Dev 5, 376-381.

McInnes, L.A., Reus, V.I., and Freimer, N.B. (1998). Mapping genes for psychiatric disorders and behavioral traits. Curr Opin Genet Dev 8, 287-292.

Millett, D. (2001). Hans Berger: from psychic energy to the EEG. Perspect Biol Med 44, 522-542.

Mountcastle, V. (1995). The evolution of ideas concerning the function of the neocortex. Cereb Cortex 5, 289-295.

Mountcastle, V.B. (1957). Modality and topographic properties of single neurons of cat's somatic sensory cortex. J Neurophysiol 20, 408-434.

Neher, E., and Sakmann, B. (1976). Single-channel currents recorded from membrane of denervated frog muscle fibres. Nature 260, 799-802.

Niedermeyer, E., and da Silva, F.H.L. (2005). Electroencephalography: basic principles, clinical applications, and related fields (Wolters Kluwer Health).

Nieuwenhuys, R. (2013). The myeloarchitectonic studies on the human cerebral cortex of the VogtVogt school, and their significance for the interpretation of functional neuroimaging data. Brain Struct Funct 218, 303-352.

Nusser, Z. (2009). Variability in the subcellular distribution of ion channels increases neuronal diversity. Trends Neurosci 32, 267-274.

O'Connor, J.P. (2003). Thomas Willis and the background to Cerebri Anatome. J R Soc Med 96, 139143.

Olson, M.V. (1993). The human genome project. Proc Natl Acad Sci 90, 4338-4344.

Parent, A. (2004). Giovanni Aldini: from animal electricity to human brain stimulation. Can J Neurol Sci 31, 576-584.

Piccolino, M. (1998). Animal electricity and the birth of electrophysiology: the legacy of Luigi Galvani. Brain Res Bull 46, 381-407.

Piccolino, M. (2000). The bicentennial of the Voltaic battery (1800-2000): the artificial electric organ. Trends Neurosci 23, 147-151.

Pravdich-Neminsky, V. (1913). Ein Versuch der Registrierung der elektrischen Gehirnerscheinungen. Zbl Physiol 27, 951-960.

Quin, C.E. (1994). The soul and the pneuma in the function of the nervous system after Galen. J R Soc Med 87, 393-395. 
Riese, W. (1951). Philippe Pinel (1745-1826); his views on human nature and disease; his medical thought. J Nerv Ment Dis 114, 313-323.

Sakmann, B. (2007). Sir Bernard Katz: 26 March 1911 - 20 April 2003. Biogr Mem Fellows R Soc 53, 185-202.

Sakmann, B., and Neher, E. (1984). Patch clamp techniques for studying ionic channels in excitable membranes. Annu Rev Physiol 46, 455-472.

Sasaki, T. (2013). The axon as a unique computational unit in neurons. Neurosci Res 75, 83-88.

Schuetze, S.M. (1983). The discovery of the action potential. Trends Neurosci 6, 164-168.

Seeman, P., Chau-Wong, M., Tedesco, J., and Wong, K. (1975). Brain receptors for antipsychotic drugs and dopamine: direct binding assays. Proc Natl Acad Sci U S A 72, 4376-4380.

Shepherd, G.M. (2009). Neuron doctrine: historical background. In Encyclopedia of Neuroscience, R.S. Editor-in-Chief: Larry, ed. (Oxford: Academic Press), 691-695.

Stefansson, H., Steinthorsdottir, V., Thorgeirsson, T.E., Gulcher, J.R., and Stefansson, K. (2004). Neuregulin 1 and schizophrenia. Ann Med 36, 62-71.

Strata, P., and Harvey, R. (1999). Dale's principle. Brain Res Bull 50, 349-350.

Sun, J., Kuo, P.H., Riley, B.P., Kendler, K.S., and Zhao, Z. (2008). Candidate genes for schizophrenia: a survey of association studies and gene ranking. Am J Med Genet B Neuropsychiatr Genet 5, 11731181.

Tandon, R. (2012). The nosology of schizophrenia: toward DSM-5 and ICD-11. Psychiatr Clin North Am 35, 557-569.

Tandon, R., Nasrallah, H.A., and Keshavan, M.S. (2009). Schizophrenia, "just the facts" 4. Clinical features and conceptualization. Schizophr Res 110, 1-23.

Todman, D. (2008). Henry Dale and the discovery of chemical synaptic transmission. Eur Neurol 60, 162-164.

Weickert, C.S., Weickert, T.W., Pillai, A., and Buckley, P.F. (2013). Biomarkers in schizophrenia: a brief conceptual consideration. Dis Markers 35, 7.

Weiner, D.B. (1992). Philippe Pinel's "Memoir on Madness" of December 11, 1794: a fundamental text of modern psychiatry. Am J Psychiatry 149, 725-732. 


\section{Chapter I}

\section{General introduction}

\section{Study rationale: Unraveling the cellular basis of schizophrenia}

What is reality? And what happens, when we lose touch with it? How we define reality is mostly determined by how our brain receives and processes external stimuli. Our sensory receptors - visual, auditory, somatosensory and olfactory - determine which aspects of our environment we can perceive. These stimuli are processed as perceptions and experiences in the brain, and give rise to thoughts, memories, and emotions. But what if we perceived a voice or an odor that somebody next to us did not perceive - is it still real? What if we felt persecuted and threatened, or as if somebody else was controlling our thoughts? If we cannot trust our senses and judgments anymore, the uncertainty of what is real or not can be deeply unsettling. This experience, the loss of touch with reality, is what patients with schizophrenia suffer from in the form of delusions and hallucinations.

Schizophrenia is a relatively common disease with an average lifetime risk of about $0.7 \%$ (Saha et al., 2005). Both genetic and environmental factors determine the susceptibility to schizophrenia, with monozygotic twins and children with two schizophrenic parents displaying the highest morbidity risk of almost 50 \% (Tsuang, 2000). Schizophrenia patients often show altered sensory perceptions, disorganized thoughts and speech, as well as difficulties in managing their emotions and in relating with others. The abnormal behavior seen in patients is paralleled by changes in their brain structure and function (Benes, 2000; Fitzsimmons et al., 2013). For example, researchers recorded electrical brain activity in a schizophrenic patient experiencing somatosensory hallucinations (a popping sensation moving from his neck to his limbs) and found abnormal oscillations in the gamma $(25-70 \mathrm{~Hz})$ range (Baldeweg et al., 1998). Understanding anomalous brain activity in schizophrenic subjects can provide important clues about the mechanisms underlying the disease, and can contribute to the development of better treatment options for patients. However, studying brain function in humans is limited by the use of non-invasive methods, which have a relatively low spatial and/or temporal resolution. As a consequence, in schizophrenic patients basic research on brain activity at the cellular level is hardly possible.

Animal models of schizophrenia can overcome this limitation since they allow the use of invasive techniques to record cellular responses with a temporal precision of $1 \mathrm{~ms}$ and a spatial precision of a few microns. The model of choice is typically the mouse since its brain physiology and genetics are comparable, with some restrictions, to humans. In addition, mice can be manipulated 
genetically, e.g. by deactivating genes that are suspected to increase the risk for schizophrenia in humans. The combination of targeted genetic manipulations and cellular recording techniques is a powerful method to investigate the effects of clinically relevant genetic changes at the cellular level.

The following section provides background information on the sensory and cognitive symptoms associated with schizophrenia and their neuronal underpinnings. It is argued that sensory dysfunctions likely contribute to cognitive deficits, and should therefore receive special attention in schizophrenia research. Furthermore, it is suggested that schizophrenia models such as the Neuregulin 1 knockout mouse are useful for investigating the cellular basis of disease-related sensory dysfunctions, in particular in the somatosensory domain.

\section{Defining schizophrenia: Overview of cognitive and sensory dysfunctions}

What are the symptoms of schizophrenia? Disturbed cognitive functioning is the most prevalent feature of schizophrenia and is therefore used as the main diagnostic criterion (Heinrichs, 2005; Tandon et al., 2009). Possible deficits include delusions and hallucinations, as well as impairments in learning and memory, attention, goal-directed behavior and emotion regulation (Aleman et al., 1999; Brüne, 2005; Heinrichs, 2005; Mujica-Parodi et al., 2000; Nuechterlein et al., 2004; Tandon et al., 2009). For example, patients often report delusions or beliefs that somebody controls their thoughts and actions. Many patients also experience hallucinations, in particular audible thoughts, arguing voices and external influences on the body, such as imaginary X-rays causing a tingling sensation in the patient's neck (Fletcher and Frith, 2009). In addition, reduced intellectual capacities are commonly associated with schizophrenia, e.g. with regard to abstract thinking and conceptual understanding, and in tasks requiring episodic and working memory (Laws, 1999; Reichenberg and Harvey, 2007; Shad et al., 2006). Many patients also suffer from disorganized thoughts and speech, are easily distracted and lack emotional awareness (Fioravanti et al., 2005; Tandon et al., 2009; Trémeau, 2006). These cognitive problems have a profound impact on the patients' lives, and are often accompanied by an increased risk for unemployment, financial difficulties, homelessness, imprisonment and suicide (Tandon et al., 2009).

In addition to reduced cognitive function, sensory dysfunction is another common feature of schizophrenia (Javitt, 2009a; Uhlhaas and Mishara, 2007). Sensory deficits in patients include increased crowding effects, i.e. a reduced ability to detect objects in a cluttered visual scene, as well as a higher propensity to miss and avoid sensory information (Brown et al., 2002; Kraehenmann et al., 2012). Unlike cognitive problems, sensory and perceptual abnormalities have traditionally not been considered as core deficits of schizophrenia and thus do not form part of the diagnostic criteria (Tandon, 2012; Tandon et al., 2013; Tandon et al., 2009). This view has been challenged in recent 
years, as both past and present research revealed that schizophrenia and schizotypic features are linked to aberrant sensory and perceptual processes in the visual, auditory, somatosensory, olfactory and vestibular systems (Butler et al., 2008; Butler et al., 2005; Huang et al., 2010; Jenkins and Röhricht, 2007; Moberg et al., 1999; Näätänen and Kähkönen, 2009; Warren and Ross, 1998). For example, schizophrenia patients perform worse than controls on auditory tasks involving the discrimination of pitch (Javitt et al., 2000) and tone intervals (Davalos et al., 2003; Todd et al., 2003). Patients also display increased startle responses in the prepulse inhibition (PPI) paradigm, which tests for sensory gating deficits (Braff et al., 1992; Keshavan et al., 2008). PPI occurs when a weaker stimulus inhibits the startle response (e.g. eye blink) to a subsequent loud stimulus (Keshavan et al., 2008). Moreover, patients show impairments in visual tasks involving form and motion perception (Brenner et al., 2003b; Chen et al., 2003; O'Donnell et al., 1996; Wang et al., 2010), spatial frequency perception (Khosravani and Goodarzi, 2013; O'Donnell et al., 2002), contrast sensitivity (Butler et al., 2009; Calderone et al., 2013), and forward/backward masking (Green et al., 2003b; Green et al., 1994). They also have more difficulties with Gestalt perception such as recognizing fragmented objects (Doniger et al., 2002; Silverstein and Keane, 2011). Moreover, several studies reported deficits in visual inhibition in schizophrenia, as demonstrated by an altered perception of center stimuli when flanked by surround stimuli that differed in contrast (Tibber et al., 2013; Yang et al., 2013), orientation (Yoon et al., 2009) or size (Tibber et al., 2013) from center stimuli. In the somatosensory domain, patients and/or their relatives display impairments in graphesthesia testing (Chang and Lenzenweger, 2004, 2005; Martin et al., 2010) and pain perception (Bonnot et al., 2009; Dworkin, 1994; Singh et al., 2006). Other studies have described a lower performance in the tactile two-point discrimination task in relatives of schizophrenic patients (Chang and Lenzenweger, 2001, 2005) and in healthy subjects with schizotypic features (Lenzenweger, 2000). An additional deficit related to somatosensory processing is the aberrant perception of body ownership in schizophrenic subjects, as illustrated by an altered susceptibility to visual-tactile illusions (Ferri et al., 2014; Peled et al., 2000; Thakkar et al., 2011). Moreover, somatosensory-related proprioceptive deficits have been linked to schizophrenia, as patients and their relatives display impairments in weight discrimination (Chang and Lenzenweger, 2005; Javitt et al., 1999; Ritzler and Rosenbaum, 1974; Rosenbaum et al., 1965; Sonder, 1955; Zubin, 1954). Furthermore, sensory dysfunctions may also extend to the olfactory domain, since some (but not all) studies showed a reduced ability to detect, identify and discriminate odors in schizophrenic subjects (Moberg et al., 1999; Nguyen et al., 2010). Finally, some evidence indicates vestibular disturbances in patients, describing a decrease in muscle tone, abnormal body posture and a higher incidence of vertigo (Gurvich et al., 2013; Hixson and Mathews, 1984). Patients were also reported to show decreased performance in eye tracking tasks 
with simultaneous stimulation of the vestibular system either by the rotation of the patient's body (Warren and Ross, 1998) or by water application in the ear canal (Myers et al., 1973). It has been suggested that there may not be a direct link between the psychopathology of schizophrenia and vestibular dysfunction, but that there are connections between the vestibular system and brain areas known to be affected in schizophrenia (Gurvich et al., 2013). Overall, the strongest evidence for sensory deficits in schizophrenia appears to derive from studies on auditory, visual and somatosensory functions. These sensory domains will therefore be in the focus of the following discussion on sensory impairments in schizophrenia.

\section{Neuronal underpinnings of cognitive and sensory abnormalities}

\subsection{Neuronal mechanisms of cognitive deficits}

The mechanisms underlying the cognitive deficits in schizophrenic patients have been the focus of extensive research. Five types of biological markers for schizophrenia, and in particular the cognitive impairments associated with it, have been identified: structural, functional, neurophysiological, neurochemical and neuropathological (Keshavan et al., 2008). Structural alterations include a reduction in total brain volume (predominantly in gray and white matter), enlarged ventricles and basal ganglia, and reduced cerebral asymmetry (Antonova et al., 2004; Keshavan et al., 2008). Functional abnormalities, as measured by changes in metabolic activity, comprise altered activation patterns in prefrontal and temporal cortices, both during tasks and resting state (Keshavan et al., 2008). In the prefrontal cortex, an increased level of noisy activity has been reported that correlates with impaired working memory function (Winterer et al., 2004) and psychotic symptoms (Winterer et al., 2006). Neurophysiological changes in event-related potentials (ERPs) and in neural oscillations have consistently been observed using electroencephalography (EEG) and magnetoencephalography (MEG; Box 1). ERPs that show alterations include the mismatch negativity (MMN), P50 and P300 responses (see Table 1 for details; Javitt et al., 2008; Keshavan et al., 2008). Aberrant patterns in neural oscillations (Table 2) were identified primarily in the gamma band, which is linked to perception, attention and memory, and in the beta band, which is important for sensory gating, attention and motor control (Lisman, 2012; Moran and Hong, 2011; Uhlhaas and Singer, 2010). In addition, abnormalities in the theta and alpha ranges have also been shown, both of which are implied in top-down control and long-range synchronization (Moran and Hong, 2011; Uhlhaas and Singer, 2010). Apart from these neurophysiological indicators, robust evidence suggests broad deficits in neurochemical signaling in schizophrenic patients. The most widely reported pathways with alterations are the dopaminergic and glutamatergic systems, but changes in $\gamma$-aminobutyric acid (GABA)-ergic, serotonergic and cholinergic signaling have also been described (Abi-Dargham, 
2007; Javitt, 2010; Keshavan et al., 2008; Lewis et al., 2005; Lisman, 2012; Marín, 2012; Marsman et al., 2013; McKinzie and Bymaster, 2012). Finally, neuropathological disease markers include changes in neuronal density and volume in prefrontal, temporal and limbic areas, disorganized placement of neurons in the temporal cortex, reduced dendritic and synaptic density in the prefrontal and temporal cortices, reduced dendritic volume in the striatum, as well as alterations in neural-glial interactions (Faludi and Mirnics, 2011; Harrison, 1999; Keshavan et al., 2008; Kondziella et al., 2007).

\section{BOX 1. Electrical signals in the human brain.}

Techniques. In human subjects, electrical brain activity is measured on the scalp surface using electroencephalography (EEG) or magnetoencephalography (MEG). EEG and MEG record the electric potential and the magnetic field, respectively, associated with the action potentials and postsynaptic potentials summed across thousands of neurons. Both techniques measure brain activity at a high temporal resolution (1 ms), but low spatial resolution (EEG: $1 \mathrm{~cm}$; MEG: $<1 \mathrm{~cm}$ ).

Analysis. Signals recorded by MEG and EEG can be analyzed in the time domain to reveal eventrelated potentials (ERPs), and in the time-frequency domain to reveal oscillatory activity. ERPs are calculated by averaging the response to a stimulus across trials, thus eliminating variable background activity. Waveform deflections are named after their directionality ('P' for positive, ' $\mathrm{N}$ ' for negative) and the time of their occurrence (e.g. P50 for a positive deflection at $50 \mathrm{~ms}$, or $\mathrm{N} 1$ as the first negative peak). Oscillations are analyzed either during baseline (also called ongoing or resting-state oscillations), or during stimulation. Stimulus-related oscillations can be further subdivided into evoked and induced oscillations. Evoked oscillations are measured by averaging single-trial responses and performing a power analysis on the average signal. The procedure is similar to the calculation of ERPs, hence evoked oscillations are also referred to as event-related oscillations (EROs). Induced oscillations are quantified by performing a power analysis on the single trial responses and subsequent averaging. While evoked oscillations appear at a fixed time interval after stimulus presentation and are thus 'phase-locked', induced oscillations do not show phase locking with respect to the stimulus. Both evoked and induced oscillations are modulated by sensory (bottom-up) as well as cognitive (top-down) processes.

Paradigms. Electrical brain activity can be studied either during resting state to reveal baseline oscillations, or during stimulation to investigate ERPs, evoked and induced oscillations. Stimulation can occur passively, without specific instructions, to study sensory responses, or as part of a cognitive task. Moreover, sensory stimuli can be presented at large intervals (several seconds) to investigate transient brain responses, or in trains of several stimuli to investigate sustained or 'steady-state' responses. Sustained stimulation is especially useful to investigate the ability of brain circuits to get entrained (or 'oscillate') at a certain frequency.

Source: (David et al., 2006; Tan et al., 2013; Uhlhaas and Singer, 2010). 
TABLE 1. Overview of ERP components that are commonly affected in schizophrenia. Left to right: Description of the ERP, its latency and source, the typical paradigm to elicit it, the cognitive and/or sensory functions associated with it, and how it is altered in schizophrenic patients.

\begin{tabular}{|c|c|c|c|c|c|}
\hline ERP & latency & source & paradigm & function & schizophrenia \\
\hline $\begin{array}{l}\text { auditory } \\
\text { P50/N1 } 1^{1,2}\end{array}$ & $50 \mathrm{~ms}$ & $\begin{array}{l}\text { temporal lobe, } \\
\text { PFC, } \\
\text { hippocampus }\end{array}$ & $\begin{array}{l}\text { paired-click: when one stimuli follows another within } 50 \mathrm{~ms} \text {, the } \\
\text { second stimulus is being ignored (gated) and its response (P50 } \\
\text { and N1) is attenuated }\end{array}$ & $\begin{array}{l}\text { sensory gating, } \\
\text { attention }\end{array}$ & $\begin{array}{l}\text { increased } \\
\text { amplitude }\end{array}$ \\
\hline \multirow[t]{2}{*}{$\begin{array}{l}\text { auditory } \\
\mathbf{P 1} \mathbf{N 1}^{3,4}\end{array}$} & $100 \mathrm{~ms}$ & temporal lobe & $\begin{array}{l}\text { oddball: in a series of standard tones, an odd tone is presented } \\
\text { that differs in loudness, pitch or length and thus elicits a large } \\
\text { N1 response; }\end{array}$ & auditory response & $\begin{array}{l}\text { oddball: reduced N1 } \\
\text { amplitude; }\end{array}$ \\
\hline & & & $\begin{array}{l}\text { prepulse inhibition (PPI): if a salient stimulus is preceded by } \\
\text { another, softer stimulus by } 100 \mathrm{~ms} \text {, the } \mathrm{P} 1 \text { response to the } \\
\text { salient stimulus is attenuated }\end{array}$ & & $\begin{array}{l}\text { PPI: increased P1, } \\
\text { reduced } \mathrm{N} 1 \\
\text { amplitude }\end{array}$ \\
\hline $\begin{array}{l}\text { visual } \\
\text { P1 }^{5,6}\end{array}$ & $100 \mathrm{~ms}$ & $\begin{array}{l}\text { occipital, } \\
\text { temporal cortices }\end{array}$ & presentation of visual stimuli & visual response & reduced amplitude \\
\hline $\begin{array}{l}\text { mismatch } \\
\text { negativity } \\
(\mathbf{M M N})^{7,8}\end{array}$ & $200 \mathrm{~ms}$ & $\begin{array}{l}\text { frontal, temporal } \\
\text { areas }\end{array}$ & oddball (see above): deviant tone elicits large $\mathrm{MMN}$ response & $\begin{array}{l}\text { attention, echoic } \\
\text { memory }\end{array}$ & reduced amplitude \\
\hline $\begin{array}{l}\text { P300 } \\
(P 3)^{4,9,10}\end{array}$ & $300 \mathrm{~ms}$ & $\begin{array}{l}\text { frontal, parietal, } \\
\text { temporal, } \\
\text { cingulate cortices }\end{array}$ & $\begin{array}{l}\text { oddball (see above): large P300 response to deviant stimulus } \\
\text { PPI (see above): large P300 response to salient stimulus (if it is a } \\
\text { non-target in a go/nogo paradigm) }\end{array}$ & $\begin{array}{l}\text { working memory, } \\
\text { attention, novelty } \\
\text { detection }\end{array}$ & reduced amplitude \\
\hline
\end{tabular}

(1) Potter et al., 2006. (2) Brockhaus-Dumke et al., 2008. (3) Foxe et al., 2011. (4) Schall et al., 1997. (5) Butler et al., 2007. (6) Schechter et al., 2005. (7) Näätänen et al., 2009. (8) Michie, 2001. (9) Jeon \& Polich, 2003. (10) Winterer et al., 2001. 
TABLE 2. Oscillations and their role in human consciousness and cognition. Source: (Basar et al., 2001; Knyazev, 2012; Moran and Hong, 2011; Uhlhaas et al., 2008).

\begin{tabular}{|c|c|c|}
\hline frequency & brain structure & suggested function \\
\hline $\begin{array}{l}\text { delta } \\
(0.5-3 \mathrm{~Hz})\end{array}$ & $\begin{array}{l}\text { all cortical structures, thalamus, } \\
\text { reticular formation }\end{array}$ & $\begin{array}{l}\text { attention, decision making, motivation, } \\
\text { pain, long-range synchronization, slow- } \\
\text { wave sleep }\end{array}$ \\
\hline $\begin{array}{l}\text { theta } \\
(4-7 \mathrm{~Hz})\end{array}$ & $\begin{array}{l}\text { hippocampus, prefrontal cortex, } \\
\text { sensory cortex }\end{array}$ & $\begin{array}{l}\text { memory, attention, spatial exploration, } \\
\text { synaptic plasticity, top-down control, } \\
\text { long-range synchronization, rapid eye- } \\
\text { movement sleep }\end{array}$ \\
\hline $\begin{array}{l}\text { alpha } \\
(8-12 \mathrm{~Hz})\end{array}$ & $\begin{array}{l}\text { thalamus, hippocampus, reticular } \\
\text { formation, sensory cortex, motor } \\
\text { cortex }\end{array}$ & $\begin{array}{l}\text { inhibition, attention, working memory, } \\
\text { movement, top-down control, long- } \\
\text { range synchronization, consciousness }\end{array}$ \\
\hline $\begin{array}{l}\text { beta } \\
(13-30 \mathrm{~Hz})\end{array}$ & $\begin{array}{l}\text { all cortical structures, subthalamic } \\
\text { nucleus, hippocampus, basal ganglia, } \\
\text { olfactory bulb }\end{array}$ & $\begin{array}{l}\text { sensory gating, attention, perception, } \\
\text { motor control, long-range } \\
\text { synchronization }\end{array}$ \\
\hline $\begin{array}{l}\text { gamma } \\
(30-100 \mathrm{~Hz})\end{array}$ & $\begin{array}{l}\text { all brain structures, retina, olfactory } \\
\text { bulb }\end{array}$ & $\begin{array}{l}\text { perception, attention, memory, synaptic } \\
\text { plasticity, motor control, binding, short- } \\
\text { range synchronization, consciousness }\end{array}$ \\
\hline
\end{tabular}

\subsection{Neuronal mechanisms of sensory deficits in schizophrenia}

Schizophrenia-related alterations in brain structure, function, neurophysiology, neurochemistry and neuropathology have also been described in the sensory domains. While the mechanisms underlying cognitive deficits are well studied and are chiefly considered "facts" in the schizophrenia literature (Keshavan et al., 2008), the mechanisms for the sensory deficits have not been clearly established and remain an area of ongoing investigations. This section presents an overview of findings on the neural basis of auditory, visual and somatosensory deficits in schizophrenia.

\subsubsection{Structural changes}

Structural brain changes in patients comprise a decrease in gray matter volume and alterations in the gyrification pattern of the auditory (Barta et al., 1990; Cachia et al., 2008; Honea et al., 2005; Kubera et al., 2014; Matsumoto et al., 2001; Modinos et al., 2013), visual (Dorph-Petersen et al., 2007; Honea et al., 2005; Schultz et al., 2013), and somatosensory cortices (Honea et al., 2005; Zhou et al., 2007). In addition, white matter abnormalities have been noted in occipital, temporal and parietal regions (Ardekani et al., 2003; Kubicki et al., 2005; Seok et al., 2007), and in interhemispheric connectivity between auditory cortices (Steinmann et al., 2014). White and gray matter reductions in the auditory cortex have been associated with the severity of auditory hallucinations in 
schizophrenic subjects (Allen et al., 2008; Hubl et al., 2004; Kubera et al., 2014; Palaniyappan et al., 2012; Steinmann et al., 2014).

\subsubsection{Functional changes}

Several lines of research using functional imaging techniques indicate aberrant activity patterns in sensory cortices of schizophrenic subjects. Most commonly, functional magnetic resonance imaging (fMRI) and positron emission tomography (PET) have been employed to measure metabolic brain activity in terms of changes in the blood oxygenation level (the blood oxygenation level-dependent or BOLD response) and in gamma rays emitted by a radioactive tracer, respectively. Changes in metabolic activity have been shown to correlate with the neural activation of the corresponding brain region (Heeger and Ress, 2002). In auditory areas (superior temporal gyrus), the BOLD response was reduced in patients when a deviant tone was presented in an oddball paradigm (Wible et al., 2001), during a vocal affect recognition task (Leitman et al., 2011), and when patients were listening to speech (Woodruff et al., 1997). In the primary visual cortex, patients displayed lower BOLD signals to grating stimuli at low spatial frequency and low contrast, which correlated with a lower contrast sensitivity (Martinez et al., 2008). In response to stimuli with higher spatial frequencies, however, patients showed increased activation in this area (Martinez et al., 2008). Another fMRI study found decreased activation of the primary visual cortex in response to stimuli with low spatial frequencies, both at low and high contrast (Calderone et al., 2013). Furthermore, enhanced activation in primary visual cortex was demonstrated with fMRI during 1,3 and $30 \mathrm{~Hz}$ photic stimulation (Taylor et al., 1997), and with PET during $8 \mathrm{~Hz}$ photic stimulation (Renshaw et al., 1994). Moreover, recent research in patients demonstrated impaired modulation of $\mathrm{fMRI}$ responses to orientation-specific contextual information in early visual cortex (V1, V2 and V3), indicating a lack of surround suppression and a disruption of inhibitory signaling (Seymour et al., 2013). In the somatosensory cortex, larger variability in the amplitude and latency of the somatosensory BOLD response was observed when patients pressed a button (Barch et al., 2003).

Not all studies have reported alterations in task-related neuronal activity, however. One study found normal BOLD response amplitudes in auditory cortex during an auditory oddball task, but reduced activation in primary motor cortex in schizophrenic patients (Ublinskiy et al., 2013). Another study observed no changes in BOLD activation in primary auditory and visual areas in response to drum beat auditory stimuli and check stimuli flickering at $6 \mathrm{~Hz}$, respectively (Braus et al., 2002). Using $8 \mathrm{~Hz}$ check stimuli and a button press response, another study showed no alterations in response magnitudes in primary visual and somatosensory cortices in patients, but did observe an increased variability of the response amplitude and latency in these areas (Barch et al., 2003). 
Furthermore, BOLD responses in the primary somatosensory cortex showed no differences between patients and controls during $100 \mathrm{~Hz}$ vibrotactile stimulation (White et al., 2010).

In addition to possible changes in task-related activation, other types of functional impairments related to schizophrenia have also been reported. First, patient studies have investigated the functional connectivity of anatomically distributed brain regions showing a temporal relationship in their activation pattern. During resting state, patients have demonstrated reduced functional connectivity in primary auditory, visual and somatosensory areas (Liang et al., 2006; Lynall et al., 2010), and increased functional connectivity between motor/somatosensory cortex and thalamus (Woodward et al., 2012). Moreover, abnormal activation has been found in primary and secondary auditory areas during auditory hallucinations (Allen et al., 2008; Shergill et al., 2000), and in visual association areas during visual hallucinations (Allen et al., 2008). In somatosensory areas, including primary somatosensory cortex, aberrant neural activity has been recorded when schizophrenic subjects experienced somatic and pain hallucinations (Baldeweg et al., 1998; Bär et al., 2002; Shergill et al., 2001). Finally, it has been suggested for both auditory (Calhoun et al., 2004) and somatosensory cortices (Reite et al., 2003) that abnormal activation patterns are the result of an altered spatial arrangement of these cortices in schizophrenic patients compared to control subjects.

\subsubsection{Neurophysiological changes}

Neurophysiological abnormalities, i.e. deviant brain responses to sensory stimuli, have been described for all sensory modalities in schizophrenic patients (Huang et al., 2010; Javitt, 2009b). Typically, studies have employed EEG or MEG to measure changes in ERPs (Table 1) and oscillations (Box 1, Table 2). These methods are used to quantify transient responses to a single stimulus or sustained responses to a train of stimuli, presented at different frequencies. Three major types of changes associated with schizophrenia can be distinguished and will be discussed subsequently for auditory, visual and somatosensory responses: (a) an abnormal magnitude of transient ERP responses, (b) a decrease in the power of oscillations following transient or sustained stimulation, and (c) reduced temporal precision of oscillations. Reduced temporal precision can be measured as the temporal relationship between oscillations and the stimulus ('phase locking'), as well as between oscillations measured in different brain areas ('phase coherence') or in different trials ('intertrial coherence'). For a more detailed description of the analysis methods, see (Gandal et al., 2012; Lee et al., 2003). Unless otherwise indicated, findings on changes in oscillatory power refer to evoked, stimulus-locked activity, which is a measure of neuronal entrainment by the stimulus, as opposed to induced activity, which is stimulus-independent and reflects the intrinsic oscillatory properties of the 
neuronal network. A summary of the neurophysiological measures of sensory processing that are affected in schizophrenia is provided in Table 3.

TABLE 3. Overview of electrophysiological alterations in schizophrenia. Less frequent findings are shown in [] brackets. For details and references, see text.

\begin{tabular}{|c|c|c|c|c|c|}
\hline measure & ERPs (amplitude) & \multicolumn{2}{|c|}{ oscillations (power) } & \multicolumn{2}{|c|}{ phase } \\
\hline stimulus & transient & transient & sustained & transient & sustained \\
\hline $\begin{array}{l}\text { auditory } \\
\text { domain }\end{array}$ & P50, P1, N1, MMN & $\begin{array}{l}\text { theta, alpha, } \\
\text { beta, gamma } \\
\text { [also delta] }\end{array}$ & $\begin{array}{l}\text { gamma } \\
\text { [also 2-16 } \\
\mathrm{Hz} \text { ] }\end{array}$ & $\begin{array}{l}\text { intertrial } \\
\text { coherence }\end{array}$ & $\begin{array}{l}\text { intertrial } \\
\text { coherence, } \\
\text { phase } \\
\text { coherence }\end{array}$ \\
\hline $\begin{array}{l}\text { visual } \\
\text { domain }\end{array}$ & $\begin{array}{l}\text { C1, P1, N1 [also N1b, N2, } \\
\text { N170/P2, MMN, P300] }\end{array}$ & $\begin{array}{l}\text { gamma } \\
\text { [also delta, } \\
\text { theta, alpha, } \\
\text { beta] }\end{array}$ & $\begin{array}{l}\text { beta, } \\
\text { gamma }\end{array}$ & $\begin{array}{l}\text { phase } \\
\text { locking, } \\
\text { intertrial } \\
\text { coherence }\end{array}$ & \\
\hline $\begin{array}{l}\text { somato- } \\
\text { sensory } \\
\text { domain }\end{array}$ & $\begin{array}{l}\text { P1 (15 ms), N1 (20 ms), P2 } \\
\text { ( } 25 \mathrm{~ms}), \mathrm{N} 2 \text { ( } 35 \mathrm{~ms}), \mathrm{P} 3 \text { ( } 45 \\
\text { ms), N3 (65 ms), } \\
\text { P6 ( } 250 \mathrm{~ms}), \text { P7 ( } 380 \mathrm{~ms}), \\
\text { N7 ( } 400 \mathrm{~ms}), \mathrm{N} 8(500 \mathrm{~ms})\end{array}$ & beta, gamma & $\begin{array}{l}\text { beta, } \\
\text { gamma } \\
\text { [also alpha } \\
\text { and } 40-450 \\
\text { Hz power] }\end{array}$ & $\begin{array}{l}\text { intertrial } \\
\text { coherence }\end{array}$ & $\begin{array}{l}\text { phase } \\
\text { locking }\end{array}$ \\
\hline
\end{tabular}

\subsubsection{Neurophysiological deficits in the auditory domain}

In the auditory domain, both ERPs and event-related oscillations (EROs) have been measured following single tone or noise stimuli to detect response differences in schizophrenic subjects. In response to transient stimuli, changes in the P50, P1 and N1 ERP responses have been identified using the oddball task (Foxe et al., 2011; Javitt et al., 2000), the paired-click paradigm (BrockhausDumke et al., 2008; Chen et al., 2013; Hall et al., 2011), the PPI paradigm (Schall et al., 1997), and an auditory reaction time paradigm (Leicht et al., 2011; Leicht et al., 2010; Wynn et al., 2014). Basically, whenever a large response was seen in normal subjects (e.g. in oddball and reaction time paradigms), schizophrenic patients showed reduced activity, and when a diminished response was expected (e.g. in PPI or paired click paradigms), schizophrenic subjects showed increased activity. The reduction in ERP response magnitude to infrequent stimuli in the oddball task can be interpreted as an impairment in stimulus detection, whereas the increase in response to normally suppressed stimuli in a gating paradigm (PPI and paired click) suggests a failure to filter out irrelevant stimuli. It is likely that both phenomena contribute to sensory and attentional processing deficits (Javitt, 2009b). Even abnormalities in later ERP components, such as the MMN, may reflect 
sensory disturbances. Patient studies found that a decrease in MMN response in auditory oddball tasks was associated with decreased tone detection thresholds (Todd et al., 2003), with deficits in matching tones differing in pitch (Javitt et al., 2000), and with impairments in recognizing emotional prosody (Jahshan et al., 2013).

In addition to abnormal ERP responses, EROs measured in response to single stimuli are also altered in schizophrenic subjects. For example, in a paired-click paradigm patients showed reduced power in the alpha/theta range $(5-12 \mathrm{~Hz}$ ) for both stimuli (Hong et al., 2008a), and reduced power in the beta/gamma range $(13-45 \mathrm{~Hz}$ ) in response to both stimuli (Hall et al., 2011). Another study analyzed responses to the first stimulus in the paired click paradigm and found reduced $1-20 \mathrm{~Hz}$ and normal 20-50 Hz evoked and induced power (Blumenfeld and Clementz, 2001). The finding of impaired processing of the first stimulus indicates that deficits in normal auditory stimulus processing contribute to the gating impairment in schizophrenic patients, in addition to altered processing of the second stimulus that indicates a filtering deficit. Further research using the auditory oddball paradigm demonstrated reductions in delta, theta and induced gamma power (28$48 \mathrm{~Hz}$ ) in response to target tones, and decreased theta, alpha and induced gamma power in response to non-targets in schizophrenic patients (Basar-Eroglu et al., 2009). Low evoked delta, theta and alpha power in patients was suggested to derive from reduced intertrial coherence (BasarEroglu et al., 2009). Reductions in induced gamma $(37-41 \mathrm{~Hz})$ have further been demonstrated in response to infrequent target stimuli in the oddball paradigm. These changes were detected only in patients diagnosed with the non-deficit type of schizophrenia (with positive symptoms that are responsive to treatment), but not in patients with the deficit-type (with treatment-resistant, persistent negative symptoms; Bucci et al., 2007). In addition to deficits in induced gamma, other patient studies using the oddball paradigm showed reductions in evoked gamma in response to target stimuli ( $40 \mathrm{~Hz}$; Gallinat et al., 2004), and in response to target and non-target stimuli (30-80 $\mathrm{Hz}$; Lenz et al., 2011). In a different line of research, reductions in the gamma response $(32-48 \mathrm{~Hz})$, the $40 \mathrm{~Hz}$ intertrial coherence and the $\mathrm{N} 1$ amplitude have been reported in patients during a pitch discrimination task (Leicht et al., 2011; Leicht et al., 2010).

Similar to abnormal responses to transient stimuli, schizophrenic subjects also showed altered sustained responses to a train of auditory stimuli (Brenner et al., 2009). In particular, tones that were presented at $30-40 \mathrm{~Hz}$, or that were amplitude-modulated in this frequency range, have been found to elicit reduced evoked and induced steady-state responses in patients (Brenner et al., 2003a; Edgar et al., 2013; Krishnan et al., 2009; Kwon et al., 1999; Light et al., 2006; Mulert et al., 2011; Spencer et al., 2008; Tsuchimoto et al., 2011; Wilson et al., 2008), despite a normal N1 ERP response amplitude (Brenner et al., 2003a). Two studies also reported increased gamma oscillations. 
One found an enhancement in induced steady-state oscillations (in this study defined as total power minus evoked power) in response to a $40 \mathrm{~Hz}$ amplitude-modulated stimulus (Teale et al., 2008). Another study used 16-44 Hz amplitude-modulated noise bursts and demonstrated a relative increase in the evoked $26-44 \mathrm{~Hz}$ steady-state responses as compared to responses to lower frequency stimuli (18-24 Hz; Hamm et al., 2012). Indeed, not only responses in the gamma range, but also lower frequency responses seem to be affected in schizophrenia. Hamm and colleagues reported a diminished auditory response in the $2-8 \mathrm{~Hz}$ band when presenting trains of frequencymodulated (5 Hz or 16-44 Hz) noise stimuli to patients (Hamm et al., 2012; Hamm et al., 2011). Moreover, responses to an amplitude-modulated $40 \mathrm{~Hz}$ tone power were reduced in patients in the 4-16 Hz band in addition to a decrease in $40 \mathrm{~Hz}$ steady-state oscillations (Edgar et al., 2013).

Furthermore, studies employing sustained stimulation indicate that the temporal precision of auditory neuronal responses is diminished in schizophrenia. During $30-40 \mathrm{~Hz}$ stimulation, patients showed delayed phase locking (Kwon et al., 1999), reduced intertrial coherence (Edgar et al., 2013; Hamm et al., 2011; Krishnan et al., 2009; Light et al., 2006; Teale et al., 2008) and impaired interhemispheric phase coherence between primary auditory cortices (Mulert et al., 2011). The lack of temporal precision was reported to correlate with both positive (Mulert et al., 2011) and negative symptoms (Hamm et al., 2011). In addition, patients have been found to display lower intertrial coherence during $80 \mathrm{~Hz}$ stimulation, which correlated negatively with auditory hallucination scores (Tsuchimoto et al., 2011).

\subsubsection{Neurophysiological deficits in the visual domain}

In the visual domain, schizophrenia-related alterations in ERP magnitude have been reported for several ERP responses to transient visual stimulation, most commonly for the P1 and N1 components (Table 1). For example, amplitude reductions in $\mathrm{P} 1$, as well as $\mathrm{N} 1$, responses have been reported in patients when viewing low spatial frequency gratings (Butler et al., 2007) and illusory squares (Spencer and Ghorashi, 2014; Spencer et al., 2003; Spencer et al., 2004). A decrease in P1 amplitude, but not in N1 amplitude, was found in patients when presenting fragmented line drawings (Foxe et al., 2001) or checks with low-luminance contrast (Schechter et al., 2005). Another study found an enhanced P1 response during a motion detection task in patients (Wang et al., 2010). While N1 amplitudes were normal in patients, the magnitude of the N2 response $(400 \mathrm{~ms}$, superior parietal cortex) was reduced, which correlated with poor detection performance (Wang et al., 2010).

Various other ERP components have also been investigated and found to be affected in schizophrenia. These include the $\mathrm{C} 1$ component (90 ms, primary visual cortex) that was reduced in patients when presenting gratings with low spatial frequency (Butler et al., 2007) or checkerboard patterns (Nunez et al., 2013). Reductions in the C1 response, as well as in the N1b response (146 
ms), have also been associated with impaired visual cortical plasticity in schizophrenia patients (Çavuş et al., 2012). Following a $9 \mathrm{~Hz}$ stimulation paradigm designed to elicit potentiation of visual evoked potentials, patients showed less enhancement in $\mathrm{C} 1$ and $\mathrm{N} 1 \mathrm{~b}$ amplitudes in response to low frequency $(0.8 \mathrm{~Hz})$ stimulation as compared to controls (Çavuş et al., 2012). Moreover, the occipital N170/P2 components were found to be increased in patients during an emotional face recognition task (Ramos-Loyo et al., 2009). Furthermore, recent studies employing a visual oddball paradigm demonstrated a decrease in the MMN response (Neuhaus et al., 2013), as well as a reduction in P300 and N1 amplitudes in schizophrenic subjects (Oribe et al., 2013).

Apart from changes in ERPs, transient stimuli have also been found to elicit abnormal EROs in schizophrenic subjects. Patients showed diminished gamma band activity in the $24-48 \mathrm{~Hz}$ range when viewing illusory squares (Spencer et al., 2003; Spencer et al., 2004), and altered theta and alpha activity during an emotional face recognition task (Ramos-Loyo et al., 2009). Moreover, reduced gamma $(30-40 \mathrm{~Hz})$ oscillations have been linked to deficits in visual masking in schizophrenic patients (Green et al., 2003a; Wynn et al., 2005). In response to illusory squares, alterations in phase locking and intertrial coherence in the 24-48 $\mathrm{Hz}$ band of EROs have been demonstrated in schizophrenic subjects, indicating deficits in neuronal synchrony that might underlie perceptual deficits (Spencer et al., 2003; Spencer et al., 2004). Furthermore, normal induced gamma power (40$70 \mathrm{~Hz}$ ), but reduced phase locking of 20-30 Hz EROs have been reported in patients when viewing Mooney faces, which are normally recognized using the Gestalt principle of perceptual closure (Uhlhaas et al., 2006). Follow-up studies presenting Mooney faces to patients and controls revealed reduced intertrial coherence $(25-60 \mathrm{~Hz})$, decreased evoked and induced gamma $(25-140 \mathrm{~Hz})$, and increased induced beta (13-25 Hz) in schizophrenic subjects (Grutzner et al., 2013; Sun et al., 2013). Most studies report schizophrenia-related changes in beta and gamma oscillations, but alterations in low-frequency oscillations are also evident. For example, reductions in theta and delta bands were observed in patients in a visual go/no paradigm, in which subjects had to respond or withhold a response to target stimuli (Bates et al., 2009).

In addition to changes in visual EROs during transient stimulation, schizophrenic patients have also been found to display deficits in the magnitude of EROs during sustained stimulation. Studies identified schizophrenia-related reductions in power of steady state visual evoked potentials at the stimulation frequency, in particular in response to stimuli flickering at $13 \mathrm{~Hz}$ (Butler et al., 2009; Butler et al., 2005; Calderone et al., 2013) and at 17-40 Hz (Krishnan et al., 2005). In addition, an increase in non-phase-locked (noise) power was reported in patients at 4-20 Hz stimulation (Krishnan et al., 2005). 


\subsubsection{Neurophysiological deficits in the somatosensory domain}

To elucidate the neuronal mechanisms underlying somatosensory deficits, studies typically employed transient stimulation such as passive vibrotactile or median nerve stimulation while sensory-evoked potentials were recorded using EEG or MEG. It has been shown that early (50-60 ms) somatosensory ERPs in schizophrenic patients differ from normal subjects in terms of their amplitude (Ikuta et al., 2007; Shagass, 1977; Shagass et al., 1978, 1979), cortical localization (Kawamura et al., 1996; Reite et al., 2003; Shagass et al., 1978) and lateralization (Cooper et al., 1985; Reite et al., 2003). Surprisingly, somatosensory ERP components showed increased amplitudes in schizophrenic subjects, while visual and auditory ERP amplitudes were reduced (Ikuta et al., 2007; Shagass, 1977). An increase in somatosensory ERP amplitude has also been found in patients using an oddball paradigm for median nerve stimulation, but the increase was restricted to the early part of the response $(40 \mathrm{~ms})$, and a decreased amplitude was found for later parts of the response (140300 ms; Huang et al., 2010). In addition, somatosensory ERPs in patients have been characterized as highly stable during the first $100 \mathrm{~ms}$, and more variable thereafter - a pattern not observed for auditory or visual ERPs (Shagass et al., 1979). Furthermore, in a somatosensory paired pulse paradigm, schizophrenic subjects showed reduced sensory gating in the secondary somatosensory cortex (Thoma et al., 2007), but normal gating in primary somatosensory cortex (Arnfred and Chen, 2004; Edgar et al., 2005).

In a different line of research, somatosensory evoked potentials were measured when subjects experienced the rubber hand illusion. The illusion is elicited when subjects view an artificial hand being stroked while their own hand, hidden behind a screen, is being stroked simultaneously. Subjects with schizophrenia experienced the illusion faster and more intensely (Peled et al., 2000), and showed altered somatosensory evoked potentials as compared to controls (Aspell et al., 2012; Peled et al., 2003). In particular, patients displayed an increase in the early ERP component (P40, 30$50 \mathrm{~ms}$ ), which originates in the primary somatosensory cortex, and a decrease in the late ERP component (110-200 ms), which is thought to arise from higher-level somatosensory regions in the parietal cortex (Aspell et al., 2012). Furthermore, transient somatosensory proprioceptive stimulation has been employed to characterize changes in ERP amplitudes and oscillatory power in schizophrenia. A sudden change in a hand-held weight elicited increased ERP responses (frontal N70 and central P200), as well as reduced beta $(19-22 \mathrm{~Hz})$ and gamma $(30-41 \mathrm{~Hz})$ power and decreased intertrial phase coherence in patients (Arnfred, 2012; Arnfred et al., 2006; Arnfred et al., 2011).

Only a few studies have used sustained vibrotactile stimulation, and each of them only tested a single stimulation frequency. One study presented patients with a $6 \mathrm{~Hz}$ tactile stimulus and measured an increased amplitude of $40-450 \mathrm{~Hz}$ oscillations, and a delayed onset of $450-850 \mathrm{~Hz}$ 
oscillations compared to controls (Norra et al., 2004; Waberski et al., 2004). The abnormal activation pattern was interpreted to reflect deficient somatosensory thalamic and/or cortical processing, and was found to correlate with the occurrence of delusions and apathy in patients (Waberski et al., 2004). In a second study, a $25 \mathrm{~Hz}$ tactile stimulation protocol was used and a decrease in intertrial coherence was found in patients compared to normal subjects (Teale et al., 2013). Finally, a third study applied $100 \mathrm{~Hz}$ stimulation and showed reduced interaction (i.e. correlation) between alpha $(10 \mathrm{~Hz})$ and gamma oscillations ( $35 \mathrm{~Hz}$ ) in schizophrenic subjects (White et al., 2010).

\subsubsection{Neurochemical changes}

Glutamatergic, GABAergic and serotonergic mechanisms ${ }^{1}$ have been proposed for sensory and perceptual dysfunctions in schizophrenia. Research has provided some indirect evidence for a schizophrenia-related dysfunction of the glutamatergic N-methyl-D-aspartate (NMDA) receptor. One study assessed visual EEG responses to low contrast stimuli in patients and revealed a reduction in contrast gain (Butler et al., 2005). Based on findings in animal models (Fox et al., 1990), the authors argued that the reduction in contrast gain is specific to an impairment in NMDA function (Butler et al., 2005). Another study revealed a relative enhancement in EEG gamma oscillations during sustained $26-44 \mathrm{~Hz}$ auditory stimulation in schizophrenic subjects when compared to activity during 18-24 Hz stimulation (Hamm et al., 2012). It has been proposed that this enhancement reflects an NMDA dysfunction since NMDA antagonists produce similar effects in pharmacological models of schizophrenia (Hamm et al., 2012; Javitt, 2007). In support of this view, the NMDA antagonist ketamine also increased gamma oscillations in response to auditory $40 \mathrm{~Hz}$ stimulation in healthy humans (Plourde et al., 1997). However, in contradiction to the findings by Hamm and colleagues (Hamm et al., 2012), most studies report a decrease, rather than an increase, in auditory steadystate responses in schizophrenic patients (see Section 3.2.3.1). A recent review argued that this decrease might reflect impaired GABAergic signaling (O'Donnell et al., 2013), given that reduced auditory steady state responses can be mimicked by treatment with the $G A B A_{A}$ agonist muscimol in a rat schizophrenia model using neonatal ventral hippocampal lesioning (Vohs et al., 2010).

Further evidence supports a connection between schizophrenia and GABAergic deficits in auditory and visual cortices. Using fluorescence microscopy, one study revealed decreased levels of an enzyme involved in GABA synthesis (glutamate decarboxylase 65, or GAD65) in layer III inhibitory boutons in primary auditory cortex of schizophrenic patients (Moyer et al., 2012). Furthermore, spectroscopic measurements of the GABA concentration showed a reduction in primary visual cortex that correlated with deficits in orientation-specific surround suppression in schizophrenic subjects

\footnotetext{
${ }^{1}$ Dopaminergic mechanisms, while playing an important role in cognitive dysfunction in schizophrenia, have hitherto not been reported to be disrupted in primary sensory areas in schizophrenic patients.
} 
(Yoon et al., 2010). Another study also reported a reduction in GABA levels in the occipital cortex, but found no association with performance in tasks assessing visual sensitivity and motion perception (Kelemen et al., 2013). In addition, post-mortem analysis of the primary visual cortex in schizophrenic patients revealed a significant reduction in GABA-related transcripts (Hashimoto et al., 2008). The study identified the largest reductions in somatostatin and parvalbumin levels, and smaller reductions in the expression of GAD67, GAT-1, GABA $A_{A}$ receptor subunits $\alpha 1$ and $\delta$, and GAD65 (Hashimoto et al., 2008). Further research is required to assess neurochemical changes in other sensory cortices.

Another line of evidence suggests serotonergic mechanisms as the basis for schizophreniarelated impairments in primary auditory cortex functioning. It has been shown that auditory ERPs are less dependent on the loudness of the stimulus in patients compared to controls, as evidenced by a reduction of the N1/P2 components (Gudlowski et al., 2009; Juckel et al., 2003; Juckel et al., 2008). A weak loudness dependence of primary auditory cortex responses is thought to reflect abnormally increased serotonergic neurotransmission (Hegerl et al., 2001). Loudness dependence can be restored in patients through treatment with the serotonergic antagonists clozapine or olanzapine (Juckel et al., 2003).

\subsubsection{Neuropathological changes}

Reductions in gray matter volume in sensory areas are a common finding in schizophrenic patients (Section 3.2.1). However, only a few studies have investigated the neuropathological underpinnings, i.e. changes in cell number and density (cell number divided by cortical volume), and in neuropil. The results derived from post-mortem tissue analyses are mostly contradictory. With regard to the number of cells, one study reported a reduction in neuronal number in primary visual cortex (DorphPetersen et al., 2007), while others did not find changes in primary auditory cortex (Dorph-Petersen et al., 2009), or in occipital and temporal areas (Pakkenberg, 1993). Moreover, studies on neuronal density in primary auditory and visual areas reported a density increase (Dorph-Petersen et al., 2009; Selemon et al., 1995), decrease (Heckers, 1997) or no change at all (Cotter et al., 2004; DorphPetersen et al., 2007; Wheeler et al., 2006).

Changes in neuropil have been investigated in both auditory and visual areas (for review, see Glausier and Lewis, 2013). In the primary visual cortex, no abnormalities in spine density of layer III pyramidal neurons were identified in schizophrenic subjects (Glantz and Lewis, 2000). In primary and association auditory cortices, patient studies revealed a decrease in the density of axon terminals and in the number of dendritic spines, as well as a reduction in somal volume of layer III pyramidal cells (Sweet et al., 2007; Sweet et al., 2004; Sweet et al., 2009). In contrast, excitatory and thalamocortical boutons were reported to be normal in patients' primary auditory cortices (Moyer et 
al., 2013). The findings of less dendritic spines but normal excitatory bouton density and number indicate that connectivity might be altered in auditory areas (Moyer et al., 2013). Thus, both a reduction in neuropil and a decrease in connectivity might account for deficits at least in the auditory domain. According to the reduced neuropil hypothesis of schizophrenia, reductions in cortical thickness in the prefrontal cortex and other cortices are due to a decreased amount of neuropil, rather than a change in the density of neurons (Selemon and Goldman-Rakic, 1999). It is currently not clear whether this hypothesis can be generalized to the sensory cortices since the available data on cellular density in sensory regions are contradictory, and since reductions in neuropil have so far been demonstrated only in the auditory cortex.

\section{The role of sensory dysfunctions in schizophrenia-related cognitive impairments}

A growing body of evidence suggests that cognitive deficits in schizophrenic patients cannot be understood in isolation, but need to be viewed in the context of alterations in early sensory processing (Butler, 2009; Haenschel and Linden, 2011; Javitt, 2009a; Rado, 1953; Uhlhaas and Mishara, 2007). The following section provides an overview of several lines of research supporting the notion that low-level (sensory) impairments contribute to higher-level (cognitive) abnormalities in schizophrenia. In addition, possible mechanistic links between sensory and cognitive deficits are reviewed.

\subsection{Various effects of sensory processing deficits on cognitive functioning}

One way in which processing deficits in primary sensory cortices affect higher-order functions is by impaired encoding of sensory information (Javitt, 2009b), thus producing 'output errors' that are transmitted to downstream brain areas. For example, evidence indicates that dysfunctions in auditory pitch processing may form the basis of difficulties in recognizing emotion and prosody during speech, whereas low-level visual deficits may contribute to impairments in face recognition (Javitt, 2009b). Difficulties in interpreting faces and prosody may, in turn, lead to disturbed emotional processing and thus poor social cognition in schizophrenic subjects (Javitt, 2009a). In addition, basic visual deficits have been proposed to contribute to problems with reading and attention (Javitt, 2009b), thus potentially affecting intellectual abilities of patients. Moreover, altered auditory and visual processing has been implicated in abnormal self-experience and in the formation of delusions (Uhlhaas and Mishara, 2007).

Furthermore, research showed that the function of primary sensory cortices is not restricted to sensory tasks, but also includes higher cognitive operations such as working memory and attention (Cohen et al., 2013; Javitt, 2009a; Muckli, 2010; Rosenkranz and Rothwell, 2004; Super, 
2003; Treue, 2001). Thus, it is possible that structural and functional changes at the level of primary sensory cortices affect the way top-down signals from higher-order cortices are received and processed ('input processing deficits').

Finally, sensory cortices play a role in the prediction of self-produced actions, such as eye movements, speech or touch (Blakemore et al., 2000; Dierks et al., 1999; Houde et al., 2002; Pynn and DeSouza, 2013). Normally, activity in sensory areas is reduced during self-generated actions to suppress the perception and awareness of the sensory consequences (Blakemore et al., 2000; Houde et al., 2002). In schizophrenic patients, however, sensory areas, including the secondary somatosensory cortex (Shergill et al., 2014), are unusually active during self-generated actions (Dierks et al., 1999; Ford and Mathalon, 2004; Ford et al., 2013; Heinks-Maldonado et al., 2007). This hyperactivation, or lack of inhibition, has been proposed to contribute to the development of hallucinations and delusions (Fletcher and Frith, 2009; Ford and Mathalon, 2004; Ford et al., 2001). The failure to correctly predict the consequences of internal processes is usually attributed to a deficit in sending corollary discharge or an efference copy from motor and frontal cortices to sensory cortices (Blakemore et al., 2000; Fletcher and Frith, 2009; Ford and Mathalon, 2004). In addition, it is conceivable that abnormal processing of motor information in the sensory areas also contributes to large 'prediction errors' and thus an inability to differentiate between internal and external stimuli.

\subsection{Mechanisms of disturbed interaction between low-level and high-level brain areas}

How are the effects of sensory output errors, input processing deficits and prediction errors on cognitive functioning mediated at the neural level? Previous research suggests that mechanisms such as the precise timing of neural activity are important for an effective information transfer between brain areas (Fries, 2005; Singer and Gray, 1995; Varela et al., 2001). In particular, beta and gamma oscillations are thought to be important for synchronizing neural activity within and between brain regions, thus allowing important features from the environment to be extracted and "bound" together (Fries, 2005; Singer and Gray, 1995). In schizophrenic patients, the magnitude of beta and gamma oscillations is reduced in primary sensory areas as well as in higher-level areas such as prefrontal and temporal cortices (Brenner et al., 2009; Gandal et al., 2012; Uhlhaas and Singer, 2010). In addition, several studies report a reduction in temporal precision, including phase locking, phase coherence and intertrial coherence. The deficits were noted predominantly in the $20-40 \mathrm{~Hz}$ range in both low- and high-level regions (Brenner et al., 2009; Gandal et al., 2012; Uhlhaas and Singer, 2010). Together, these findings can be interpreted to reflect an impairment in information transfer within and between brain areas in schizophrenic patients.

Apart from precisely timed neural activity, low and high level areas in patients display several other deficits that may affect communication between these regions. At the functional level, 
these deficits include an increased level of neural noise (Krishnan et al., 2005; Winterer et al., 2000), and a change in response amplitude in schizophrenic patients (Keshavan et al., 2008; Sections 3.1 and 3.2.2). Whether this change consists of an amplitude increase or reduction may depend on stimulus characteristics (Martinez et al., 2008) and the behavioral state of the subject (Salomon et al., 2011).

In addition to functional deficits, low and high level regions in schizophrenic subjects show aberrant connectivity patterns, neuropathological changes in white and gray matter, as well as neurochemical alterations (Keshavan et al., 2008; Sections 3.1, 3.2.1, 3.2.4 and 3.2.5). Importantly, all these factors affect the excitatory-inhibitory balance in the brain. It is conceivable that functional deficits comprising altered neural oscillations, cortical noise and response amplitudes are tightly linked to an imbalance in the excitatory-inhibitory circuitry. As a result, information transmission within and between low- and high-level brain areas is impaired, and stimulus encoding and processing is compromised in schizophrenia. This line of reasoning is in accordance with the functional dysconnectivity hypothesis of schizophrenia, which attributes sensory and cognitive deficits to abnormally reduced or enhanced interactions between neuronal networks (Stephan et al., 2009; Uhlhaas, 2013; Uhlhaas and Singer, 2010).

\section{Mouse models offer a tool to study the cellular basis of schizophrenia-related dysfunctions}

Despite the progress in illuminating the functional underpinnings of sensory dysfunctions in schizophrenia using EEG, MEG and fMRI in humans, the cellular mechanisms are poorly understood. Genetic mouse models of schizophrenia provide researchers with the possibility to conduct invasive recordings with maximal temporal and spatial resolution, and to investigate the contribution of a specific gene that enhances the risk to develop schizophrenia in humans. Various animal models of schizophrenia exist that have proven useful in understanding different disease parameters, such as cognitive, behavioral and genetic alterations (Gainetdinov et al., 2001; Lipska and Gogos, 2011; Papaleo et al., 2012; Young et al., 2010). For example, mice heterozygous for the schizophrenia risk gene NRG1 (Meyer and Birchmeier, 1995) display various endophenotypes of schizophrenia, including deficits in auditory novelty detection (MMN; see Table 1 for details), contextual fear conditioning and social interaction (Ehrlichman et al., 2009), as well as hyperlocomotion and impaired sensory gating after pharmacological challenge (Duffy et al., 2008). While many promising mouse models of schizophrenia are available (Gainetdinov et al., 2001; Papaleo et al., 2012), the NRG1 mutants are of particular interest. NRG1 has been associated with an increased susceptibility for schizophrenia in several meta analyses (Agim et al., 2013; Li et al., 2006; Munafo et al., 2006), ranks 16th among more than 500 reported risk genes (Sun et al., 2008), and shows a strong 
association with schizophrenia-related endophenotypes (Greenwood et al., 2011; Greenwood et al., 2012). In addition, evidence indicates that NRG1 may be particularly linked to a specific subtype of schizophrenia spectrum disorders, the nondeficit type of schizophrenia (Bakker et al., 2004). Patients of the nondeficit type generally have a better clinical outcome since their negative symptoms do not persist all the time, and their positive symptoms improve with medication (Grover and Kulhara, 2008; Kirkpatrick et al., 2001). Linking disease subtypes to specific genetic markers is an important step towards understanding the range of schizophrenia symptoms and their severity, and towards developing more targeted treatments for patients.

\subsection{NRG1 as a schizophrenia susceptibility gene}

A large number of studies have identified and replicated an association of variants of the NRG1 gene with schizophrenia in diverse populations (Agim et al., 2013; Alaerts et al., 2009; Bousman et al., 2013; Fukui et al., 2006; Georgieva et al., 2008; Greenwood et al., 2011; Greenwood et al., 2012; Huertas-Vazquez et al., 2013; Kukshal et al., 2013; Li et al., 2006; Li et al., 2004; Mohamad Shariati et al., 2011; Munafo et al., 2006; Naz et al., 2011; Papiol et al., 2011; Stefansson et al., 2003; Thomson et al., 2007; Walker et al., 2010; Yang, 2012; Yokley et al., 2012). Specific changes in the NRG1 gene, or 'polymorphisms', have been associated with various endophenotypes of schizophrenia (Table 4), including a reduction and delay of the auditory P300 response (Kang et al., 2012), impairments in sensorimotor gating (PPI; Hong et al., 2008b; Roussos et al., 2011), as well as deficits in smooth eye pursuit and antisaccade tasks (Schmechtig et al., 2010; Smyrnis et al., 2011). Furthermore, NRG1 polymorphisms have been linked to deficits in working memory, executive functioning, verbal learning, abstraction, spatial processing, sensory-motor dexterity, as well as to alterations in the P50 response amplitude (first stimulus) and the habituation to the startle response in a PPI paradigm (Greenwood et al., 2011; Greenwood et al., 2012). Other studies showed that NRG1 polymorphisms are connected with alterations in $\mathrm{fMRI}$ activation patterns during visual matching (Mechelli et al., 2010), sentence completion (Hall et al., 2006), as well as memory encoding and retrieval (Krug et al., 2010). In subjects with familial risk for schizophrenia, NRG1 polymorphisms are related to an increased risk of developing psychotic symptoms and a reduction in premorbid IQ (Hall et al., 2006). These reports strongly indicate a detrimental effect of NRG1 mutations on cognitive function. Nevertheless, there might also be positive effects and thus evolutionary benefits associated with NRG1 polymorphisms, as researchers found a link between NRG1 polymorphisms and creativity in people scoring high on measures of intellectual and academic achievement (Keri, 2009). 
TABLE 4. Endophenotypes of schizophrenia associated with NRG1 polymorphisms. EEG: electroencephalography. EMG: electromyography. fMRI: functional magnetic resonance imaging. PPI: prepulse inhibition.

\begin{tabular}{|c|c|c|c|}
\hline method & task & affected outcome measures & references \\
\hline \multirow[t]{6}{*}{ behavior } & $\begin{array}{l}\text { working memory: } \\
\text { letter-number span }\end{array}$ & $\begin{array}{l}\text { repetition of letters and } \\
\text { numbers in the order dictated }\end{array}$ & $\begin{array}{l}\text { (Greenwood et } \\
\text { al., 2012) }\end{array}$ \\
\hline & $\begin{array}{l}\text { executive functioning: } \\
\text { Wisconsin Card Sorting Test - } \\
64 \text { Card Version }\end{array}$ & $\begin{array}{l}\text { number of preservative } \\
\text { responses and categories } \\
\text { completed }\end{array}$ & $\begin{array}{l}\text { (Greenwood et } \\
\text { al., 2012) }\end{array}$ \\
\hline & $\begin{array}{l}\text { verbal learning: } \\
\text { California Verbal Learning Test }\end{array}$ & recall of words & $\begin{array}{l}\text { (Greenwood et } \\
\text { al., 2011) }\end{array}$ \\
\hline & $\begin{array}{l}\text { abstraction: } \\
\text { four objects from which to } \\
\text { choose the one that does not } \\
\text { belong }\end{array}$ & error rate & $\begin{array}{l}\text { (Greenwood et } \\
\text { al., 2011) }\end{array}$ \\
\hline & $\begin{array}{l}\text { spatial processing: } \\
\text { recognizing two lines presented } \\
\text { at an angle in a simultaneously } \\
\text { presented array of lines }\end{array}$ & error rate & $\begin{array}{l}\text { (Greenwood et } \\
\text { al., 2011) }\end{array}$ \\
\hline & $\begin{array}{l}\text { sensory-motor dexterity: } \\
\text { mouse clicks on target stimulus }\end{array}$ & error rate & $\begin{array}{l}\text { (Greenwood et } \\
\text { al., 2011) }\end{array}$ \\
\hline \multirow[t]{2}{*}{$\begin{array}{l}\text { eye } \\
\text { tracking }\end{array}$} & $\begin{array}{l}\text { smooth eye pursuit: } \\
\text { visual target moving at different } \\
\text { speeds }\end{array}$ & $\begin{array}{l}\text { distance (error) to target and } \\
\text { saccade frequency }\end{array}$ & $\begin{array}{l}\text { (Smyrnis et al., } \\
\text { 2011) }\end{array}$ \\
\hline & $\begin{array}{l}\text { antisaccade task: } \\
\text { target dot jumps from screen } \\
\text { center to periphery and subjects } \\
\text { are asked to look at mirror image } \\
\text { position }\end{array}$ & $\begin{array}{l}\text { antisaccade gain, measured as } \\
\text { primary saccade amplitude } \\
\text { (suppressed reflex to follow } \\
\text { the target) divided by target } \\
\text { amplitude (mirror image } \\
\text { position) }\end{array}$ & $\begin{array}{l}\text { (Schmechtig et } \\
\text { al., 2010) }\end{array}$ \\
\hline EMG & $\begin{array}{l}P P I: \\
\text { auditory weak prepulse (S1) and } \\
\text { startle stimulus (S2) at 30-120 ms } \\
\text { interval }\end{array}$ & $\begin{array}{l}\text { suppression of startle } \\
\text { response and habituation of } \\
\text { the eye blink response to the } \\
\text { startle stimulus }\end{array}$ & $\begin{array}{l}\text { (Greenwood et } \\
\text { al., 2011; Hong } \\
\text { et al., 2008b; } \\
\text { Roussos et al., } \\
\text { 2011) }\end{array}$ \\
\hline \multirow[t]{2}{*}{ EEG } & $\begin{array}{l}P P I: \\
\text { auditory prepulse (S1) and startle } \\
\text { stimulus (S2) at } 500 \mathrm{~ms} \text { interval }\end{array}$ & $\begin{array}{l}\text { P50 amplitude to the startle } \\
\text { stimulus }\end{array}$ & $\begin{array}{l}\text { (Greenwood et } \\
\text { al., 2012) }\end{array}$ \\
\hline & $\begin{array}{l}\text { oddball: } \\
\text { two auditory stimuli: one } \\
\text { frequent tone and one rare target }\end{array}$ & $\begin{array}{l}\text { P300 amplitude and latency in } \\
\text { response to target }\end{array}$ & $\begin{array}{l}\text { (Kang et al., } \\
\text { 2012) }\end{array}$ \\
\hline
\end{tabular}

- table continued on the next page - 


\begin{tabular}{|c|c|c|c|}
\hline \multirow[t]{4}{*}{ fMRI } & $\begin{array}{l}\text { visual matching: } \\
\text { matching an image at the screen } \\
\text { bottom to one of two images } \\
\text { presented at the top of the } \\
\text { screen }\end{array}$ & $\begin{array}{l}\text { increased fMRI activation in } \\
\text { precuneus, cuneus, middle } \\
\text { occipital gyrus, angular gyrus, } \\
\text { caudate nucleus }\end{array}$ & $\begin{array}{l}\text { (Mechelli et al. } \\
\text { 2010) }\end{array}$ \\
\hline & $\begin{array}{l}\text { sentence completion: } \\
\text { Hayling sentence completion task }\end{array}$ & $\begin{array}{l}\text { decreased activity in medial } \\
\text { prefrontal cortex and } \\
\text { temporo-occipital junction }\end{array}$ & $\begin{array}{l}\text { (Hall et al., } \\
\text { 2006) }\end{array}$ \\
\hline & $\begin{array}{l}\text { memory encoding: } \\
\text { presentation of single pictures or } \\
\text { neutral faces }\end{array}$ & $\begin{array}{l}\text { lower activity in fusiform gyri, } \\
\text { cingulate gyrus, middle frontal } \\
\text { gyrus and middle occipital } \\
\text { gyrus }\end{array}$ & $\begin{array}{l}\text { (Krug et al., } \\
2010)\end{array}$ \\
\hline & $\begin{array}{l}\text { memory retrieval: } \\
\text { choosing a previously seen } \\
\text { picture or face among two images }\end{array}$ & $\begin{array}{l}\text { lower activity in middle } \\
\text { occipital gyrus }\end{array}$ & $\begin{array}{l}\text { (Krug et al., } \\
2010)\end{array}$ \\
\hline
\end{tabular}

\subsection{NRG1 signaling}

The NRG1 gene, together with the NRG2-4 genes, produces six types of NRG1 proteins (NRG1 I-VI; Fig. 1) and at least 31 isoforms through alternative splicing (Mei and Xiong, 2008). Most isoforms are synthesized as pro-proteins anchored to the cellular membrane, and undergo proteolytic cleavage (Corfas et al., 2004). All isoforms contain an epidermal growth factor (EGF)-like domain that signals through ErbB2-4 transmembrane receptor tyrosine kinases (Corfas et al., 2004). Various types of signaling pathways have been described, as reviewed by (Mei and Xiong, 2008). In the forward signaling pathway, the NRG1 transmembrane pro-protein is cleaved and acts as a ligand for the ErbB receptor, inducing ErbB dimerization. This leads to the activation of the ErbB kinase domain and the phosphorylation of the intracellular domains. The phosphorylation activates further signaling cascades, including the Raf-MEK-ERK and PI3K-Akt-S6K pathways that control gene transcription and translation in the nucleus. In backward signaling, the NRG1 pro-protein serves as a receptor for ErB4, thus stimulating intracellular signaling. In addition, the NRG1 pro-protein (NRG1 type III) can undergo proteolytic cleavage to release its intracellular domain, which then translocates to the nucleus and regulates the expression of the PSD95 protein (Mei and Xiong, 2008). Deficits in the NRG1-ErbB4 signaling pathway are thought to play an important role not only in schizophrenia, but may also be linked to other disorders, including Alzheimer's disease, epilepsy, bipolar disorder, depression, anxiety, and autism (Bertram et al., 2007; Fleck et al., 2012; Marballi et al., 2012; Pinto et al., 2010; Taylor et al., 2013; Wang et al., 2013). 


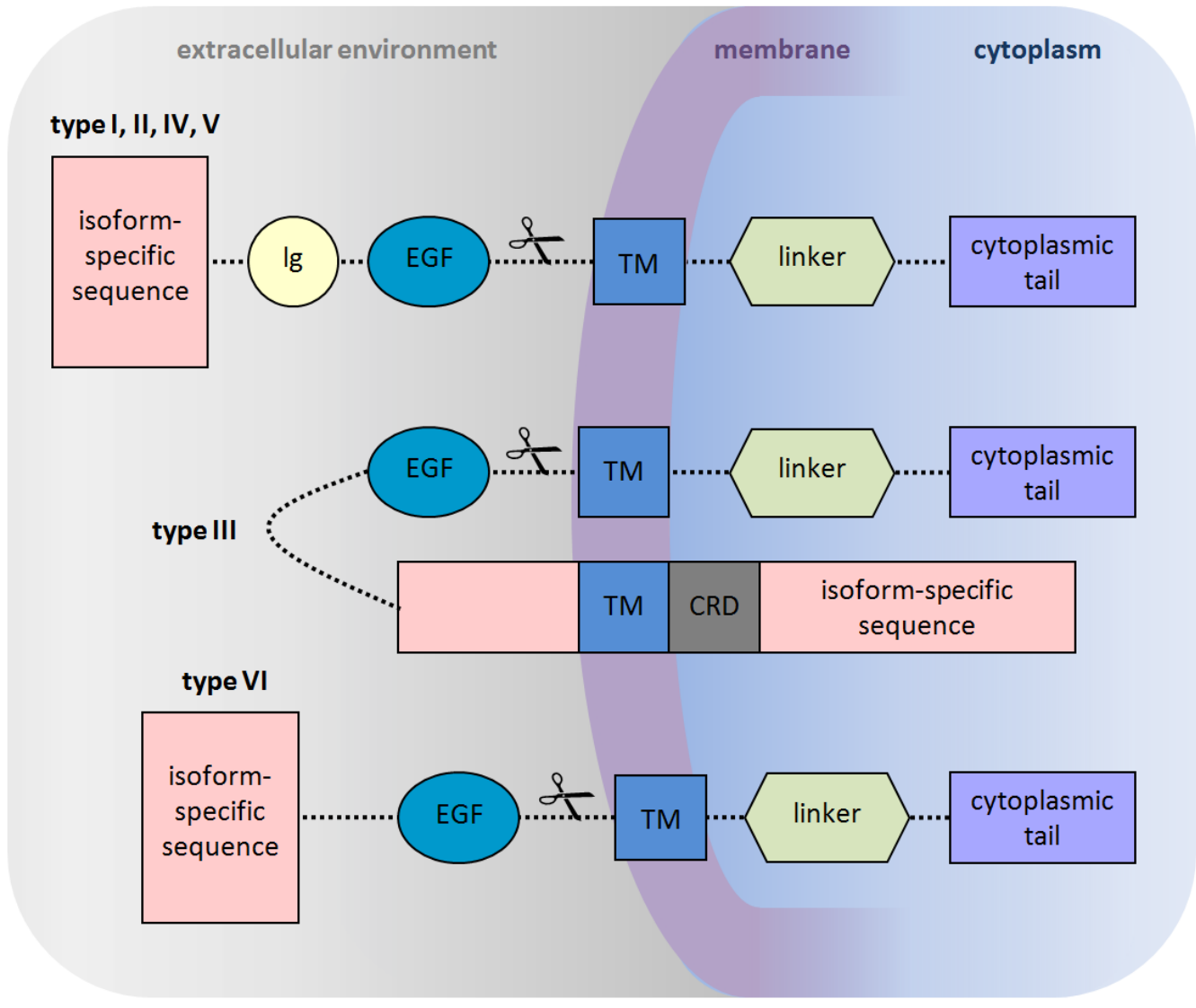

FIGURE 1. NRG1 isoforms and protein domains. All isoforms (I-VI) contain an epidermal growth factor (EGF)-like domain and a transmembrane (TM) domain. Types I, II, IV and V have an immunoglobulin (Ig)-like domain. Unlike the other isoforms, type III contains a cysteine-rich domain (CRD) as well as a TM domain in the type-specific sequence. Linker regions and cytoplasmic tails differ depending on the splice variant. Pro-membrane proteins are proteolytically cleaved at indicated sites (\&<). Figure modified based on (Mei and Xiong, 2008).

\section{$\underline{5.3 \text { NRG1 expression patterns }}$}

NRG1 is widely expressed in the peripheral and central nervous system (Gerecke et al., 2001; Ho et al., 1995; Meyer et al., 1997; Zhang et al., 2006). A hybridization study targeting all NRG1 isoforms showed that NRG1 is mainly expressed by neurons in the rat brain (Chen et al., 1994). High levels of the NRG1 transcripts were detected in sensory and motor neurons of the brainstem and spinal chord, in the cerebellum, and in various structures of the diencephalon, including the supraoptic nuclei, the reticular nucleus of the thalamus, the medial habenular nucleus, and the hypothalamus (Chen et al., 1994). In the cerebrum, NRG1 transcripts were found in the septal nuclei, the diagonal band of Broca, the basal nucleus of Meynert in the forebrain, the amygdala, the dentate gyrus of the hippocampus, and cortical neurons (Chen et al., 1994). Further studies showed that NRG1 isoforms are differentially expressed in different cortical layers in mice. Type I and II isoforms are mainly found in layers II, III and VIb, while type III is mainly localized in layer V (Mei and Xiong, 2008). 
Moreover, the expression of NRG1 type III has been specifically localized to the soma, axon and dendrites of cortical neurons (Chen et al., 2010a). These neurons mostly consisted of pyramidal cells, but an expression in inhibitory neurons cannot be excluded (Yachi Chen, personal communication). Furthermore, NRG1 type III has also been detected in pyramidal neurons of the amygdala and cingulate cortex (Jiang et al., 2013).

The NRG1 expression pattern described in rodents has been largely confirmed in the human brain (Law et al., 2004). In situ hybridization targeting all NRG1 isoforms revealed high expression patterns in cortical layers III-V (Law et al., 2004). In addition, immunohistochemical stainings against membrane-bound, but not soluble (type III) NRG1 isoforms revealed strong NRG1 expression in layers III and V, weaker expression in layers IV and VI, and no expression in layer I (Law et al., 2004). In schizophrenic patients, aberrant expression and cleavage of different NRG1 isoforms have been identified in the prefrontal cortex, hippocampus, and cerebellum (Bertram et al., 2007; Chong et al., 2008; Harrison and Law, 2006; Hashimoto et al., 2004; Law et al., 2006; Marballi et al., 2012; Parlapani et al., 2010).

\subsection{Functional significance of NRG1}

Various lines of research indicate that NRG1 and its receptor ErbB4 modulate excitatory and inhibitory synaptic transmission in neurons (Fazzari et al., 2010; Geddes et al., 2011; Hahn et al., 2006; Ting et al., 2011; Wen et al., 2010; Woo et al., 2007), which is perturbed in schizophrenic patients (Inan et al., 2013; Javitt, 2010; Lisman, 2012; Marsman et al., 2013; Wang, 2006). NRG1ErbB4 signaling has been implied in inhibitory synapse formation onto pyramidal cells (Fazzari et al., 2010), and in excitatory synapse formation onto GABAergic interneurons in mouse hippocampus and cortex (Ting et al., 2011). NRG-ErbB4 activation has also been implicated in enhancing the release of GABA in an activity-dependent fashion in rat prefrontal cortex (Woo et al., 2007). Moreover, NRG1ErB4 signaling has been found to modulate NMDA receptor activation by interacting with the PSD95 complex present in the postsynaptic densities of neurons. This interaction has been reported to be disturbed in schizophrenia (Hahn et al., 2006). NRG1 has further been found to activate the NR2B subunit of the NMDA receptor via ErbB4, Fyn and Pyk2 kinases in mouse hippocampal neurons (Bjarnadottir et al., 2007), and to regulate NMDA receptor function via Src in mouse hippocampus and prefrontal cortex (Pitcher et al., 2011). In addition, the NRG1-ErbB4 pathway controls $\alpha$-amino3-hydroxy-5-methyl-4-isoxazole propionic acid (AMPA) receptor activity in rat hippocampal pyramidal neurons (Li et al., 2007) and in mouse neocortical neurons (Abe et al., 2011). Furthermore, NRG1 is involved in the targeting of acetylcholine receptors to sensory axons (Hancock et al., 2008), and in nociceptive function in sensory neurons (Canetta et al., 2011). NRG1 also regulates 
acetylcholine receptor expression in hippocampal neurons projecting to the nucleus accumbens (Zhong et al., 2008). As a regulator of excitatory-inhibitory signal transmission, the NRG1-ErbB4 pathway directly affects cellular electrophysiology and plasticity, as demonstrated by deficits in hippocampal long-term potentiation and kainate-induced gamma oscillations in NRG1 and ErbB4 knockout mice (Bjarnadottir et al., 2007; Chen et al., 2010b; Fisahn et al., 2009).

Apart from synapse development, NRG1 signaling is also important for the dendritic arborization of pyramidal neurons (Chen et al., 2010a), the development of midbrain dopaminergic neurons (Carlsson et al., 2011; Zhang et al., 2004), the radial and tangential migration of neurons, the guidance of thalamocortical axons, the myelination and ensheathment of nerves in the peripheral nervous system, the formation and myelination of oligodendrocytes in the central nervous system, and the development of neuromuscular junctions (Birchmeier, 2009; Mei and Xiong, 2008).

\subsection{NRG1 mouse mutants}

Various types of NRG1 mutant mice are available (Lu et al., 2011). Since homozygous knockout mice are not viable, the NRG1 gene is either heterozygously expressed or overexpressed in the mutants. Mutations are targeted to different domains of the NRG1 gene, including the EGF-like domain, the transmembrane (TM) domain, the immunoglobulin (Ig) domain, and the cystein-rich domain (CRD; Lu et al., 2011). Depending on the targeted domain, the genetic mutation affects all NRG1 isoforms (EGF, TM: I-VI) or only some of the isoforms (Ig: I, II, VI, V; CRD: III; see Fig. 1).

Mice over- and underexpressing NRG1 display various endophenotypes of schizophrenia, such as reduced social interactions, hyperactivity, impaired PPI, heightened anxiety, impaired working memory, decreased latent inhibition and reduced fear conditioning (Chen et al., 2008; Chesworth et al., 2012; Deakin et al., 2012; Duffy et al., 2010; Duffy et al., 2008; Ehrlichman et al., 2009; Gerlai et al., 2000; Karl et al., 2007; Kato et al., 2010; O'Tuathaigh et al., 2006; Rimer et al., 2005; van den Buuse et al., 2009). In addition, an EEG-measured MMN response (50-75 ms) to deviant auditory stimuli has been found to be altered in NRG1 heterozygous mice (Ehrlichman et al., 2009). These behavioral and electrophysiological deficits likely result from NRG1-induced changes in glutamatergic, GABAergic, dopaminergic, serotonergic and cholinergic neuronal signaling (Bjarnadottir et al., 2007; Dean et al., 2008; Hancock et al., 2008; Jiang et al., 2013; Kato et al., 2011; Kato et al., 2010; Newell et al., 2013; O'Tuathaigh et al., 2010; Ting et al., 2011; Woo et al., 2007) as well as changes in hormonal signaling (Taylor et al., 2011). The fact that over- and underexpressing $N R G 1$ induces partially overlapping behavioral impairments may be explained with the 'inverted-U model' of NRG1 signaling, which states that either too low or too high NRG1 activation exerts detrimental effects on synaptic connectivity (Role and Talmage, 2007). 


\section{Somatosensation in mice as a model system for studying schizophrenia-related sensory deficits}

The endophenotypic characterization of the NRG1 mouse model exemplifies the general focus in translational schizophrenia research on understanding disease-specific cognitive dysfunctions (Jones et al., 2011; Papaleo et al., 2012), while possible contributions of underlying sensory deficits have remained largely unexplored. The advantage of using mice for studying sensory disease mechanisms lies not only in the availability of genetic tools, but also in the straightforward anatomy of the mouse somatosensory system where the cellular principles of sensory information processing can be easily investigated using in vivo electrophysiology (Box 2). The arrangement of whiskers on the mystacial pad is preserved at the cortical level, and information coming from a single whisker is represented in a single cortical column, the 'barrel column' (Woolsey and Van der Loos, 1970).

\section{BOX 2. Electrical signals in the animal brain.}

Techniques. In animals, measuring brain responses in vivo typically involves invasive recordings in anesthetized or awake conditions. Typically, glass micropipettes are used for intracellular recordings, while metal or silicon microelectrodes are used for extracellular recordings. These invasive techniques are characterized by a very high temporal $(\mathrm{ms})$ and spatial resolution $(\mu \mathrm{m})$.

Analysis. Intracellular recordings convey information about intrinsic and synaptic properties of the neurons by measuring the membrane potential or current and the resistance. Extracellular recordings measure voltage changes at low frequencies $(0.1-300 \mathrm{~Hz})$ reflecting postsynaptic potentials of a local neuronal population (the 'local field potentials' or LFPs), and voltage changes at high frequencies $(600-6000 \mathrm{~Hz}$ ) reflecting action potentials of nearby neurons ('multi units'). The action potentials (or 'spikes') can be sorted off-line to derive single-unit clusters, which are thought to reflect activity from single neurons. Similar to EEG and MEG signals (Box 1), extracellular LFPs can be analyzed in the time domain and in the time-frequency domain to reveal stimulus-related evoked and induced oscillations. In addition, the intracellularly or extracellularly recorded action potentials can be quantified in terms of their firing rate to investigate cellular receptive field properties and adaptation dynamics. Furthermore, the latency of action potentials and LFPs can be examined to reveal the degree of phase locking or temporal precision with respect to a stimulus.

Paradigms. Action potentials and LFPs can be recorded during baseline and stimulation conditions. Under anesthesia, stimuli are applied passively to investigate sensory responses, while stimulation in awake animals may be passive or linked to a specific task. Stimuli are applied separately or in trains to study transient and sustained (steady-state) responses, respectively.

Source: (Chorev et al., 2009; Nicolelis et al., 2008; Scanziani and Hausser, 2009). 


\subsection{The whisker-to-barrel system}

In rodents, the main sensory organ are the mystacial whiskers, also known as vibrissae. In mice, whiskers are up to $3 \mathrm{~cm}$ long, and in rats up to $5 \mathrm{~cm}$. A distinction can be made between 40-70 microvibrissae $(<7 \mathrm{~mm})$, which are located rostrally on the snout and oriented frontally, and 30-35 macrovibrissae (> $4 \mathrm{~mm}$ ), which are positioned more caudally and oriented laterally (Brecht et al., 1997). Henceforth, we use the term whiskers or vibrissae to refer specifically to macrovibrissae. In both mice and rats, whiskers are organized in rows A-E, and in arcs 1-7 (Fig. 2). The whiskers are located in hair follicles, which contain a follicle sinus and are innervated by axons of trigeminal ganglion cells that form the infraorbital nerve. During whisker motion, mechanical energy is transmitted to the follicle and transduced into action potentials by specialized nerve receptors, which include Merkel cells, lanceolate endings, and club-shaped endings (Diamond and Arabzadeh, 2013; Feldmeyer et al., 2013). Responses of trigeminal ganglion cells are classified into slowly adapting and rapidly adapting, and have been shown to be sensitive to whisker velocity, acceleration and position (Diamond and Arabzadeh, 2013; Fox, 2008). Trigeminal ganglion cells receive information from a single whisker, and project to the brainstem trigeminal nuclei, which comprise the principal nucleus and three spinal nuclei. The trigeminal nuclei contain clusters of neurons, called 'barrellettes', that encode signals from predominantly one whisker, thus forming a somatotopic representation of the whisker grid (Feldmeyer et al., 2013). From the brainstem, information is transmitted via the lemniscal and paralemniscal pathways to the thalamus and cortex. The lemniscal pathway originates in the principal nucleus of the brainstem and projects to the ventro-posteriormedial nucleus of the thalamus, which contains somatotopically organized cellular compartments, the 'barrelloids'. The paralemniscal pathway projects from the spinal nuclei to the posterior nuclei of the thalamus. The lemniscal and paralemniscal pathways terminate in the primary somatosensory cortex, which is also known as 'barrel cortex' due to the barrel-like appearance of the neuronal clusters in layer IV (Fig. 3). Each barrel marks the width of a cortical column that spans layers I-VI and is dedicated to processing incoming information mainly from a single whisker, also referred to as the principal whisker. The area surrounding the cortical columns is known as the 'septum', which is more pronounced in rats than in mice (Feldmeyer et al., 2013). While lemniscal projections target primarily layer IV of the barrel column, paralemniscal projections arrive mainly in layer IV of the septal column. In addition, secondary projections are sent from the lemniscal pathway to layers II, III, $\mathrm{Vb}$ and $\mathrm{VI}$ in the barrel column, and from the paralemniscal pathway to layers II and III of the septal column and layers I and Va of the barrel column (Alloway, 2008). 


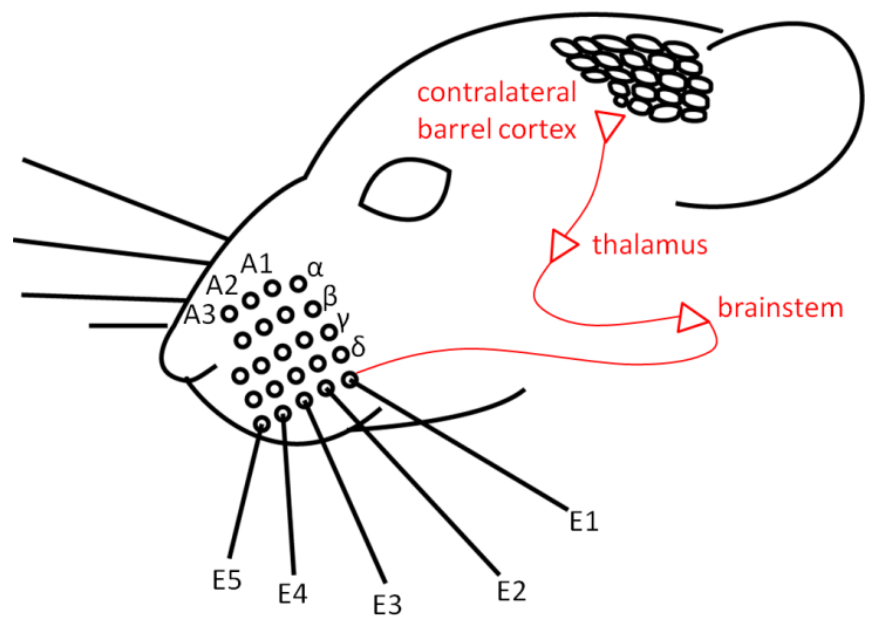

FIGURE 2. The whisker-to-barrel pathway. Rodents possess 4 straddlers $(\alpha-\delta)$, and around 30 macrovibrissae that are organized in rows (A-E) and arcs (1-7, with rows $A$ and $B$ only containing 4 whiskers; note that not all whiskers are displayed here). Information from a single whisker is projected via the brainstem and thalamus to the contralateral primary somatosensory cortex. Synaptic connections are displayed as red triangles.
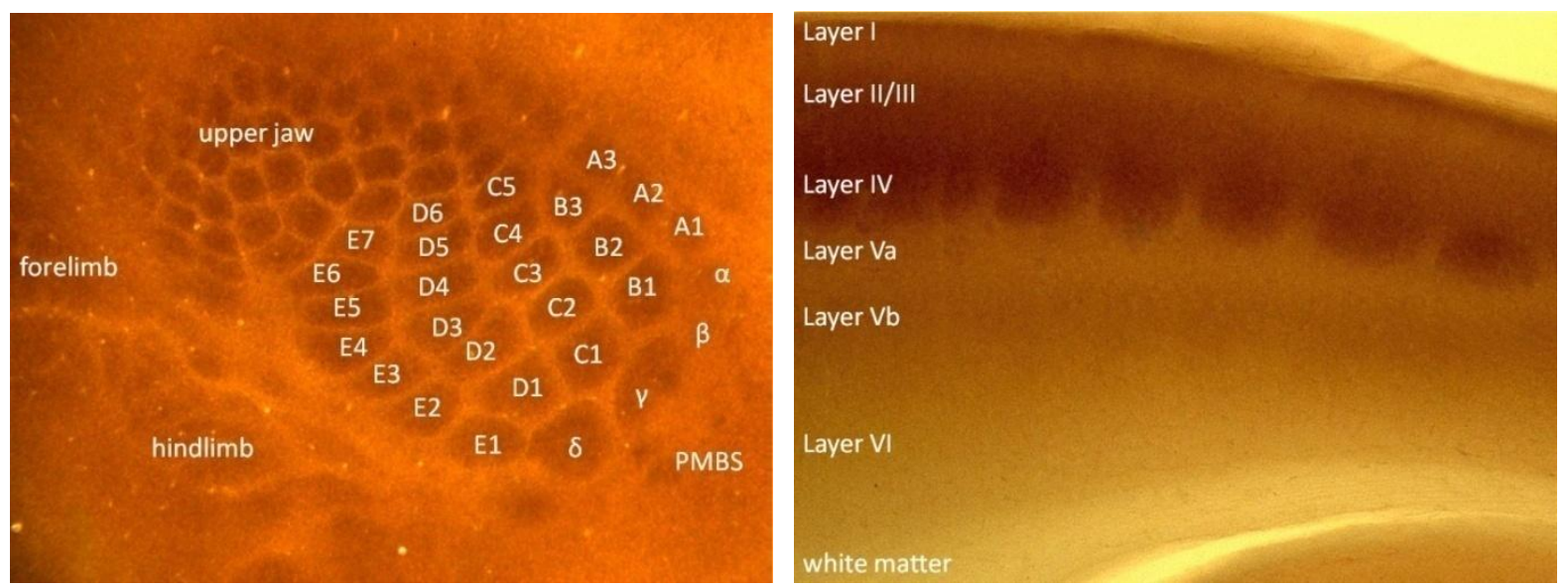

FIGURE 3. Barrel cortex somatotopy. Left panel. Tangential section of the primary somatosensory cortex in an adult BL6 mouse. Tissue was stained using cytochrome oxidase, revealing distinct histological compartments ('barrels') of the postero-medial barrel subfield (PMBS) that receives input from the macrovibrissae. Right panel. Thalamocortical, cytochrome oxidase-stained slice showing the six-layered cortical structure. Barrels are confined to layer IV, and demarcate the lateral boundary of the cortical column that spans all six layers.

\section{$\underline{6.2 \text { Rodent whisking-related behavior and barrel cortex responses }}$}

Rodents use sensory input from whisking for navigating the environment, social interaction, as well as object detection and discrimination (Carvell and Simons, 1990; Guić-Robles et al., 1989; Mayrhofer et al., 2013; O'Connor et al., 2010; Wolfe et al., 2011). To palpate objects or other animals, the whiskers are swept rhythmically forth and back at frequencies ranging from 1 to $20 \mathrm{~Hz}$ (Berg and Kleinfeld, 2003; Carvell and Simons, 1990; Fanselow and Nicolelis, 1999; Voigts et al., 2008; Wolfe et al., 2011). In mice, whisker movements occur preferentially around $3 \mathrm{~Hz}$ during quiescence and around 8-10 Hz during exploration (Cao et al., 2012; Söhnchen et al., 2010; Wesson 
et al., 2008). It has been suggested that the different whisking frequencies during active and quiet behaviors might facilitate stimulus discrimination and detection, respectively (Moore et al., 1999; Nicolelis and Fanselow, 2002). In addition, rat studies found that barrel cortex responses are specifically tuned to these frequency ranges. Tuning properties have been described in terms of adaptation of the firing rate, cortical spread of the response, receptive field size, angular tuning, and phase locking. In response to whisker stimulation at low frequencies $(1-3 \mathrm{~Hz})$, firing rates show little adaptation (Garabedian et al., 2003; Khatri et al., 2004) and are more wide-spread in the cortex (Sheth et al., 1998). At higher frequencies, firing rates display strong adaptation (Ahissar et al., 2001; Chung et al., 2002; Khatri et al., 2004; Simons, 1978), a limited spread in the cortex (Sheth et al., 1998), reduced receptive field size (Katz et al., 2006), and sharpened angular tuning (Khatri and Simons, 2007). Moreover, stimulation at frequencies that are relevant for exploratory behavior (5-10 $\mathrm{Hz}$ ) results in enhanced firing rates and increased phase locking of the spikes, indicating resonant or band-pass properties (Garabedian et al., 2003).

In addition to active whisker motion in the $1-20 \mathrm{~Hz}$ range, whiskers display passive vibratory properties as they are swept across smooth or rough textures. Depending on the whisker length, these resonance effects result in a high-speed micromotion of the whisker ranging from approximately $50-200 \mathrm{~Hz}$ (Ritt et al., 2008). Using sustained vibrotactile whisker stimulation up to several hundred $\mathrm{Hz}$, research in rat barrel cortex revealed that high frequency stimuli are encoded by variations in firing rate (Ahissar et al., 2001; Ahissar et al., 2000; Arabzadeh et al., 2003; Arabzadeh et al., 2005; Gerdjikov et al., 2010) and phase locking of action potentials (Ewert et al., 2008; Jones et al., 2004; Khatri et al., 2004; Melzer et al., 2006; Panzeri and Diamond, 2010), and possibly by an increase in gamma power $(30-70 \mathrm{~Hz})$ of the local field potentials at stimulation frequencies above $130 \mathrm{~Hz}$ (Ewert et al., 2008).

\section{Study aim: Characterizing sensory responses in the NRG1 schizophrenia model}

The aim of this PhD work was to elucidate the cellular mechanisms of sensory dysfunctions in schizophrenia. To this end, we investigated somatosensory information processing in mice heterozygous for the schizophrenia risk gene NRG1. Neuronal responses to whisker deflection across different frequencies $(1-70 \mathrm{~Hz})$ were characterized in mouse barrel cortex using in vivo extracellular recordings (Methods, Chapter II). We first established a baseline for barrel cortex responses in BL6 mice (Chapter III), which were previously studied only in rats. These baseline measures were then used to compare control animals with heterozygous NRG1 knock-outs during low-frequency (1-15 $\mathrm{Hz}$, Chapter IV) and high-frequency stimulation (20-70 Hz, Chapter V). We identified frequencydependent alterations with respect to the magnitude and phase locking of cellular responses, as well 
as changes in gamma power $(20-40 \mathrm{~Hz})$ in the NRG1 mutants. The findings are discussed in the context of abnormalities in EEG/MEG response magnitude and timing to frequency-modulated auditory, visual and somatosensory stimuli in schizophrenic patients. In addition, a model of microcircuitry abnormalities is proposed to explain the observed response deficits in NRG1 mutants (Discussion, Chapter VI).

\section{REFERENCES}

Abe, Y., Namba, H., Kato, T., Iwakura, Y., and Nawa, H. (2011). Neuregulin-1 signals from the periphery regulate AMPA receptor sensitivity and expression in GABAergic interneurons in developing neocortex. J Neurosci 31, 5699-5709.

Abi-Dargham, A. (2007). Alterations of serotonin transmission in schizophrenia. Int Rev Neurobiol 78, 133-164.

Agim, Z.S., Esendal, M., Briollais, L., Uyan, O., Meschian, M., Martinez, L.A., Ding, Y., Basak, A.N., and Ozcelik, H. (2013). Discovery, validation and characterization of Erbb4 and Nrg1 haplotypes using data from three genome-wide association studies of schizophrenia. PLoS One 8, 3.

Ahissar, E., Sosnik, R., Bagdasarian, K., and Haidarliu, S. (2001). Temporal frequency of whisker movement. II. Laminar organization of cortical representations. J Neurophysiol 86, 354-367.

Ahissar, E., Sosnik, R., and Haidarliu, S. (2000). Transformation from temporal to rate coding in a somatosensory thalamocortical pathway. Nature 406, 302-306.

Alaerts, M., Ceulemans, S., Forero, D., Moens, L.N., De Zutter, S., Heyrman, L., Lenaerts, A.S., Norrback, K.F., De Rijk, P., Nilsson, L.G., et al. (2009). Support for NRG1 as a susceptibility factor for schizophrenia in a northern Swedish isolated population. Arch Gen Psychiatry 66, 828-837.

Aleman, A., Hijman, R., de Haan, E.H., and Kahn, R.S. (1999). Memory impairment in schizophrenia: a meta-analysis. Am J Psychiatry 156, 1358-1366.

Allen, P., Laroi, F., McGuire, P.K., and Aleman, A. (2008). The hallucinating brain: a review of structural and functional neuroimaging studies of hallucinations. Neurosci Biobehav Rev 32, 175191.

Alloway, K.D. (2008). Information processing streams in rodent barrel cortex: the differential functions of barrel and septal circuits. Cereb Cortex 18, 979-989.

Antonova, E., Sharma, T., Morris, R., and Kumari, V. (2004). The relationship between brain structure and neurocognition in schizophrenia: a selective review. Schizophr Res 70, 117-145.

Arabzadeh, E., Petersen, R.S., and Diamond, M.E. (2003). Encoding of whisker vibration by rat barrel cortex neurons: implications for texture discrimination. J Neurosci 23, 9146-9154.

Arabzadeh, E., Zorzin, E., and Diamond, M.E. (2005). Neuronal encoding of texture in the whisker sensory pathway. PLoS Biol 3, e17.

Ardekani, B.A., Nierenberg, J., Hoptman, M.J., Javitt, D.C., and Lim, K.O. (2003). MRI study of white matter diffusion anisotropy in schizophrenia. Neuroreport 14, 2025-2029.

Arnfred, S.M. (2012). Proprioceptive information processing in schizophrenia. Dan Med J 59.

Arnfred, S.M., and Chen, A.C. (2004). Exploration of somatosensory P50 gating in schizophrenia spectrum patients: reduced P50 amplitude correlates to social anhedonia. Psychiatry Res 125, 147-160.

Arnfred, S.M., Hemmingsen, R.P., and Parnas, J. (2006). Delayed early proprioceptive information processing in schizophrenia. Br J Psychiatry 189, 558-559.

Arnfred, S.M., Morup, M., Thalbitzer, J., Jansson, L., and Parnas, J. (2011). Attenuation of beta and gamma oscillations in schizophrenia spectrum patients following hand posture perturbation. Psychiatry Res 185, 215-224. 
Aspell, J.E., Palluel, E., and Blanke, O. (2012). Early and late activity in somatosensory cortex reflects changes in bodily self-consciousness: an evoked potential study. Neuroscience 216, 110-122.

Bakker, S.C., Hoogendoorn, M.L.C., Selten, J.P., Verduijn, W., Pearson, P.L., Sinke, R.J., and Kahn, R.S. (2004). Neuregulin 1: genetic support for schizophrenia subtypes. Mol Psychiatry 9, 1061-1063.

Baldeweg, T., Spence, S., Hirsch, S.R., and Gruzelier, J. (1998). $\gamma$-band electroencephalographic oscillations in a patient with somatic hallucinations. Lancet 352, 620-621.

Bär, K.-J., Gaser, C., Nenadic, I., and Sauer, H. (2002). Transient activation of a somatosensory area in painful hallucinations shown by fMRI. Neuroreport 13, 805-808.

Barch, D.M., Mathews, J.R., Buckner, R.L., Maccotta, L., Csernansky, J.G., and Snyder, A.Z. (2003). Hemodynamic responses in visual, motor, and somatosensory cortices in schizophrenia. Neuroimage 20, 1884-1893.

Barta, P.E., Pearlson, G.D., Powers, R.E., Richards, S.S., and Tune, L.E. (1990). Auditory hallucinations and smaller superior temporal gyral volume in schizophrenia. Am J Psychiatry 147, 1457-1462.

Basar-Eroglu, C., Schmiedt-Fehr, C., Mathes, B., Zimmermann, J., and Brand, A. (2009). Are oscillatory brain responses generally reduced in schizophrenia during long sustained attentional processing? Int J Psychophysiol 71, 75-83.

Basar, E., Basar-Eroglu, C., Karakas, S., and Schurmann, M. (2001). Gamma, alpha, delta, and theta oscillations govern cognitive processes. Int J Psychophysiol 39, 241-248.

Bates, A.T., Kiehl, K.A., Laurens, K.R., and Liddle, P.F. (2009). Low-frequency EEG oscillations associated with information processing in schizophrenia. Schizophr Res 115, 222-230.

Benes, F.M. (2000). Emerging principles of altered neural circuitry in schizophrenia. Brain Res Brain Res Rev 31, 251-269.

Berg, R.W., and Kleinfeld, D. (2003). Rhythmic whisking by rat: retraction as well as protraction of the vibrissae is under active muscular control. J Neurophysiol 89, 104-117.

Bertram, I., Bernstein, H.G., Lendeckel, U., Bukowska, A., Dobrowolny, H., Keilhoff, G., Kanakis, D., Mawrin, C., Bielau, H., Falkai, P., et al. (2007). Immunohistochemical evidence for impaired neuregulin-1 signaling in the prefrontal cortex in schizophrenia and in unipolar depression. Ann $\mathrm{N}$ Y Acad Sci, 147-156.

Birchmeier, C. (2009). ErbB receptors and the development of the nervous system. Exp Cell Res 315, 611-618.

Bjarnadottir, M., Misner, D.L., Haverfield-Gross, S., Bruun, S., Helgason, V.G., Stefansson, H., Sigmundsson, A., Firth, D.R., Nielsen, B., Stefansdottir, R., et al. (2007). Neuregulin1 (NRG1) signaling through Fyn modulates NMDA receptor phosphorylation: differential synaptic function in NRG1+/- knock-outs compared with wild-type mice. J Neurosci 27, 4519-4529.

Blakemore, S.J., Wolpert, D., and Frith, C. (2000). Why can't you tickle yourself? Neuroreport 11, R11-16.

Blumenfeld, L.D., and Clementz, B.A. (2001). Response to the first stimulus determines reduced auditory evoked response suppression in schizophrenia: single trials analysis using MEG. Clin Neurophysiol 112, 1650-1659.

Bonnot, O., Anderson, G.M., Cohen, D., Willer, J.C., and Tordjman, S. (2009). Are patients with schizophrenia insensitive to pain? A reconsideration of the question. Clin J Pain 25, 244-252.

Bousman, C.A., Yung, A.R., Pantelis, C., Ellis, J.A., Chavez, R.A., Nelson, B., Lin, A., Wood, S.J., Amminger, G.P., Velakoulis, D., et al. (2013). Effects of NRG1 and DAOA genetic variation on transition to psychosis in individuals at ultra-high risk for psychosis. Transl Psychiatry 30, 23.

Braff, D.L., Grillon, C., and Geyer, M.A. (1992). Gating and habituation of the startle reflex in schizophrenic patients. Arch Gen Psychiatry 49, 206-215.

Braus, D.F., Weber-Fahr, W., Tost, H., Ruf, M., and Henn, F.A. (2002). Sensory information processing in neuroleptic-naive first-episode schizophrenic patients: a functional magnetic resonance imaging study. Arch Gen Psychiatry 59, 696-701.

Brecht, M., Preilowski, B., and Merzenich, M.M. (1997). Functional architecture of the mystacial vibrissae. Behav Brain Res 84, 81-97. 
Brenner, C.A., Krishnan, G.P., Vohs, J.L., Ahn, W.-Y., Hetrick, W.P., Morzorati, S.L., and O'Donnell, B.F. (2009). Steady state responses: electrophysiological assessment of sensory function in schizophrenia. Schizophr Bull 35, 1065-1077.

Brenner, C.A., Sporns, O., Lysaker, P.H., and O'Donnell, B.F. (2003a). EEG synchronization to modulated auditory tones in schizophrenia, schizoaffective disorder, and schizotypal personality disorder. Am J Psychiatry 160, 2238-2240.

Brenner, C.A., Wilt, M.A., Lysaker, P.H., Koyfman, A., and O'Donnell, B.F. (2003b). Psychometrically matched visual-processing tasks in schizophrenia spectrum disorders. J Abnorm Psychol 112, 2837.

Brockhaus-Dumke, A., Schultze-Lutter, F., Mueller, R., Tendolkar, I., Bechdolf, A., Pukrop, R., Klosterkoetter, J., and Ruhrmann, S. (2008). Sensory gating in schizophrenia: P50 and N100 gating in antipsychotic-free subjects at risk, first-episode, and chronic patients. Biol Psychiatry 64, 376384.

Brown, C., Cromwell, R.L., Filion, D., Dunn, W., and Tollefson, N. (2002). Sensory processing in schizophrenia: missing and avoiding information. Schizophr Res 55, 187-195.

Brüne, M. (2005). "Theory of mind" in schizophrenia: a review of the literature. Schizophr Bull 31, 21-42.

Bucci, P., Mucci, A., Merlotti, E., Volpe, U., and Galderisi, S. (2007). Induced gamma activity and event-related coherence in schizophrenia. Clin EEG Neurosci 38, 96-104.

Butler, P. (2009). 3.2 Early-stage visual processing deficits in schizophrenia. Handbook of Neurochemistry and Molecular Neurobiology: Schizophrenia 2, 331.

Butler, P.D., Abeles, I.Y., Weiskopf, N.G., Tambini, A., Jalbrzikowski, M., Legatt, M.E., Zemon, V., Loughead, J., Gur, R.C., and Javitt, D.C. (2009). Sensory contributions to impaired emotion processing in schizophrenia. Schizophr Bull 35, 1095-1107.

Butler, P.D., Martinez, A., Foxe, J.J., Kim, D., Zemon, V., Silipo, G., Mahoney, J., Shpaner, M., Jalbrzikowski, M., and Javitt, D.C. (2007). Subcortical visual dysfunction in schizophrenia drives secondary cortical impairments. Brain 130, 417-430.

Butler, P.D., Silverstein, S.M., and Dakin, S.C. (2008). Visual perception and its impairment in schizophrenia. Biol Psychiatry 64, 40.

Butler, P.D., Zemon, V., Schechter, I., Saperstein, A.M., Hoptman, M.J., Lim, K.O., Revheim, N., Silipo, G., and Javitt, D.C. (2005). Early-stage visual processing and cortical amplification deficits in schizophrenia. Arch Gen Psychiatry 62, 495-504.

Cachia, A., Paillere-Martinot, M.L., Galinowski, A., Januel, D., de Beaurepaire, R., Bellivier, F., Artiges, E., Andoh, J., Bartres-Faz, D., Duchesnay, E., et al. (2008). Cortical folding abnormalities in schizophrenia patients with resistant auditory hallucinations. Neuroimage 39, 927-935.

Calderone, D.J., Martinez, A., Zemon, V., Hoptman, M.J., Hu, G., Watkins, J.E., Javitt, D.C., and Butler, P.D. (2013). Comparison of psychophysical, electrophysiological, and fMRI assessment of visual contrast responses in patients with schizophrenia. Neuroimage 67, 153-162.

Calhoun, V.D., Kiehl, K.A., Liddle, P.F., and Pearlson, G.D. (2004). Aberrant localization of synchronous hemodynamic activity in auditory cortex reliably characterizes schizophrenia. Biol Psychiatry 55, 842-849.

Canetta, S.E., Luca, E., Pertot, E., Role, L.W., and Talmage, D.A. (2011). Type III Nrg1 back signaling enhances functional TRPV1 along sensory axons contributing to basal and inflammatory thermal pain sensation. PLoS One 6, e25108.

Cao, Y., Roy, S., Sachdev, R.N., and Heck, D.H. (2012). Dynamic correlation between whisking and breathing rhythms in mice. J Neurosci 32, 1653-1659.

Carlsson, T., Schindler, F.R., Höllerhage, M., Depboylu, C., Arias-Carrión, O., Schnurrbusch, S., Rösler, T.W., Wozny, W., Schwall, G.P., Groebe, K., et al. (2011). Systemic administration of neuregulin$1 \beta 1$ protects dopaminergic neurons in a mouse model of Parkinson's disease. J Neurochem 117, 1066-1074. 
Carvell, G., and Simons, D. (1990). Biometric analyses of vibrissal tactile discrimination in the rat. J Neurosci 10, 2638-2648.

Çavuş, I., Reinhart, R.M.G., Roach, B.J., Gueorguieva, R., Teyler, T.J., Clapp, W.C., Ford, J.M., Krystal, J.H., and Mathalon, D.H. (2012). Impaired visual cortical plasticity in schizophrenia. Biol Psychiatry $71,512-520$.

Chang, B.P., and Lenzenweger, M.F. (2001). Somatosensory processing in the biological relatives of schizophrenia patients: a signal detection analysis of two-point discrimination. J Abnorm Psychol 110,433

Chang, B.P., and Lenzenweger, M.F. (2004). Investigating graphesthesia task performance in the biological relatives of schizophrenia patients. Schizophr Bull 30, 327-334.

Chang, B.P., and Lenzenweger, M.F. (2005). Somatosensory processing and schizophrenia liability: proprioception, exteroceptive sensitivity, and graphesthesia performance in the biological relatives of schizophrenia patients. J Abnorm Psychol 114, 85.

Chen, M.S., Bermingham-McDonogh, O., Danehy, F.T., Jr., Nolan, C., Scherer, S.S., Lucas, J., Gwynne, D., and Marchionni, M.A. (1994). Expression of multiple neuregulin transcripts in postnatal rat brains. J Comp Neurol 349, 389-400.

Chen, Y., Hancock, M.L., Role, L.W., and Talmage, D.A. (2010a). Intramembranous valine linked to schizophrenia is required for neuregulin 1 regulation of the morphological development of cortical neurons. J Neurosci 30, 9199-9208.

Chen, Y., Nakayama, K., Levy, D., Matthysse, S., and Holzman, P. (2003). Processing of global, but not local, motion direction is deficient in schizophrenia. Schizophr Res 61, 215-227.

Chen, Y.H., Edgar, J.C., Huang, M., Hunter, M.A., Epstein, E., Howell, B., Lu, B.Y., Bustillo, J., Miller, G.A., and Canive, J.M. (2013). Frontal and superior temporal auditory processing abnormalities in schizophrenia. Neuroimage Clin 2, 695-702.

Chen, Y.J., Johnson, M.A., Lieberman, M.D., Goodchild, R.E., Schobel, S., Lewandowski, N., Rosoklija, G., Liu, R.C., Gingrich, J.A., Small, S., et al. (2008). Type III neuregulin-1 is required for normal sensorimotor gating, memory-related behaviors, and corticostriatal circuit components. J Neurosci 28, 6872-6883.

Chen, Y.J., Zhang, M., Yin, D.M., Wen, L., Ting, A., Wang, P., Lu, Y.S., Zhu, X.H., Li, S.J., Wu, C.Y., et al. (2010b). ErbB4 in parvalbumin-positive interneurons is critical for neuregulin 1 regulation of longterm potentiation. Proc Natl Acad Sci U S A 107, 21818-21823.

Chesworth, R., Downey, L., Logge, W., Killcross, S., and Karl, T. (2012). Cognition in female transmembrane domain neuregulin 1 mutant mice. Behav Brain Res 226, 218-223.

Chong, V.Z., Thompson, M., Beltaifa, S., Webster, M.J., Law, A.J., and Weickert, C.S. (2008). Elevated neuregulin-1 and ErbB4 protein in the prefrontal cortex of schizophrenic patients. Schizophr Res 100, 270-280.

Chorev, E., Epsztein, J., Houweling, A.R., Lee, A.K., and Brecht, M. (2009). Electrophysiological recordings from behaving animals - going beyond spikes. Curr Opin Neurobiol 19, 513-519.

Chung, S., Li, X., and Nelson, S.B. (2002). Short-term depression at thalamocortical synapses contributes to rapid adaptation of cortical sensory responses in vivo. Neuron 34, 437-446.

Cohen, Y.E., Popper, A.N., and Fay, R.R. (2013). Neural correlates of auditory cognition, Vol 45 (Springer).

Cooper, J.E., Andrews, H., and Barber, C. (1985). Stable abnormalities in the lateralisation of early cortical somatosensory evoked potentials in schizophrenic patients. Br J Psychiatry 146, 585-593.

Corfas, G., Roy, K., and Buxbaum, J.D. (2004). Neuregulin 1-erbB signaling and the molecular/cellular basis of schizophrenia. Nat Neurosci 7, 575-580.

Cotter, D., Mackay, D., Frangou, S., Hudson, L., and Landau, S. (2004). Cell density and cortical thickness in Heschl's gyrus in schizophrenia, major depression and bipolar disorder. $\mathrm{Br} \mathrm{J}$ Psychiatry 185, 258-259.

Davalos, D.B., Kisley, M.A., and Ross, R.G. (2003). Effects of interval duration on temporal processing in schizophrenia. Brain Cogn 52, 295-301. 
David, O., Kilner, J.M., and Friston, K.J. (2006). Mechanisms of evoked and induced responses in MEG/EEG. Neuroimage 31, 1580-1591.

Deakin, I.H., Nissen, W., Law, A.J., Lane, T., Kanso, R., Schwab, M.H., Nave, K.A., Lamsa, K.P., Paulsen, O., Bannerman, D.M., et al. (2012). Transgenic overexpression of the type I isoform of neuregulin 1 affects working memory and hippocampal oscillations but not long-term potentiation. Cereb Cortex 22, 1520-1529.

Dean, B., Karl, T., Pavey, G., Boer, S., Duffy, L., and Scarr, E. (2008). Increased levels of serotonin 2A receptors and serotonin transporter in the CNS of neuregulin 1 hypomorphic/mutant mice. Schizophr Res 99, 341-349.

Diamond, M.E., and Arabzadeh, E. (2013). Whisker sensory system - from receptor to decision. Prog Neurobiol 103, 28-40.

Dierks, T., Linden, D.E.J., Jandl, M., Formisano, E., Goebel, R., Lanfermann, H., and Singer, W. (1999). Activation of Heschl's gyrus during auditory hallucinations. Neuron 22, 615-621.

Doniger, G.M., Foxe, J.J., Murray, M.M., Higgins, B.A., and Javitt, D.C. (2002). Impaired visual object recognition and dorsal/ventral stream interaction in schizophrenia. Arch Gen Psychiatry 59, 10111020.

Dorph-Petersen, K.A., Delevich, K.M., Marcsisin, M.J., Zhang, W., Sampson, A.R., Gundersen, H.J., Lewis, D.A., and Sweet, R.A. (2009). Pyramidal neuron number in layer 3 of primary auditory cortex of subjects with schizophrenia. Brain Res 18, 42-57.

Dorph-Petersen, K.A., Pierri, J.N., Wu, Q., Sampson, A.R., and Lewis, D.A. (2007). Primary visual cortex volume and total neuron number are reduced in schizophrenia. J Comp Neurol 501, 290301.

Duffy, L., Cappas, E., Lai, D., Boucher, A.A., and Karl, T. (2010). Cognition in transmembrane domain neuregulin 1 mutant mice. Neuroscience 170, 800-807.

Duffy, L., Cappas, E., Scimone, A., Schofield, P.R., and Karl, T. (2008). Behavioral profile of a heterozygous mutant mouse model for EGF-like domain neuregulin 1. Behav Neurosci 122, 748759.

Dworkin, R.H. (1994). Pain insensitivity in schizophrenia. Schizophr Bull 20, 235-248.

Edgar, J.C., Chen, Y.H., Lanza, M., Howell, B., Chow, V.Y., Heiken, K., Liu, S., Wootton, C., Hunter, M.A., Huang, M., et al. (2013). Cortical thickness as a contributor to abnormal oscillations in schizophrenia? Neuroimage Clin 4, 122-129.

Edgar, J.C., Miller, G.A., Moses, S.N., Thoma, R.J., Huang, M.X., Hanlon, F.M., Weisend, M.P., Sherwood, A., Bustillo, J., and Adler, L.E. (2005). Cross-modal generality of the gating deficit. Psychophysiology 42, 318-327.

Ehrlichman, R.S., Luminais, S.N., White, S.L., Rudnick, N.D., Ma, N., Dow, H.C., Kreibich, A.S., Abel, T., Brodkin, E.S., Hahn, C.G., et al. (2009). Neuregulin 1 transgenic mice display reduced mismatch negativity, contextual fear conditioning and social interactions. Brain Res 1294, 116-127.

Ewert, T.A., Vahle-Hinz, C., and Engel, A.K. (2008). High-frequency whisker vibration is encoded by phase-locked responses of neurons in the rat's barrel cortex. J Neurosci 28, 5359-5368.

Faludi, G., and Mirnics, K. (2011). Synaptic changes in the brain of subjects with schizophrenia. Int J Dev Neurosci 29, 305-309.

Fanselow, E.E., and Nicolelis, M.A. (1999). Behavioral modulation of tactile responses in the rat somatosensory system. J Neurosci 19, 7603-7616.

Fazzari, P., Paternain, A.V., Valiente, M., Pla, R., Luján, R., Lloyd, K., Lerma, J., Marín, O., and Rico, B. (2010). Control of cortical GABA circuitry development by Nrg1 and ErbB4 signalling. Nature 464, 1376-1380.

Feldmeyer, D., Brecht, M., Helmchen, F., Petersen, C.C., Poulet, J.F., Staiger, J.F., Luhmann, H.J., and Schwarz, C. (2013). Barrel cortex function. Prog Neurobiol 103, 3-27.

Ferri, F., Costantini, M., Salone, A., Di lorio, G., Martinotti, G., Chiarelli, A., Merla, A., Di Giannantonio, M., and Gallese, V. (2014). Upcoming tactile events and body ownership in schizophrenia. Schizophr Res 152, 51-57. 
Fioravanti, M., Carlone, O., Vitale, B., Cinti, M.E., and Clare, L. (2005). A meta-analysis of cognitive deficits in adults with a diagnosis of schizophrenia. Neuropsychol Rev 15, 73-95.

Fisahn, A., Neddens, J., Yan, L., and Buonanno, A. (2009). Neuregulin-1 modulates hippocampal gamma oscillations: implications for schizophrenia. Cereb Cortex 19, 612-618.

Fitzsimmons, J., Kubicki, M., and Shenton, M.E. (2013). Review of functional and anatomical brain connectivity findings in schizophrenia. Curr Opin Psychiatry 26, 172-187.

Fleck, D., Garratt, A.N., Haass, C., and Willem, M. (2012). BACE1 dependent neuregulin processing: review. Curr Alzheimer Res 9, 178-183.

Fletcher, P.C., and Frith, C.D. (2009). Perceiving is believing: a Bayesian approach to explaining the positive symptoms of schizophrenia. Nat Rev Neurosci 10, 48-58.

Ford, J.M., and Mathalon, D.H. (2004). Electrophysiological evidence of corollary discharge dysfunction in schizophrenia during talking and thinking. J Psychiatr Res 38, 37-46.

Ford, J.M., Mathalon, D.H., Kalba, S., Whitfield, S., Faustman, W.O., and Roth, W.T. (2001). Cortical responsiveness during inner speech in schizophrenia: an event-related potential study. Am J Psychiatry 158, 1914-1916.

Ford, J.M., Palzes, V.A., Roach, B.J., and Mathalon, D.H. (2013). Did I do that? Abnormal predictive processes in schizophrenia when button pressing to deliver a tone. Schizophr Bull 10, 10.

Fox, K. (2008). Barrel cortex (Cambridge University Press).

Fox, K., Sato, H., and Daw, N. (1990). The effect of varying stimulus intensity on NMDA-receptor activity in cat visual cortex. J Neurophysiol 64, 1413-1428.

Foxe, J.J., Doniger, G.M., and Javitt, D.C. (2001). Early visual processing deficits in schizophrenia: impaired P1 generation revealed by high-density electrical mapping. Neuroreport 12, 3815-3820.

Foxe, J.J., Yeap, S., Snyder, A.C., Kelly, S.P., Thakore, J.H., and Molholm, S. (2011). The N1 auditory evoked potential component as an endophenotype for schizophrenia: high-density electrical mapping in clinically unaffected first-degree relatives, first-episode, and chronic schizophrenia patients. Eur Arch Psychiatry Clin Neurosci 261, 331-339.

Fries, P. (2005). A mechanism for cognitive dynamics: neuronal communication through neuronal coherence. Trends Cogn Sci 9, 474-480.

Fukui, N., Muratake, T., Kaneko, N., Amagane, H., and Someya, T. (2006). Supportive evidence for neuregulin 1 as a susceptibility gene for schizophrenia in a Japanese population. Neurosci Lett 396, 117-120.

Gainetdinov, R.R., Mohn, A.R., and Caron, M.G. (2001). Genetic animal models: focus on schizophrenia. Trends Neurosci 24, 527-533.

Gallinat, J., Winterer, G., Herrmann, C.S., and Senkowski, D. (2004). Reduced oscillatory gamma-band responses in unmedicated schizophrenic patients indicate impaired frontal network processing. Clin Neurophysiol 115, 1863-1874.

Gandal, M.J., Edgar, J.C., Klook, K., and Siegel, S.J. (2012). Gamma synchrony: towards a translational biomarker for the treatment-resistant symptoms of schizophrenia. Neuropharmacology 62, 15041518.

Garabedian, C.E., Jones, S.R., Merzenich, M.M., Dale, A., and Moore, C.I. (2003). Band-pass response properties of rat SI neurons. J Neurophysiol 90, 1379-1391.

Geddes, A.E., Huang, X.-F., and Newell, K.A. (2011). Reciprocal signalling between NR2 subunits of the NMDA receptor and neuregulin1 and their role in schizophrenia. Prog Neuropsychopharmacol Biol Psychiatry 35, 896-904.

Georgieva, L., Dimitrova, A., Ivanov, D., Nikolov, I., Williams, N.M., Grozeva, D., Zaharieva, I., Toncheva, D., Owen, M.J., Kirov, G., et al. (2008). Support for neuregulin 1 as a susceptibility gene for bipolar disorder and schizophrenia. Biol Psychiatry 64, 419-427.

Gerdjikov, T.V., Bergner, C.G., Stuttgen, M.C., Waiblinger, C., and Schwarz, C. (2010). Discrimination of vibrotactile stimuli in the rat whisker system: behavior and neurometrics. Neuron 65, 530-540. 
Gerecke, K.M., Wyss, J.M., Karavanova, I., Buonanno, A., and Carroll, S.L. (2001). ErbB transmembrane tyrosine kinase receptors are differentially expressed throughout the adult rat central nervous system. J Comp Neurol 433, 86-100.

Gerlai, R., Pisacane, P., and Erickson, S. (2000). Heregulin, but not ErbB2 or ErbB3, heterozygous mutant mice exhibit hyperactivity in multiple behavioral tasks. Behav Brain Res 109, 219-227.

Glantz, L.A., and Lewis, D.A. (2000). Decreased dendritic spine density on prefrontal cortical pyramidal neurons in schizophrenia. Arch Gen Psychiatry 57, 65-73.

Glausier, J.R., and Lewis, D.A. (2013). Dendritic spine pathology in schizophrenia. Neuroscience 251, 90-107.

Green, M.F., Mintz, J., Salveson, D., Nuechterlein, K.H., Breitmeyer, B., Light, G.A., and Braff, D.L. (2003a). Visual masking as a probe for abnormal gamma range activity in schizophrenia. Biol Psychiatry 53, 1113-1119.

Green, M.F., Nuechterlein, K.H., Breitmeyer, B., Tsuang, J., and Mintz, J. (2003b). Forward and backward visual masking in schizophrenia: influence of age. Psychol Med 33, 887-895.

Green, M.F., Nuechterlein, K.H., and Mintz, J. (1994). Backward masking in schizophrenia and mania. II. Specifying the visual channels. Arch Gen Psychiatry 51, 945-951.

Greenwood, T.A., Lazzeroni, L.C., Murray, S.S., Cadenhead, K.S., Calkins, M.E., Dobie, D.J., Green, M.F., Gur, R.E., Gur, R.C., Hardiman, G., et al. (2011). Analysis of 94 candidate genes and 12 endophenotypes for schizophrenia from the Consortium on the Genetics of Schizophrenia. Am J Psychiatry 168, 930-946.

Greenwood, T.A., Light, G.A., Swerdlow, N.R., Radant, A.D., and Braff, D.L. (2012). Association analysis of 94 candidate genes and schizophrenia-related endophenotypes. PLoS One 7, 13.

Grover, S., and Kulhara, P. (2008). Deficit schizophrenia: concept and validity. Indian J Psychiatry 50, 61-66.

Grutzner, C., Wibral, M., Sun, L., Rivolta, D., Singer, W., Maurer, K., and Uhlhaas, P.J. (2013). Deficits in high- $(>60 \mathrm{~Hz})$ gamma-band oscillations during visual processing in schizophrenia. Front Hum Neurosci 7.

Gudlowski, Y., Özgürdal, S., Witthaus, H., Gallinat, J., Hauser, M., Winter, C., Uhl, I., Heinz, A., and Juckel, G. (2009). Serotonergic dysfunction in the prodromal, first-episode and chronic course of schizophrenia as assessed by the loudness dependence of auditory evoked activity. Schizophr Res 109, 141-147.

Guić-Robles, E., Valdivieso, C., and Guajardo, G. (1989). Rats can learn a roughness discrimination using only their vibrissal system. Behav Brain Res 31, 285-289.

Gurvich, C., Maller, J.J., Lithgow, B., Haghgooie, S., and Kulkarni, J. (2013). Vestibular insights into cognition and psychiatry. Brain Res 1537, 244-259.

Haenschel, C., and Linden, D. (2011). Exploring intermediate phenotypes with EEG: working memory dysfunction in schizophrenia. Behav Brain Res 216, 481-495.

Hahn, C.-G., Wang, H.-Y., Cho, D.-S., Talbot, K., Gur, R.E., Berrettini, W.H., Bakshi, K., Kamins, J., Borgmann-Winter, K.E., and Siegel, S.J. (2006). Altered neuregulin 1-erbB4 signaling contributes to NMDA receptor hypofunction in schizophrenia. Nat Med 12, 824-828.

Hall, J., Whalley, H.C., Job, D.E., Baig, B.J., McIntosh, A.M., Evans, K.L., Thomson, P.A., Porteous, D.J., Cunningham-Owens, D.G., Johnstone, E.C., et al. (2006). A neuregulin 1 variant associated with abnormal cortical function and psychotic symptoms. Nat Neurosci 9, 1477-1478.

Hall, M.H., Taylor, G., Salisbury, D.F., and Levy, D.L. (2011). Sensory gating event-related potentials and oscillations in schizophrenia patients and their unaffected relatives. Schizophr Bull 37, 11871199.

Hamm, J.P., Gilmore, C.S., and Clementz, B.A. (2012). Augmented gamma band auditory steady-state responses: support for NMDA hypofunction in schizophrenia. Schizophr Res 138, 1-7.

Hamm, J.P., Gilmore, C.S., Picchetti, N.A., Sponheim, S.R., and Clementz, B.A. (2011). Abnormalities of neuronal oscillations and temporal integration to low- and high-frequency auditory stimulation in schizophrenia. Biol Psychiatry 69, 989-996. 
Hancock, M.L., Canetta, S.E., Role, L.W., and Talmage, D.A. (2008). Presynaptic type III neuregulin1ErbB signaling targets \{alpha\}7 nicotinic acetylcholine receptors to axons. J Cell Biol 181, 511-521.

Harrison, P.J. (1999). The neuropathology of schizophrenia. A critical review of the data and their interpretation. Brain 122, 593-624.

Harrison, P.J., and Law, A.J. (2006). Neuregulin 1 and schizophrenia: genetics, gene expression, and neurobiology. Biol Psychiatry 60, 132-140.

Hashimoto, R., Straub, R.E., Weickert, C.S., Hyde, T.M., Kleinman, J.E., and Weinberger, D.R. (2004). Expression analysis of neuregulin-1 in the dorsolateral prefrontal cortex in schizophrenia. Mol Psychiatry 9, 299-307.

Hashimoto, T., Bazmi, H.H., Mirnics, K., Wu, Q., Sampson, A.R., and Lewis, D.A. (2008). Conserved regional patterns of GABA-related transcript expression in the neocortex of subjects with schizophrenia. Am J Psychiatry 165, 479-489.

Heckers, S. (1997). Neuropathology of schizophrenia: cortex, thalamus, basal ganglia, and neurotransmitter-specific projection systems. Schizophr Bull 23, 403-421.

Heeger, D.J., and Ress, D. (2002). What does fMRI tell us about neuronal activity? Nat Rev Neurosci 3, 142-151.

Hegerl, U., Gallinat, J., and Juckel, G. (2001). Event-related potentials: do they reflect central serotonergic neurotransmission and do they predict clinical response to serotonin agonists? J Affect Disord 62, 93-100.

Heinks-Maldonado, T.H., Mathalon, D.H., Houde, J.F., Gray, M., Faustman, W.O., and Ford, J.M. (2007). Relationship of imprecise corollary discharge in schizophrenia to auditory hallucinations. Arch Gen Psychiatry 64, 286-296.

Heinrichs, R.W. (2005). The primacy of cognition in schizophrenia. Am Psychol 60, 229.

Hixson, V.J., and Mathews, A.W. (1984). Sensory integration and chronic schizophrenia: past, present and future. The Canadian Journal of Occupational Therapy 51, 19-24.

Ho, W.H., Armanini, M.P., Nuijens, A., Phillips, H.S., and Osheroff, P.L. (1995). Sensory and motor neuron-derived factor. A novel heregulin variant highly expressed in sensory and motor neurons. J Biol Chem 270, 14523-14532.

Honea, R., Crow, T.J., Passingham, D., and Mackay, C.E. (2005). Regional deficits in brain volume in schizophrenia: a meta-analysis of voxel-based morphometry studies. Am J Psychiatry 162, 22332245.

Hong, L.E., Summerfelt, A., Mitchell, B.D., McMahon, R.P., Wonodi, I., Buchanan, R.W., and Thaker, G.K. (2008a). Sensory gating endophenotype based on its neural oscillatory pattern and heritability estimate. Arch Gen Psychiatry 65, 1008-1016.

Hong, L.E., Wonodi, I., Stine, O.C., Mitchell, B.D., and Thaker, G.K. (2008b). Evidence of missense mutations on the neuregulin 1 gene affecting function of prepulse inhibition. Biol Psychiatry 63, 17-23.

Houde, J.F., Nagarajan, S.S., Sekihara, K., and Merzenich, M.M. (2002). Modulation of the auditory cortex during speech: an MEG study. J Cogn Neurosci 14, 1125-1138.

Huang, M.-X., Lee, R., Gaa, K., Song, T., Harrington, D., Loh, C., Theilmann, R., Edgar, J.C., Miller, G., Canive, J., et al. (2010). Somatosensory system deficits in schizophrenia revealed by MEG during a median-nerve oddball task. Brain Topogr 23, 82-104.

Hubl, D., Koenig, T., Strik, W., Federspiel, A., Kreis, R., Boesch, C., Maier, S.E., Schroth, G., Lovblad, K., and Dierks, T. (2004). Pathways that make voices: white matter changes in auditory hallucinations. Arch Gen Psychiatry 61, 658-668.

Huertas-Vazquez, A., Teodorescu, C., Reinier, K., Uy-Evanado, A., Chugh, H., Jerger, K., Ayala, J., Gunson, K., Jui, J., Newton-Cheh, C., et al. (2013). A common missense variant in the neuregulin 1 gene is associated with both schizophrenia and sudden cardiac death. Heart Rhythm 21, 994-998.

Ikuta, T., Furuta, N., Kihara, S., Okura, M., Nagamine, I., Nakayama, H., Ishimoto, Y., Kaneda, Y., Tomotake, M., Izaki, Y., et al. (2007). Differences in waveforms of cerebral evoked potentials 
among healthy subjects, schizophrenics, manic-depressives and epileptics. J Med Invest 54, 303315.

Inan, M., Petros, T.J., and Anderson, S.A. (2013). Losing your inhibition: linking cortical GABAergic interneurons to schizophrenia. Neurobiol Dis 53, 36-48.

Jahshan, C., Wynn, J.K., and Green, M.F. (2013). Relationship between auditory processing and affective prosody in schizophrenia. Schizophr Res 143, 348-353.

Javitt, D.C. (2007). Glutamate and schizophrenia: phencyclidine, N-methyl-D-aspartate receptors, and dopamine-glutamate interactions. Int Rev Neurobiol 78, 69-108.

Javitt, D.C. (2009a). Sensory processing in schizophrenia: neither simple nor intact. Schizophr Bull 35, 1059-1064.

Javitt, D.C. (2009b). When doors of perception close: bottom-up models of disrupted cognition in schizophrenia. Annu Rev Clin Psychol 5, 249-275.

Javitt, D.C. (2010). Glutamatergic theories of schizophrenia. Isr J Psychiatry Relat Sci 47, 4-16.

Javitt, D.C., Liederman, E., Cienfuegos, A., and Shelley, A.-M. (1999). Panmodal processing imprecision as a basis for dysfunction of transient memory storage systems in schizophrenia. Schizophr Bull 25, 763-775.

Javitt, D.C., Shelley, A.-M., and Ritter, W. (2000). Associated deficits in mismatch negativity generation and tone matching in schizophrenia. Clin Neurophysiol 111, 1733-1737.

Javitt, D.C., Spencer, K.M., Thaker, G.K., Winterer, G., and Hajos, M. (2008). Neurophysiological biomarkers for drug development in schizophrenia. Nat Rev Drug Discov 7, 68-83.

Jenkins, G., and Röhricht, F. (2007). From cenesthesias to cenesthopathic schizophrenia: a historical and phenomenological review. Psychopathology 40, 361-368.

Jeon, Y.W., and Polich, J. (2003). Meta-analysis of P300 and schizophrenia: patients, paradigms, and practical implications. Psychophysiology 40,684-701.

Jiang, L., Emmetsberger, J., Talmage, D.A., and Role, L.W. (2013). Type III neuregulin 1 is required for multiple forms of excitatory synaptic plasticity of mouse cortico-amygdala circuits. J Neurosci 33, 9655-9666.

Jones, C., Watson, D., and Fone, K. (2011). Animal models of schizophrenia. Br J Pharmacol 164, 1162-1194.

Jones, L.M., Depireux, D.A., Simons, D.J., and Keller, A. (2004). Robust temporal coding in the trigeminal system. Science 304, 1986-1989.

Juckel, G., Gallinat, J., Riedel, M., Sokullu, S., Schulz, C., Möller, H.-J., Müller, N., and Hegerl, U. (2003). Serotonergic dysfunction in schizophrenia assessed by the loudness dependence measure of primary auditory cortex evoked activity. Schizophr Res 64, 115-124.

Juckel, G., Gudlowski, Y., Müller, D., Özgürdal, S., Brüne, M., Gallinat, J., Frodl, T., Witthaus, H., Uhl, I., Wutzler, A., et al. (2008). Loudness dependence of the auditory evoked N1/P2 component as an indicator of serotonergic dysfunction in patients with schizophrenia - a replication study. Psychiatry Res 158, 79-82.

Kang, C., Yang, X., Xu, X., Liu, H., Su, P., and Yang, J. (2012). Association study of neuregulin 1 gene polymorphisms with auditory p300 in schizophrenia. Am J Med Genet B Neuropsychiatr Genet 4, 422-428.

Karl, T., Duffy, L., Scimone, A., Harvey, R.P., and Schofield, P.R. (2007). Altered motor activity, exploration and anxiety in heterozygous neuregulin 1 mutant mice: implications for understanding schizophrenia. Genes Brain Behav 6, 677-687.

Kato, T., Abe, Y., Sotoyama, H., Kakita, A., Kominami, R., Hirokawa, S., Ozaki, M., Takahashi, H., and Nawa, H. (2011). Transient exposure of neonatal mice to neuregulin-1 results in hyperdopaminergic states in adulthood: implication in neurodevelopmental hypothesis for schizophrenia. Mol Psychiatry 16, 307-320.

Kato, T., Kasai, A., Mizuno, M., Fengyi, L., Shintani, N., Maeda, S., Yokoyama, M., Ozaki, M., and Nawa, H. (2010). Phenotypic characterization of transgenic mice overexpressing neuregulin-1. PLoS One 5, e14185. 
Katz, Y., Heiss, J.E., and Lampl, I. (2006). Cross-whisker adaptation of neurons in the rat barrel cortex. J Neurosci 26, 13363-13372.

Kawamura, T., Nakasato, N., Seki, K., Kanno, A., Fujita, S., Fujiwara, S., and Yoshimoto, T. (1996). Neuromagnetic evidence of pre-and post-central cortical sources of somatosensory evoked responses. Electroencephalogr Clin Neurophysiol 100, 44-50.

Kelemen, O., Kiss, I., Benedek, G., and Keri, S. (2013). Perceptual and cognitive effects of antipsychotics in first-episode schizophrenia: the potential impact of GABA concentration in the visual cortex. Prog Neuropsychopharmacol Biol Psychiatry 47, 13-19.

Keri, S. (2009). Genes for psychosis and creativity: a promoter polymorphism of the neuregulin 1 gene is related to creativity in people with high intellectual achievement. Psychol Sci 20, 10701073.

Keshavan, M.S., Tandon, R., Boutros, N.N., and Nasrallah, H.A. (2008). Schizophrenia, "just the facts": what we know in 2008: Part 3: neurobiology. Schizophr Res 106, 89-107.

Khatri, V., Hartings, J.A., and Simons, D.J. (2004). Adaptation in thalamic barreloid and cortical barrel neurons to periodic whisker deflections varying in frequency and velocity. J Neurophysiol 92, 3244-3254.

Khatri, V., and Simons, D.J. (2007). Angularly nonspecific response suppression in rat barrel cortex. Cereb Cortex 17, 599-609.

Khosravani, N., and Goodarzi, M.A. (2013). Patients with schizophrenia show deficits on spatial frequency doubling. Vision Res 93, 49-53.

Kirkpatrick, B., Buchanan, R.W., Ross, D.E., and Carpenter, W.T., Jr. (2001). A separate disease within the syndrome of schizophrenia. Arch Gen Psychiatry 58, 165-171.

Knyazev, G.G. (2012). EEG delta oscillations as a correlate of basic homeostatic and motivational processes. Neurosci Biobehav Rev 36, 677-695.

Kondziella, D., Brenner, E., Eyjolfsson, E.M., and Sonnewald, U. (2007). How do glial-neuronal interactions fit into current neurotransmitter hypotheses of schizophrenia? Neurochem Int 50, 291-301.

Kraehenmann, R., Vollenweider, F.X., Seifritz, E., and Kometer, M. (2012). Crowding deficits in the visual periphery of schizophrenia patients. PLoS One 7, 26.

Krishnan, G., Hetrick, W., Brenner, C., Shekhar, A., Steffen, A., and O'Donnell, B. (2009). Steady state and induced auditory gamma deficits in schizophrenia. Neuroimage 47, 1711.

Krishnan, G.P., Vohs, J.L., Hetrick, W.P., Carroll, C.A., Shekhar, A., Bockbrader, M.A., and O'Donnell, B.F. (2005). Steady state visual evoked potential abnormalities in schizophrenia. Clin Neurophysiol 116, 614-624.

Krug, A., Markov, V., Krach, S., Jansen, A., Zerres, K., Eggermann, T., Stocker, T., Shah, N.J., Nothen, M.M., Treutlein, J., et al. (2010). The effect of Neuregulin 1 on neural correlates of episodic memory encoding and retrieval. Neuroimage 53, 985-991.

Kubera, K.M., Sambataro, F., Vasic, N., Wolf, N.D., Frasch, K., Hirjak, D., Thomann, P.A., and Wolf, R.C. (2014). Source-based morphometry of gray matter volume in patients with schizophrenia who have persistent auditory verbal hallucinations. Prog Neuropsychopharmacol Biol Psychiatry 50, 102-109.

Kubicki, M., McCarley, R.W., and Shenton, M.E. (2005). Evidence for white matter abnormalities in schizophrenia. Curr Opin Psychiatry 18, 121-134.

Kukshal, P., Bhatia, T., Bhagwat, A.M., Gur, R.E., Gur, R.C., Deshpande, S.N., Nimgaonkar, V.L., and Thelma, B.K. (2013). Association study of Neuregulin-1 gene polymorphisms in a north Indian schizophrenia sample. Schizophr Res 144, 24-30.

Kwon, J.S., O'Donnell, B.F., Wallenstein, G.V., Greene, R.W., Hirayasu, Y., Nestor, P.G., Hasselmo, M.E., Potts, G.F., Shenton, M.E., and McCarley, R.W. (1999). Gamma frequency-range abnormalities to auditory stimulation in schizophrenia. Arch Gen Psychiatry 56, 1001-1005.

Law, A.J., Lipska, B.K., Weickert, C.S., Hyde, T.M., Straub, R.E., Hashimoto, R., Harrison, P.J., Kleinman, J.E., and Weinberger, D.R. (2006). Neuregulin 1 transcripts are differentially expressed 
in schizophrenia and regulated by 5' SNPs associated with the disease. Proc Natl Acad Sci U S A 103, 6747-6752.

Law, A.J., Shannon Weickert, C., Hyde, T.M., Kleinman, J.E., and Harrison, P.J. (2004). Neuregulin-1 (NRG-1) mRNA and protein in the adult human brain. Neuroscience 127, 125-136.

Laws, K.R. (1999). A meta-analytic review of Wisconsin Card Sort studies in schizophrenia: general intellectual deficit in disguise? Cogn Neuropsychiatry 4, 1-30.

Lee, K.H., Williams, L.M., Breakspear, M., and Gordon, E. (2003). Synchronous gamma activity: a review and contribution to an integrative neuroscience model of schizophrenia. Brain Res Brain Res Rev 41, 57-78.

Leicht, G., Karch, S., Karamatskos, E., Giegling, I., Moller, H.J., Hegerl, U., Pogarell, O., Rujescu, D., and Mulert, C. (2011). Alterations of the early auditory evoked gamma-band response in firstdegree relatives of patients with schizophrenia: hints to a new intermediate phenotype. J Psychiatr Res 45, 699-705.

Leicht, G., Kirsch, V., Giegling, I., Karch, S., Hantschk, I., Moller, H.J., Pogarell, O., Hegerl, U., Rujescu, D., and Mulert, C. (2010). Reduced early auditory evoked gamma-band response in patients with schizophrenia. Biol Psychiatry 67, 224-231.

Leitman, D.I., Wolf, D.H., Laukka, P., Ragland, J.D., Valdez, J.N., Turetsky, B.I., Gur, R.E., and Gur, R.C. (2011). Not pitch perfect: sensory contributions to affective communication impairment in schizophrenia. Biol Psychiatry 70, 611-618.

Lenz, D., Fischer, S., Schadow, J., Bogerts, B., and Herrmann, C.S. (2011). Altered evoked gammaband responses as a neurophysiological marker of schizophrenia? Int J Psychophysiol 79, 25-31.

Lenzenweger, M.F. (2000). Two-point discrimination thresholds and schizotypy: illuminating a somatosensory dysfunction. Schizophr Res 42, 111-124.

Lewis, D.A., Hashimoto, T., and Volk, D.W. (2005). Cortical inhibitory neurons and schizophrenia. Nat Rev Neurosci 6, 312-324.

Li, B., Woo, R.S., Mei, L., and Malinow, R. (2007). The neuregulin-1 receptor erbB4 controls glutamatergic synapse maturation and plasticity. Neuron 54, 583-597.

Li, D., Collier, D.A., and He, L. (2006). Meta-analysis shows strong positive association of the neuregulin 1 (NRG1) gene with schizophrenia. Hum Mol Genet 15, 1995-2002.

Li, T., Stefansson, H., Gudfinnsson, E., Cai, G., Liu, X., Murray, R.M., Steinthorsdottir, V., Januel, D., Gudnadottir, V.G., Petursson, H., et al. (2004). Identification of a novel neuregulin 1 at-risk haplotype in Han schizophrenia Chinese patients, but no association with the Icelandic/Scottish risk haplotype. Mol Psychiatry 9, 698-704.

Liang, M., Zhou, Y., Jiang, T., Liu, Z., Tian, L., Liu, H., and Hao, Y. (2006). Widespread functional disconnectivity in schizophrenia with resting-state functional magnetic resonance imaging. Neuroreport 17, 209-213.

Light, G.A., Hsu, J.L., Hsieh, M.H., Meyer-Gomes, K., Sprock, J., Swerdlow, N.R., and Braff, D.L. (2006). Gamma band oscillations reveal neural network cortical coherence dysfunction in schizophrenia patients. Biol Psychiatry 60, 1231-1240.

Lipska, B.K., and Gogos, J.A. (2011). Animal models of schizophrenia. Schizophrenia, Third Edition, 462-481.

Lisman, J. (2012). Excitation, inhibition, local oscillations, or large-scale loops: what causes the symptoms of schizophrenia? Curr Opin Neurobiol 22, 537-544.

Lu, Y., Yin, D.-M., Xiong, W.-C., and Mei, L. (2011). Modeling schizophrenia in neuregulin 1 and ErbB4 mutant mice. In Animal Models of Schizophrenia and Related Disorders (Springer), 261-277.

Lynall, M.E., Bassett, D.S., Kerwin, R., McKenna, P.J., Kitzbichler, M., Muller, U., and Bullmore, E. (2010). Functional connectivity and brain networks in schizophrenia. J Neurosci 30, 9477-9487.

Maravall, M., Petersen, R., Fairhall, A., Arabzadeh, E., and Diamond, M. (2007). Shifts in coding properties and maintenance of information transmission during adaptation in barrel cortex. PLoS Biol 5, e19. 
Marballi, K., Cruz, D., Thompson, P., and Walss-Bass, C. (2012). Differential neuregulin 1 cleavage in the prefrontal cortex and hippocampus in schizophrenia and bipolar disorder: preliminary findings. PLoS One 7, 10.

Marín, O. (2012). Interneuron dysfunction in psychiatric disorders. Nat Rev Neurosci 13, 107-120.

Marsman, A., van den Heuvel, M.P., Klomp, D.W., Kahn, R.S., Luijten, P.R., and Hulshoff Pol, H.E. (2013). Glutamate in schizophrenia: a focused review and meta-analysis of (1)H-MRS studies. Schizophr Bull 39, 120-129.

Martin, P., Tewesmeier, M., Albers, M., Schmid, G., and Ch, S. (2010). Towards an understanding of sensory soft signs of schizophrenia. Psychopathology 28, 281-284.

Martinez, A., Hillyard, S.A., Dias, E.C., Hagler, D.J., Jr., Butler, P.D., Guilfoyle, D.N., Jalbrzikowski, M., Silipo, G., and Javitt, D.C. (2008). Magnocellular pathway impairment in schizophrenia: evidence from functional magnetic resonance imaging. J Neurosci 28, 7492-7500.

Matsumoto, H., Simmons, A., Williams, S., Hadjulis, M., Pipe, R., Murray, R., and Frangou, S. (2001). Superior temporal gyrus abnormalities in early-onset schizophrenia: similarities and differences with adult-onset schizophrenia. Am J Psychiatry 158, 1299-1304.

Mayrhofer, J.M., Skreb, V., von der Behrens, W., Musall, S., Weber, B., and Haiss, F. (2013). Novel two-alternative forced choice paradigm for bilateral vibrotactile whisker frequency discrimination in head-fixed mice and rats. J Neurophysiol 109, 273-284.

McKinzie, D.L., and Bymaster, F.P. (2012). Muscarinic mechanisms in psychotic disorders. Handb Exp Pharmacol 213, 233-265.

Mechelli, A., Viding, E., Kumar, A., Tognin, S., Kane, F., and McGuire, P. (2010). Influence of neuregulin 1 genotype on neural substrate of perceptual matching in children. Behav Genet 40, 157-166.

Mei, L., and Xiong, W.C. (2008). Neuregulin 1 in neural development, synaptic plasticity and schizophrenia. Nat Rev Neurosci 9, 437-452.

Melzer, P., Champney, G.C., Maguire, M.J., and Ebner, F.F. (2006). Rate code and temporal code for frequency of whisker stimulation in rat primary and secondary somatic sensory cortex. Exp Brain Res 172, 370-386.

Meyer, D., and Birchmeier, C. (1995). Multiple essential functions of neuregulin in development. Nature 378, 386-390.

Meyer, D., Yamaai, T., Garratt, A., Riethmacher-Sonnenberg, E., Kane, D., Theill, L.E., and Birchmeier, C. (1997). Isoform-specific expression and function of neuregulin. Development 124, 3575-3586.

Michie, P.T. (2001). What has MMN revealed about the auditory system in schizophrenia? Int J Psychophysiol 42, 177-194.

Moberg, P.J., Agrin, R., Gur, R.E., Gur, R.C., Turetsky, B.I., and Doty, R.L. (1999). Olfactory dysfunction in schizophrenia: a qualitative and quantitative review. Neuropsychopharmacology 21, 325-340.

Modinos, G., Costafreda, S.G., van Tol, M.-J., McGuire, P.K., Aleman, A., and Allen, P. (2013). Neuroanatomy of auditory verbal hallucinations in schizophrenia: a quantitative meta-analysis of voxel-based morphometry studies. Cortex 49, 1046-1055.

Mohamad Shariati, S.A., Behmanesh, M., and Galehdari, H. (2011). A study of the association between SNP8NRG241930 in the 5' end of neuroglin 1 gene with schizophrenia in a group of Iranian patients. Cell J 13, 91-96.

Moore, C., Nelson, S., and Sur, M. (1999). Dynamics of neuronal processing in rat somatosensory cortex. Trends Neurosci 22, 513-520.

Moran, L.V., and Hong, L.E. (2011). High vs low frequency neural oscillations in schizophrenia. Schizophr Bull 37, 659-663.

Moyer, C.E., Delevich, K.M., Fish, K.N., Asafu-Adjei, J.K., Sampson, A.R., Dorph-Petersen, K.-A., Lewis, D.A., and Sweet, R.A. (2012). Reduced glutamate decarboxylase 65 protein within primary auditory cortex inhibitory boutons in schizophrenia. Biol Psychiatry 72, 734-743. 
Moyer, C.E., Delevich, K.M., Fish, K.N., Asafu-Adjei, J.K., Sampson, A.R., Dorph-Petersen, K.-A., Lewis, D.A., and Sweet, R.A. (2013). Intracortical excitatory and thalamocortical boutons are intact in primary auditory cortex in schizophrenia. Schizophr Res 149, 127-134.

Muckli, L. (2010). What are we missing here? Brain imaging evidence for higher cognitive functions in primary visual cortex V1. Int J Imaging Syst Technol 20, 131-139.

Mujica-Parodi, L.R., Malaspina, D., and Sackeim, H.A. (2000). Logical processing, affect, and delusional thought in schizophrenia. Harv Rev Psychiatry 8, 73-83.

Mulert, C., Kirsch, V., Pascual-Marqui, R., McCarley, R.W., and Spencer, K.M. (2011). Long-range synchrony of gamma oscillations and auditory hallucination symptoms in schizophrenia. Int $J$ Psychophysiol 79, 55-63.

Munafo, M.R., Thiselton, D.L., Clark, T.G., and Flint, J. (2006). Association of the NRG1 gene and schizophrenia: a meta-analysis. Mol Psychiatry 11, 539-546.

Myers, S., Caldwell, D., and Purcell, G. (1973). Vestibular dysfunction in schizophrenia. Biol Psychiatry 7, 255-261.

Näätänen, R., and Kähkönen, S. (2009). Central auditory dysfunction in schizophrenia as revealed by the mismatch negativity ( $M M N)$ and its magnetic equivalent $\mathrm{MMNm}$ : a review. Int J Neuropsychopharmacol 12, 125-135.

Naz, M., Riaz, M., and Saleem, M. (2011). Potential role of Neuregulin 1 and TNF-alpha (-308) polymorphism in schizophrenia patients visiting hospitals in Lahore, Pakistan. Mol Biol Rep 38, 4709-4714.

Neuhaus, A.H., Brandt, E.S.L., Goldberg, T.E., Bates, J.A., and Malhotra, A.K. (2013). Evidence for impaired visual prediction error in schizophrenia. Schizophr Res 147, 326-330.

Newell, K.A., Karl, T., and Huang, X.F. (2013). A neuregulin 1 transmembrane domain mutation causes imbalanced glutamatergic and dopaminergic receptor expression in mice. Neuroscience $248,670-680$.

Nguyen, A.D., Shenton, M.E., and Levitt, J.J. (2010). Olfactory dysfunction in schizophrenia: a review of neuroanatomy and psychophysiological measurements. Harv Rev Psychiatry 18, 279-292.

Nicolelis, M.A., and Fanselow, E.E. (2002). Thalamocortical optimization of tactile processing according to behavioral state. Nat Neurosci 5, 517-523.

Nicolelis, M.A., Wiest, M., Thomson, E., and Meloy, J. (2008). Chapter 6 - Multielectrode recordings in the somatosensory system. In Nicolelis MAL, ed. Methods for Neural Ensemble Recordings. 2nd edition. Boca Raton (FL): CRC Press.

Norra, C., Waberski, T.D., Kawohl, W., Kunert, H.J., Hock, D., Gobbele, R., Buchner, H., and Hoff, P. (2004). High-frequency somatosensory thalamocortical oscillations and psychopathology in schizophrenia. Neuropsychobiology 49, 71-80.

Nuechterlein, K.H., Barch, D.M., Gold, J.M., Goldberg, T.E., Green, M.F., and Heaton, R.K. (2004). Identification of separable cognitive factors in schizophrenia. Schizophr Res 72, 29-39.

Nunez, D., Rauch, J., Herwig, K., Rupp, A., Andermann, M., Weisbrod, M., Resch, F., and Oelkers-Ax, R. (2013). Evidence for a magnocellular disadvantage in early-onset schizophrenic patients: a source analysis of the N80 visual-evoked component. Schizophr Res 144, 16-23.

O'Connor, D.H., Clack, N.G., Huber, D., Komiyama, T., Myers, E.W., and Svoboda, K. (2010). Vibrissabased object localization in head-fixed mice. J Neurosci 30, 1947-1967.

O'Donnell, B.F., Potts, G.F., Nestor, P.G., Stylianopoulos, K.C., Shenton, M.E., and McCarley, R.W. (2002). Spatial frequency discrimination in schizophrenia. J Abnorm Psychol 111, 620-625.

O'Donnell, B.F., Swearer, J.M., Smith, L.T., Nestor, P.G., Shenton, M.E., and McCarley, R.W. (1996). Selective deficits in visual perception and recognition in schizophrenia. Am J Psychiatry 153, 687692.

O'Donnell, B.F., Vohs, J.L., Krishnan, G.P., Rass, O., Hetrick, W.P., and Morzorati, S.L. (2013). Chapter 6 - The auditory steady-state response (ASSR): a translational biomarker for schizophrenia. In Supplements to Clinical Neurophysiology, E. Başar, and G.G. Yener, eds. (Elsevier), 101-112. 
O'Tuathaigh, C.M., Harte, M., O'Leary, C., O'Sullivan, G.J., Blau, C., Lai, D., Harvey, R.P., Tighe, O., Fagan, A.J., Kerskens, C., et al. (2010). Schizophrenia-related endophenotypes in heterozygous neuregulin-1 'knockout' mice. Eur J Neurosci 31, 349-358.

O'Tuathaigh, C.M., O'Sullivan, G.J., Kinsella, A., Harvey, R.P., Tighe, O., Croke, D.T., and Waddington, J.L. (2006). Sexually dimorphic changes in the exploratory and habituation profiles of heterozygous neuregulin-1 knockout mice. Neuroreport 17, 79-83.

Oribe, N., Hirano, Y., Kanba, S., del Re, E.C., Seidman, L.J., Mesholam-Gately, R., Spencer, K.M., McCarley, R.W., and Niznikiewicz, M.A. (2013). Early and late stages of visual processing in individuals in prodromal state and first episode schizophrenia: An ERP study. Schizophr Res 146, 95-102.

Pakkenberg, B. (1993). Total nerve cell number in neocortex in chronic schizophrenics and controls estimated using optical disectors. Biol Psychiatry 34, 768-772.

Palaniyappan, L., Balain, V., Radua, J., and Liddle, P.F. (2012). Structural correlates of auditory hallucinations in schizophrenia: a meta-analysis. Schizophr Res 137, 169-173.

Panzeri, S., and Diamond, M.E. (2010). Information carried by population spike times in the whisker sensory cortex can be decoded without knowledge of stimulus time. Front Synaptic Neurosci 2.

Papaleo, F., Lipska, B.K., and Weinberger, D.R. (2012). Mouse models of genetic effects on cognition: relevance to schizophrenia. Neuropharmacology 62, 1204-1220.

Papiol, S., Begemann, M., Rosenberger, A., Friedrichs, H., Ribbe, K., Grube, S., Schwab, M.H., Jahn, H., Gunkel, S., Benseler, F., et al. (2011). A phenotype-based genetic association study reveals the contribution of neuregulin 1 gene variants to age of onset and positive symptom severity in schizophrenia. Am J Med Genet B Neuropsychiatr Genet 3, 340-345.

Parlapani, E., Schmitt, A., Wirths, O., Bauer, M., Sommer, C., Rueb, U., Skowronek, M.H., Treutlein, J., Petroianu, G.A., Rietschel, M., et al. (2010). Gene expression of neuregulin-1 isoforms in different brain regions of elderly schizophrenia patients. World J Biol Psychiatry 11, 243-250.

Peled, A., Pressman, A., Geva, A.B., and Modai, I. (2003). Somatosensory evoked potentials during a rubber-hand illusion in schizophrenia. Schizophr Res 64, 157-163.

Peled, A., Ritsner, M., Hirschmann, S., Geva, A.B., and Modai, I. (2000). Touch feel illusion in schizophrenic patients. Biol Psychiatry 48, 1105-1108.

Pinto, D., Pagnamenta, A.T., Klei, L., Anney, R., Merico, D., Regan, R., Conroy, J., Magalhaes, T.R., Correia, C., Abrahams, B.S., et al. (2010). Functional impact of global rare copy number variation in autism spectrum disorders. Nature 466, 368-372.

Pitcher, G.M., Kalia, L.V., Ng, D., Goodfellow, N.M., Yee, K.T., Lambe, E.K., and Salter, M.W. (2011). Schizophrenia susceptibility pathway neuregulin 1-ErbB4 suppresses Src upregulation of NMDA receptors. Nat Med 17, 470-478.

Plourde, G., Baribeau, J., and Bonhomme, V. (1997). Ketamine increases the amplitude of the $40-\mathrm{Hz}$ auditory steady-state response in humans. Br J Anaesth 78, 524-529.

Potter, D., Summerfelt, A., Gold, J., and Buchanan, R.W. (2006). Review of clinical correlates of P50 sensory gating abnormalities in patients with schizophrenia. Schizophr Bull 32, 692-700.

Pynn, L.K., and DeSouza, J.F. (2013). The function of efference copy signals: implications for symptoms of schizophrenia. Vision Res 76, 124-133.

Rado, S. (1953). Recent advances of psychoanalytic therapy. Res Publ Assoc Res Nerv Ment Dis 31, 42-58; passim.

Ramos-Loyo, J., Gonzalez-Garrido, A.A., Sanchez-Loyo, L.M., Medina, V., and Basar-Eroglu, C. (2009). Event-related potentials and event-related oscillations during identity and facial emotional processing in schizophrenia. Int J Psychophysiol 71, 84-90.

Reichenberg, A., and Harvey, P.D. (2007). Neuropsychological impairments in schizophrenia: integration of performance-based and brain imaging findings. Psychol Bull 133, 833-858.

Reite, M., Teale, P., Rojas, D.C., Benkers, T.L., and Carlson, J. (2003). Anomalous somatosensory cortical localization in schizophrenia. Am J Psychiatry 160, 2148-2153. 
Renshaw, P.F., Yurgelun-Todd, D.A., and Cohen, B.M. (1994). Greater hemodynamic response to photic stimulation in schizophrenic patients: an echo planar MRI study. Am J Psychiatry.

Rimer, M., Barrett, D.W., Maldonado, M.A., Vock, V.M., and Gonzalez-Lima, F. (2005). Neuregulin-1 immunoglobulin-like domain mutant mice: clozapine sensitivity and impaired latent inhibition. Neuroreport 16, 271-275.

Ritt, J.T., Andermann, M.L., and Moore, C.I. (2008). Embodied information processing: vibrissa mechanics and texture features shape micromotions in actively sensing rats. Neuron 57, 599-613.

Ritzler, B., and Rosenbaum, G. (1974). Proprioception in schizophrenics and normals: effects of stimulus intensity and interstimulus interval. J Abnorm Psychol 83, 106.

Role, L.W., and Talmage, D.A. (2007). Neurobiology: new order for thought disorders. Nature 448, 263-265.

Rosenbaum, G., Flenning, F., and Rosen, H. (1965). Effects of weight intensity on discrimination thresholds of normals and schizophrenics. J Abnorm Psychol 70, 446.

Rosenkranz, K., and Rothwell, J.C. (2004). The effect of sensory input and attention on the sensorimotor organization of the hand area of the human motor cortex. J Physiol 561, 307-320.

Roussos, P., Giakoumaki, S.G., Adamaki, E., and Bitsios, P. (2011). The influence of schizophreniarelated neuregulin-1 polymorphisms on sensorimotor gating in healthy males. Biol Psychiatry 69, 479-486.

Saha, S., Chant, D., Welham, J., and McGrath, J. (2005). A systematic review of the prevalence of schizophrenia. PLoS Med 2, 31.

Salomon, R., Bleich-Cohen, M., Hahamy-Dubossarsky, A., Dinstien, I., Weizman, R., Poyurovsky, M., Kupchik, M., Kotler, M., Hendler, T., and Malach, R. (2011). Global functional connectivity deficits in schizophrenia depend on behavioral state. J Neurosci 31, 12972-12981.

Scanziani, M., and Hausser, M. (2009). Electrophysiology in the age of light. Nature 461, 930-939.

Schall, U., Schön, A., Zerbin, D., Bender, S., Eggers, C., and Oades, R.D. (1997). A left temporal lobe impairment of auditory information processing in schizophrenia: an event-related potential study. Neurosci Lett 229, 25-28.

Schechter, I., Butler, P.D., Zemon, V.M., Revheim, N., Saperstein, A.M., Jalbrzikowski, M., Pasternak, R., Silipo, G., and Javitt, D.C. (2005). Impairments in generation of early-stage transient visual evoked potentials to magno- and parvocellular-selective stimuli in schizophrenia. Clin Neurophysiol 116, 2204-2215.

Schmechtig, A., Vassos, E., Kumari, V., Hutton, S.B., Collier, D.A., Morris, R.G., Williams, S.C., and Ettinger, U. (2010). Association of Neuregulin 1 rs3924999 genotype with antisaccades and smooth pursuit eye movements. Genes Brain Behav 9, 621-627.

Schultz, C.C., Wagner, G., Koch, K., Gaser, C., Roebel, M., Schachtzabel, C., Nenadic, I., Reichenbach, J.R., Sauer, H., and Schlosser, R.G. (2013). The visual cortex in schizophrenia: alterations of gyrification rather than cortical thickness - a combined cortical shape analysis. Brain Struct Funct 218, 51-58.

Selemon, L.D., and Goldman-Rakic, P.S. (1999). The reduced neuropil hypothesis: a circuit based model of schizophrenia. Biol Psychiatry 45, 17-25.

Selemon, L.D., Rajkowska, G., and Goldman-Rakic, P.S. (1995). Abnormally high neuronal density in the schizophrenic cortex. A morphometric analysis of prefrontal area 9 and occipital area 17. Arch Gen Psychiatry 52, 805-818.

Seok, J.H., Park, H.J., Chun, J.W., Lee, S.K., Cho, H.S., Kwon, J.S., and Kim, J.J. (2007). White matter abnormalities associated with auditory hallucinations in schizophrenia: a combined study of voxel-based analyses of diffusion tensor imaging and structural magnetic resonance imaging. Psychiatry Res 156, 93-104.

Seymour, K., Stein, T., Sanders, L.L., Guggenmos, M., Theophil, I., and Sterzer, P. (2013). Altered contextual modulation of primary visual cortex responses in schizophrenia. Neuropsychopharmacology 38, 2607-2612. 
Shad, M.U., Tamminga, C.A., Cullum, M., Haas, G.L., and Keshavan, M.S. (2006). Insight and frontal cortical function in schizophrenia: a review. Schizophr Res 86, 54-70.

Shagass, C. (1977). Early evoked potentials. Schizophr Bull 3, 80-92.

Shagass, C., Roemer, R.A., Straumanis, J.J., and Amadeo, M. (1978). Evoked potential correlates of psychosis. Biol Psychiatry 13, 163.

Shagass, C., Roemer, R.A., Straumanis, J.J., and Amadeo, M. (1979). Temporal variability of somatosensory, visual, and auditory evoked potentials in schizophrenia. Arch Gen Psychiatry 36, 1341.

Shergill, S.S., Brammer, M.J., Williams, S.C.R., Murray, R.M., and McGuire, P.K. (2000). Mapping auditory hallucinations in schizophrenia using functional magnetic resonance imaging. Arch Gen Psychiatry 57, 1033-1038.

Shergill, S.S., Cameron, L.A., Brammer, M.J., Williams, S.C., Murray, R.M., and McGuire, P.K. (2001). Modality specific neural correlates of auditory and somatic hallucinations. J Neurol Neurosurg Psychiatry 71, 688-690.

Shergill, S.S., White, T.P., Joyce, D.W., Bays, P.M., Wolpert, D.M., and Frith, C.D. (2014). Functional magnetic resonance imaging of impaired sensory prediction in schizophrenia. JAMA Psychiatry 71, 28-35.

Sheth, B.R., Moore, C.I., and Sur, M. (1998). Temporal modulation of spatial borders in rat barrel cortex. J Neurophysiol 79, 464-470.

Silverstein, S.M., and Keane, B.P. (2011). Perceptual organization impairment in schizophrenia and associated brain mechanisms: review of research from 2005 to 2010. Schizophr Bull 37, 690-699.

Simons, D.J. (1978). Response properties of vibrissa units in rat SI somatosensory neocortex. J Neurophysiol 41, 798-820.

Singer, W., and Gray, C.M. (1995). Visual feature integration and the temporal correlation hypothesis. Annu Rev Neurosci 18, 555-586.

Singh, M.K., Giles, L.L., and Nasrallah, H.A. (2006). Pain insensitivity in schizophrenia: trait or state marker? J Psychiatr Pract 12, 90-102.

Smyrnis, N., Kattoulas, E., Stefanis, N.C., Avramopoulos, D., Stefanis, C.N., and Evdokimidis, I. (2011). Schizophrenia-related neuregulin-1 single-nucleotide polymorphisms lead to deficient smooth eye pursuit in a large sample of young men. Schizophr Bull 37, 822-831.

Söhnchen, J., Grosheva, M., Kiryakova, S., Hübbers, C.U., Sinis, N., Skouras, E., Ankerne, J., Kaidoglou, K., Fries, J.W.U., Irintchev, A., et al. (2010). Recovery of whisking function after manual stimulation of denervated vibrissal muscles requires brain-derived neurotrophic factor and its receptor tyrosine kinase B. Neuroscience 170, 372-380.

Sonder, S.L. (1955). Perceptual tests and acute and chronic status as predictors of improvement in psychotic patients. J Consult Psychol 19, 387.

Spencer, K.M., and Ghorashi, S. (2014). Oscillatory dynamics of Gestalt perception in schizophrenia revisited. Front Psychol 5.

Spencer, K.M., Nestor, P.G., Niznikiewicz, M.A., Salisbury, D.F., Shenton, M.E., and McCarley, R.W. (2003). Abnormal neural synchrony in schizophrenia. J Neurosci 23, 7407-7411.

Spencer, K.M., Nestor, P.G., Perlmutter, R., Niznikiewicz, M.A., Klump, M.C., Frumin, M., Shenton, M.E., and McCarley, R.W. (2004). Neural synchrony indexes disordered perception and cognition in schizophrenia. Proc Natl Acad Sci U S A 101, 17288-17293.

Spencer, K.M., Salisbury, D.F., Shenton, M.E., and McCarley, R.W. (2008). Gamma-band auditory steady-state responses are impaired in first episode psychosis. Biol Psychiatry 64, 369-375.

Stefansson, H., Sarginson, J., Kong, A., Yates, P., Steinthorsdottir, V., Gudfinnsson, E., Gunnarsdottir, S., Walker, N., Petursson, H., Crombie, C., et al. (2003). Association of neuregulin 1 with schizophrenia confirmed in a Scottish population. Am J Hum Genet 72, 83-87.

Steinmann, S., Leicht, G., and Mulert, C. (2014). Interhemispheric auditory connectivity: structure and function related to auditory verbal hallucinations (Front Hum Neurosci. 2014 Feb 11;8:55. eCollection 2014.). 
Stephan, K.E., Friston, K.J., and Frith, C.D. (2009). Dysconnection in schizophrenia: from abnormal synaptic plasticity to failures of self-monitoring. Schizophr Bull 35, 509-527.

Sun, J., Kuo, P.H., Riley, B.P., Kendler, K.S., and Zhao, Z. (2008). Candidate genes for schizophrenia: a survey of association studies and gene ranking. Am J Med Genet B Neuropsychiatr Genet 5, 11731181.

Sun, L., Castellanos, N., Grutzner, C., Koethe, D., Rivolta, D., Wibral, M., Kranaster, L., Singer, W., Leweke, M.F., and Uhlhaas, P.J. (2013). Evidence for dysregulated high-frequency oscillations during sensory processing in medication-naive, first episode schizophrenia. Schizophr Res 150, 519-525.

Super, H. (2003). Working memory in the primary visual cortex. Arch Neurol 60, 809-812.

Sweet, R.A., Bergen, S.E., Sun, Z., Marcsisin, M.J., Sampson, A.R., and Lewis, D.A. (2007). Anatomical evidence of impaired feedforward auditory processing in schizophrenia. Biol Psychiatry 61, 854864.

Sweet, R.A., Bergen, S.E., Sun, Z., Sampson, A.R., Pierri, J.N., and Lewis, D.A. (2004). Pyramidal cell size reduction in schizophrenia: evidence for involvement of auditory feedforward circuits. Biol Psychiatry 55, 1128-1137.

Sweet, R.A., Henteleff, R.A., Zhang, W., Sampson, A.R., and Lewis, D.A. (2009). Reduced dendritic spine density in auditory cortex of subjects with schizophrenia. Neuropsychopharmacology 34 , 374-389.

Tan, H.R., Lana, L., and Uhlhaas, P.J. (2013). High-frequency neural oscillations and visual processing deficits in schizophrenia. Front Psychol 4, 621.

Tandon, R. (2012). The nosology of schizophrenia: toward DSM-5 and ICD-11. Psychiatr Clin North Am 35, 557-569.

Tandon, R., Gaebel, W., Barch, D.M., Bustillo, J., Gur, R.E., Heckers, S., Malaspina, D., Owen, M.J., Schultz, S., Tsuang, M., et al. (2013). Definition and description of schizophrenia in the DSM-5. Schizophr Res 150, 3-10.

Tandon, R., Nasrallah, H.A., and Keshavan, M.S. (2009). Schizophrenia, "just the facts" 4. Clinical features and conceptualization. Schizophr Res 110, 1-23.

Taylor, S.B., Taylor, A.R., and Koenig, J.I. (2013). The interaction of disrupted Type II Neuregulin 1 and chronic adolescent stress on adult anxiety- and fear-related behaviors. Neuroscience 249, 31-42.

Taylor, S.B., Taylor, A.R., Markham, J.A., Geurts, A.M., Kanaskie, B.Z., and Koenig, J.I. (2011). Disruption of the neuregulin 1 gene in the rat alters HPA axis activity and behavioral responses to environmental stimuli. Physiol Behav 104, 205-214.

Taylor, S.F., Tandon, R., and Koeppe, R.A. (1997). PET study of greater visual activation in schizophrenia. Am J Psychiatry 154, 1296-1298.

Teale, P., Collins, D., Maharajh, K., Rojas, D.C., Kronberg, E., and Reite, M. (2008). Cortical source estimates of gamma band amplitude and phase are different in schizophrenia. Neuroimage 42, 1481-1489.

Teale, P., Pasko, B., Collins, D., Rojas, D., and Reite, M. (2013). Somatosensory timing deficits in schizophrenia. Psychiatry Res 212, 73-78.

Thakkar, K.N., Nichols, H.S., McIntosh, L.G., and Park, S. (2011). Disturbances in body ownership in schizophrenia: evidence from the rubber hand illusion and case study of a spontaneous out-ofbody experience. PLoS One 6, 31.

Thoma, R.J., Hanlon, F.M., Huang, M., Miller, G.A., Moses, S.N., Weisend, M.P., Jones, A., Paulson, K.M., Irwin, J., and Cañive, J.M. (2007). Impaired secondary somatosensory gating in patients with schizophrenia. Psychiatry Res 151, 189-199.

Thomson, P.A., Christoforou, A., Morris, S.W., Adie, E., Pickard, B.S., Porteous, D.J., Muir, W.J., Blackwood, D.H., and Evans, K.L. (2007). Association of Neuregulin 1 with schizophrenia and bipolar disorder in a second cohort from the Scottish population. Mol Psychiatry 12, 94-104.

Tibber, M.S., Anderson, E.J., Bobin, T., Antonova, E., Seabright, A., Wright, B., Carlin, P., Shergill, S.S., and Dakin, S.C. (2013). Visual surround suppression in schizophrenia. Front Psychol 4, 88. 
Ting, A.K., Chen, Y., Wen, L., Yin, D.M., Shen, C., Tao, Y., Liu, X., Xiong, W.C., and Mei, L. (2011). Neuregulin 1 promotes excitatory synapse development and function in GABAergic interneurons. J Neurosci 31, 15-25.

Todd, J., Michie, P.T., and Jablensky, A.V. (2003). Association between reduced duration mismatch negativity (MMN) and raised temporal discrimination thresholds in schizophrenia. Clin Neurophysiol 114, 2061-2070.

Trémeau, F. (2006). A review of emotion deficits in schizophrenia. Dialogues Clin Neurosci 8, 59.

Treue, S. (2001). Neural correlates of attention in primate visual cortex. Trends Neurosci 24, 295300.

Tsuang, M. (2000). Schizophrenia: genes and environment. Biol Psychiatry 47, 210-220.

Tsuchimoto, R., Kanba, S., Hirano, S., Oribe, N., Ueno, T., Hirano, Y., Nakamura, I., Oda, Y., Miura, T., and Onitsuka, T. (2011). Reduced high and low frequency gamma synchronization in patients with chronic schizophrenia. Schizophr Res 133, 99-105.

Ublinskiy, M.V., Semenova, N.A., Akhadov, T.A., Petryaykin, A.V., Lebedeva, I.S., Efremkin, A.F., Tyurneva, A.S., and Kaleda, V.G. (2013). Characteristics of hemodynamic response functions in the brain of patients with schizophrenia in execution of auditory paradigm oddball. Dokl Biochem Biophys 453, 288-291.

Uhlhaas, P.J. (2013). Dysconnectivity, large-scale networks and neuronal dynamics in schizophrenia. Curr Opin Neurobiol 23, 283-290.

Uhlhaas, P.J., Haenschel, C., Nikolic, D., and Singer, W. (2008). The role of oscillations and synchrony in cortical networks and their putative relevance for the pathophysiology of schizophrenia. Schizophr Bull 34, 927-943.

Uhlhaas, P.J., Linden, D.E., Singer, W., Haenschel, C., Lindner, M., Maurer, K., and Rodriguez, E. (2006). Dysfunctional long-range coordination of neural activity during Gestalt perception in schizophrenia. J Neurosci 26, 8168-8175.

Uhlhaas, P.J., and Mishara, A.L. (2007). Perceptual anomalies in schizophrenia: integrating phenomenology and cognitive neuroscience. Schizophr Bull 33, 142-156.

Uhlhaas, P.J., and Singer, W. (2010). Abnormal neural oscillations and synchrony in schizophrenia. Nat Rev Neurosci 11, 100-113.

van den Buuse, M., Wischhof, L., Lee, R.X., Martin, S., and Karl, T. (2009). Neuregulin 1 hypomorphic mutant mice: enhanced baseline locomotor activity but normal psychotropic drug-induced hyperlocomotion and prepulse inhibition regulation. Int J Neuropsychopharmacol 12, 1383-1393.

Varela, F., Lachaux, J.P., Rodriguez, E., and Martinerie, J. (2001). The brainweb: phase synchronization and large-scale integration. Nat Rev Neurosci 2, 229-239.

Vohs, J.L., Chambers, R.A., Krishnan, G.P., O'Donnell, B.F., Berg, S., and Morzorati, S.L. (2010). GABAergic modulation of the $40 \mathrm{~Hz}$ auditory steady-state response in a rat model of schizophrenia. Int J Neuropsychopharmacol 13, 487-497.

Voigts, J., Sakmann, B., and Celikel, T. (2008). Unsupervised whisker tracking in unrestrained behaving animals. J Neurophysiol 100, 504-515.

Waberski, T.D., Norra, C., Kawohl, W., Thyerlei, D., Hock, D., Klostermann, F., Curio, G., Buchner, H., Hoff, P., and Gobbele, R. (2004). Electrophysiological evidence for altered early cerebral somatosensory signal processing in schizophrenia. Psychophysiology 41, 361-366.

Walker, R.M., Christoforou, A., Thomson, P.A., McGhee, K.A., Maclean, A., Muhleisen, T.W., Strohmaier, J., Nieratschker, V., Nothen, M.M., Rietschel, M., et al. (2010). Association analysis of Neuregulin 1 candidate regions in schizophrenia and bipolar disorder. Neurosci Lett 478, 9-13.

Wang, H., Li, R., and Shen, Y. (2013). beta-Secretase: its biology as a therapeutic target in diseases. Trends Pharmacol Sci 34, 215-225.

Wang, J., Brown, R., Dobkins, K.R., McDowell, J.E., and Clementz, B.A. (2010). Diminished parietal cortex activity associated with poor motion direction discrimination performance in schizophrenia. Cereb Cortex 20, 1749-1755. 
Wang, X.-J. (2006). Toward a prefrontal microcircuit model for cognitive deficits in schizophrenia. Pharmacopsychiatry $39,80-87$.

Warren, S., and Ross, R.G. (1998). Deficient cancellation of the vestibular ocular reflex in schizophrenia. Schizophr Res 34, 187-193.

Wen, L., Lu, Y.S., Zhu, X.H., Li, X.M., Woo, R.S., Chen, Y.J., Yin, D.M., Lai, C., Terry, A.V., Jr., Vazdarjanova, A., et al. (2010). Neuregulin 1 regulates pyramidal neuron activity via ErbB4 in parvalbumin-positive interneurons. Proc Natl Acad Sci U S A 107, 1211-1216.

Wesson, D.W., Donahou, T.N., Johnson, M.O., and Wachowiak, M. (2008). Sniffing behavior of mice during performance in odor-guided tasks. Chem Senses 33, 581-596.

Wheeler, D.G., Dixon, G., and Harper, C.G. (2006). No differences in calcium-binding protein immunoreactivity in the posterior cingulate and visual cortex: schizophrenia and controls. Prog Neuropsychopharmacol Biol Psychiatry 30, 630-639.

White, T.P., Joseph, V., O'Regan, E., Head, K.E., Francis, S.T., and Liddle, P.F. (2010). Alpha-gamma interactions are disturbed in schizophrenia: a fusion of electroencephalography and functional magnetic resonance imaging. Clin Neurophysiol 121, 1427-1437.

Wible, C.G., Kubicki, M., Yoo, S.S., Kacher, D.F., Salisbury, D.F., Anderson, M.C., Shenton, M.E., Hirayasu, Y., Kikinis, R., Jolesz, F.A., et al. (2001). A functional magnetic resonance imaging study of auditory mismatch in schizophrenia. Am J Psychiatry 158, 938-943.

Wilson, T.W., Hernandez, O.O., Asherin, R.M., Teale, P.D., Reite, M.L., and Rojas, D.C. (2008). Cortical gamma generators suggest abnormal auditory circuitry in early-onset psychosis. Cereb Cortex 18, 371-378.

Winterer, G., Coppola, R., Goldberg, T.E., Egan, M.F., Jones, D.W., Sanchez, C.E., and Weinberger, D.R. (2004). Prefrontal broadband noise, working memory, and genetic risk for schizophrenia. Am J Psychiatry 161, 490-500.

Winterer, G., Mulert, C., Mientus, S., Gallinat, J., Schlattmann, P., Dorn, H., and Herrmann, W.M. (2001). P300 and LORETA: comparison of normal subjects and schizophrenic patients. Brain Topogr 13, 299-313.

Winterer, G., Musso, F., Beckmann, C., Mattay, V., Egan, M., Jones, D., Callicott, J., Coppola, R., and Weinberger, D. (2006). Instability of prefrontal signal processing in schizophrenia. Am J Psychiatry $163,1960-1968$.

Winterer, G., Ziller, M., Dorn, H., Frick, K., Mulert, C., Wuebben, Y., Herrmann, W.M., and Coppola, R. (2000). Schizophrenia: reduced signal-to-noise ratio and impaired phase-locking during information processing. Clin Neurophysiol 111, 837-849.

Wolfe, J., Mende, C., and Brecht, M. (2011). Social facial touch in rats. Behav Neurosci 125, 900-910.

Woo, R.S., Li, X.M., Tao, Y., Carpenter-Hyland, E., Huang, Y.Z., Weber, J., Neiswender, H., Dong, X.P., Wu, J., Gassmann, M., et al. (2007). Neuregulin-1 enhances depolarization-induced GABA release. Neuron 54, 599-610.

Woodruff, P.W., Wright, I.C., Bullmore, E.T., Brammer, M., Howard, R.J., Williams, S.C., Shapleske, J., Rossell, S., David, A.S., McGuire, P.K., et al. (1997). Auditory hallucinations and the temporal cortical response to speech in schizophrenia: a functional magnetic resonance imaging study. Am J Psychiatry 154, 1676-1682.

Woodward, N.D., Karbasforoushan, H., and Heckers, S. (2012). Thalamocortical dysconnectivity in schizophrenia. Am J Psychiatry 169, 1092-1099.

Woolsey, T.A., and Van der Loos, H. (1970). The structural organization of layer IV in the somatosensory region (SI) of mouse cerebral cortex. The description of a cortical field composed of discrete cytoarchitectonic units. Brain Res 17, 205-242.

Wynn, J.K., Jahshan, C., and Green, M.F. (2014). Multisensory integration in schizophrenia: a behavioural and event-related potential study. Cogn Neuropsychiatry 8,8 .

Wynn, J.K., Light, G.A., Breitmeyer, B., Nuechterlein, K.H., and Green, M.F. (2005). Event-related gamma activity in schizophrenia patients during a visual backward-masking task. Am J Psychiatry $162,2330-2336$. 
Yang, E., Tadin, D., Glasser, D.M., Hong, S.W., Blake, R., and Park, S. (2013). Visual context processing in schizophrenia. Clin Psychol Sci 1, 5-15.

Yang, S.A. (2012). Association between a missense polymorphism (rs3924999, Arg253Gln) of neuregulin 1 and schizophrenia in Korean population. Exp Neurobiol 21, 158-163.

Yokley, J.L., Prasad, K.M., Chowdari, K.V., Talkowski, M.E., Wood, J., Gur, R.C., Gur, R.E., Almasy, L., Nimgaonkar, V.L., and Pogue-Geile, M.F. (2012). Genetic associations between neuregulin-1 SNPs and neurocognitive function in multigenerational, multiplex schizophrenia families. Psychiatr Genet 22, 70-81.

Yoon, J.H., Maddock, R.J., Rokem, A., Silver, M.A., Minzenberg, M.J., Ragland, J.D., and Carter, C.S. (2010). GABA concentration is reduced in visual cortex in schizophrenia and correlates with orientation-specific surround suppression. J Neurosci 30, 3777-3781.

Yoon, J.H., Rokem, A.S., Silver, M.A., Minzenberg, M.J., Ursu, S., Ragland, J.D., and Carter, C.S. (2009). Diminished orientation-specific surround suppression of visual processing in schizophrenia. Schizophr Bull 35, 1078-1084.

Young, J.W., Zhou, X., and Geyer, M.A. (2010). Animal models of schizophrenia. In Behavioral Neurobiology of Schizophrenia and Its Treatment (Springer), 391-433.

Zhang, L., Fletcher-Turner, A., Marchionni, M.A., Apparsundaram, S., Lundgren, K.H., Yurek, D.M., and Seroogy, K.B. (2004). Neurotrophic and neuroprotective effects of the neuregulin glial growth factor-2 on dopaminergic neurons in rat primary midbrain cultures. J Neurochem 91, 1358-1368.

Zhang, Z., Prentiss, L., Heitzman, D., Stahl, R.C., DiPino, F., Jr., and Carey, D.J. (2006). Neuregulin isoforms in dorsal root ganglion neurons: effects of the cytoplasmic domain on localization and membrane shedding of Nrg-1 type I. J Neurosci Res 84, 1-12.

Zhong, C., Du, C., Hancock, M., Mertz, M., Talmage, D.A., and Role, L.W. (2008). Presynaptic type III neuregulin 1 is required for sustained enhancement of hippocampal transmission by nicotine and for axonal targeting of alpha7 nicotinic acetylcholine receptors. J Neurosci 28, 9111-9116.

Zhou, S.Y., Suzuki, M., Takahashi, T., Hagino, H., Kawasaki, Y., Matsui, M., Seto, H., and Kurachi, M. (2007). Parietal lobe volume deficits in schizophrenia spectrum disorders. Schizophr Res 89, 3548.

Zubin, J. (1954). Psychological prognosis in early and chronic schizophrenic patients. US Public Health Progress Report (Rep No M586C) Public Healthy Service, Washington, DC, US. 


\section{Chapter II}

\section{Methods}

\section{Animals}

Animal procedures adhered to the ethical guidelines of the NIH and were approved by the Institutional Animal Care and Use Committee of the University of Pennsylvania. Twenty-nine adult mice aged 4-6 months were used for the procedures, of which 6 were C57/BL6 mice, 14 were heterozygous Neuregulin 1 (NRG1) knockout mice (NRG1 +/-), and 9 were wildtype mice (NRG1 +/+, or WT). Animals were obtained from S. Siegel and T. Brodkin (University of Pennsylvania). The NRG1 mutants were originally created by fusing $\beta$-galactosidase to exon 6 of the NRG1 allele, which is the $\mathrm{N}$-terminal of the EGF-like domain that is present in all NRG1 isoforms (Meyer and Birchmeier, 1995). Thus, the mutation affects all types of NRG1 transcripts (Meyer et al., 1997). The mice were maintained on a C57BL/6/129 hybrid background (Ehrlichman et al., 2009; Siegel and Brodkin labs, personal communication). Mice were genotyped twice using tail clips both after birth and after death. Polymerase chain reaction (PCR; 35 cycles, annealing at $60^{\circ} \mathrm{C}$ ) was performed with the REDExtract-NAmp Tissue PCR Kit (Sigma-Aldrich) and the following primers: Primer 1 (NDF-): 5'-TGC TGC TTT CTT CGC TCT TCA GAA GC-3'. Primer 2 (NDF+): 5'-GAG ATG GTC ATG TCC TTG TCA CTA AC-3'. Primer 3 (NDFneo): 5'-CGA ATT CGC CAA TGA CAA GAC GCT G-3'.

\section{Preparation}

Mice were initially sedated with xylazine (13 mg/kg i.p.; Butler Schein Animal Health, Dublin, Ohio) and after $15 \mathrm{~min}$, anesthetized with $3.5 \%$ isoflurane (Abbott, North Chicago, Illinois). All surgical procedures were carried out under isoflurane maintained between $1 \%$ and $1.5 \%$. After performing a tracheotomy, animals were artificially ventilated with the mouse ventilator MiniVent 845 (Harvard Apparatus; $140-170$ strokes/min, 180-220 $\mu \mathrm{l} /$ stroke) and placed in the stereotaxic frame (model 1730, David Kopf Instruments, Tujunga, California; Fig. 1). Mice received a single dose of glycopyrrolate $(0.02 \mathrm{mg} / \mathrm{kg}$ i.p.; American Regent, Shirley, New York) and dexamethasone $(4 \mathrm{mg} / \mathrm{kg}$ i.p.; American Regent) to reduce brain swelling and secretions, respectively. A craniotomy was performed over the barrel cortex (3.2-4.3 $\mathrm{mm}$ lateral, 0.6-1.6 $\mathrm{mm}$ posterior to Bregma) and the dura was carefully resected. After the probe was inserted, the cortex was left to recover for about $1 \mathrm{~h}$ before recordings began. Throughout the recordings, isoflurane was replaced by fentanyl (10-40 $\mu \mathrm{g} / \mathrm{kg} /$ hour i.p.) in order to maintain the animal in a sedated state. If the animals presented any sign 
of discomfort, isoflurane $0.1-0.5 \%$ was added to supply this anesthesia regimen. Body temperature was maintained at $35-37^{\circ} \mathrm{C}$ with a heating pad and a thermometer.

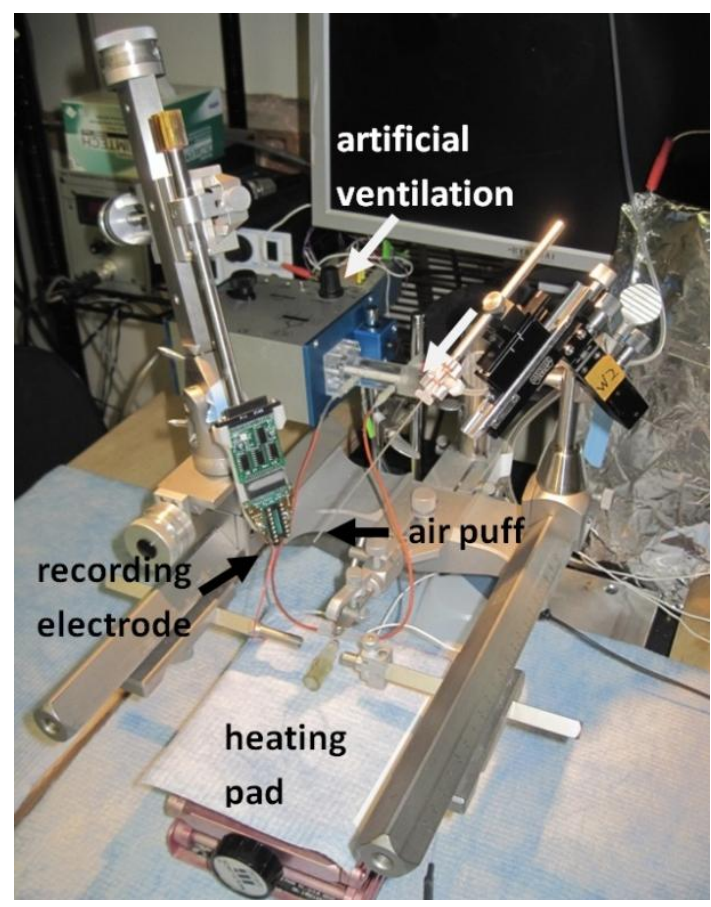

FIGURE 1. Recording and stimulation setup. The animal first received a mixture of isoflurane and oxygen through a custom-made face mask as shown in the picture. After the tracheotomy, the mask was replaced by tubing that was fitted to the size of the trachea and connected to an artificial ventilator. The mouse was placed on a heating pad in a stereotactic frame. The recording electrode and air puff stimulator were mounted on the frame and could be adjusted in position as needed.

\section{Electrophysiology}

Recordings (Fig. 2 and $\mathbf{3}$ ) were performed with 16-channel silicon probes configured as $2 \times 2$ tetrodes (Neuronexus, Ann Arbor, Michigan). The probe consisted of two shanks, spaced $150 \mu \mathrm{m}$ apart, with two tetrodes each, also spaced $150 \mu \mathrm{m}$ apart. Each tetrode was made of four electrodes placed in a diamond shape. Electrodes had a diameter of $11 \mu \mathrm{m}$ and were $25 \mu \mathrm{m}$ apart. This configuration was chosen for its advantages in measuring and analyzing unit activity. Probes were carefully inserted into the brain perpendicular to the surface and lowered to layers II/III and IV under visual guidance and based on readings from the micromanipulator. Signals were amplified (x 5000) and filtered (local field potentials: $0.1-300 \mathrm{~Hz}$; spikes: $600 \mathrm{~Hz}-6 \mathrm{kHz}$ ), and digitized at $33.657 \mathrm{kHz}$ (Cheetah, Neuralynx). Waveforms crossing set thresholds (100-120 $\mu \mathrm{V}$ ) were captured via the A/D card and analyzed offline. Potential cells were first identified using automated clustering software utilizing peak and trough feature sets (KlustaKwik). These clusters were then examined manually for waveform shape in order to discard non-cell clusters, and combine clusters that captured waveforms from the same cell. These clusters were further refined by hand upon examination of the interspike intervals (SpikeSort3D, Neuralynx). Offline re-evaluation of clusters was essential to avoid false clusters or extra clusters typically added by the automatic clustering routine. Most tetrodes had one to three 
separable cells. Interspike intervals were calculated and single units with action potentials $>2 \%$ within a bin of $2 \mathrm{~ms}$ were excluded from the analysis. We considered as multi-unit activities all spikes recorded by one tetrode.

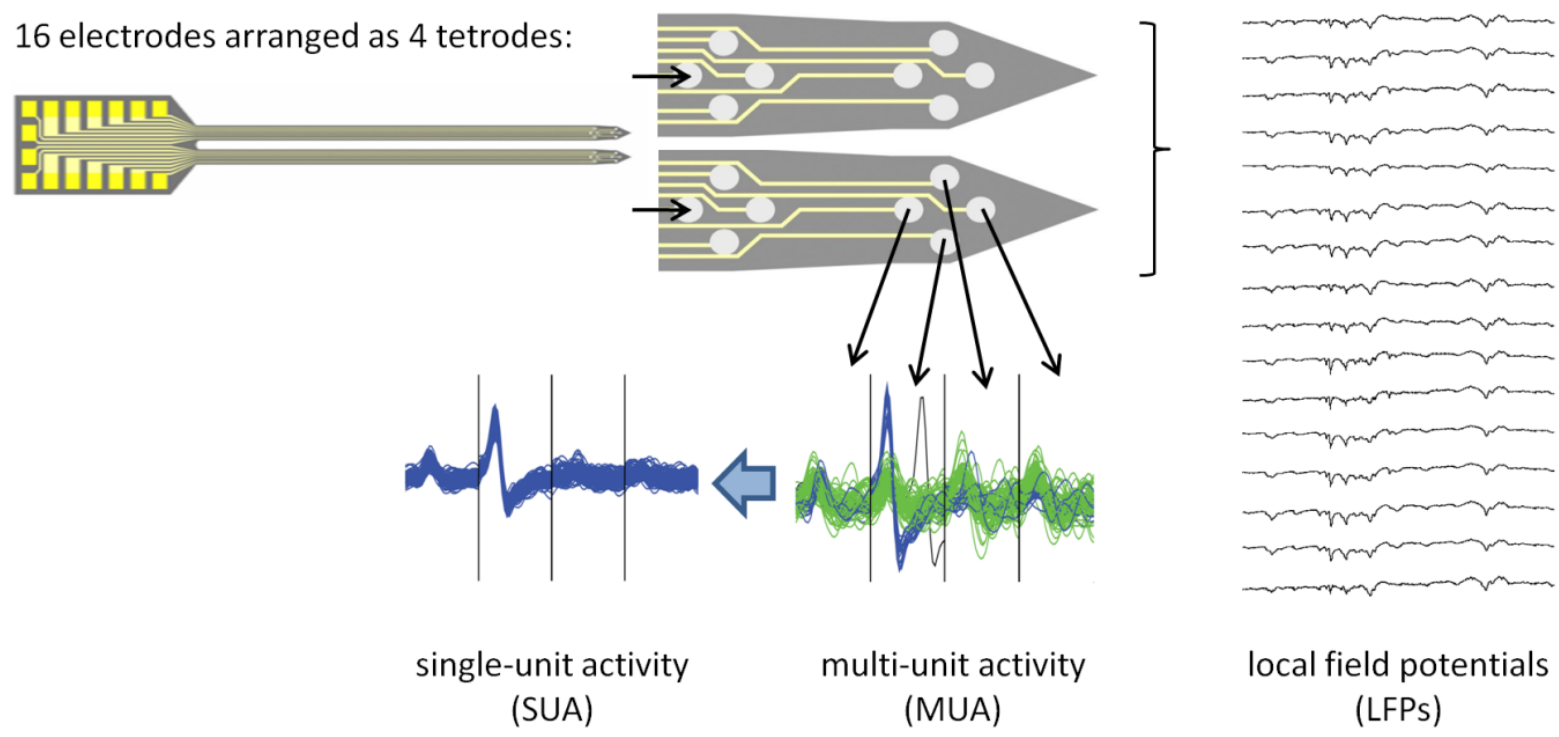

FIGURE 2. Neural recording probe. The probe consisted of 16 electrodes arranged in clusters of four tetrodes (top images; with permission from Neuronexus). The recorded signal was filtered for low (0.1-300 Hz) and high (0.6-6 kHz) frequencies to yield local field potentials (LFPs) and unit activity, respectively. The recorded signal consisted of one LFP per electrode, one multi-unit activity (MUA) per tetrode, and 1-3 single units (SUA) per tetrode. The tetrode configuration allowed recording each unit from four different angles, which facilitated offline clustering. The SUA comprises similar waveform shapes and is assumed to represent spiking activity of a single cell (see also Fig. 3).

\section{Stimulation}

Whiskers were trimmed to $0.7 \mathrm{~cm}$ and stimulated with air puffs delivered with Picospritzer III (General Valve, Fairfield, New Jersey; 70 psi at the source). Air puffs were applied with a glass capillary for precise stimulation of 2 to 5 whisker tips (usually whiskers in rows C/D, arcs 3/4). Stimulation was targeted to evoke the largest response in local field potentials and multi-unit spiking with the shortest latency (Histogram software, Neuralynx). Air puff stimuli were controlled by Igor software (WaveMetrics Inc., Lake Oswego, Oregon). Low frequency stimuli consisted of a $5 \mathrm{~s}$ train of square pulses (width: $2 \mathrm{~ms}$ ) applied at a frequency of $1 \mathrm{~Hz}$, and $3 \mathrm{~s}$ trains of pulses applied at frequencies of $3,5,8,10,12$ and $15 \mathrm{~Hz}$. All trains of stimuli were separated by a $5 \mathrm{~s}$ interval. Trains were pseudo-randomized and repeated 40 times each. High frequency stimuli consisted of $1 \mathrm{~s}$ trains of square pulses (width: $2 \mathrm{~ms}$ ) repeated every $5 \mathrm{~s}$, delivered at frequencies ranging from 10 to $70 \mathrm{~Hz}$ ( $70 \mathrm{~Hz}$ being the maximum frequency the Picospritzer is able to deliver). Each stimulus train was presented 50 times in a pseudo-randomized order. 
(A)

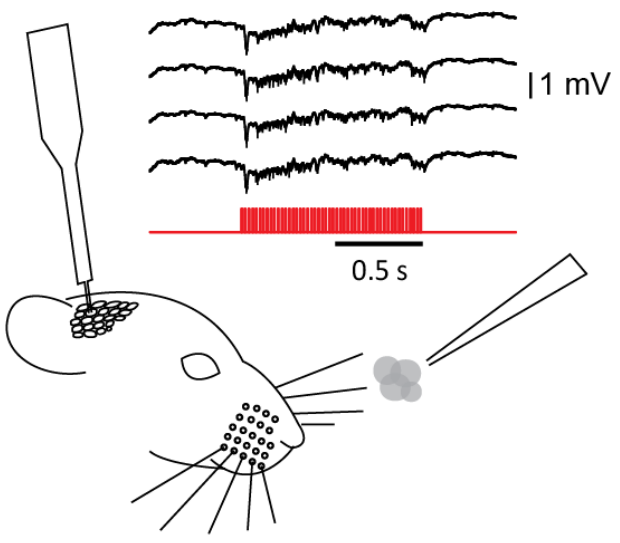

(C)

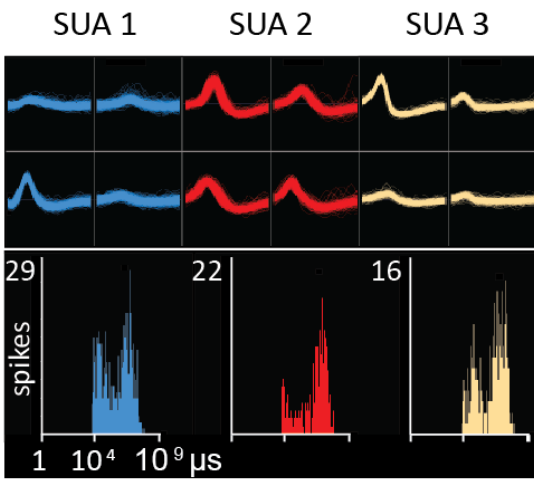

(B)

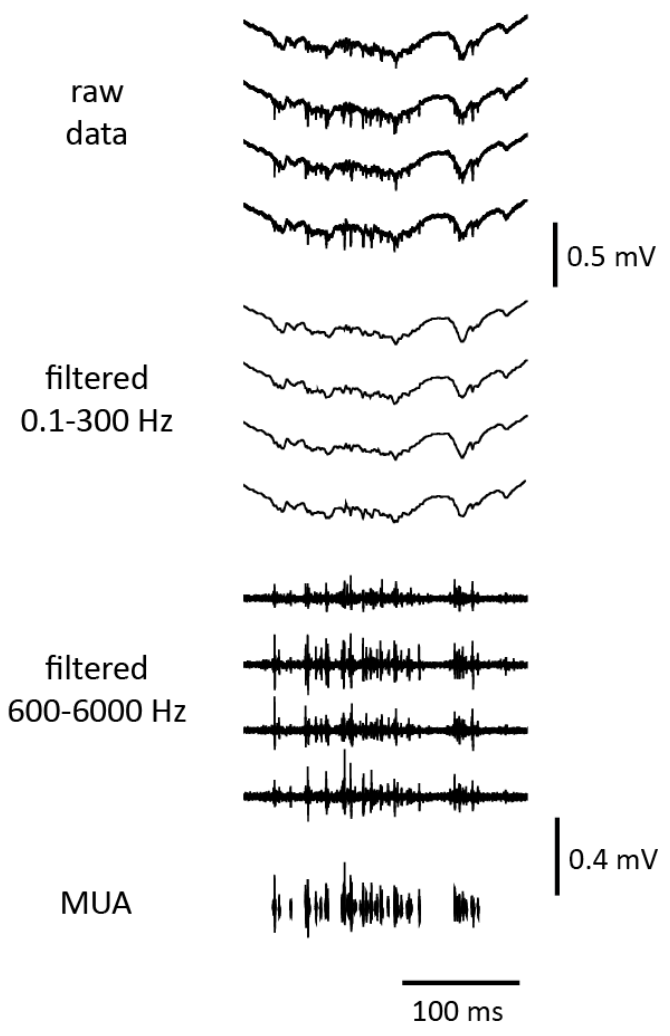

FIGURE 3. Recordings and signal processing. A. Tetrode recordings were performed while applying air puff stimuli at different frequencies $(20-70 \mathrm{~Hz}$, trains of $1 \mathrm{~Hz})$ to 2-5 whiskers at a time. Contralateral responses were recorded in layers II-IV in the barrel field of the primary somatosensory cortex. Shown are examples of raw traces (black) recorded at a single tetrode recorded during $70 \mathrm{~Hz}$ stimulation (red). $B$. The raw data was low-pass filtered $(0.1-300 \mathrm{~Hz})$ to obtain local field potentials, and high-pass filtered $(0.6-6 \mathrm{kHz})$ to obtain the MUA, representing local spiking activity. $C$. The MUA was further analyzed offline with SpikeSort3D to isolate SUA. The top row shows that for every SUA, four spike shapes recorded at four tetrode channels are available for feature analysis. Features such as the amplitude of the peak and trough were used to cluster similar spike shapes that are thought to emerge from the same neuron. In the cluster display (top right), every dot represents one spike recorded from the same tetrode in 3D feature space. Spikes with similar characteristics tend to be in closer proximity and can thus be identified as a distinct SUA. As an additional criterion, SUAs comprise less than $2 \%$ of the spikes that occur at rates faster than every 2 ms. The interspike interval histograms of the three example SUAs are shown in the bottom row.

\section{Analysis}

Off-line analysis was performed using Spike2 software (Cambridge Electronic Design, Cambridge, England) and statistical tests were assessed using Igor Pro (Wavemetrics, Lake Oswego, Oregon), SPSS (version 20.0, SPSS Inc., Chicago, Illinois) or Xlstat (Addinsoft, Brooklyn, New York). 
(A)

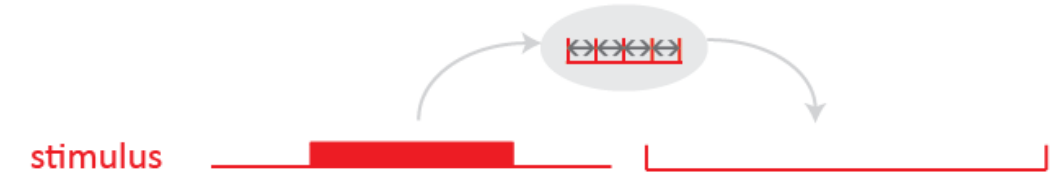

(B)

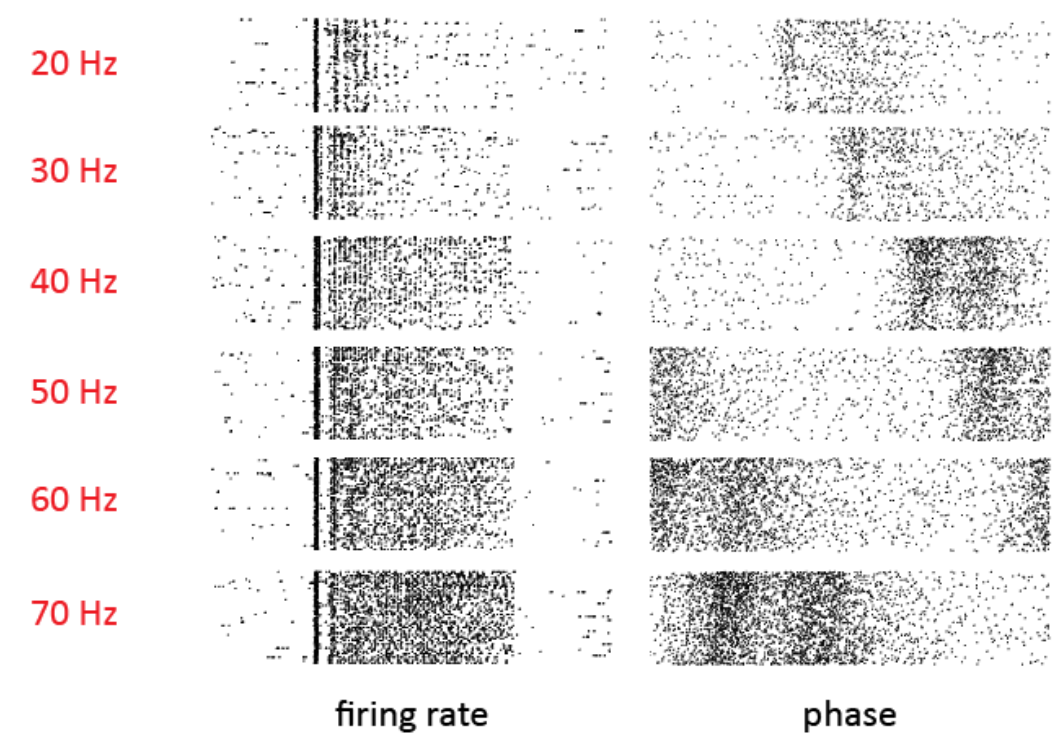

(C)

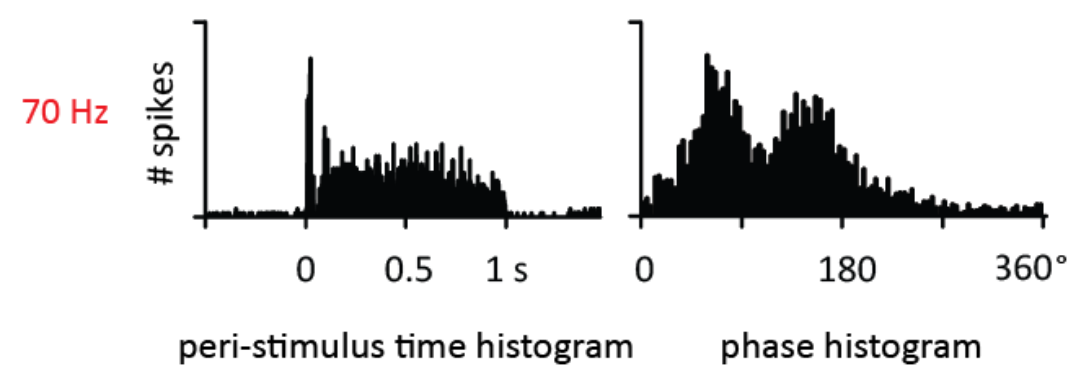

FIGURE 4. Histogram representation of spiking activity. Firing rates were quantified either throughout the stimulus train to obtain peri-stimulus-time histograms (PSTH; left panel) or during the interval (or 'cycle') between two successive stimuli to obtain phase histograms (right panel). $A$. Schematic of the applied stimulus. The stimulus is shown in full length (left) and magnified in the interval display (right). Note that the interval length [time] depends on the stimulus frequency and is therefore represented as phase [degrees]. $B$. Example of sensory evoked MUA response in WT mice. Top-to-bottom: Responses to $20-70 \mathrm{~Hz}$ stimulation. Left-to-right: Peri-stimulus raster plots and phase raster plots for each stimulus frequency, where every line represents one trial and every dot represents one spike. C. Example PSTH (left) and phase histogram (right). Histograms were constructed by summing spikes across all trials per condition (shown here are $70 \mathrm{~Hz}$ responses).

\section{$\underline{5.1 \text { Firing rates and signal-to-noise ratio }}$}

Peri-stimulus time histograms (PSTHs; Fig. 4) of neuronal activity were constructed by first counting the number of spikes in each bin (size: $1 \mathrm{~ms}$ ) across all trials and dividing by the total number of trials to determine the mean firing rate (MFR). The MFR was then divided by the bin size to express neuronal responses in $\mathrm{Hz}$. Responses were divided into onset and sustained activity. The magnitude 
of the onset response was measured as the MFR during the first $0.05 \mathrm{~s}$ post-stimulus onset. Sustained responses were calculated as the MFR between 0.05-1 s (high frequency experiment) or 0.05-3 s (low frequency experiment) post-stimulus onset. Baseline firing was defined as spontaneous firing in the absence of stimulation and was calculated across all trials in each condition. In addition, the spike signal-to-noise ratio (SNR) was calculated for onset and sustained responses by dividing the MFR during stimulation by the MFR during baseline.

\subsection{Adaptation of firing rates}

To assess dynamical changes in firing rates during the stimulus train, adaptation was measured in two ways. The first method analyzes each stimulus cycle during a stimulus train. For each cycle, the MFR during the first $50 \mathrm{~ms}$ after the onset of the stimulus cycle is calculated. The response to each stimulus cycle is then divided by the spike response to the first cycle to yield an adaptation ratio. The second method calculates an adaptation ratio by dividing the MFR during the early part of the stimulus train (0-1 s after stimulus train onset) by the late part of the stimulus response $(2-3 \mathrm{~s})$. The first method offers a greater temporal resolution, while the second method allows a more straightforward comparison of early and late adaptation effects.

\subsection{Response precision}

Temporal fidelity of neuronal responses was measured in terms of phase locking and temporal dispersion. First, phase histograms (Fig. 4) were generated for sustained responses during the stimulus train, excluding the onset response. For each stimulation condition, stimulus-evoked spikes were counted during the time between two successive stimuli in a stimulus train (the 'cycle') and plotted on a $0-360^{\circ}$ axis (100 bins). To determine the degree of phase locking of sustained responses to the stimulus, vector strength $r$ was calculated according to the following formula:

$$
r=\frac{L}{n}=\frac{1}{n} \sqrt{\left(\sum_{j=1}^{n} \cos \theta_{j}\right)^{2}+\left(\sum_{j=1}^{n} \sin \theta_{j}\right)^{2}}
$$

$L$ is the vector length, $n$ is the total number of spikes in the phase histogram for a given stimulation frequency, $\theta$ is the phase angle at which a spike occurs: $\theta=2 \pi(\mathrm{t} / \mathrm{T}) . T$ is the period of the stimulation frequency and $t$ is the time at which the spike occurs. To assess the statistical significance $p$ of the vector strength, the Rayleigh statistic was used: $p=\exp \left(-n r^{2}\right)$. To evaluate the temporal precision of spiking as a function of stimulation frequency, temporal dispersion $d$ was calculated according to the following formula:

$d=\frac{\sqrt{2(1-r)}}{2 \pi f}$ 
$r$ is vector strength and $f$ is the stimulation frequency. Values of vector strength and temporal dispersion were included in the population analysis if phase histograms contained $>45$ spikes and $p$ $<0.05$ (low frequency experiment) or $p<0.001$ (high frequency experiment).

\subsection{Inclusion criteria}

Multi-unit activity (MUA) was included in the analysis if the responses were large, showed frequency modulation and a short onset latency $(14+/-1.5 \mathrm{~ms})$. Mean onset latency was determined based on the PSTH calculated across all stimulation conditions. Onset latency is defined as the first bin that exceeds the maximum spike count measured during baseline and that is at least 2.5 SD above baseline activity. Baseline activity is the spiking average measured for $1.5 \mathrm{~s}$ before stimulus presentation across all trials. To test whether MUA responses were significant, PSTHs were computed for each MUA across all trials (bin size: $50 \mathrm{~ms}$ ). MUA responses were compared to a Poisson distribution with $\mu$ equal to the mean number of spikes per pre-stimulus bin. If the probability of observing an equal or greater number of spikes was less than $0.1 \%$, the response was considered significant:

$\mathrm{P}(\mathrm{x}>\mu)=(\mathrm{e}-\mu \mu \mathrm{x}) / \mathrm{x}$ !

$x$ is the first bin after stimulus presentation and $\mu$ is the average of $1.5 \mathrm{~s}$ of baseline spiking (30 bins) before stimulus presentation. From those multi units that fulfill all criteria, single units were derived. From the pool of single units (SUAs), only those were included in the analysis that were modulated by stimulation frequency, i.e. increased spiking during $70 \mathrm{~Hz}$ stimulation as compared to $20 \mathrm{~Hz}$ stimulation (see Section 3 for further SUA criteria).

\subsection{Local field potentials}

Local field potentials (LFPs) included in the power analysis were derived from tetrodes at which MUA responses with short latencies (14 $\pm 1.5 \mathrm{~ms}$ ) and clear stimulus responses (PSTH analysis) were simultaneously recorded. Power spectral analysis was performed with a 8192 point Hanning window on all recorded LFPs. Power was measured for sustained responses 0.15-1 s after stimulus onset, thus excluding onset responses (high frequency experiment). Baseline power was measured during a $0.85 \mathrm{~s}$ window, $1 \mathrm{~s}$ before stimulus onset. Power measures quantified during stimulation and baseline conditions included absolute gamma in the $20-40 \mathrm{~Hz}$ range (19.7-39.7 Hz), and total power in the $5-100 \mathrm{~Hz}$ range $(5.3-99.3 \mathrm{~Hz})$. In addition, relative gamma was calculated by dividing absolute gamma by the total power spectrum, thus accounting for possible influences in the low frequency range on gamma power. From 16 LFPs recorded in each trial, four LFPs that showed maximal relative gamma values were included in the analysis of gamma SNR. Gamma SNR was measured by dividing relative gamma during stimulation by relative gamma during baseline. 
Two types of gamma oscillations were quantified. The first are gamma oscillations induced by high-frequency $(50-70 \mathrm{~Hz})$ stimulation and the second are steady-state gamma oscillations evoked by stimuli in the gamma range. Induced oscillations are not locked to the stimulus onset and may reflect higher-order processes (e.g. information binding across barrel columns; Ewert et al., 2008), while steady-state oscillations show stimulus locking and reflect frequency-specific stimulus properties. Here both kinds of oscillations were quantified by measuring $20-40 \mathrm{~Hz}$ power during each trial of high $(50-70 \mathrm{~Hz})$ or low $(20-40 \mathrm{~Hz})$ frequency stimulation, and subsequent averaging.

The correlation between spike SNR and gamma SNR was assessed using Spearman's rank order correlation. The analysis included LFPs with the highest gamma SNRs in response to $50-70 \mathrm{~Hz}$, as well as the spike SNRs and vector strength values of MUAs measured in response to $50-70 \mathrm{~Hz}$ at the corresponding tetrode.

\section{Histology}

For cytochrome oxidase stainings, brains were removed, cut tangentially $(100 \mu \mathrm{m})$ and stored in $4 \%$ paraformaldehyde overnight. Slices were washed with $0.1 \mathrm{M}$ phosphate buffer for $3 \times 15 \mathrm{~min}$ on a shaker at room temperature. The sections were then incubated overnight at $4^{\circ} \mathrm{C}$ in a solution of 100 $\mathrm{ml}$ phosphate buffer, $2.4 \mathrm{mg}$ sucrose, $24 \mathrm{mg}$ Cytochrome C (equine, Sigma C2506) and $10 \mathrm{mg}$ of diaminobenzidine (in the dark, on a shaker incubator). Subsequently, slices were rinsed with phosphate buffer (6 x $10 \mathrm{~min}$ ), mounted on slides and coverslipped with Eukitt (Sigma 03989).

\section{REFERENCES}

Ehrlichman, R.S., Luminais, S.N., White, S.L., Rudnick, N.D., Ma, N., Dow, H.C., Kreibich, A.S., Abel, T., Brodkin, E.S., Hahn, C.G., et al. (2009). Neuregulin 1 transgenic mice display reduced mismatch negativity, contextual fear conditioning and social interactions. Brain Res 1294, 116-127.

Ewert, T.A., Vahle-Hinz, C., and Engel, A.K. (2008). High-frequency whisker vibration is encoded by phase-locked responses of neurons in the rat's barrel cortex. J Neurosci 28, 5359-5368.

Meyer, D., and Birchmeier, C. (1995). Multiple essential functions of neuregulin in development. Nature 378, 386-390.

Meyer, D., Yamaai, T., Garratt, A., Riethmacher-Sonnenberg, E., Kane, D., Theill, L.E., and Birchmeier, C. (1997). Isoform-specific expression and function of neuregulin. Development 124, 3575-3586. 


\section{Chapter III}

\section{Barrel cortex responses to frequency-modulated whisker stimulation in} mice

\section{Abstract}

Mice are a valuable tool for assessing the impact of mutations of pathological risk genes on neuronal response properties. In particular, the primary somatosensory cortex is the model of choice to investigate sensory information processing. However, normal response properties of primary sensory neurons are not well understood in mice, and have mainly been studied in rats and monkeys so far. Here we characterize changes in firing rates and local field potentials in the mouse primary somatosensory cortex during sustained whisker stimulation at frequencies ranging from 1 to $70 \mathrm{~Hz}$. The findings revealed (1) low-frequency $(8 \mathrm{~Hz})$ band-pass effects in firing rate, adaptation and temporal precision, (2) temporally precise and monotonically increasing spiking activity in the 20-70 $\mathrm{Hz}$ range, and (3) augmented $20-40 \mathrm{~Hz}$ power at the highest $(70 \mathrm{~Hz})$ stimulation frequency. Our results in mice largely confirm previous findings in rats, and suggest frequency-specific modes of neuronal processing.

\section{Introduction}

To scrutinize and navigate their environment, mice and rats rely mainly on the mystacial vibrissae, or whiskers, that are swept rhythmically across surfaces and objects. Whisking occurs at a rate of $1 \mathrm{~Hz}$ at rest, 8-10 Hz during exploration and 15-25 Hz during foveal whisking (Berg and Kleinfeld, 2003; Carvell and Simons, 1990; Mitchinson et al., 2011; Voigts et al., 2008). In addition, whiskers of different lengths display different resonance properties as they are swept across smooth or rough textures, resulting in a high-speed micromotion of the whisker ranging from approximately 50-200 $\mathrm{Hz}$ (Ritt et al., 2008). Based on the importance of frequency-related information for rodent behavior, an eminent question is how this information is encoded at the neural level. Using sustained, frequency-modulated whisker stimulation in rats, studies have identified rate coding (Ahissar et al., 2001; Ahissar et al., 2000; Arabzadeh et al., 2003; Arabzadeh et al., 2005; Gerdjikov et al., 2010) and temporal coding (Ewert et al., 2008; Jones et al., 2004; Khatri et al., 2004; Melzer et al., 2006; Panzeri and Diamond, 2010) for frequency at the level of the primary somatosensory (barrel) cortex. In addition, increased gamma power $(30-70 \mathrm{~Hz})$ of local field potentials (LFPs) has been reported at high-frequency stimulation ( $\geq 130 \mathrm{~Hz}$; Ewert et al., 2008). 
Given the variety of whisk patterns and their impact on perceptual accuracy (Carvell and Simons, 1995; Harvey, 2001), it is conceivable that neuronal responses differ as a function of stimulation frequency to facilitate optimal stimulus processing (Moore et al., 1999; Moore, 2004; Nicolelis and Fanselow, 2002). For example, firing rate and phase locking, a measure of the temporal precision of spikes, have been found to be band-passed around $8 \mathrm{~Hz}$ in rats (Garabedian et al., 2003), which corresponds to the predominant whisking frequency during exploration (Harvey, 2001; Jin et al., 2004; Mitchinson et al., 2011; Wolfe et al., 2011). Frequency-dependent differences also exist with respect to the extent to which neuronal responses adapt (i.e. depress) during a stimulus train. Rat studies reported little adaptation at low frequencies (1-3 Hz), and an increasing degree of adaptation at higher stimulation frequencies (Ahissar et al., 2001; Chung et al., 2002; Garabedian et al., 2003; Khatri et al., 2004; Simons, 1978). Sensory adaptation has been suggested to increase the efficiency of the neural code (Fairhall et al., 2001; Maravall et al., 2007; Wark et al., 2007), and to enhance performance to detect and discriminate stimuli (Kohn and Whitsel, 2002; Maravall et al., 2007; Moore et al., 1999). At frequencies up to $100 \mathrm{~Hz}$, firing rate has been found to increase monotonically. While firing rate levels off at higher frequencies (Arabzadeh et al., 2003; Berg and Kleinfeld, 2003), phase locking persists and is accompanied by enhanced gamma power (Ewert et al., 2008). These frequency-dependent changes in neural responses have been characterized in rats, but are currently not well understood in mice.

The purpose of this study was to characterize basic response properties of the mouse barrel cortex to whisker stimulation at low $(1-15 \mathrm{~Hz})$ and high $(10-70 \mathrm{~Hz})$ stimulation frequencies. We assessed the frequency dependency of neuronal activity with respect to firing rate, adaptation and temporal precision in the low frequency conditions, and with respect to firing rate, temporal precision and gamma oscillations in the high frequency conditions. All analyzed measures showed frequency-specific modulations, suggesting neuronal tuning to behaviorally relevant frequencies.

\section{Methods}

The methods are described in detail in Chapter II. In summary, C57/BL6 mice were anesthetized with isoflurane and fentanyl. Multi-unit activity (MUA) was acquired using tetrodes placed in layers II/III and IV of the barrel cortex. Whiskers were stimulated with air puffs presented in trains of $3 \mathrm{~Hz}$ at 1$15 \mathrm{~Hz}$ (low frequency experiment), or in trains of $1 \mathrm{~Hz}$ at 10-70 Hz (high frequency experiment).

For the low frequency experiment, MUAs were first analyzed in terms of their mean firing rates (MFR) during baseline and stimulation conditions. Based on the peri-stimulus time histogram (PSTH) of the MUA, the MFR was calculated for onset (0-50 ms after stimulus onset) and sustained responses (0.05-3 s after stimulus onset). In addition, adaptation of the MFR was evaluated by 
summing spikes during the first $50 \mathrm{~ms}$ during each stimulus cycle of the stimulus train, and normalizing each response by the response to the first cycle. In addition, adaptation was characterized during early and late windows of the stimulus response by dividing the MFR during 0-1 $\mathrm{s}$ after stimulus onset by the MFR during 2-3 s after stimulus onset. Furthermore, the temporal precision of spiking activity was measured based on the phase histogram. The distribution of spikes in the phase histogram was used to calculate the vector strength and the temporal dispersion of the responses. High temporal precision is recognized by a peak in the phase histogram, a high value of vector strength $r$ (ranging from 0 to 1 ), and a low amount of temporal dispersion $d$ (in $\mathrm{ms}$ ). Values of vector strength and temporal dispersion were included in the analysis if the phase histograms contained $>45$ spikes and vector strength values were significant at $p<0.05$.

For the high frequency experiment, PSTHs were calculated for each MUA, and the MFR was measured for sustained responses (0.05-1 s after stimulus onset) to assess frequency-specific changes in firing rate. Moreover, vector strength and temporal dispersion of spiking activity was evaluated 0.05-1 s post stimulus onset. Values of vector strength and temporal dispersion derived from single MUAs were included in the population analysis if they met the criteria (phase histograms with $>45$ spikes and vector strength significant at $p<0.001$ ). Additionally, changes in gamma power (20-40 Hz) of the LFPs were measured during sustained responses (0.15-1 s after stimulus onset). Gamma power was measured during each trial and then averaged. This procedure reveals the induced gamma components, which are not time-locked to the stimulus onset. Power was assessed in terms of total power $(5-100 \mathrm{~Hz})$, absolute gamma power $(20-40 \mathrm{~Hz})$ and relative gamma power (absolute gamma divided by the total power spectrum). In addition, the ratio of relative gamma during stimulation and relative gamma during baseline was calculated to study changes in the signalto-noise ratio (SNR) of gamma oscillations. Out of 16 acquired LFPs in each recording session, the 4 LFPs with the highest relative gamma values were selected for the power analysis.

Statistical comparisons were performed using non-parametic tests. For single paired comparisons, the Wilcoxon signed rank test was applied. For multiple paired comparisons, the repeated-measures Friedman's test was used, or the Skillings-Mack test in case samples were missing. Unpaired statistical analysis was carried out with the Mann-Whitney test. Data in the text and figures are presented as mean $\pm \mathrm{SE}$. 


\section{Results}

\section{$\underline{4.1 \text { Responses to low frequency }(1-15 \mathrm{~Hz}) \text { stimulation }}$}

\subsubsection{Firing rate}

MUAs $(n=14)$ were recorded while stimulating whiskers with $3 \mathrm{~s}$ long trains of air puffs presented at low frequencies ranging from 1 to $15 \mathrm{~Hz}$. Response dynamics changed across stimulation frequencies, as illustrated in the example MUAs and population averages in Figure 1. Responses were divided into onset responses, measured during the first $50 \mathrm{~ms}$ following stimulus onset, and sustained responses, measured during the entire train of stimulation, but excluding the onset response $(0.05-3 \mathrm{~s})$. Figure 2 shows the MFR of onset and sustained responses to low frequency stimulation. Since all stimuli in the stimulus trains are the same and only vary according to their presentation frequency, onset responses are not expected to change considerably across conditions. In contrast, sustained responses are entrained by the stimulus and may thus differ as a function of stimulus frequency. As expected, onset responses were similar in magnitude across all stimulation conditions (Friedman, $\mathrm{p}>0.05$ ), while sustained responses were significantly modulated by stimulation frequency (Friedman, $p<0.0001$ ). The findings indicate that information about stimulation frequency is encoded by sustained neuronal activity, and that sustained responses to 1$15 \mathrm{~Hz}$ stimulation are band-passed around $8 \mathrm{~Hz}$.

\subsubsection{Adaptation}

To test whether different magnitudes of sustained responses resulted from different degrees of adaptation, adaptation ratios were calculated across conditions by normalizing each response in a stimulus cycle by the response to the onset of the stimulus (Fig. 3A, inset). Responses were measured by summing MFRs during the first $50 \mathrm{~ms}$ of the stimulus cycle. Thus, adaptation ratios $<1$ indicate adaptation of responses during the stimulus train, while ratios $>1$ indicate response facilitation. Adaptation was found to increase with increasing stimulation frequency. No adaptation was observed in the $1 \mathrm{~Hz}$ condition, while stimulation at $3 \mathrm{~Hz}$ and $5 \mathrm{~Hz}$ (Fig. $\mathbf{3 A}$ ) as well as $12 \mathrm{~Hz}$ and $15 \mathrm{~Hz}$ (Fig. 3B) induced strong response adaptation. Responses to $8-10 \mathrm{~Hz}$ stimuli on average showed facilitation during the first second after stimulus onset, and then a short period of adaptation that asymptotically decreased and reached steady state (Fig. 3B). Note that the degree of facilitation varied across MUAs during $8 \mathrm{~Hz}$ (Fig. 3C) and $10 \mathrm{~Hz}$ stimulation (Fig 3D). Overall, the results suggest that response facilitation observed predominantly with $8 \mathrm{~Hz}$ stimulation accounts for the increased sustained activity in this condition. 
(A)

(B)
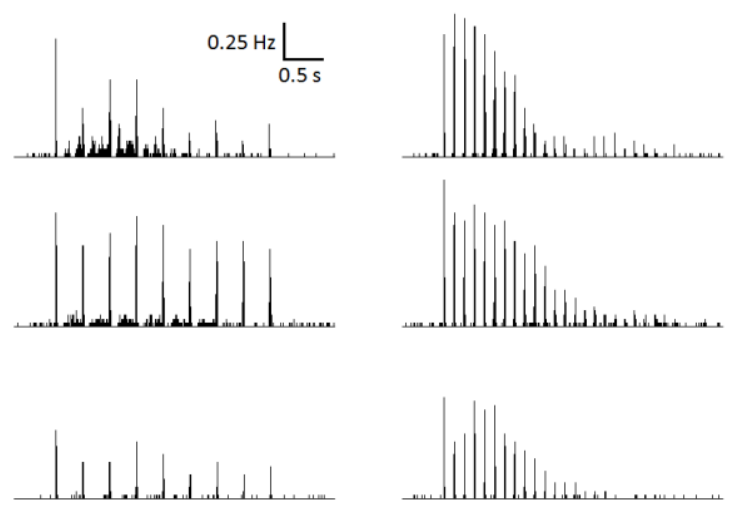

(C)
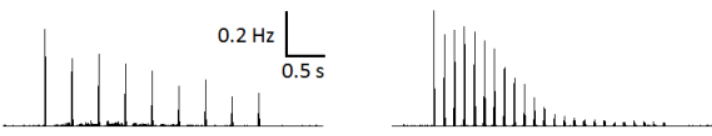

$10 \mathrm{~Hz}$

$15 \mathrm{~Hz}$
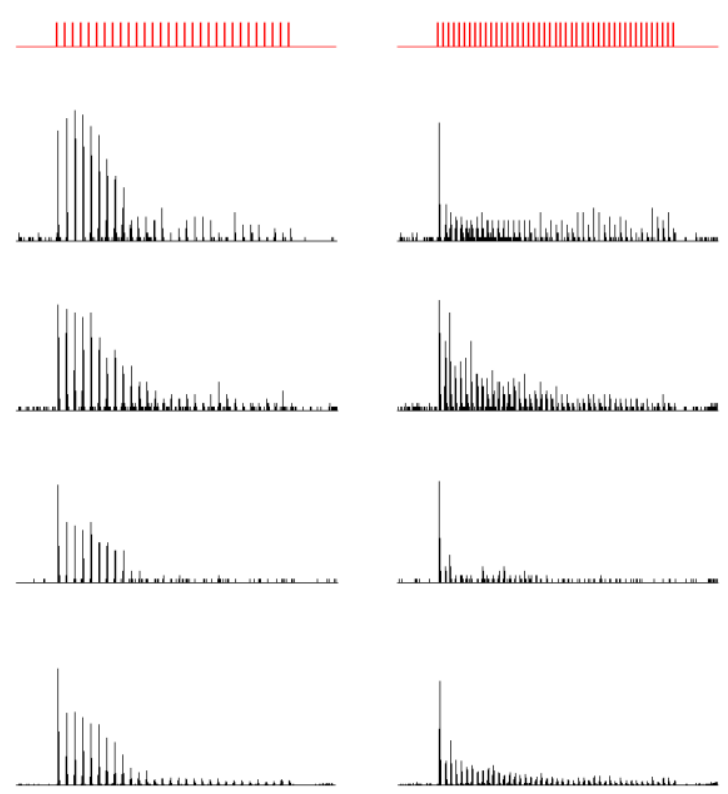

FIGURE 1. MUA response dynamics during low frequency stimulation. A. Stimuli were presented in trains of $3 \mathrm{~s}$ at different frequencies (7 frequencies ranging from 1-15 Hz). Shown are four sample stimuli at $3 \mathrm{~Hz}, 8 \mathrm{~Hz}, 10 \mathrm{~Hz}$ and $15 \mathrm{~Hz}$. B. PSTH of three example MUAs (top to bottom; bin size: 1 $\mathrm{ms}$ ). Responses are shown as MFR to a single stimulus presentation, measured across 40 trials per stimulation condition. C. Mean MUA population PSTH $(n=14)$.

(A)

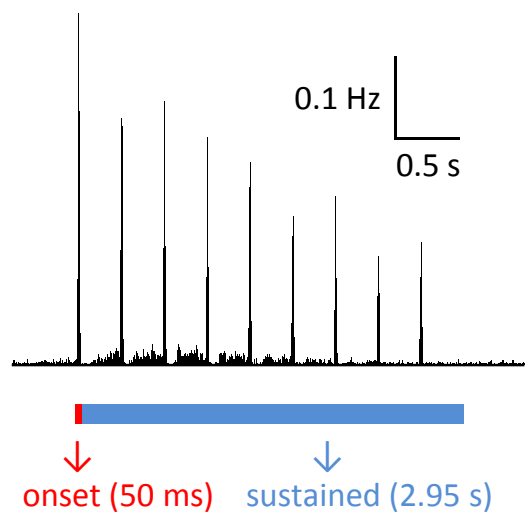

(B) firing rate

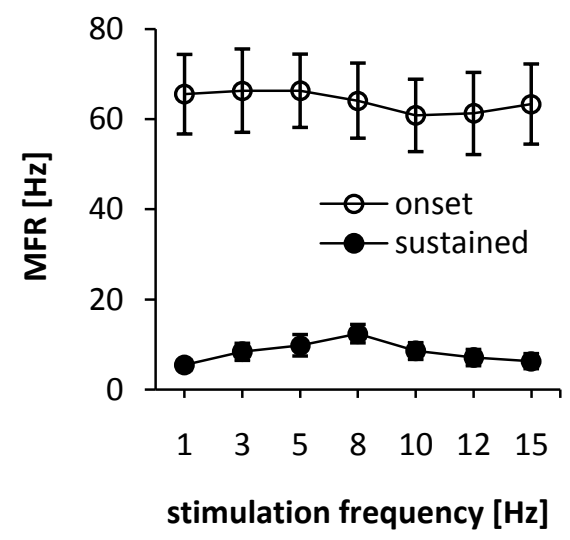

FIGURE 2. Firing rates during low-frequency stimulation (1-15 Hz). A. Example response to $3 \mathrm{~Hz}$ stimulus illustrating the distinction between onset responses (0-0.05 $\mathrm{s}$ post stimulus onset) and sustained responses (0.05-3 s post stimulus onset). B. Average onset (empty circles) and sustained responses (filled circles) across stimulation conditions ( $n=14$ MUAs). Stimulation frequency had a significant impact on sustained responses (Friedman's test, $Q=45.1, p<0.0001$ ), but not onset responses (Friedman's test, $Q=7.4, p=0.29$ ). 
(A)

1-5 Hz adaptation

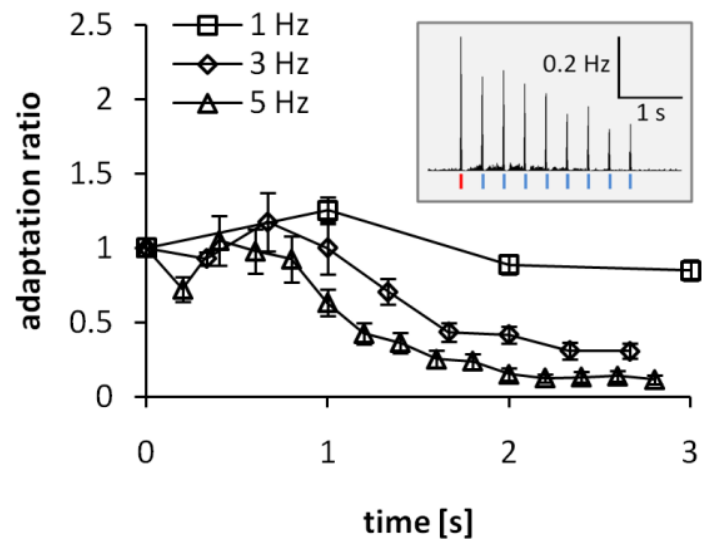

(C)

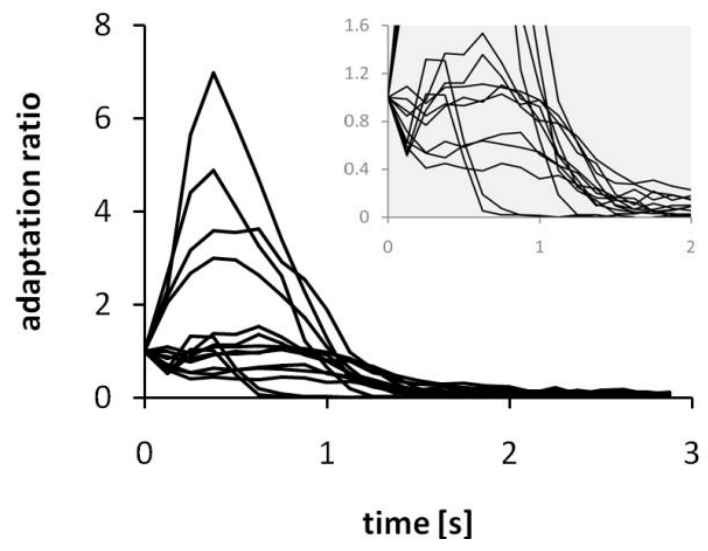

(B)

8-15 Hz adaptation

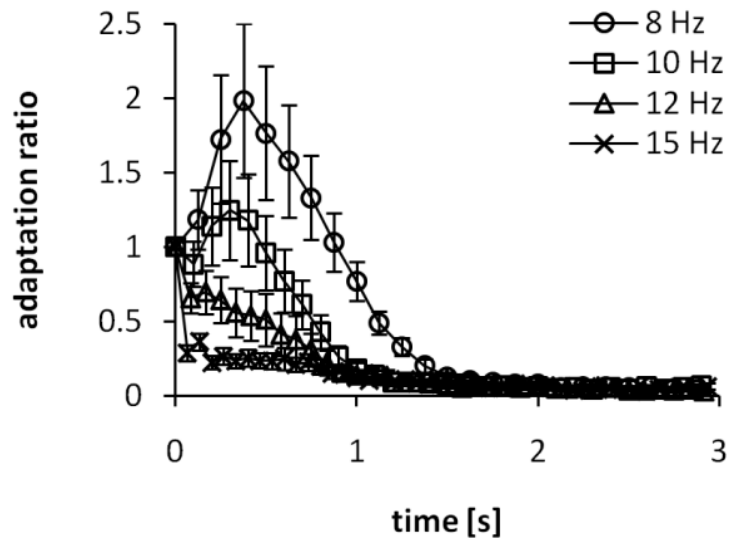

(D)

$10 \mathrm{~Hz}$ adaptation

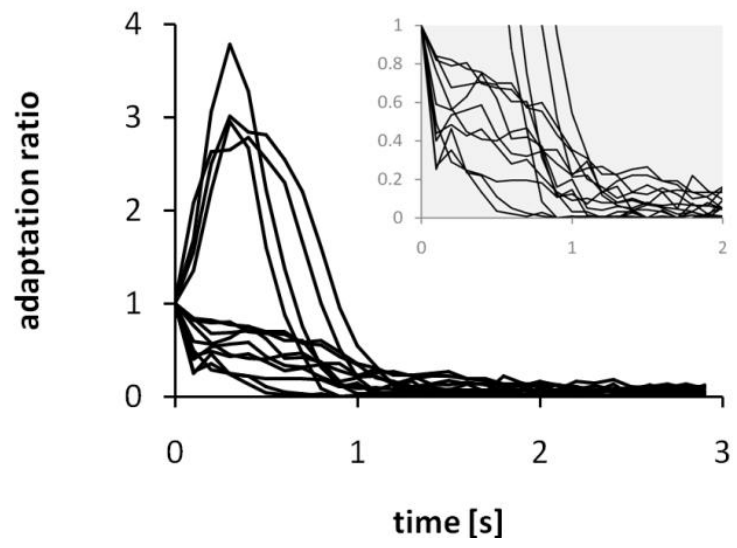

FIGURE 3. MUA adaptation to low frequency stimulation. Adaptation ratios were calculated by dividing each response to successive stimuli in a stimulus train by the response to the first stimulus. A. Population average of responses to $1-5 \mathrm{~Hz}$ stimulation ( $n=14 \mathrm{MUAs})$. Inset: Example PSTH $(3 \mathrm{~Hz})$. Indicated below are the time windows (50 ms each) for measuring responses to the first stimulus (red bar) and responses to successive stimuli in the stimulus train (blue bars). B. Population average of responses to $8-12 \mathrm{~Hz}$ stimulation. $C$. Average adaptation of single MUAs to stimulation at $8 \mathrm{~Hz}$. Inset displays same data as the main figure, but with different scaling. Four out of 14 of MUAs (28.6 $\%$ ) showed response facilitation (ratio $>1$ ) immediately after the onset response (compare MUA in Fig. 1B, top). Six out of 14 MUAs (42.9\%) initially showed response adaptation mainly during the first $300 \mathrm{~ms}$ after stimulus onset, followed by response facilitation (inset, compare MUAs in Fig. 1B, middle and bottom). Three of 14 MUAs (21.4 \%) showed only adaptation and no facilitation, and one MUA (7.1\%) showed neither adaptation nor facilitation (ratio close to 1) during the first second after the $8 \mathrm{~Hz}$ stimulus. Response facilitation never lasted longer than $1 \mathrm{~s}$ post-stimulus onset for all recorded MUAs. D. Average adaptation of single MUAs to stimulation at $10 \mathrm{~Hz}$. Same conventions used as in panel C. Four out of 14 (28.6\%) of MUAs facilitated strongly (compare MUA Fig. 1B, top). Six MUAs (42.9 \%) adapted steadily (inset; compare MUA Fig. 1B, bottom), and 4 MUAs (28.6 \%) showed initial adaptation around $150 \mathrm{~ms}$, a small recovery period around 250-550 ms post-stimulus onset and stronger adaptation thereafter (inset; compare MUA Fig. 1B, middle row).

The dynamics of adaptation were further characterized by comparing firing rates during the first (0-1s) and last (2-3s) seconds from stimulus onset of low frequency stimulation trains (Fig. 4). 
Friedman's repeated measures test revealed a significant modulation of firing rates during the first $(p<0.0001)$ and second time window $(p<0.0001)$. Response magnitudes differed between the two time windows across all frequencies (Wilcoxon, $p=0.001)^{2}$. The MFR was largest in response to $8 \mathrm{~Hz}$ stimulation during the first time window, reflecting the strongest facilitation (Fig. 4A). In addition, firing rates were at a minimum at $8-10 \mathrm{~Hz}$ stimulation during the second time window, reflecting strongest adaptation (Fig. 4A, inset). Dividing firing rates during the first by the second time window yielded an alternative measure of adaptation to illustrate at which frequencies responses were most dynamically modulated (Fig. 4B). The mean adaptation ratio peaked at $8 \mathrm{~Hz}$ since differences between augmented (0-1 s) and adapted responses (2-3 s) were largest at this frequency. In contrast, the adaptation ratio was smallest at $1 \mathrm{~Hz}$ stimulation since neither facilitation nor adaptation occurred in this condition.

(A)

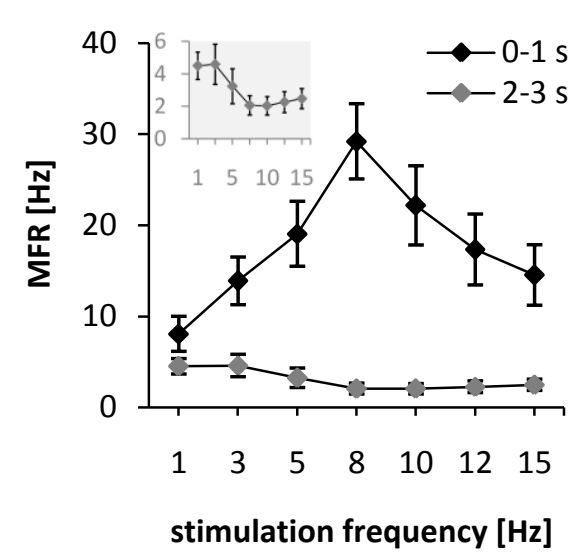

(B) adaptation

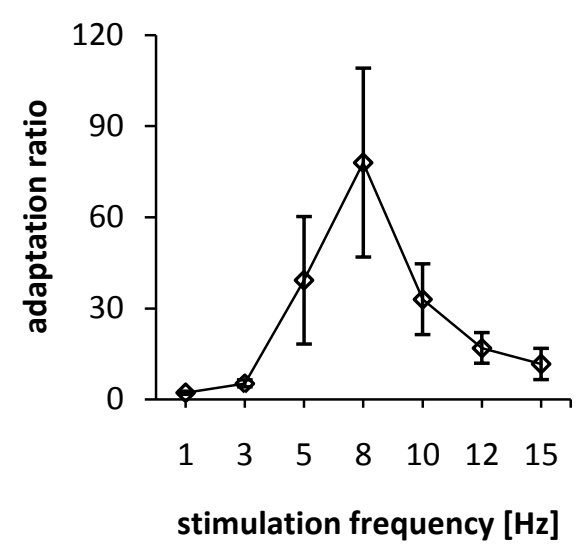

FIGURE 4. Dynamics of MUA response adaptation. A. MFR of MUAs $(n=14)$ was modulated by stimulus frequency during the first second following stimulus onset (black diamonds; Friedman, $Q=$ $5, p<0.0001$ ), and during the last second of stimulation (gray diamonds; see inset for enlarged scale; Friedman, $Q=49.4, p<0.0001$ ). Adaptation is stronger during the last second of stimulation, therefore responses are smaller as compared to the first second. Sustained responses are augmented during 8-10 $\mathrm{Hz}$ stimulation, with stronger facilitation in the first second following stimulus onset than in the last second. Significant differences in MFR between the first and second time window were found across all frequencies (Wilcoxon, significant at $p=0.001$, Bonferronicorrected significance level: $p=0.007)$. B. Adaptation ratio calculated by dividing the sustained response during the first second following stimulation (0-1 s) by the response during the last second of a $3 \mathrm{~s}$ stimulus train (2-3 s). The largest ratio and thus the largest response adaptation is seen around $8 \mathrm{~Hz}$ stimulation.

\footnotetext{
${ }^{2}$ Based on the population data, we did not expect to see a statistical difference in the $1 \mathrm{~Hz}$ condition since MUAs showed on average little adaptation (see Fig. 3A). The result may be due to an overly sensitive statistical test (Wilcoxon test for paired samples). Using an unpaired analysis (Mann-Whitney), no differences appeared in the $1 \mathrm{~Hz}$ condition, while differences in all other conditions would be confirmed. We therefore advise caution in interpreting the statistical result at $1 \mathrm{~Hz}$.
} 


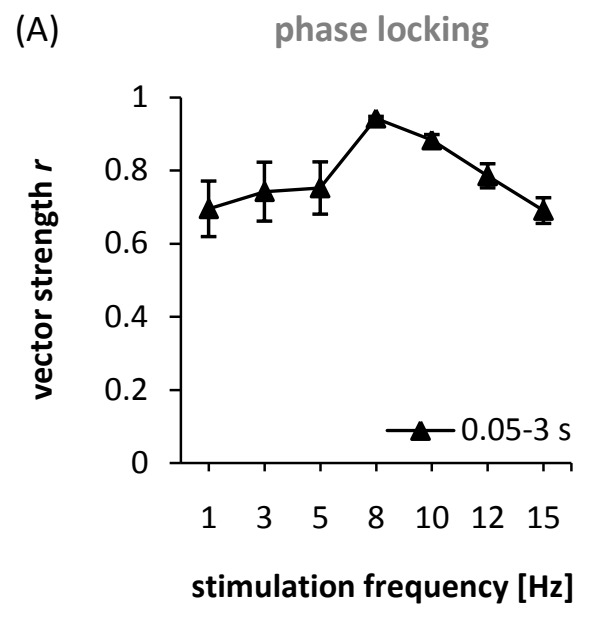

(C)

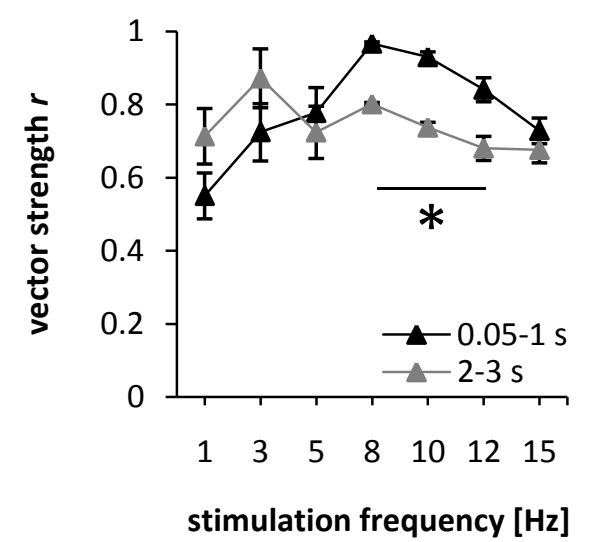

(B) temporal dispersion

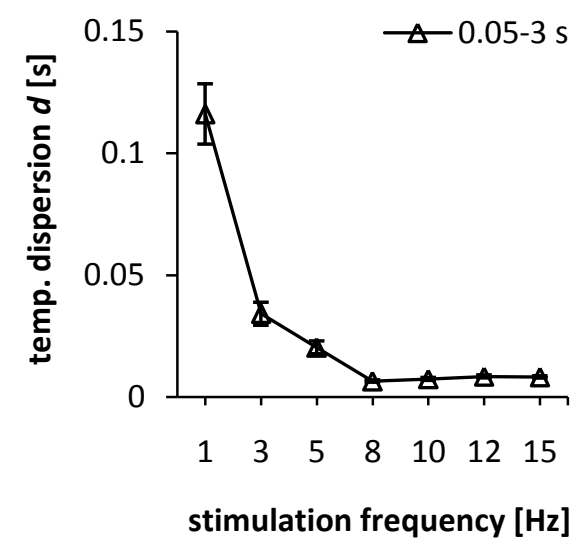

(D)

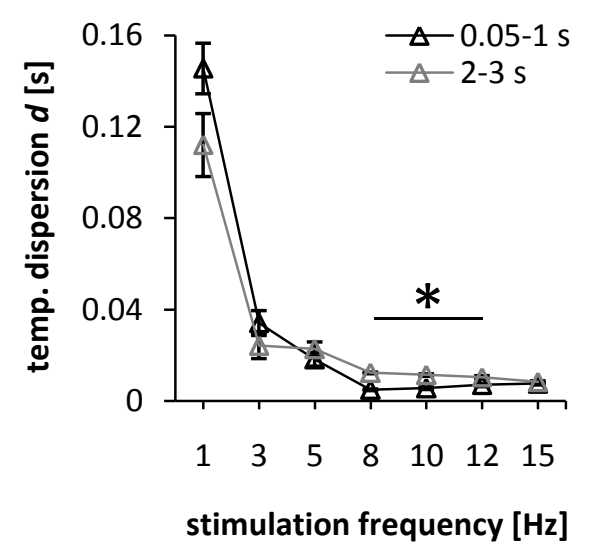

FIGURE 5. The temporal fidelity of neuronal responses is dynamically modulated. Vector strength $r$ (left column) and temporal dispersion $d$ (right column) were calculated for sustained MUA responses in different time windows during $1-15 \mathrm{~Hz}$ stimulation. $A$. Average vector strength $0.05-3 \mathrm{~s}$ following stimulus onset $(n=14)$ changed as a function of stimulation frequency (Friedman, $Q=41.2, p<$ $0.0001)$. B. Average temporal dispersion $0.05-3 \mathrm{~s}$ after stimulus onset $(n=14)$ was modulated by stimulus frequency (Friedman, $Q=60.3, p<0.0001$ ). C. Average vector strength $0.05-1 \mathrm{~s}$ (black triangles; $n=14$ ) and $2-3$ s post stimulus onset (gray triangles; $n=12$ ). * Significant differences in vector strength between the first and second time window (see Table 1 for details). D. Temporal dispersion $0.05-1 \mathrm{~s}$ (black triangles; $n=14$ ) and 2-3 s (gray triangles; $n=12$ ) following stimulus onset. * Significant differences in temporal dispersion between the first and second time window (see Table 2 for details).

\subsubsection{Temporal precision}

To investigate whether the temporal precision of neuronal firing changes across stimulation conditions, the degree of phase locking and temporal dispersion of sustained MUA responses $(n=$ 14; unless otherwise indicated) was measured using vector strength analysis (see Methods, Section 3 and Chapter II). Higher values of vector strength $r$ denote better phase locking (perfect locking at $r=$ 1), while lower values of temporal dispersion $d[\mathrm{~ms}]$ indicate higher temporal precision. The measure 
of temporal dispersion is based on the vector strength, but takes into account the stimulus interval, which decreases with increasing stimulation frequency.

First, we characterized temporal precision $0.05-3 \mathrm{~s}$ post stimulus onset, the time window corresponding to sustained responses described in Figure 2. Friedman's test revealed a significant impact of stimulation frequency on vector strength $(p<0.0001)$ and temporal dispersion $(p<$ 0.0001). We found maximal vector strength during $8-10 \mathrm{~Hz}$ stimulation and lower values for all other conditions (Fig. 5A). Similarly, temporal dispersion was smallest for responses to 8-10 Hz stimuli, and larger for other conditions (Fig. 5B). Most temporal dispersion was noted at $1 \mathrm{~Hz}$ stimulation frequency.

Next, we asked whether the temporal precision of neuronal firing changes during the response, as observed for firing rates (see Fig. 4A). We therefore compared vector strength and temporal dispersion values $0.05-1 \mathrm{~s}$ (excluding onset) and 2-3 s following stimulus onset (Fig. $\mathbf{5 C , D}$ ). Of note, some MUAs had to be excluded from the vector strength and temporal dispersion calculation in the 2-3 s window due to an insufficient number of action potentials in the phase histograms (see Methods, Section 3 and Chapter II). Thus, the number of MUAs was reduced ( $n=7-$ 12) during the 2-3 s window as compared to the 0.05-1 s time window $(n=14)$. We observed that on average, the MUAs displaying most spike rate facilitation during the first time window also showed most adaptation during the second time window. Hence the MUAs with the strongest band-pass effects in spike rate are most likely to drop out from the temporal precision analysis. We reasoned that the selection bias introduced by the drop out would be aggravated when using paired statistical analysis compared to using unpaired tests. We therefore chose unpaired analysis (Mann-Whitney) for assessing differences in vector strength and temporal dispersion.

The results revealed that temporal precision was higher at 8-12 $\mathrm{Hz}$ during the first time window than during the second, as suggested by significantly elevated vector strength values (Fig. 5C, Table 1), and significantly reduced temporal dispersion in this frequency range (Fig. 5D; Table 2; see also example phase histograms in Fig. 6). To exclude possible flaws introduced by the unpaired statistical analysis, we also ran a paired analysis for comparison. The results matched the unpaired analysis, with the exception that differences in vector strength in the 8-12 $\mathrm{Hz}$ range did not survive the multiple comparison correction (significant at $p=0.016$; data not shown). Taken together, these results indicate that the band-pass properties of phase-locking and temporal dispersion largely unfold during the first second following stimulation onset and degrade during later time windows. 
TABLE 1. Comparison of vector strength of sustained responses during the first (0.05-1 s following stimulus onset) and second time window (2-3 s). Differences were assessed using the Mann-Whitney test. Vector strength $r$ (mean $\pm \mathrm{SE}$ ), number of MUAs $(n)$, the test statistic and $p$-value are listed per stimulation condition. Bonferroni-corrected significance level: $p=0.007$.

\begin{tabular}{ccccccc}
\hline frequency & $\mathbf{0 . 0 5 - 1 ~ s}$ & $\mathbf{2 - 3} \mathbf{s}$ & $\mathbf{0 . 0 5 - 1} \mathbf{s}$ & $\mathbf{2 - 3} \mathbf{s}$ & $\mathbf{U}$ & $\mathbf{p}$ \\
& $\boldsymbol{r}$ & $\boldsymbol{r}$ & $\mathbf{n}$ & $\mathbf{n}$ & & \\
\hline $\mathbf{1 ~ H z}$ & $0.55 \pm 0.06$ & $0.71 \pm 0.06$ & 14 & 12 & 49 & 0.076 \\
$\mathbf{3 ~ H z}$ & $0.72 \pm 0.08$ & $0.87 \pm 0.03$ & 14 & 11 & 60 & 0.373 \\
$\mathbf{5 ~ H z}$ & $0.78 \pm 0.07$ & $0.72 \pm 0.06$ & 14 & 10 & 99 & 0.096 \\
$\mathbf{8 ~ H z}$ & $0.97 \pm 0.00$ & $0.80 \pm 0.03$ & 14 & 7 & 98 & $<\mathbf{0 . 0 0 0 1}$ \\
$\mathbf{1 0 ~ H z}$ & $0.93 \pm 0.01$ & $0.74 \pm 0.03$ & 14 & 7 & 96 & $<\mathbf{0 . 0 0 0 1}$ \\
$\mathbf{1 2 ~ H z}$ & $0.84 \pm 0.03$ & $0.68 \pm 0.04$ & 14 & 8 & 96 & $\mathbf{0 . 0 0 5}$ \\
$\mathbf{1 5 ~ H z}$ & $0.73 \pm 0.04$ & $0.67 \pm 0.04$ & 14 & 8 & 71 & 0.330 \\
\hline
\end{tabular}

TABLE 2. Differences in temporal dispersion of sustained responses during the first $(0.05-1 \mathrm{~s}$ following stimulus onset) and second time window (2-3 s). Statistical comparisons were performed using unpaired t-tests. Displayed are the temporal dispersion $d$ (mean $\pm \mathrm{SE}$ ) and number of MUAs ( $\mathrm{n}$ ) for each time window per condition. In addition, the t-statistic, the degrees of freedom (df) and the p-value are shown for each comparison.

\begin{tabular}{ccccccc}
\hline frequency & $\mathbf{0 . 0 5 - 1 ~ s}$ & $\mathbf{2 - 3} \mathbf{s}$ & $\mathbf{0 . 0 5 - 1 ~ s}$ & $\mathbf{2 - 3} \mathbf{s}$ & $\mathbf{t}(\mathbf{d f})$ & $\mathbf{p}$ \\
& $\boldsymbol{d}[\mathbf{m s}]$ & $\boldsymbol{d}[\mathbf{m s}]$ & $\mathbf{n}$ & $\mathbf{n}$ & & \\
\hline $\mathbf{1 ~ H z}$ & $145.56 \pm 11.07$ & $112.06 \pm 13.36$ & 14 & 12 & $1.9(24)$ & 0.063 \\
$\mathbf{3 ~ H z}$ & $34.17 \pm 5.44$ & $24.17 \pm 3.69$ & 14 & 11 & $1.4(23)$ & 0.165 \\
$\mathbf{5 ~ H z}$ & $18.30 \pm 2.99$ & $22.76 \pm 2.13$ & 14 & 10 & $-1.1(22)$ & 0.275 \\
$\mathbf{8 ~ H z}$ & $4.96 \pm 0.36$ & $12.35 \pm 0.89$ & 14 & 7 & $-9.2(19)$ & $<\mathbf{0 . 0 0 0 1}$ \\
$\mathbf{1 0 ~ H z}$ & $5.64 \pm 0.55$ & $11.39 \pm 0.76$ & 14 & 7 & $-6.1(19)$ & $<\mathbf{0 . 0 0 0 1}$ \\
$\mathbf{1 2 ~ H z}$ & $7.03 \pm 0.72$ & $10.45 \pm 0.69$ & 14 & 8 & $-3.2(20)$ & $\mathbf{0 . 0 0 5}$ \\
$\mathbf{1 5 ~ H z}$ & $7.60 \pm 0.51$ & $8.40 \pm 0.59$ & 14 & 8 & $-1.0(20)$ & 0.341 \\
\hline
\end{tabular}

\subsection{Responses to high-frequency $(10-70 \mathrm{~Hz})$ stimulation}

\subsubsection{Firing rate}

The high frequency experiment involved whisker stimulation at $10-70 \mathrm{~Hz}$ in trains of $1 \mathrm{~s}$. Quantitative data were derived from 16 MUAs (Fig. 7). To assess response dynamics at different stimulation frequencies, firing rates were calculated for sustained responses $0.05-1 \mathrm{~s}$ after stimulus onset. In line with our observations in the low frequency experiment, sustained activity was modulated by stimulation frequency (Friedman, $p<0.0001$; Fig. 8). The modulation of MFRs by stimulation frequency suggests that neurons encode vibratory information using a rate code. 


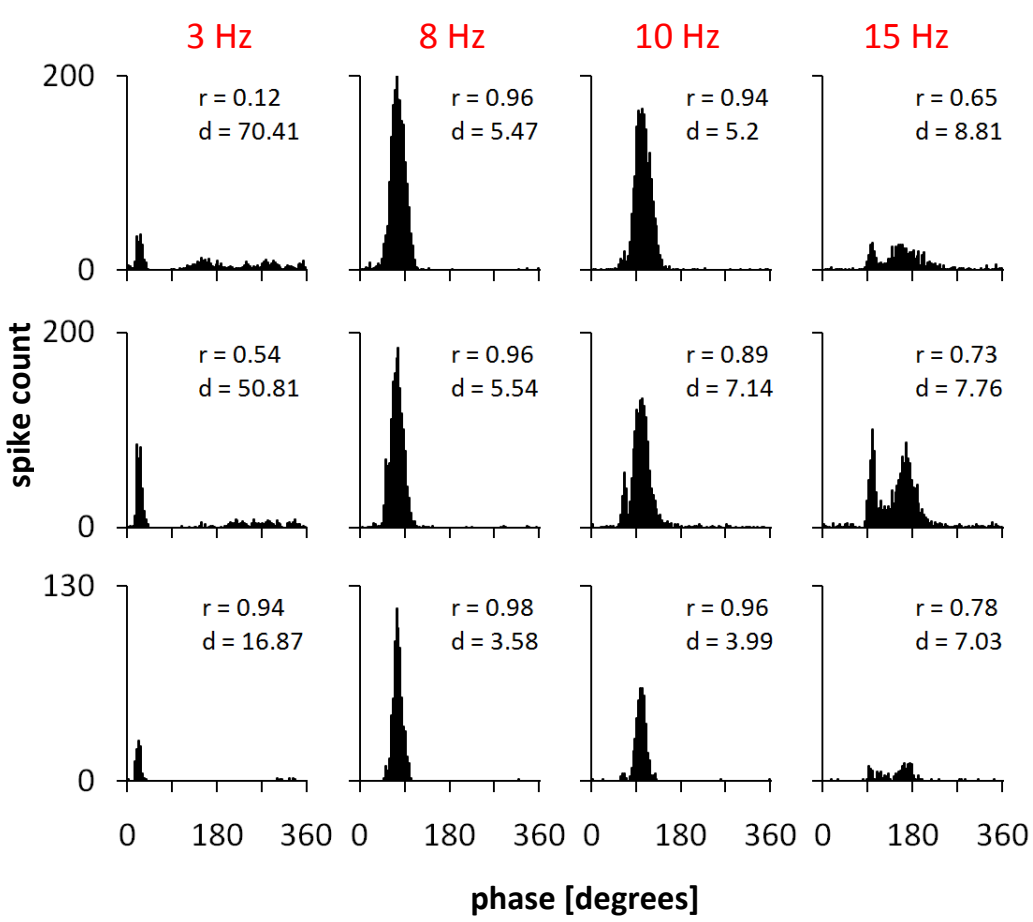

FIGURE 6. Phase histograms of three MUAs at four sample stimulation frequencies $(3 \mathrm{~Hz}, 8 \mathrm{~Hz}, 10 \mathrm{~Hz}$, $15 \mathrm{~Hz}$ ). The three example MUAs (top to bottom) are the same as depicted in Fig. 1B. Phase histograms were calculated for sustained responses $0.05-1 \mathrm{~s}$ following stimulus onset. Values of vector strength $r$ and temporal dispersion $d[\mathrm{~ms}]$ are indicated for each unit and condition.

(A)

$20 \mathrm{~Hz}$ ШШШШШШШШШШ

(B)

$$
0.25 \mathrm{~Hz} \underset{0.2 \mathrm{~s}}{\longleftarrow}
$$
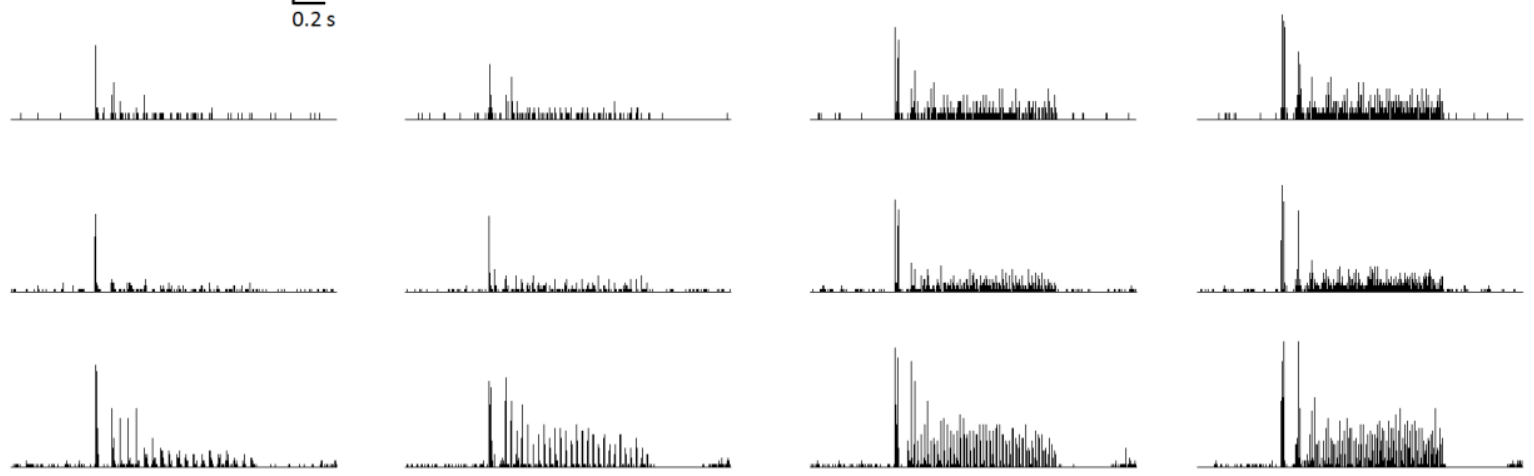

(C)
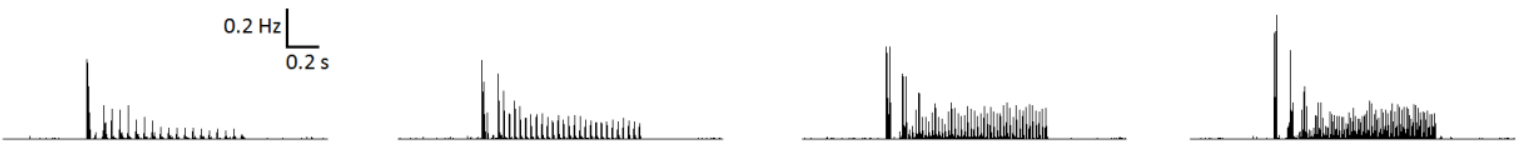

FIGURE 7. MUA responses to high frequency $(10-70 \mathrm{~Hz})$ stimuli. $A$. Whiskers were stimulated with air puffs, presented in trains of $1 \mathrm{~s}$ at varying frequencies. Four example frequencies are depicted. $B$. Responses of three representative MUAs (top to bottom) to stimuli detailed in Panel A. Responses were averaged across 50 trials and accumulated into PSTHs (bin size: $1 \mathrm{~ms}$ ). C. Population PSTH calculated from mean MUA responses to a given stimulation frequency ( $n=16$ MUAs). 
(A) example PSTH

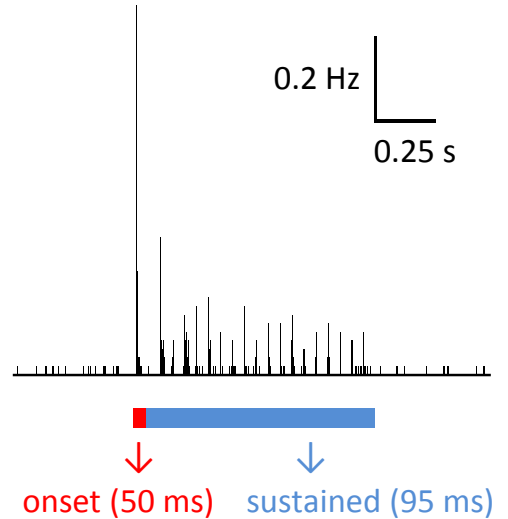

(B) firing rate

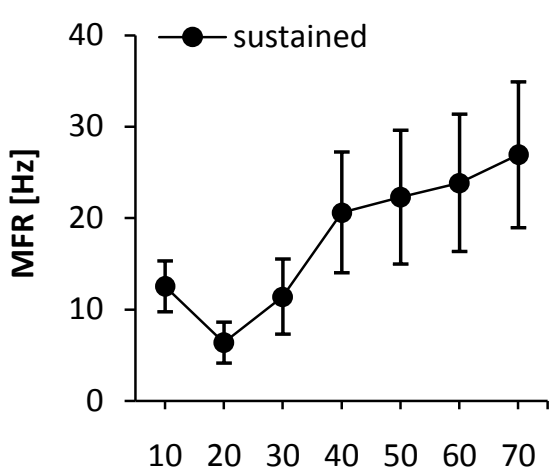

stimulation frequency $[\mathrm{Hz}]$

FIGURE 8. Firing rates during high-frequency stimulation $(10-70 \mathrm{~Hz})$. A. Example PSTH during $20 \mathrm{~Hz}$ stimulation. The MFRs were quantified during the sustained part of the response $(0.05-1 \mathrm{~s})$ to identify stimulus-specific changes in spike rate. $B$. MFRs of sustained responses ( $n=16$ MUAs) changed as a function of stimulation frequency (Friedman, $Q=58.9, p<0.0001$ ).

\subsubsection{Temporal precision}

The frequency dependency of sustained responses was further analyzed by measuring their degree of phase locking and temporal dispersion across conditions. Phase histograms of three representative MUAs are shown in Figure 9. Across conditions, vector strength was significantly modulated by stimulation frequency (Skillings-Mack, $p<0.0001$ ), with a trend to decrease at higher frequencies (Fig. 10A). Sustained responses to $10 \mathrm{~Hz}$ stimuli were highly phase locked, with a mean vector strength of $0.90 \pm 0.01$, which is comparable to the degree of phase locking observed in the $10 \mathrm{~Hz}$ condition of the low frequency experiment. At $70 \mathrm{~Hz}$, vector strength of sustained responses dropped to $0.54 \pm 0.03$, indicating a loss of temporal precision at high stimulus frequencies. However, when taking into account the interval length across which vector strength is measured, we found smaller temporal dispersion of spikes and thus increased precision at higher frequencies (Fig. 10B). Temporal dispersion varied as a function of stimulus frequency (Skillings-Mack test, $p<0.0001$ ) and showed an overall decrease at increasing stimulation frequencies. Thus, despite reduced phase locking at higher frequencies, spiking activity becomes temporally more precise. The results indicate that neurons in the barrel cortex use a temporal code in addition to a rate code to transmit vibratory information. 


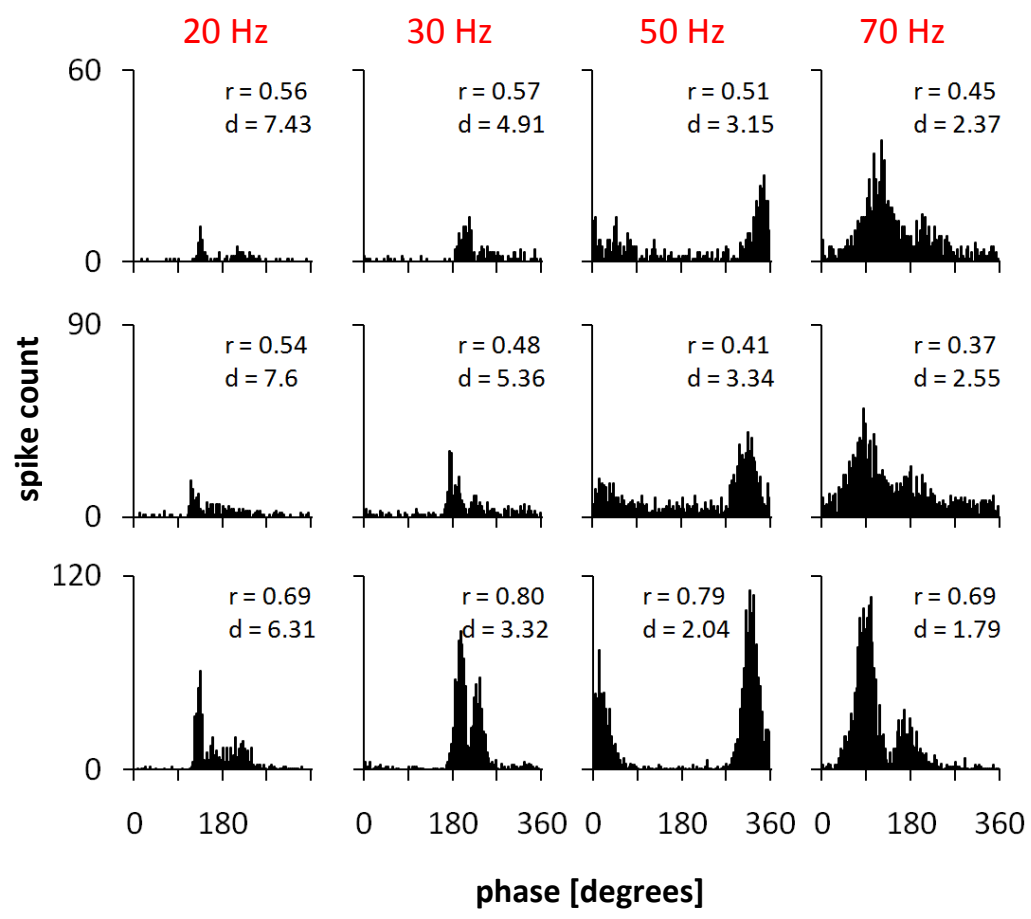

FIGURE 9. MUA phase histograms. Shown are three sample MUAs (top to bottom; same MUAs as shown in Fig. 6B) during $10 \mathrm{~Hz}, 30 \mathrm{~Hz}, 50 \mathrm{~Hz}$ and $70 \mathrm{~Hz}$ stimulation conditions (left to right). Vector strength $r$ and temporal dispersion $d[\mathrm{~ms}]$ are displayed for every MUA and condition.

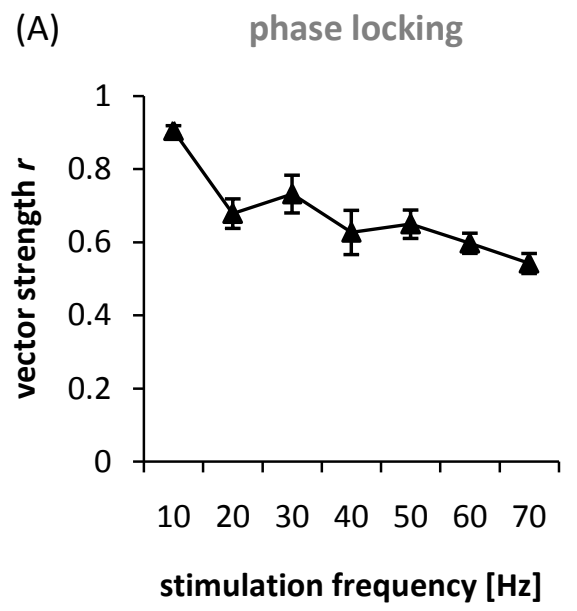

(B) temporal dispersion

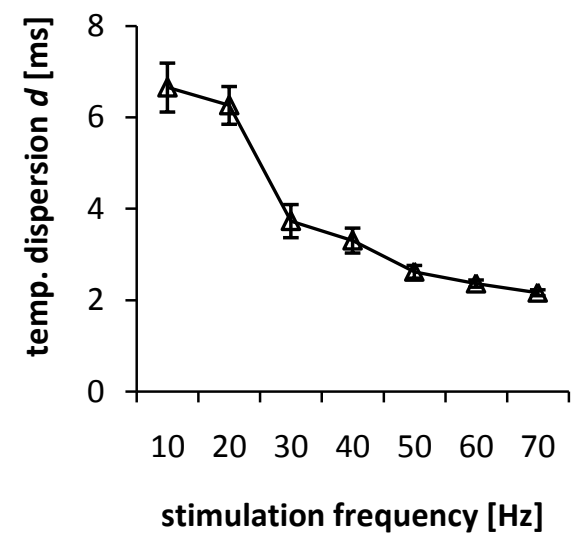

FIGURE 10. Temporal fidelity of neural responses to high frequency stimuli. A. Average vector strength of MUA responses $(n=16)$ differed as a function of stimulus frequency (Skillings-Mack, $Q=$ $51.7, p<0.0001)$. B. Average temporal dispersion values of MUAs $(n=16)$ was modulated by stimulus frequency (Skillings-Mack, $Q=66.3, p<0.0001$ ).

FIGURE 11 (next page). Single-trial LFPs and gamma power. Left-to-right: High-frequency stimulation conditions (50-70 Hz). Bottom-to-top: Stimuli, example raw LFP response $(0.1-300 \mathrm{~Hz})$, the same response filtered in the gamma range $(20-40 \mathrm{~Hz})$, and the corresponding power spectrum of the sustained response $(0.15-1 \mathrm{~s})$ averaged from single trials. Power spectra display one peak in the gamma range (marked by arrow), one at $60 \mathrm{~Hz}$ (noise), and one at the stimulation frequency. 

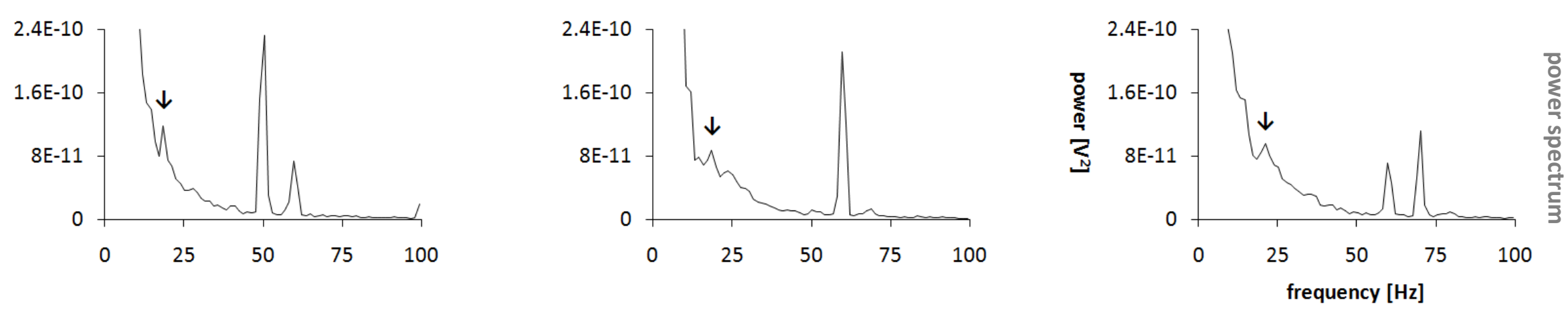

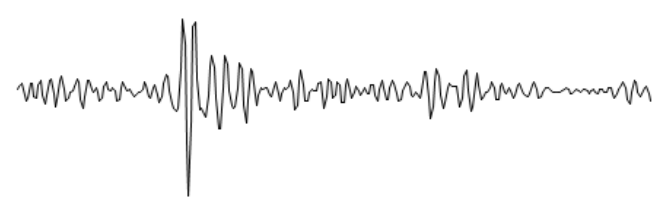
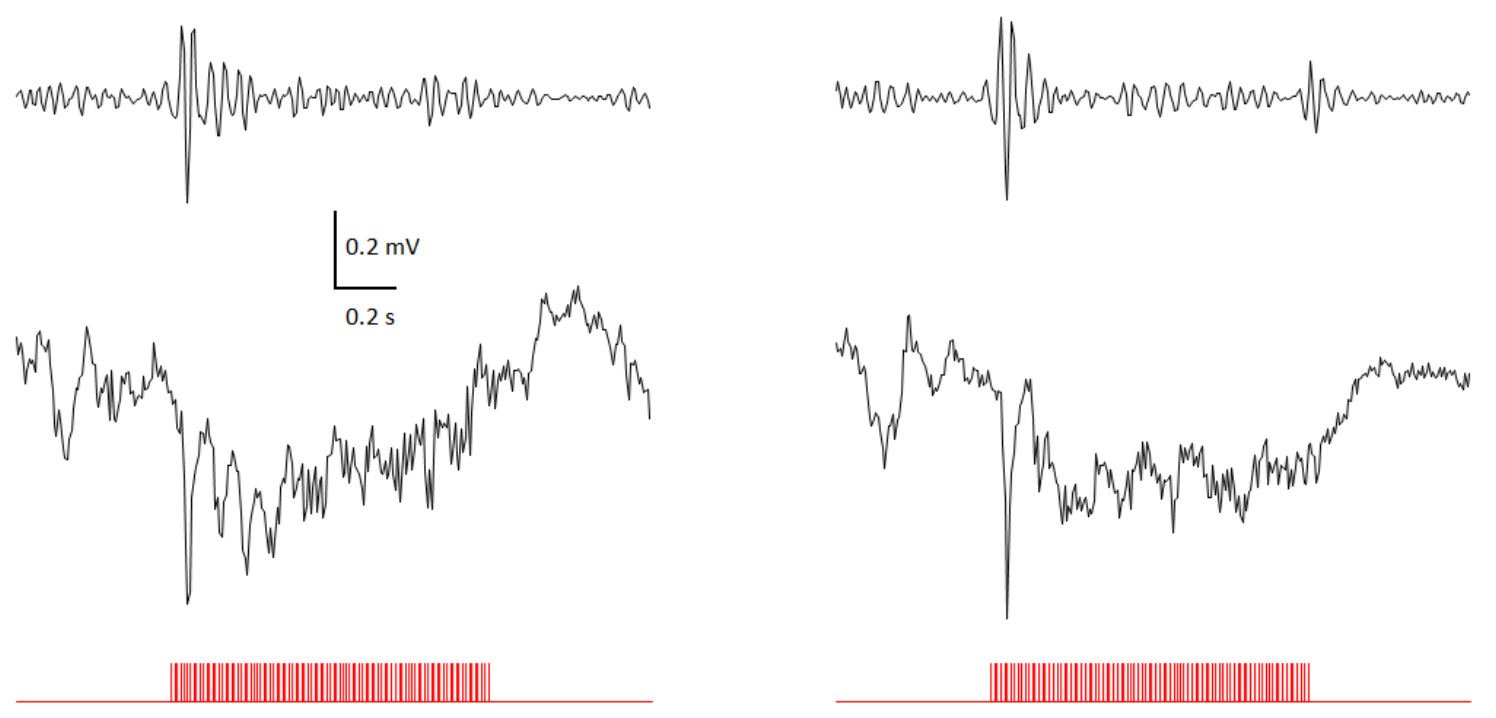

$50 \mathrm{~Hz}$

$60 \mathrm{~Hz}$

$\frac{7}{7}$
$\frac{7}{0}$
$\frac{1}{0}$
$\frac{0}{0}$
$\frac{7}{0}$
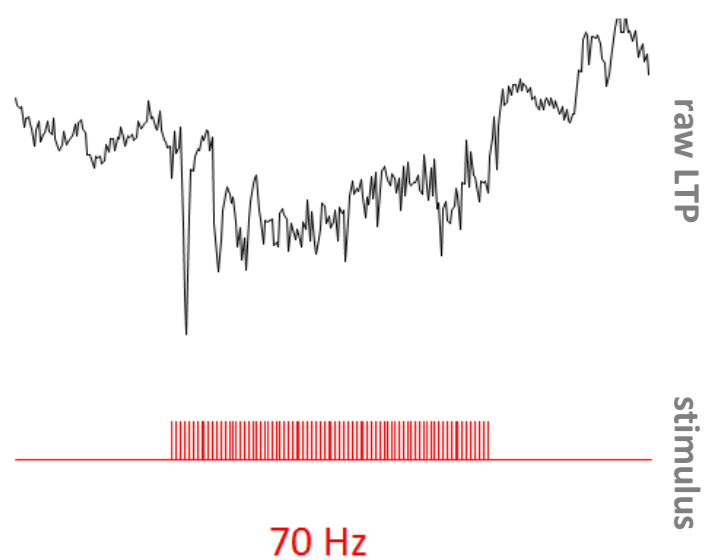


\subsubsection{Gamma oscillations}

Finally, we attempted to replicate in mice earlier findings in rats of induced gamma oscillations during high frequency $(130-190 \mathrm{~Hz})$ stimulation (Ewert et al., 2008), and investigate possible changes in gamma power across stimulation conditions. For technical reasons we were limited to $70 \mathrm{~Hz}$ as the maximal stimulation frequency. Given these constraints, we analyzed induced gamma power only during the highest attainable stimulation frequencies $(50-70 \mathrm{~Hz})$. Inspection of the power spectra derived from 12 LFPs indicated an increase in absolute gamma power in the $20-40 \mathrm{~Hz}$ range during stimulation, with additional peaks at the stimulation frequency and at $60 \mathrm{~Hz}$ (Fig. 11). The

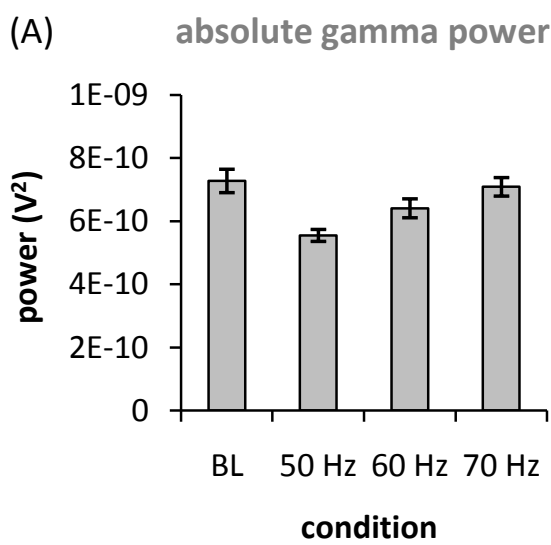

(C)

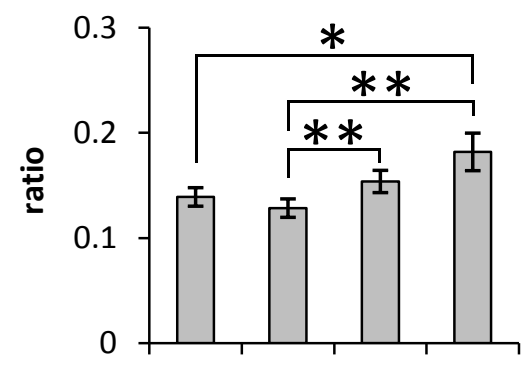

BL $\quad 50 \mathrm{~Hz} 60 \mathrm{~Hz} 70 \mathrm{~Hz}$ condition

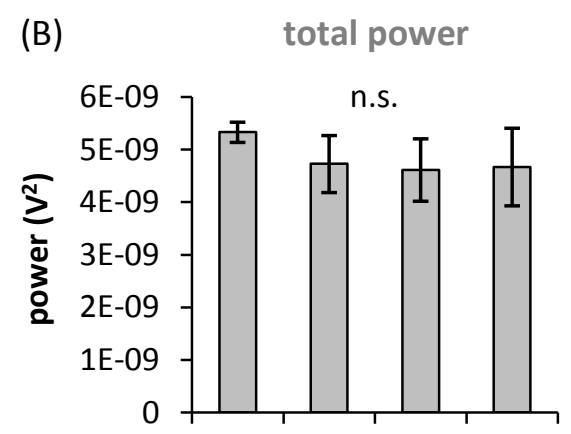

BL $\quad 50 \mathrm{~Hz} 60 \mathrm{~Hz} 70 \mathrm{~Hz}$ condition

(D)

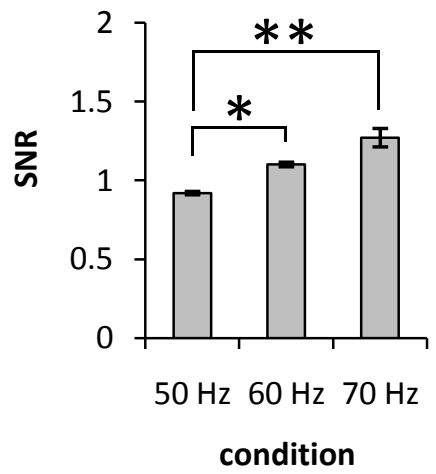

FIGURE 12. Power analysis during $50-70 \mathrm{~Hz}$ stimulation. Power was calculated based on single-trial averages of power spectra derived from 12 LFPs. Power during stimulation was measured 0.15-1 s after stimulus onset, and baseline (BL) power was measured 1-0.15 s before stimulus onset. $A$. Absolute gamma power $(20-40 \mathrm{~Hz})$. B. Total power (5-100 Hz). No differences ('n.s.') were detected across stimulation and baseline conditions (Friedman, $Q=4, p=0.26$ ). $C$. Relative gamma power. Relative gamma was measured by dividing absolute gamma power by total power. Relative gamma was modulated across conditions (Friedman, $Q=7.8, p<0.0001$; see Table 3 for details). Star indicates significant differences between conditions at $p=0.004\left({ }^{*}\right)$ or $p<0.0001\left(^{* *}\right)$. D. Gamma SNR. Gamma SNR was defined as relative gamma during stimulation divided by relative gamma during baseline. Gamma SNR varied across conditions (Friedman, $Q=6, p<0.0001$; see Table 4 for details). Star denotes significant differences between conditions at $p=0.001\left({ }^{*}\right)$ or $p<0.0001(* *)$. 
latter peak suggested the presence of electrical noise, while the former two peaks indicated stimulation-specific activity. To quantify changes in the gamma range, we calculated relative gamma, defined as the ratio of absolute gamma power (20-40 Hz; Fig. 12A) and total power (5-100 Hz; Fig. 12B). Importantly, total power did not differ significantly between stimulation and baseline conditions (Friedman, $p>0.05$ ). In line with the idea that gamma is stronger at higher stimulation frequencies, we found that relative gamma was significantly increased during $70 \mathrm{~Hz}$ compared to stimulation at 50 and $60 \mathrm{~Hz}$ and during baseline conditions (Fig. 12C; Friedman, $p<0.0001$, followed by post-hoc comparisons, see Table 3 for details). The result suggests that $70 \mathrm{~Hz}$ is sufficient to induce a detectable increase in relative gamma power in mouse barrel cortex. We also quantified the gamma SNR, measured as relative gamma during stimulation divided by relative gamma during baseline. We found a significant modulation of gamma SNR by stimulation frequency (Friedman, $\mathrm{p}<$ 0.0001), with higher frequencies displaying a higher gamma SNR (Fig. 12D, Table 4). Together, these findings indicate a role for induced gamma during high-frequency stimulation.

TABLE 3. Relative gamma compared across conditions. Friedman's test for paired samples $(Q=30.9$, $p<0.0001$ ) was followed by post-hoc tests using Nemenyi's procedure, for which $p$-values are displayed below (printed in bold to indicate significance). Bonferroni-corrected significance level: $p=$ 0.008. $\mathrm{BL}=$ baseline.

\begin{tabular}{ccccc}
\hline & $\mathrm{BL}$ & $50 \mathrm{~Hz}$ & $60 \mathrm{~Hz}$ & $70 \mathrm{~Hz}$ \\
\hline $\mathrm{BL}$ & & 0.040 & 0.018 & $\mathbf{0 . 0 0 4}$ \\
$50 \mathrm{~Hz}$ & 0.040 & & $<\mathbf{0 . 0 0 0 1}$ & $<\mathbf{0 . 0 0 0 1}$ \\
$60 \mathrm{~Hz}$ & 0.018 & $<\mathbf{0 . 0 0 0 1}$ & & 0.635 \\
$70 \mathrm{~Hz}$ & $\mathbf{0 . 0 0 4}$ & $<\mathbf{0 . 0 0 0 1}$ & 0.635 & \\
\hline
\end{tabular}

TABLE 4. Gamma SNR compared across conditions. Friedman's test $(Q=18.67, p<0.0001)$ and Nemenyi's post-hoc tests were used to assess differences in gamma SNR across conditions. P-values are shown below (in bold if significant). Bonferroni-corrected significance level: $p=0.0167$.

\begin{tabular}{cccc}
\hline & $50 \mathrm{~Hz}$ & $60 \mathrm{~Hz}$ & $70 \mathrm{~Hz}$ \\
\hline $50 \mathrm{~Hz}$ & & $\mathbf{0 . 0 0 1}$ & $<\mathbf{0 . 0 0 0 1}$ \\
$60 \mathrm{~Hz}$ & $\mathbf{0 . 0 0 1}$ & & 0.414 \\
$70 \mathrm{~Hz}$ & $<\mathbf{0 . 0 0 0 1}$ & 0.414 & \\
\hline
\end{tabular}

\section{Discussion}

This study evaluated mouse barrel cortex responses to sustained whisker stimulation at $1-70 \mathrm{~Hz}$ with respect to frequency-specific changes in spike rate, temporal fidelity of spikes, and gamma 
oscillations. The results from the low $(1-15 \mathrm{~Hz})$ and high frequency $(10-70 \mathrm{~Hz})$ experiments are discussed in the context of prior findings in rats.

\subsection{Low-frequency band-pass effects in firing rate and precision}

The central finding of sustained MUA responses showing a band-pass effect in spike rate (Fig. 2B), phase locking (Fig. 5A) and temporal dispersion (Fig. 5B) around 8-10 Hz parallels reports of enhanced spike rate and phase locking of sustained responses in the 5-10 $\mathrm{Hz}$ range in rat barrel cortex (Garabedian et al., 2003; Melzer et al., 2006). The band-pass properties are in line with previous results in rat barrel cortex about facilitation of responses to the preferred direction of vibrissa deflection at $8 \mathrm{~Hz}$ stimulation rate (Garabedian, 2002). The preferential increase in firing rate and firing precision at frequencies in the whisking frequency range has been suggested to support optimal stimulus processing in the somatosensory system (Garabedian et al., 2003; Moore, 2004).

Despite the overall agreement of the results, some open questions remain. One is whether band-pass response properties are specific to neurons in barrel hollows, as reported by Garabedian and colleagues (2003), or to septal neurons, as reported by Melzer and colleagues (2006). Our study cannot conclusively answer this question, but due to the larger surface of barrel hollows relative to septa in mouse barrel cortex, it is likely that we recorded most band-pass responses in the barrels. In line with our findings, Garabedian et al. (2003) observed 8-10 Hz band-pass effects with respect to firing rate and phase locking in barrels at the level of MUAs in rats. However, another rat study (Melzer et al., 2006) found 8-12 Hz band-pass properties in firing rate at the single neuron level in septa, but not in barrels. We believe that the observations by Garabedian and colleagues are more representative since they recorded from large neuronal populations at 64 sites, while Melzer and colleagues analyzed only 6 neurons in the septa and 6 neurons in the barrels. Leaving averaged responses aside, the authors reported band pass-like properties in 3/6 septal neurons and 2/6 barrel neurons (Melzer et al., 2006). We conjecture that the occurrence of band-pass properties is likely not restricted to septal neurons, but also occurs in barrels.

Another open question is why some groups have not found any band-pass effects in the barrels (Ahissar et al., 2001; Ahissar et al., 2000; Khatri et al., 2004; Melzer et al., 2006) despite using similar stimulation paradigms to the study by Garabedian and colleagues and our study. Several factors may have contributed to the divergent results. First, anesthesia affects neuronal response properties including patterns of adaptation (Castro-Alamancos, 2004), hence differences in how deeply animals were anesthetized in the various studies may have influenced the results. In this context, it is noteworthy that most studies not observing the band-pass phenomena (Ahissar et al., 2001; Ahissar et al., 2000; Melzer et al., 2006) deeply anesthetized the animals with urethane, as opposed to a very light level of anesthesia employed by our study. Moreover, the time window of 
response integration could influence the firing rate results. For example, Melzer and colleagues (2006) who did not observe changes in firing rates in barrel neurons, averaged responses during a 1min epoch during which stimuli were applied. If band-pass effects are strongest during the first few seconds following stimulus onset, as suggested by our data, the measurement approach used by Melzer and colleagues may not have been sufficiently sensitive to detect any band-pass modulation of firing rates. Other groups chose a short time window for response integration, e.g. $25 \mathrm{~ms}$ following stimulus onset in order to analyze cycle-by-cycle responses (Khatri et al., 2004). Since response latencies increase with increasing stimulation frequencies, part of the response to higher stimulation frequencies may be cut off by using short intervals (Garabedian et al., 2003), thus possibly masking facilitation effects. Furthermore, some studies applied rather long individual stimuli (e.g. 20-50 ms square pulses, Ahissar et al., 2001) as compared to shorter pulse widths used in our study ( $2 \mathrm{~ms}$ ), which may affect the calculated mean firing rates. Further studies are needed to elucidate the impact of anesthesia regimens, measures of firing rate assessment and stimulus parameters on band-pass properties.

A final question relates to the hypothesis formulated by Garabedian and colleagues (2003) about possible differences in band-pass effects between rats and mice. Based on the assumption that mice whisk at higher frequencies than rats, the authors speculated that the band-pass frequency range should be slightly higher in mice than in rats. If no differences were to be found, the authors argued that band-pass properties likely derive from intrinsic properties of the cortical circuitry rather than from whisking behavior. Our findings can be interpreted to support the hypothesis that band-pass properties relate to whisking frequency since we found band-pass properties to be most pronounced at $8-10 \mathrm{~Hz}$, while Garabedian and colleagues reported the strongest effects in the $5-8 \mathrm{~Hz}$ range. The problem with the hypothesis is that it is hard to predict exactly to what extent the amplified frequency range should differ between species. Studies reported dominant whisking frequencies in rats around $8 \mathrm{~Hz}$ during exploration (Harvey, 2001; Jin et al., 2004; Mitchinson et al., 2011; Wolfe et al., 2011), and some mouse studies reported similar frequencies (Cao et al., 2012; Kiryakova et al., 2010; Söhnchen et al., 2010). Other mouse studies observed exploratory whisking in mice predominantly at $11 \mathrm{~Hz}$ (Mitchinson et al., 2011), 14-16 Hz (Roy et al., 2011), or 19-20 Hz (Jin et al., 2004; Voigts et al., 2008). These whisking frequency ranges have also been found in rats, e.g. 7-12 Hz during whisker twitching (Fanselow and Nicolelis, 1999), 1$20 \mathrm{~Hz}$ during texture discrimination (Carvell and Simons, 1990), and 5-15 Hz range during exploration (Berg and Kleinfeld, 2003; Jin et al., 2004). Based on the range of frequencies reported in rats and mice, it is difficult to hypothesize which frequency is the one employed most of the time, and hence preferentially amplified by cortical responses. 
We can therefore not exclude the possibility that other mechanisms besides the whisking frequency range contribute to the band-pass effect. An observation reminiscent of the band-pass phenomenon is the augmenting response, which denotes an increase in cortical sensory response amplitudes when the thalamus or cortex is stimulated at rates around $10 \mathrm{~Hz}$ (Morison and Dempsey, 1943; Nunez et al., 1993). Augmenting responses have originally been described in cats (Dempsey and Morison, 1943), indicating that whisking behavior is not relevant to the observed effects. Evidence suggests that the phenomenon depends on cortical, rather than thalamic, mechanisms (Castro-Alamancos and Connors, 1996a, c; Morin and Steriade, 1981; Nunez et al., 1993) and on the behavioral state of the animal (Castro-Alamancos and Connors, 1996b). Rats showed somatosensory augmenting responses both during anesthesia (Castro-Alamancos and Connors, 1996a) and immobilized or resting awake state (Castro-Alamancos and Connors, 1996b). To what extent augmenting responses are related to the band-pass effects observed in our study is a question that remains open for future investigations.

\section{$\underline{5.2 \text { Temporal modulation of low-frequency band-pass effects }}$}

Our results show that response facilitation during the first second after stimulus onset accounts for the $8 \mathrm{~Hz}$ band-pass effect in spike rate (Fig. 3 and 4). Conversely, the 8-12 Hz band-pass effect in phase locking and temporal dispersion was most pronounced during the early time window (0.05-1 s following stimulus onset), but disappeared during the 2-3 s window (Fig. 5C,D). During the late time window, we noted a tendency for spike rate and temporal precision to be increased in the 1-3 Hz range. These findings indicate that band-pass effects are dynamically modulated.

Previously, rat studies reported a modulation of the spike rate as a function of time, in particular adaptation effects at stimulation frequencies above 1-3 Hz (Ahissar et al., 2001; Chung et al., 2002; Khatri et al., 2004; Simons, 1978). Adaptation of spike rate is thought to enhance stimulus representations in the barrel cortex (Maravall et al., 2007). Time-dependent modulations in firing precision have, to the best of our knowledge, not been described yet by other studies. Whether the band-pass dynamics we observed are related to intrinsic properties of the cells or the cortical architecture, and whether they are exploited during whisking behavior, is currently not known.

Our finding of band-pass effects mainly unfolding during an earlier time window may seem at odds with the report by Garabedian et al. (2003) that described firing rate and phase locking band-pass effects in the time window of 1-5 s following stimulus onset. Since Garabedian and colleagues did not analyze the first second following stimulation, it is not clear whether the time course of the effects observed in their study is comparable to ours. Our analyses indicate, however, that the $8-10 \mathrm{~Hz}$ band-pass effects are preserved when averaging over larger time windows (0.05-3 s). This is shown for firing rates in Figure 2, and for phase locking and temporal dispersion in Figure 
5A and 5B, respectively. Thus, the effects observed during a larger time window reported by Garabedian and colleagues are not necessarily incompatible with our findings of band-pass effects evolving during an early time window.

\subsection{Precise firing and monotonically increasing rates at $20-70 \mathrm{~Hz}$}

In the high-frequency conditions, we found a monotonic increase in firing rates of sustained MUA in the $20-70 \mathrm{~Hz}$ range (Fig. 8B). Responses to $10 \mathrm{~Hz}$ were augmented compared to $20 \mathrm{~Hz}$ as a result of the band-pass effect described in Section 5.1. The observed rate increase in the 20-70 $\mathrm{Hz}$ range confirms for the first time in mice previous reports in rat barrel cortex (Arabzadeh et al., 2003; Khatri et al., 2004; Kleinfeld et al., 2006), thus strengthening the hypothesis of a rate code for stimulation frequency. Some divergence seems to exists, however. Some authors do not interpret the observed increase in MFR as large enough to constitute a rate code (Khatri et al., 2004), but other authors do (Arabzadeh et al., 2003). The different views may be related to the different frequency bands studied. The meta analysis by Kleinfeld and colleagues (2006) reconciled the findings in rat studies by showing that MFRs increased linearly at increasing stimulation frequencies when plotted on a logarithmic scale - a pattern also observed in the $20-70 \mathrm{~Hz}$ range in our study.

We further reported phase-locked activity up to $70 \mathrm{~Hz}$ (Fig. 10A), in agreement with previous studies in rat barrel cortex (Ewert et al., 2008; Garabedian et al., 2003; Khatri et al., 2004). Extending these results, we demonstrated a reduction in temporal dispersion of responses at higher stimulation frequencies (Fig. 10B), supporting the notion of temporal coding of stimulation frequency in addition to rate coding. As previously pointed out by Kathri and colleagues (2004), phase-locked activity may be more easily detectable using high velocity stimuli (i.e. pulses) as compared to low velocity stimuli (i.e. sines). This observation could explain why some studies applying slower stimuli (Arabzadeh et al., 2003) did not observe phase-locked activity.

\subsection{Induced gamma oscillations during $70 \mathrm{~Hz}$ stimulation}

Analyzing sustained LFP responses during high frequency stimulation $(50-70 \mathrm{~Hz})$, we observed a peak in absolute gamma power in the $20-40 \mathrm{~Hz}$ range (Fig. 11), and significantly increased relative gamma power at $70 \mathrm{~Hz}$ compared to baseline (Fig. 12C). In addition, we noted a steady increase in gamma SNR from 50 to $70 \mathrm{~Hz}$, indicating a possible role for gamma oscillations in coding high frequency stimuli. Since the analyses are based on a relatively small sample of LPFs, the results should be considered preliminary. The observation that gamma oscillations appeared to develop during the last part of the response (Fig. 11, filtered LPF trace) is in agreement with a previous rat study (Ewert et al., 2008). The gamma band reported by Ewert and colleagues $(30-70 \mathrm{~Hz})$ is somewhat higher than ours $(20-40 \mathrm{~Hz})$, which may be a result of the higher stimulation frequencies used $(\geq 130 \mathrm{~Hz})$. Future 
studies should test stimulation frequencies above $70 \mathrm{~Hz}$ in mice to better compare induced gamma power to previous findings in rats.

\section{REFERENCES}

Ahissar, E., Sosnik, R., Bagdasarian, K., and Haidarliu, S. (2001). Temporal frequency of whisker movement. II. Laminar organization of cortical representations. J Neurophysiol 86, 354-367.

Ahissar, E., Sosnik, R., and Haidarliu, S. (2000). Transformation from temporal to rate coding in a somatosensory thalamocortical pathway. Nature 406, 302-306.

Arabzadeh, E., Petersen, R.S., and Diamond, M.E. (2003). Encoding of whisker vibration by rat barrel cortex neurons: implications for texture discrimination. J Neurosci 23, 9146-9154.

Arabzadeh, E., Zorzin, E., and Diamond, M.E. (2005). Neuronal encoding of texture in the whisker sensory pathway. PLoS Biol 3, e17.

Berg, R.W., and Kleinfeld, D. (2003). Rhythmic whisking by rat: retraction as well as protraction of the vibrissae is under active muscular control. J Neurophysiol 89, 104-117.

Cao, Y., Roy, S., Sachdev, R.N., and Heck, D.H. (2012). Dynamic correlation between whisking and breathing rhythms in mice. J Neurosci 32, 1653-1659.

Carvell, G., and Simons, D. (1990). Biometric analyses of vibrissal tactile discrimination in the rat. The J Neurosci 10, 2638-2648.

Carvell, G.E., and Simons, D.J. (1995). Task- and subject-related differences in sensorimotor behavior during active touch. Somatosens Mot Res 12, 1-9.

Castro-Alamancos, M.A. (2004). Dynamics of sensory thalamocortical synaptic networks during information processing states. Prog Neurobiol 74, 213-247.

Castro-Alamancos, M.A., and Connors, B.W. (1996a). Cellular mechanisms of the augmenting response: short-term plasticity in a thalamocortical pathway. J Neurosci 16, 7742-7756.

Castro-Alamancos, M.A., and Connors, B.W. (1996b). Short-term plasticity of a thalamocortical pathway dynamically modulated by behavioral state. Science $272,274-277$.

Castro-Alamancos, M.A., and Connors, B.W. (1996c). Spatiotemporal properties of short-term plasticity sensorimotor thalamocortical pathways of the rat. J Neurosci 16, 2767-2779.

Chung, S., Li, X., and Nelson, S.B. (2002). Short-term depression at thalamocortical synapses contributes to rapid adaptation of cortical sensory responses in vivo. Neuron 34, 437-446.

Dempsey, E., and Morison, R. (1943). The electrical activity of a thalamocortical relay system. Am J Physiol - Legacy Content 138, 283-296.

Ewert, T.A., Vahle-Hinz, C., and Engel, A.K. (2008). High-frequency whisker vibration is encoded by phase-locked responses of neurons in the rat's barrel cortex. J Neurosci 28, 5359-5368.

Fairhall, A.L., Lewen, G.D., Bialek, W., and van Steveninck, R.R.d.R. (2001). Efficiency and ambiguity in an adaptive neural code. Nature 412, 787-792.

Fanselow, E.E., and Nicolelis, M.A. (1999). Behavioral modulation of tactile responses in the rat somatosensory system. J Neurosci 19, 7603-7616.

Garabedian, C.E., Jones, S.R., Merzenich, M.M., Dale, A., and Moore, C.I. (2003). Band-pass response properties of rat SI neurons. J Neurophysiol 90, 1379-1391.

Garabedian, C.E.M., M. M.; Moore, C. I. (2002). Frequency-dependent sharpening of direction tuning in rat SI. Soc Neurosci Abst.

Gerdjikov, T.V., Bergner, C.G., Stuttgen, M.C., Waiblinger, C., and Schwarz, C. (2010). Discrimination of vibrotactile stimuli in the rat whisker system: behavior and neurometrics. Neuron 65, 530-540.

Harvey, M.A., Bermejo, R., Zeigler, H.P. (2001). Discriminative whisking in the head-fixed rat: optoelectronic monitoring during tactile detection and discrimination tasks. Somatosens Mot Res $18,211-222$. 
Jin, T.E., Witzemann, V., and Brecht, M. (2004). Fiber types of the intrinsic whisker muscle and whisking behavior. J Neurosci 24, 3386-3393.

Jones, L.M., Depireux, D.A., Simons, D.J., and Keller, A. (2004). Robust temporal coding in the trigeminal system. Science 304, 1986-1989.

Khatri, V., Hartings, J.A., and Simons, D.J. (2004). Adaptation in thalamic barreloid and cortical barrel neurons to periodic whisker deflections varying in frequency and velocity. J Neurophysiol 92, 3244-3254.

Kiryakova, S., Söhnchen, J., Grosheva, M., Schuetz, U., Marinova, T., Dzhupanova, R., Sinis, N., Hübbers, C., Skouras, E., and Ankerne, J. (2010). Recovery of whisking function promoted by manual stimulation of the vibrissal muscles after facial nerve injury requires insulin-like growth factor 1 (IGF-1). Exp Neurol 222, 226-234.

Kleinfeld, D., Ahissar, E., and Diamond, M.E. (2006). Active sensation: insights from the rodent vibrissa sensorimotor system. Curr Opin Neurobiol 16, 435-444.

Kohn, A., and Whitsel, B.L. (2002). Sensory cortical dynamics. Behav Brain Res 135, 119-126.

Maravall, M., Petersen, R., Fairhall, A., Arabzadeh, E., and Diamond, M. (2007). Shifts in coding properties and maintenance of information transmission during adaptation in barrel cortex. PLoS Biol 5, e19.

Melzer, P., Champney, G.C., Maguire, M.J., and Ebner, F.F. (2006). Rate code and temporal code for frequency of whisker stimulation in rat primary and secondary somatic sensory cortex. Exp Brain Res 172, 370-386.

Mitchinson, B., Grant, R.A., Arkley, K., Rankov, V., Perkon, I., and Prescott, T.J. (2011). Active vibrissal sensing in rodents and marsupials. Philos Trans R Soc Lond B Biol Sci 366, 3037-3048.

Moore, C., Nelson, S., and Sur, M. (1999). Dynamics of neuronal processing in rat somatosensory cortex. Trends Neurosci 22, 513-520.

Moore, C.I. (2004). Frequency-dependent processing in the vibrissa sensory system. J Neurophysiol 91, 2390-2399.

Morin, D., and Steriade, M. (1981). Development from primary to augmenting responses in the somatosensory system. Brain Res 205, 49-66.

Morison, R., and Dempsey, E. (1943). Mechanism of thalamocortical augmentation and repetition. Am J Physiol.

Nicolelis, M.A., and Fanselow, E.E. (2002). Thalamocortical optimization of tactile processing according to behavioral state. Nat Neurosci 5, 517-523.

Nunez, A., Amzica, F., and Steriade, M. (1993). Electrophysiology of cat association cortical cells in vivo: intrinsic properties and synaptic responses. J Neurophysiol 70, 418-430.

Panzeri, S., and Diamond, M.E. (2010). Information carried by population spike times in the whisker sensory cortex can be decoded without knowledge of stimulus time. Front Synaptic Neurosci 2.

Ritt, J.T., Andermann, M.L., and Moore, C.I. (2008). Embodied information processing: vibrissa mechanics and texture features shape micromotions in actively sensing rats. Neuron 57, 599-613.

Roy, S., Bryant, J.L., Cao, Y., and Heck, D.H. (2011). High-precision, three-dimensional tracking of mouse whisker movements with optical motion capture technology. Front Behav Neurosci 5, 00027.

Simons, D.J. (1978). Response properties of vibrissa units in rat SI somatosensory neocortex. J Neurophysiol 41, 798-820.

Söhnchen, J., Grosheva, M., Kiryakova, S., Hübbers, C.U., Sinis, N., Skouras, E., Ankerne, J., Kaidoglou, K., Fries, J.W.U., Irintchev, A., et al. (2010). Recovery of whisking function after manual stimulation of denervated vibrissal muscles requires brain-derived neurotrophic factor and its receptor tyrosine kinase B. Neuroscience 170, 372-380.

Voigts, J., Sakmann, B., and Celikel, T. (2008). Unsupervised whisker tracking in unrestrained behaving animals. J Neurophysiol 100, 504-515.

Wark, B., Lundstrom, B.N., and Fairhall, A. (2007). Sensory adaptation. Curr Opin Neurobiol 17, 423429. 
Chapter III

Wolfe, J., Mende, C., and Brecht, M. (2011). Social facial touch in rats. Behav Neurosci 125, 900-910. 


\section{Chapter IV}

\section{Altered resonance properties of somatosensory responses in the NRG1 mouse model of schizophrenia}

\section{Abstract}

To reveal the neuronal underpinnings of sensory processing deficits in schizophrenic patients, previous studies have investigated brain activity in response to sustained sensory stimulation at various frequencies. This paradigm evoked entrained neural activity at the stimulation frequency and harmonics thereof. During visual and auditory stimulation that elicits enhanced or 'resonant' responses in healthy controls, schizophrenic subjects displayed reduced activity. The present study sought to elucidate the cellular basis of disease-related deficits in sensory resonance properties using the Neuregulin 1 (NRG1) mouse model of schizophrenia. We applied repetitive whisker stimulation at $1-15 \mathrm{~Hz}$, a range relevant to the whisking behavior in mice, and measured cellular activity in the primary somatosensory cortex. We found aberrant frequency-dependent response modulation with respect to firing rate and temporal fidelity in $N R G 1$ mutants at low $(1-3 \mathrm{~Hz})$ and high $(8 \mathrm{~Hz})$ frequencies. Moreover, we observed larger sensory-evoked responses in NRG1 mice, an increased level of spontaneous activity, and a reduced neural signal-to-noise ratio at low $(1-3 \mathrm{~Hz})$ and high $(8 \mathrm{~Hz})$ frequencies. The results are consistent with an imbalance in the excitatory-inhibitory circuitry in NRG1 mutants, and demonstrate for the first time that a mutation of the schizophreniarisk gene NRG1 impairs neuronal resonance and encoding of perceptual information in the somatosensory cortex.

\section{Introduction}

Schizophrenia patients suffer from a variety of perceptual and sensational disturbances in the visual, auditory, somatosensory and olfactory domains (Butler et al., 2008; Butler et al., 2005; Huang et al., 2010; Jenkins and Röhricht, 2007; Moberg et al., 1999; Näätänen and Kähkönen, 2009). Past research in patients found that neural responses to sustained auditory and visual stimulation were less entrained by the stimulus. Thus, oscillatory activity in patients was reduced in magnitude and temporal precision, and these effects were frequency-specific (Brenner et al., 2009; Tan et al., 2013). In particular, responses in schizophrenic subjects were not enhanced at frequencies that typically elicit highly entrained, 'resonant' responses in normal subjects (Brenner et al., 2009; Emir et al., 2008; Jin et al., 2000). While healthy subjects showed resonant activity during sustained stimulation 
at $8 \mathrm{~Hz}$ in the visual domain (Emir et al., 2008) and at $40 \mathrm{~Hz}$ in the auditory domain (Picton et al., 2003), these patterns were disrupted in patients (Jin et al., 2000; Jin et al., 1995; Rice et al., 1989; Tsuchimoto et al., 2011). In addition, patients displayed altered baseline activity in these frequency ranges (Jin et al., 2000; Jin et al., 1995; Venables et al., 2009), indicating a possible relationship with the stimulus-related deficits. In the somatosensory domain, only one study investigated responses to sustained somatosensory stimulation in schizophrenic subjects and found reduced temporal precision (i.e. intertrial phase coherence) using a $25 \mathrm{~Hz}$ stimulus (Teale et al., 2013). It is currently unknown whether aberrant somatosensory responses also occur at other stimulus frequencies, whether alterations in baseline activity play a role in somatosensory response deficits, and whether resonance properties in the somatosensory domain might be disturbed in schizophrenia.

Mouse models of schizophrenia offer the opportunity to study the effects of specific genetic manipulations on cognitive, behavioral and perceptual processes (Gainetdinov et al., 2001; Lipska and Gogos, 2011; Papaleo et al., 2012; Young et al., 2010). For example, mice heterozygous for the schizophrenia susceptibility gene Neuregulin 1 (NRG1; Meyer and Birchmeier, 1995) exhibit various endophenotypes of schizophrenia, including deficits in auditory novelty detection (mismatch negativity), contextual fear conditioning and social interaction (Ehrlichman et al., 2009), as well as hyperlocomotion and impaired sensory gating after pharmacological challenge (Duffy et al., 2008). The NRG1 gene is among the most promising candidate genes for schizophrenia. A large number of studies have identified and replicated an association of variants of the NRG1 gene with schizophrenia in diverse populations (Agim et al., 2013; Alaerts et al., 2009; Bousman et al., 2013; Fukui et al., 2006; Georgieva et al., 2008; Greenwood et al., 2011; Greenwood et al., 2012; HuertasVazquez et al., 2013; Kukshal et al., 2013; Li et al., 2006; Li et al., 2004; Mohamad Shariati et al., 2011; Munafo et al., 2006; Naz et al., 2011; Papiol et al., 2011; Stefansson et al., 2003a; Stefansson et al., 2003b; Thomson et al., 2007; Walker et al., 2010; Yang, 2012; Yokley et al., 2012). NRG1 and its receptor ErbB4 have been implied in modulating excitatory and inhibitory synaptic transmission (Fazzari et al., 2010; Geddes et al., 2011; Hahn et al., 2006; Ting et al., 2011; Wen et al., 2010; Woo et al., 2007), which is disrupted in schizophrenic patients (Akbarian et al., 1995; Bartha et al., 1997; Beasley and Reynolds, 1997; Benes et al., 1991; Eastwood et al., 1995; Harrison et al., 1991; Hashimoto et al., 2003; Humphries et al., 1996; Kegeles et al., 2012; Perry et al., 1979; Sherman et al., 1991; Simpson et al., 1989; Volk et al., 2000; Volk et al., 2001).

The NRG1 mouse model of schizophrenia has been used to study electrophysiological, morphological and biochemical alterations mainly in the limbic system (Chen et al., 2008; Deakin et al., 2012; Jiang et al., 2013; Nason et al., 2011), whereas somatosensory information processing has not been specifically examined yet. Cellular responses and resonance effects during somatosensory 
stimulation can be easily studied in the mouse whisker system thanks to its straightforward anatomical organization. Sensory projections from a single whisker are processed in a single cortical column, the 'barrel column' (Woolsey and Van der Loos, 1970). Barrel cortex responses in rodents show resonance properties at stimulation frequencies that are behaviorally relevant for the animals. In particular, firing rate and phase locking (i.e. the temporal precision of neuronal responses with respect to the stimulus) are increased during $5-10 \mathrm{~Hz}$ stimulation in mice (Chapter III) and rats (Garabedian et al., 2003), indicating cellular band-pass characteristics in the frequency range at which whisker motion occurs during exploratory behavior (Cao et al., 2012; Carvell and Simons, 1990).

To examine the cellular basis of deficits in sensory resonant responses in schizophrenia, we characterized primary somatosensory cortex activity in mice heterozygous for the schizophrenia risk gene NRG1. We applied sustained stimulation at 1-15 Hz since band-pass properties have previously been shown around $8 \mathrm{~Hz}$ in mice and rats. We assessed neural activity with respect to firing rate, adaptation and temporal precision (phase locking) in mutants and control mice. In addition, we quantified spiking activity during baseline conditions to examine potential alterations in spontaneous firing patterns that may alter stimulus-evoked responses.

\section{Methods}

For a complete description of the materials and methods, the reader is referred to Chapter II. Briefly, wildtype (WT; $N R G 1+/+$ ) and NRG1 (+/-) mice were kept under light isoflurane-fentanyl anesthesia while whiskers were stimulated and multi-unit activity (MUA) was recorded in the barrel cortex. Air puffs were applied to whiskers in 3 s long trains at 1, 3, 5, 8, 10, 12 and $15 \mathrm{~Hz}$. Only MUAs showing large responses, clear frequency modulation and short onset latencies (14 $\pm 1.5 \mathrm{~ms}$ ) were included in the analysis.

The mean firing rate (MFR) was first analyzed during stimulation conditions and normalized by baseline MFR to calculate the signal-to-noise ratio (SNR). MFR and SNR were calculated for onset responses (0-50 ms after stimulus onset) and sustained responses (0.05-3 s). Baseline firing was determined in a $50 \mathrm{~ms}(-0.05-0 \mathrm{~s})$ time window or $2.95 \mathrm{~s}$ time window $(-1.5-0 \mathrm{~s} ; 3.05-5 \mathrm{~s})$.

Adaptation of firing rates was assessed using an adaptation ratio. For each stimulus cycle during the stimulus train, the MFR during the first $50 \mathrm{~ms}$ after stimulus onset was calculated and divided by the response to the first cycle (train onset). The ratio indicates the degree to which responses adapt during the stimulus train compared to the response to the onset of the stimulus train. To evaluate early and late changes in adaptation during the stimulus response, the MFR during 0-1 s after stimulus onset was divided by the MFR during 2-3 s after stimulus onset. 
Temporal fidelity of responses was measured using vector strength analysis. Vector strength is assessed based on the spike distribution of the phase histogram, where a peak indicates good phase locking and a flat distribution suggests no phase locking. In addition, temporal dispersion of the responses was measured to assess the spread of the spike response. As an inclusion criterion, phase histograms contained $>45$ spikes, and vector strength values were significant at $p<0.05$. Temporal dispersion values were only derived if phase locking was significant.

For statistical purposes, data was tested for assumptions of normality (Shapiro-Wilk test), homogeneity of variance (Levene's test), and sphericity (Mauchly's test). Where appropriate, parametric (t-test, F-test) or non-parametric (Mann-Whitney $U$ ) tests were used for statistical comparisons. When sphericity was violated for repeated measures (RM) analysis of variance (ANOVA), the degrees of freedom (df) were adjusted with the Greenhouse-Geisser correction (G-G). Population averages are described in the text as mean $\pm \mathrm{SE}$; error bars in figures indicate SE.

For verifying that the NRG1 mutation did not affect the gross anatomy of the barrel cortex, cytochrome oxidase stainings were performed to visualize barrel patterns in mutants and control mice.

\section{Results}

\subsection{Aberrant firing rates during baseline and stimulation conditions in NRG1 mice}

To test whether NRG1 neurons showed typical resonance properties in their firing rate during sustained whisker stimulation around $8 \mathrm{~Hz}$, we recorded local cellular activity (MUA) while stimulating the whiskers with $3 \mathrm{~s}$ long trains of air puffs at 7 frequencies between $1 \mathrm{~Hz}$ and $15 \mathrm{~Hz}$. Peri-stimulus time histograms (PSTHs) were calculated for 11 WT MUAs and 11 NRG1 MUAs. Figure 1 shows three example MUA responses for WT and NRG1 mice. All responses are displayed with the same scaling, and it is apparent that mutants show larger response magnitudes and higher levels of spontaneous activity. Moreover, responses to the four example frequencies shown in Figure 1 indicate that response dynamics change with stimulation frequency in both WT and NRG1 mice.

To quantify neural activity in WT mice and mutants, responses were divided into onset responses, measured during the first $50 \mathrm{~ms}$ following stimulus onset, and sustained responses, measured during the entire train of stimulation, but excluding the onset response (0.05-3 s; Fig. 2). Since all pulses in the stimulus trains are identical and only differ in terms of their presentation frequency, onset responses were not expected to vary notably across conditions, while sustained responses may be modulated by the stimulation frequency and display resonant properties. In accordance with previous findings (see Chapter III), onset responses did not differ across stimulation conditions in WT (RM ANOVA, $\mathrm{p}>0.05$ ) and NRG1 mice (RM ANOVA, $\mathrm{p}>0.05$ ). In contrast, sustained 
firing rates varied as a function of stimulation frequency in WT (RM ANOVA, $p=0.001$ ) and mutant mice (RM ANOVA, $\mathrm{p}<0.001$ ). Compared to control animals, NRG1 mutants displayed elevated stimulus-evoked firing rates at the level of onset responses (MFR collapsed across conditions; MannWhitney, $p<0.0001$; Fig. 2A, left panel) and sustained responses (Mann-Whitney, $p<0.0001$; Table 1, Fig. 2A, right panel). Importantly, sustained firing rates peaked in the $8 \mathrm{~Hz}$ condition in WT mice (Fig. 2A, right panel inset; compare also Table 1), showing clear resonance effects as previously described in BL6 mice (Chapter III). In contrast, sustained firing rates in NRG1 mutants increased from 1 to $8 \mathrm{~Hz}$ and leveled off at $8-15 \mathrm{~Hz}$, without showing an identifiable peak.

Next we sought to relate stimulus-evoked firing rates to spontaneous firing rates. Alterations in baseline activity have previously been described in schizophrenic subjects (Jin et al., 2000; Jin et al., 1995; Venables et al., 2009) and may influence stimulus-related activity, especially when baseline corrections are performed (Gandal et al., 2012a; Tsuchimoto et al., 2011). Baseline firing rates were elevated in mutants relative to control mice during two time windows (50 ms and $2.95 \mathrm{~s}$; MannWhitney, $p<0.0001$; Fig. 2B). For every MUA, the stimulus-evoked firing rates measured during the onset $(50 \mathrm{~ms})$ and sustained part of the response ( $2.95 \mathrm{~s})$ were then divided by baseline responses measured during the $50 \mathrm{~ms}$ and 2.95 time window, respectively. This evoked-to-baseline ratio, or SNR, was reduced in NRG1 animals compared to WT mice for both onset and sustained responses (Fig. 2C). The SNR of onset responses did not differ in WT (RM ANOVA, G-G, $F(1.1,11.3)=0.9, p>$ 0.05 ) and NRG1 animals (RM ANOVA, G-G, F $(2.8,27.8)=0.6, p>0.05)$, and was therefore pooled across conditions. Statistical comparison revealed a decrease in onset SNR in NRG1 mice compared to WT mice (Mann-Whitney, $\mathrm{p}<0.0001$ ). Furthermore, the SNR of sustained responses was reduced in NRG1 mutants in the 1, 3 and $8 \mathrm{~Hz}$ conditions (Mann-Whitney, $\mathrm{p} \leq 0.001$; Table 2). WT mice displayed the highest SNR at $8 \mathrm{~Hz}$, confirming the band-pass characteristics identified at the level of MFRs, while NRG1 mice lacked this effect. 
(A)

WT

$3 \mathrm{~Hz}$

$8 \mathrm{~Hz}$

$10 \mathrm{~Hz}$

$15 \mathrm{~Hz}$

$\perp \perp|\perp||||| \mid$
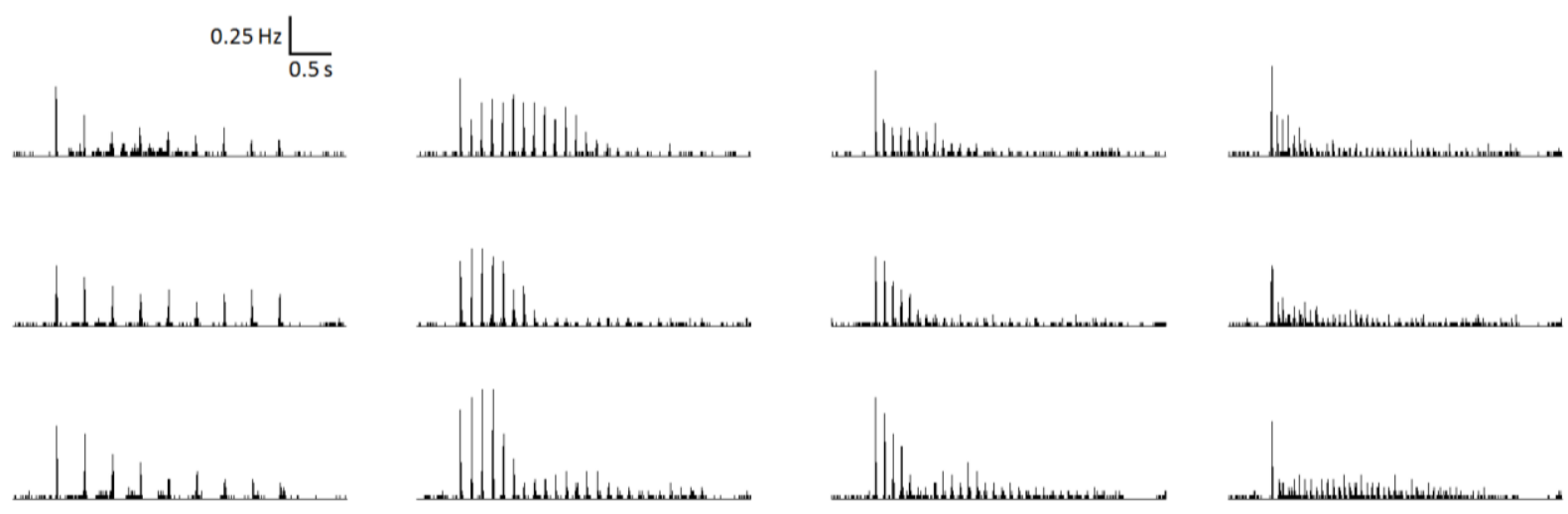

(B) $3 \mathrm{~Hz}$

$10 \mathrm{~Hz}$

ШШШШШШШШШШШШШШШШШ
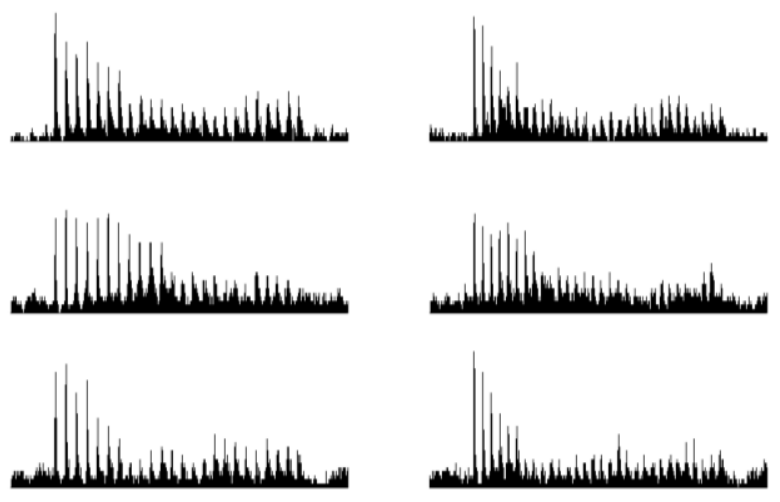
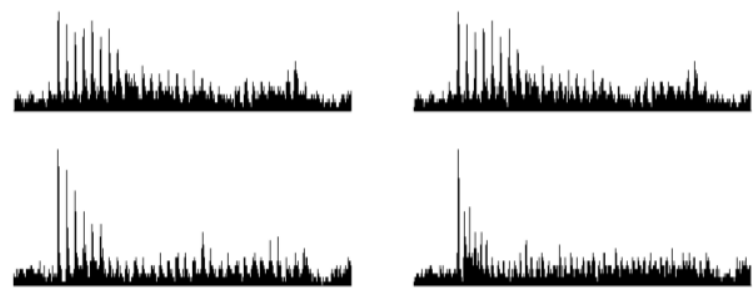

FIGURE 1. Response dynamics during repetitive whisker stimulation. Four example stimuli and three representative MUAs are shown for WT $(A)$ and NRG1 mice $(B)$. PSTHs (bin size: $1 \mathrm{~ms}$ ) were calculated by averaging responses for each MUA across 40 trials. WT and NRG1 responses are displayed at the same scale. A. WT MUAs (top to bottom) were modulated by the stimulation frequency and showed a low level of baseline activity. B. NRG1 MUAs (top to bottom) were also modulated by stimulus frequency, but appeared larger in magnitude. In contrast to WT mice, baseline activity was elevated in the mutants. 
(A)

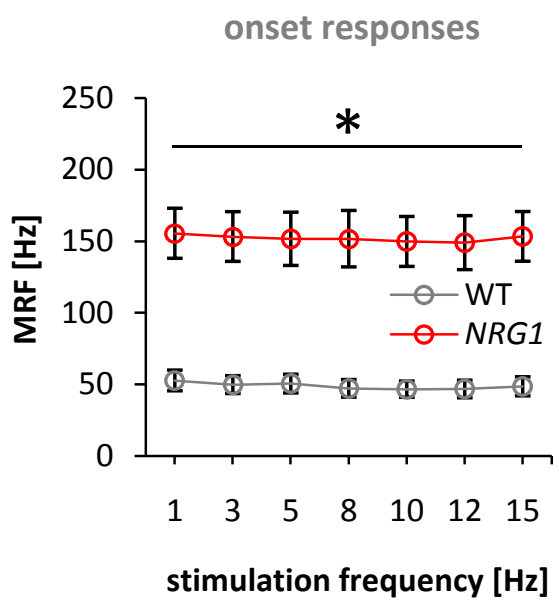

(B)

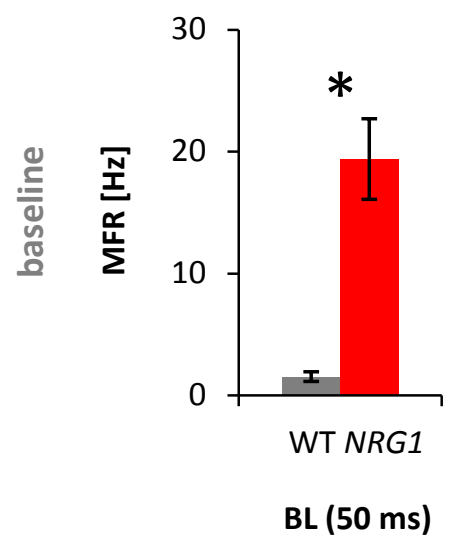

(C)

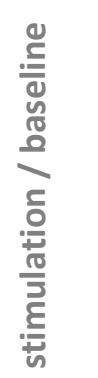

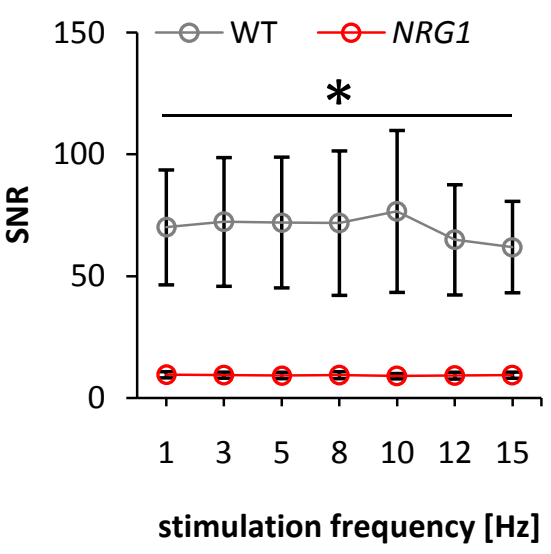
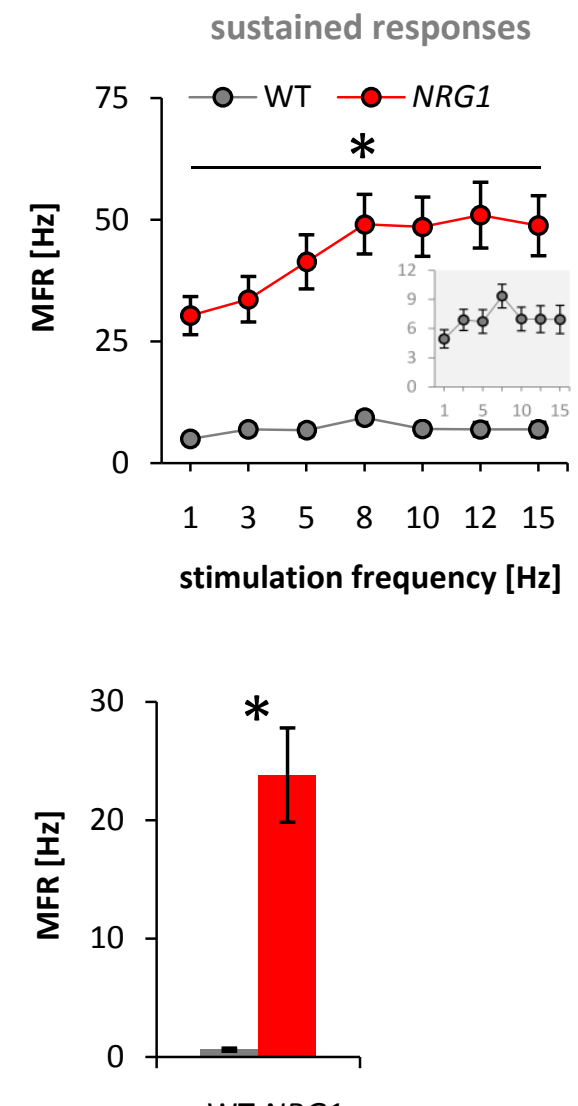

WT NRG1

BL (2.95 s)

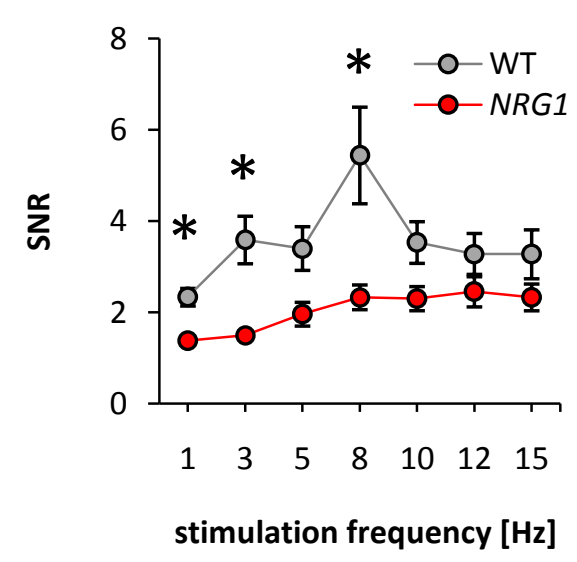

FIGURE 2. Firing rates during stimulation and baseline conditions. Onset responses (left column) and sustained responses (right column) in WT ( $n=11$ MUAs) and NRG1 mice ( $n=11$ MUAs). A. Firing rates during stimulation. Onset responses (left) were not modulated by stimulus frequency in neither group (WT: RM ANOVA, G-G, F $(2.6,26.0)=2.5, \mathrm{p}=0.09$; NRG1: RM ANOVA, G-G, F (2.5, $25.2)=0.5, p=0.66$ ), while sustained responses (right) varied as a function of stimulation frequency in WT (RM ANOVA, G-G, F $(2.2,22.3)=9.3, \mathrm{p}=0.001)$ and NRG1 mice (RM ANOVA, G-G, F $(1.3,12.8)$ $=22.3, \mathrm{p}<0.001$ ). NRG1 mice showed elevated firing rates during onset responses (pooled; WT: $49.00 \pm 6.26$; NRG1: $152.01 \pm 18.0$; Mann-Whitney, $\mathrm{U}=4, \mathrm{p}<0.0001$ ) and sustained responses (see Table 1 for details). Right panel inset: WT data at different scale. $B$. Baseline firing rates. Baseline (BL) responses were measured during a $50 \mathrm{~ms}$ (left) or $2.95 \mathrm{~s}$ (right) time window. During both windows, spontaneous firing was enhanced in NRG1 mutants (Mann-Whitney; [continued on the next page] 
[legend continued] $50 \mathrm{~ms}: \mathrm{U}=0, \mathrm{p}<0.0001 ; 2.95 \mathrm{~s}: \mathrm{U}=0, \mathrm{p}<0.0001)$. C. SNR or evoked-to-baseline ratio. The SNR of onset responses (left) was not significantly modulated by stimulation frequencies in WT (RM ANOVA, G-G, F(1.1, 11.3) = 0.9, $\mathrm{p}=0.37$ ) and NRG1 mice (RM ANOVA, G-G, F $(2.8,27.8)=$ $0.6, p=0.59$ ). Mutants showed reductions in SNR for onset responses (pooled; WT: $69.94 \pm 25.79$; NRG1: $9.31 \pm 1.28$; Mann-Whitney, $U=121, p<0.0001$ ) and sustained responses (see Table 2 for details). Significant between-group differences are marked by *.

TABLE 1. Between-group differences in MFR of sustained responses. Shown are the MFR \pm SE of WT $(\mathrm{n}=11)$ and NRG1 $(\mathrm{n}=11)$ MUAs well as the Mann-Whitney $U$ and the corresponding $\mathrm{p}$ value (printed in bold to indicate significance). Bonferroni-corrected significance level: $p=0.007$.

\begin{tabular}{ccccc}
\hline frequency & WT MFR [Hz] & NRG1 MFR [Hz] & $\mathbf{U}$ & $\mathbf{p}$ \\
\hline $\mathbf{1 ~ H z}$ & $4.94 \pm 0.93$ & $30.31 \pm 3.92$ & 0 & $<\mathbf{0 . 0 0 0 1}$ \\
$\mathbf{3 ~ H z}$ & $6.90 \pm 1.10$ & $33.68 \pm 4.68$ & 0 & $<\mathbf{0 . 0 0 0 1}$ \\
$\mathbf{5 ~ H z}$ & $6.73 \pm 1.23$ & $41.36 \pm 5.56$ & 2 & $<\mathbf{0 . 0 0 0 1}$ \\
$\mathbf{8 ~ H z}$ & $9.34 \pm 1.22$ & $49.11 \pm 6.13$ & 1 & $<\mathbf{0 . 0 0 0 1}$ \\
$\mathbf{1 0 ~ H z}$ & $6.98 \pm 1.23$ & $48.58 \pm 6.09$ & 0 & $<\mathbf{0 . 0 0 0 1}$ \\
$\mathbf{1 2} \mathbf{~ H z}$ & $6.96 \pm 1.39$ & $50.96 \pm 6.76$ & 1 & $<\mathbf{0 . 0 0 0 1}$ \\
$\mathbf{1 5} \mathbf{~ H z}$ & $6.92 \pm 1.47$ & $48.73 \pm 6.17$ & 1 & $<\mathbf{0 . 0 0 0 1}$ \\
\hline
\end{tabular}

TABLE 2. Between-group differences in SNR of sustained responses. The SNR of $W T(n=11)$ and $N R G 1(\mathrm{n}=11)$ sustained responses was compared per condition (Mann-Whitney). Displayed are the mean SNR \pm SE of WT and NRG1 responses, the Mann-Whitney $U$ and the corresponding $p$ value (highlighted in bold if significant). Bonferroni-corrected significance level: $p=0.007$.

\begin{tabular}{ccccc}
\hline frequency & WT SNR & NRG1 SNR & U & p \\
\hline $\mathbf{1 ~ H z}$ & $2.33 \pm 0.19$ & $1.38 \pm 0.09$ & 112 & $<\mathbf{0 . 0 0 1}$ \\
$\mathbf{3 ~ H z}$ & $3.59 \pm 0.52$ & $1.50 \pm 0.09$ & 116 & $<\mathbf{0 . 0 0 0 1}$ \\
$\mathbf{5 ~ H z}$ & $3.40 \pm 0.48$ & $1.96 \pm 0.26$ & 95 & 0.023 \\
$\mathbf{8 ~ H z}$ & $5.44 \pm 1.06$ & $2.33 \pm 0.27$ & 107 & $\mathbf{0 . 0 0 1}$ \\
$\mathbf{1 0 ~ H z}$ & $3.53 \pm 0.46$ & $2.30 \pm 0.26$ & 89 & 0.065 \\
$\mathbf{1 2 ~ H z}$ & $3.28 \pm 0.45$ & $2.45 \pm 0.33$ & 84 & 0.133 \\
$\mathbf{1 5} \mathbf{~ H z}$ & $3.27 \pm 0.54$ & $2.33 \pm 0.29$ & 81 & 0.193 \\
\hline
\end{tabular}

\subsection{NRG1 responses show abnormal adaptation and facilitation patterns}

To further elucidate how stimulation frequency modulates response magnitudes in NRG1 mutants, we examined response adaptation during each cycle of the stimulus train. As established previously (Higley and Contreras, 2006, 2007; Khatri et al., 2004), adaptation was measured by calculating for each stimulus cycle the MFR during the first $50 \mathrm{~ms}$ following stimulus presentation, and dividing by the response to the first cycle. Thus, an adaptation ratio $<1$ indicates adaptation of responses to a 
given stimulus, while a ratio $>1$ indicates response facilitation. The time window of $50 \mathrm{~ms}$ per stimulus cycle was chosen since it captured most stimulus-related responses (compare PSTHs in Fig. 1, which are displayed with 1 ms resolution). In agreement with prior findings in BL6 mice (Chapter III), WT mice demonstrated virtually no adaptation at $1 \mathrm{~Hz}$ and an increasing level of adaptation at increasing stimulation frequencies (Fig. 3A,B), with the notable exception of the $8 \mathrm{~Hz}$ condition, where responses were facilitated during the first 600 ms (Fig. 3B). Similarly, NRG1 responses displayed no adaptation at $1 \mathrm{~Hz}$ and adapted with increasing stimulation frequencies (Fig. $\mathbf{3 C}, \mathbf{D}$ ). Contrary to WT mice, however, NRG1 mutants did not show an $8 \mathrm{~Hz}$-specific response facilitation (Fig. 3E).

In both WT and NRG1 animals, the time course of adaptation depended on the stimulus frequency. In the $3 \mathrm{~Hz}$ and $5 \mathrm{~Hz}$ conditions, adaptation of responses proceeded slowly and did not reach a steady state within the $3 \mathrm{~s}$ stimulus train. In the $8-15 \mathrm{~Hz}$ conditions, in contrast, adaptation reached a steady state $2 \mathrm{~s}$ post stimulus onset (Fig. 3A-D). To quantify steady-state adaptation, the adaptation ratios calculated for stimulus cycles 2-3 s after stimulus onset were averaged for the 8-15 $\mathrm{Hz}$ stimulation conditions. NRG1 mutants demonstrated elevated levels of steady-state adaptation compared to WT mice across the tested conditions (Mann-Whitney, $p<0.0001$; Fig. 3F).

Based on the observation that the time course of adaptation differed depending on the stimulation frequency, we wanted to examine these dynamics in more detail. Thus, we quantified firing rates during two time windows: 0-1 $\mathrm{s}$ and 2-3 $\mathrm{s}$ following stimulus onset (Fig. 4). During the first time window (0-1 s), WT mice showed a peak in MFR at $8 \mathrm{~Hz}$ (Fig. 4A, black diamonds), while NRG1 responses increased their MFR with increasing stimulus frequency (Fig. 4B, black diamonds). During the second time window (2-3 s), WT responses were not modulated by stimulus frequency (Fig. 4A, gray diamonds), whereas NRG1 responses increased again with stimulus frequency (Fig. 4B, gray diamonds). Dividing responses during the first window (0-1 s) by responses during the second time window (2-3 s) yielded an additional measure of adaptation that revealed differences in the degree of frequency-dependent modulation of response dynamics between WT and NRG1 mice (Fig. 4C). When WT and NRG1 responses were compared per condition, NRG1 mice showed a smaller adaptation ratio than WT mice in all conditions with the exception of the $5 \mathrm{~Hz}$ condition, where still a trend was observed (Table 3). The largest difference in adaptation ratio was observed in the $8 \mathrm{~Hz}$ condition. 
(A)

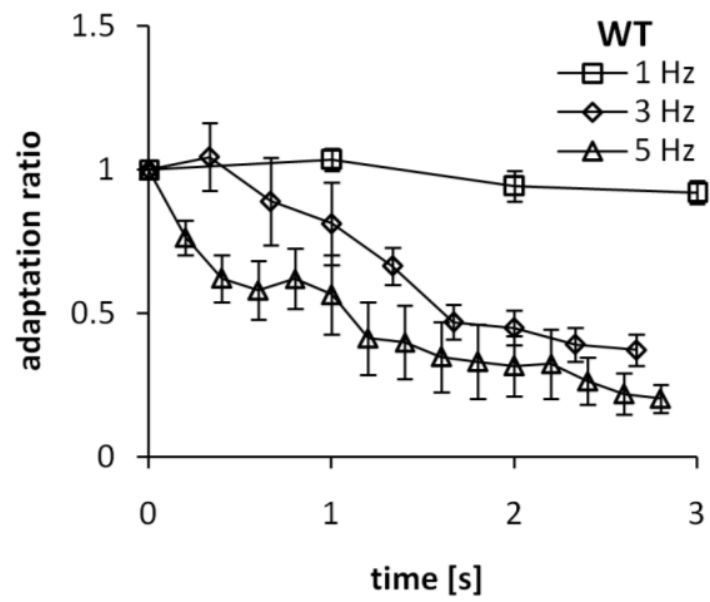

(C)

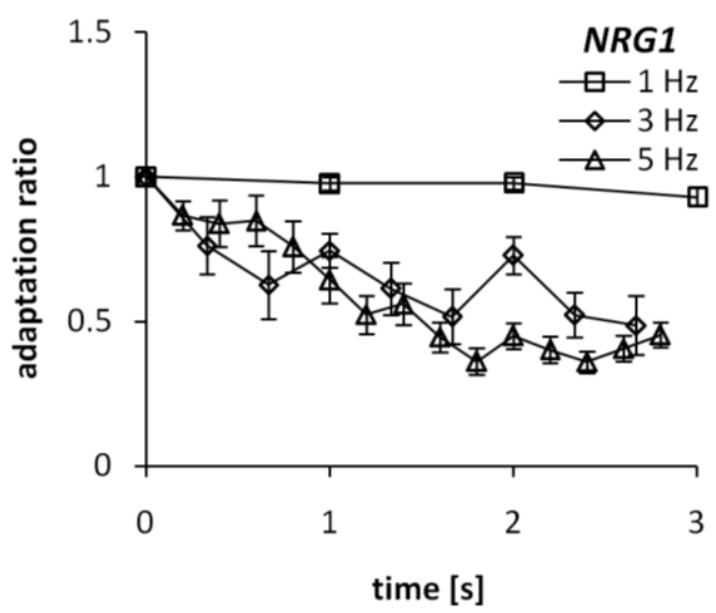

(E)

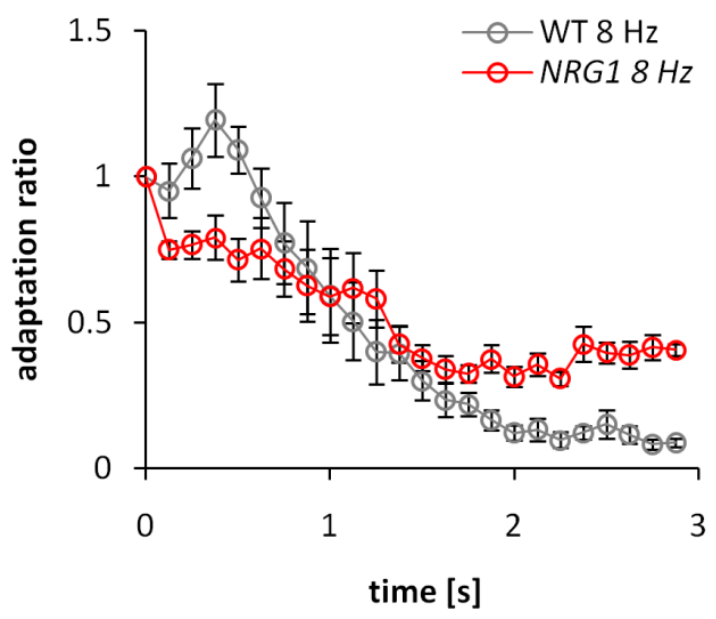

(B)

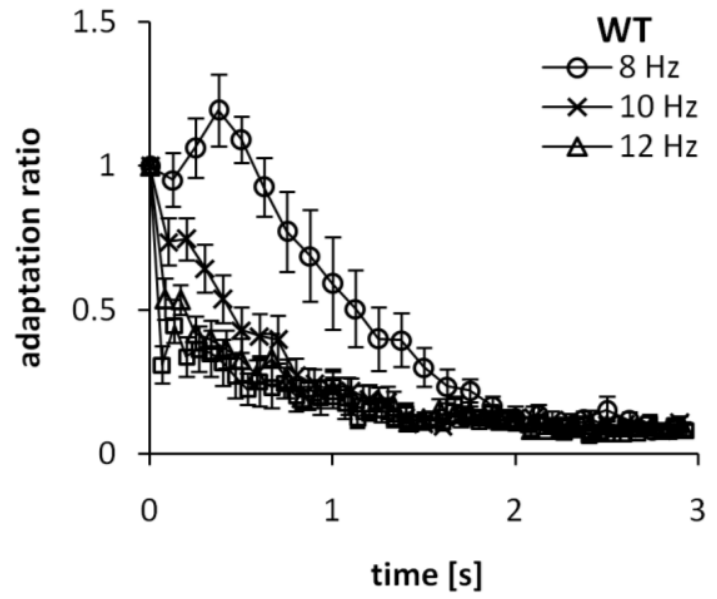

(D)

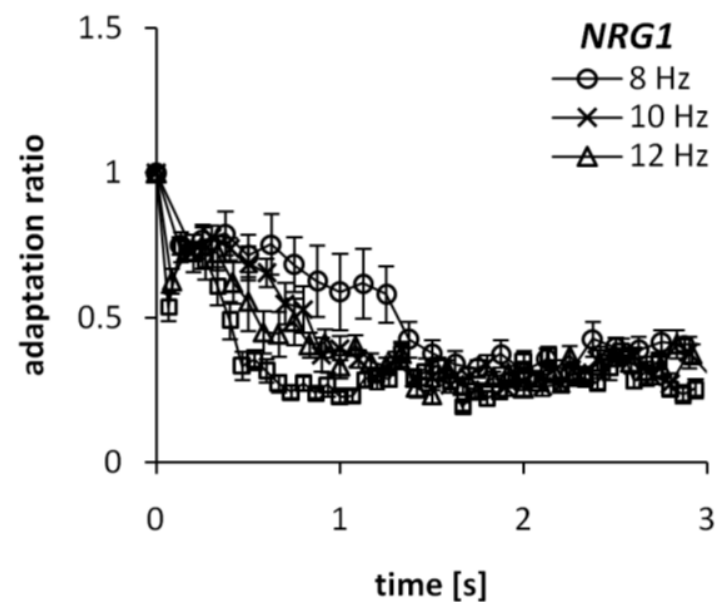

(F)

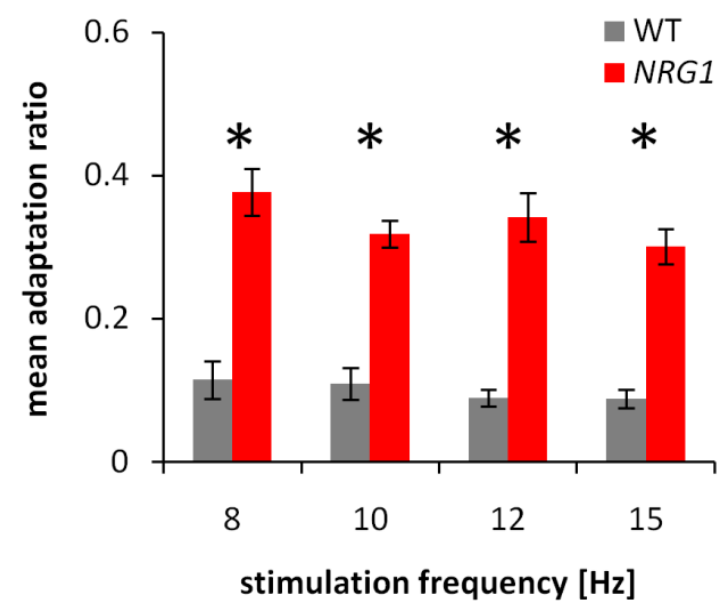

FIGURE 3. Adaptation of firing rates. The MFR during the first $50 \mathrm{~ms}$ during a stimulus cycle was divided by the response to the first cycle to calculate adaptation ratios in WT ( $\mathrm{n}=11)$ and NRG1 MUAs $(\mathrm{n}=11)$. A, B. Adaptation of WT responses to $1-5 \mathrm{~Hz}(A)$ and 8-15 $\mathrm{Hz}$ stimuli $(B)$. C, D. NRG1 response adaptation to $1-5 \mathrm{~Hz}(C)$ and $8-15 \mathrm{~Hz}$ stimuli $(D)$. E. Comparison of WT and NRG1 responses to $8 \mathrm{~Hz}$ stimulation. NRG1 responses were not facilitated during the first part of the response, but displayed an increased level of steady-state activity 2-3 s following stimulus onset. $F$. Steady-state adaptation ratios (2-3 s) during 8-15 Hz stimulation were increased in NRG1 mice (Mann-Whitney tests, $p<0.0001$ for all compared frequencies; Bonferroni-corrected significance level $=0.01$ ). 
(A)

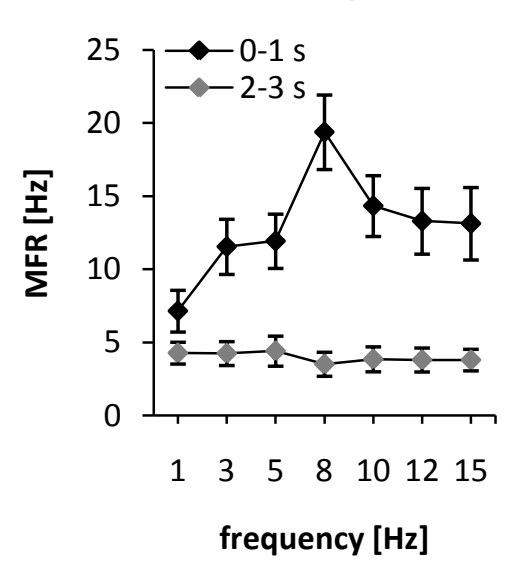

(B) NRG1 firing rate

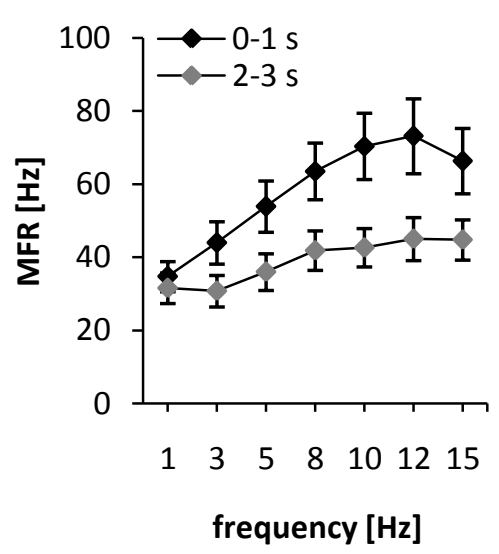

(C) adaptation

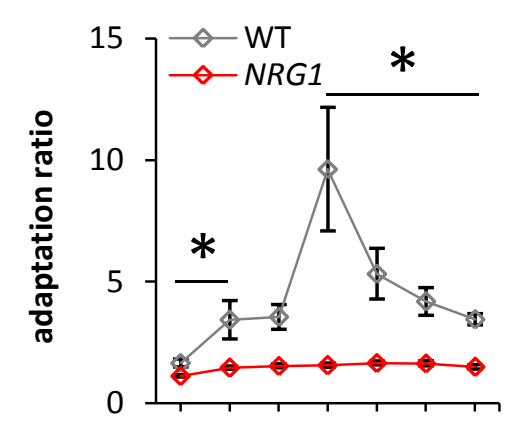

$\begin{array}{lllllll}1 & 3 & 5 & 8 & 10 & 12 & 15\end{array}$ frequency $[\mathrm{Hz}]$

FIGURE 4. Response dynamics. Firing rates during stimulation changed as a function of stimulation frequency and time. Responses were assessed during two time windows: 0-1 $\mathrm{s}$ and 2-3 $\mathrm{s}$ following stimulus onset. $A$. MFR of WT responses ( $n=11$ MUAs) differed during the first and the second time window (0-1 s: black; 2-3 s: gray). The band-pass properties around $8 \mathrm{~Hz}$ are most evident during the first second following stimulus onset. $B$. MFR of NRG1 responses ( $n=11$ MUAs) during the first and the second time window (0-1 s: black; 2-3 s: gray). Responses appeared to be less dynamically modulated than WT responses. $C$. Adaptation ratio calculated by dividing the MFR during the first time window (0-1 s) by the MFR during the second time window (2-3 s). Facilitation around $8 \mathrm{~Hz}$ was observed in WT mice but was absent in NRG1 mutants. NRG1 adaptation ratios were significantly smaller than WT ratios in all conditions with the exception of the $5 \mathrm{~Hz}$ condition (see Table 3 for details).

TABLE 3. Between-group differences in adaptation ratio. Adaptation ratio was measured by dividing the MFR 0-1 s following stimulus onset by the MFR 2-3 s following stimulus onset. The adaptation ratios of WT ( $n=11$ MUAs) and NRG1 responses ( $n=11$ MUAs) were compared per condition using Mann-Whitney tests. The mean adaptation ratio \pm SE of WT and NRG1 responses are shown as well as the Mann-Whitney $U$ and the corresponding $\mathrm{p}$ value (printed in bold if significant). Bonferronicorrected significance level $=0.007$.

\begin{tabular}{ccccc}
\hline frequency & WT ratio & NRG1 ratio & U & p \\
\hline $\mathbf{1 ~ H z}$ & $1.65 \pm 0.16$ & $1.13 \pm 0.05$ & 104 & $\mathbf{0 . 0 0 3}$ \\
$\mathbf{3 ~ H z}$ & $3.43 \pm 0.79$ & $1.46 \pm 0.07$ & 117 & $<\mathbf{0 . 0 0 0 1}$ \\
$\mathbf{5 ~ H z}$ & $3.55 \pm 0.51$ & $1.54 \pm 0.08$ & 100 & 0.008 \\
$\mathbf{8 ~ H z}$ & $9.63 \pm 2.54$ & $1.57 \pm 0.09$ & 121 & $<\mathbf{0 . 0 0 0 1}$ \\
$\mathbf{1 0 ~ H z}$ & $5.33 \pm 1.04$ & $1.66 \pm 0.08$ & 119 & $<\mathbf{0 . 0 0 0 1}$ \\
$\mathbf{1 2 ~ H z}$ & $4.18 \pm 0.57$ & $1.64 \pm 0.11$ & 121 & $<\mathbf{0 . 0 0 0 1}$ \\
$\mathbf{1 5 ~ H z}$ & $3.45 \pm 0.23$ & $1.49 \pm 0.09$ & 118 & $<\mathbf{0 . 0 0 0 1}$ \\
\hline
\end{tabular}

\subsection{Temporal fidelity of neuronal responses is reduced in NRG1 mutants}

Previous studies showed that the $8 \mathrm{~Hz}$ resonance effect in the barrel cortex is not only observed at the level of spike rates, but also at the level of phase locking, a measure of the temporal precision of 
neuronal firing (Garabedian et al., 2003). We therefore examined temporal precision across stimulation frequencies in WT and NRG1 mice. Due to the response dynamics during the course of the $3 \mathrm{~s}$ long stimulus train (see Section 4.2), analyses were performed separately for an early (0.05-1 s) and late time window (2-3 s). To avoid confounding by the onset response, the first 50 ms were excluded from the analysis of the early time window. We used two established measures for quantifying the temporal precision of neuronal responses: vector strength $r$ and temporal dispersion $d$ (Ashida et al., 2010; Ewert et al., 2008; Khatri et al., 2004). Both measures are calculated based on the phase histogram of the MUA, which displays the number of spikes during each stimulus cycle (the inter-stimulus interval) on a $0-360^{\circ}$ scale. Vector strength measures the peak of the phase histogram to evaluate the degree of phase locking (independent of the inter-stimulus interval), and temporal dispersion describes the jitter of the responses in time (taking into account the interstimulus interval). Firing is temporally precise if the vector strength is high (perfect phase locking at $r$ $=1$ ) and the temporal dispersion (measured in ms) is low (see Methods, Section 3).

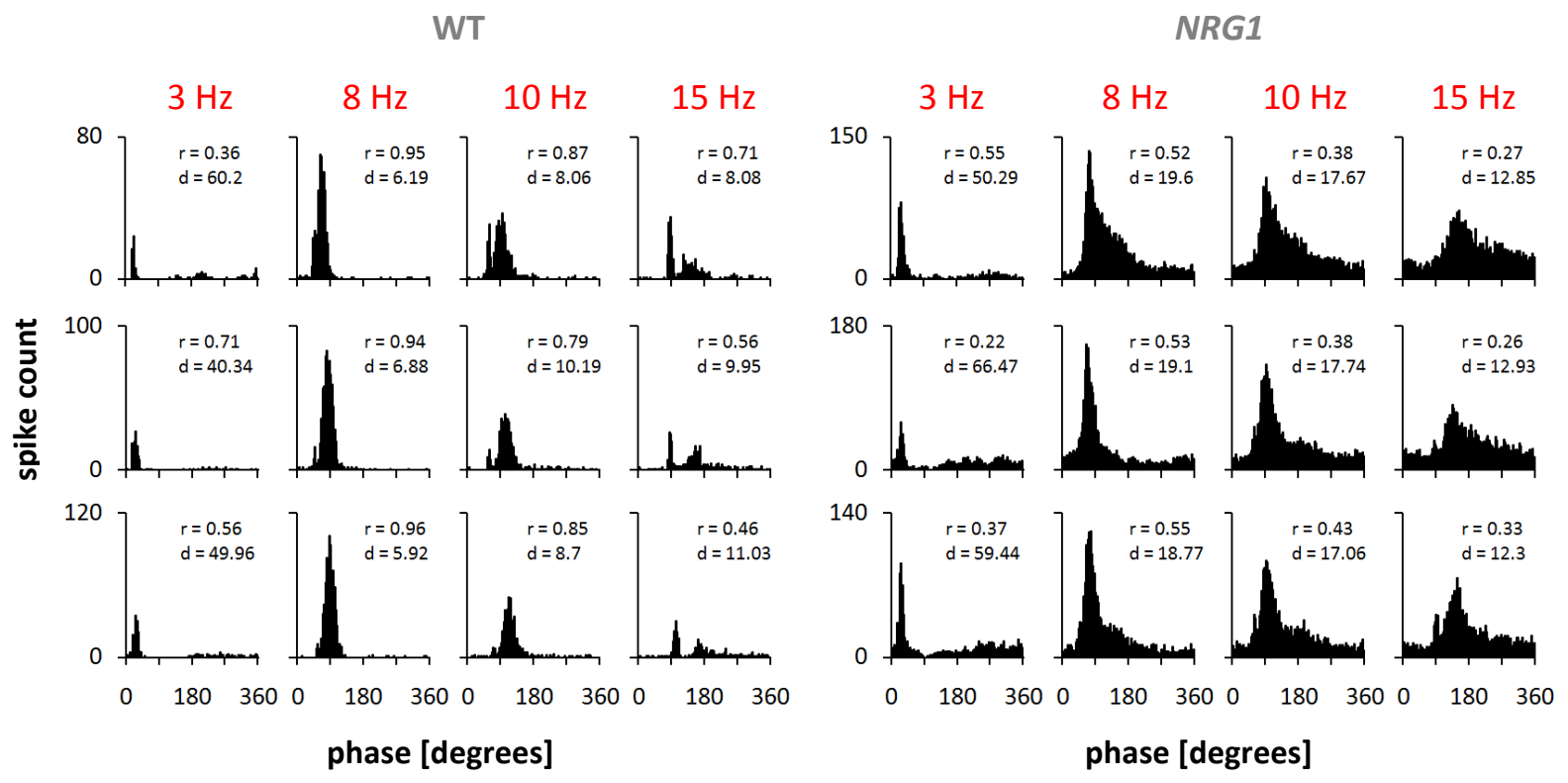

FIGURE 5. Phase histograms. Phase histograms of three representative WT MUAs (top to bottom; left panel) and NRG1 MUAs (top to bottom; right panel) in response to four example stimuli (left to right). The same MUAs as shown as in Figure 1A,B. Histograms were calculated for responses 0.05-1 $s$ post stimulus onset. Vector strength $r$ and temporal dispersion $d[\mathrm{~ms}]$ are displayed for each histogram. NRG1 responses were more noisy and therefore less phase-locked than WT responses.

During the early time window (0.05-1 s), phase histograms of both WT and NRG1 mice showed a peak in the distribution of spikes at $8-10 \mathrm{~Hz}$, indicating good phase locking (Fig. 5). At the population level, both groups displayed a resonance effect around $8 \mathrm{~Hz}$ (Fig. 6A). However, vector 
strength was lower for NRG1 mice than for WT mice in the 5-15 Hz conditions, with the largest reduction at $8 \mathrm{~Hz}$ (t-test, $\mathrm{p}<0.0001$; Table 6). Similarly, temporal dispersion was high in NRG1 mutants in the $5-15 \mathrm{~Hz}$ range (Fig. 6B), with the largest difference compared to WT levels in the $8 \mathrm{~Hz}$ condition ( $t$-test, $p<0.0001 ;$ Table 7). These data suggest an impaired temporal precision of neuronal firing in NRG1 animals in the resonance frequency band during the first part of the response (0.05-1 s).

(A.1)

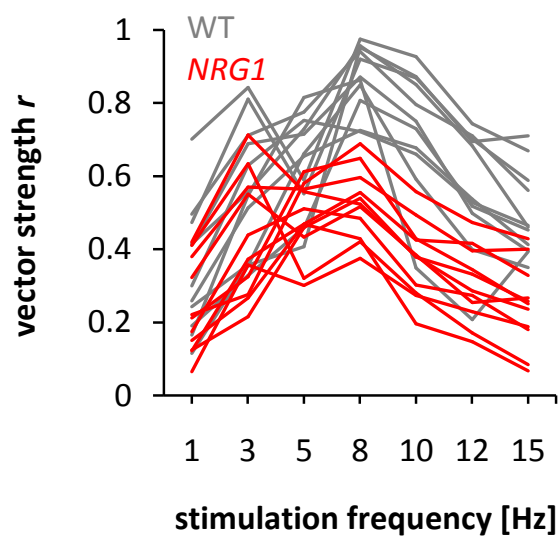

(A.2)

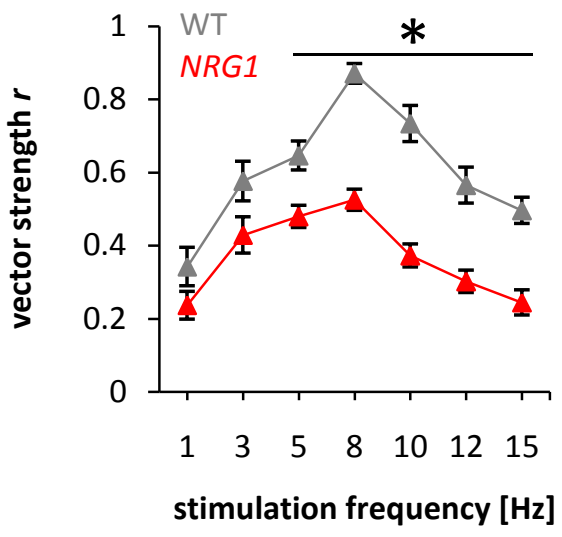

(B.1) temporal dispersion

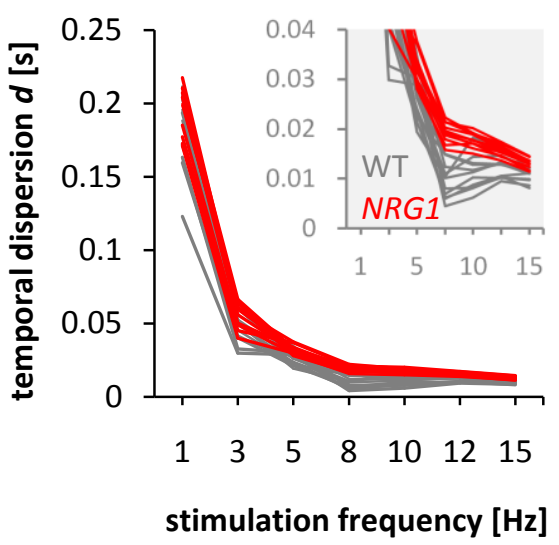

(B.2)

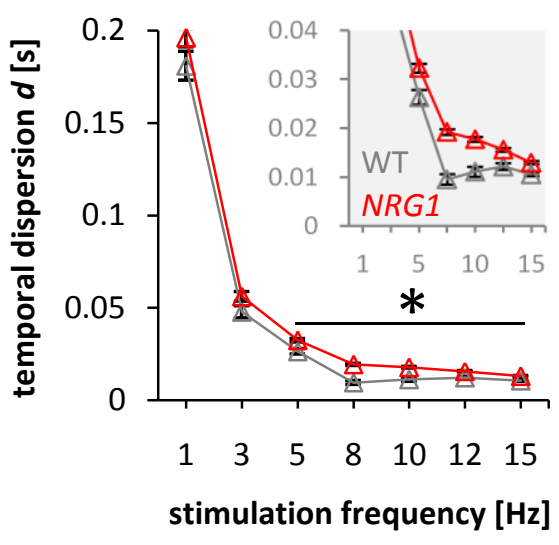

FIGURE 6. Temporal precision of neuronal firing 0.05-1 s post stimulus onset. Measures of phase locking (vector strength; left column) and temporal dispersion (right column) were calculated for 11 WT (gray traces) and 11 NRG1 MUAs (red traces). A. Vector strength for each MUA (A1) and for the population (A2) across stimulation conditions. NRG1 mice showed a generally reduced level of phase locking, with the biggest reduction compared to WT responses at $8 \mathrm{~Hz}$ (see Table 6 for details). $B$. Temporal dispersion for each MUA (B1) and the population (B2) across stimulation conditions. Insets show same data at a different scale. NRG1 mice displayed higher levels of temporal dispersion, indicating lower temporal precision, particularly in the $8 \mathrm{~Hz}$ and $10 \mathrm{~Hz}$ conditions (see Table 7 for details). * Significant between-group differences. 
TABLE 6. Between-group differences in vector strength measured 0.05-1 s post stimulus onset. Group differences were assessed per condition using unpaired t-tests. The mean vector strength $r \pm$ SE of WT $(n=11)$ and NRG1 responses $(n=11)$ are shown as well as the t statistic, the degrees of freedom (df) and the corresponding $p$ value (in bold for significant differences). Bonferroni-corrected significance level: $p=0.007$.

\begin{tabular}{ccccc}
\hline frequency & $\mathbf{W T} \boldsymbol{r}$ & $\mathbf{N R G 1} \boldsymbol{r}$ & $\mathbf{t}$ (df) & $\mathbf{p}$ \\
\hline $\mathbf{1 ~ H z}$ & $0.34 \pm 0.05$ & $0.24 \pm 0.04$ & $1.6(20)$ & 0.118 \\
$\mathbf{3 ~ H z}$ & $0.58 \pm 0.05$ & $0.43 \pm 0.05$ & $2.0(20)$ & 0.059 \\
$\mathbf{5 ~ H z}$ & $0.65 \pm 0.04$ & $0.48 \pm 0.03$ & $3.3(20)$ & $\mathbf{0 . 0 0 3}$ \\
$\mathbf{8 ~ H z}$ & $0.87 \pm 0.03$ & $0.53 \pm 0.03$ & $8.7(20)$ & $<\mathbf{0 . 0 0 0 1}$ \\
$\mathbf{1 0 ~ H z}$ & $0.73 \pm 0.05$ & $0.37 \pm 0.03$ & $6.2(20)$ & $<\mathbf{0 . 0 0 0 1}$ \\
$\mathbf{1 2 ~ H z}$ & $0.57 \pm 0.05$ & $0.30 \pm 0.03$ & $4.5(20)$ & $<\mathbf{0 . 0 0 1}$ \\
$\mathbf{1 5 ~ H z}$ & $0.50 \pm 0.04$ & $0.43 \pm 0.03$ & $5.1(20)$ & $<\mathbf{0 . 0 0 0 1}$ \\
\hline
\end{tabular}

TABLE 7. Between-group differences in temporal dispersion 0.05-1 $\mathrm{s}$ following stimulus onset. Unpaired t-tests were used for comparing temporal dispersion of WT ( $\mathrm{n}=11 \mathrm{MUAs}$ ) and NRG1 responses ( $n=11$ MUAs) per condition. Shown are the mean temporal dispersion $d \pm S E$ for WT and $N R G 1$ responses, the t-statistic, degrees of freedom (df) and the corresponding $\mathrm{p}$ value (in bold to indicate significance). Bonferroni-corrected significance level: $p=0.007$.

\begin{tabular}{ccccc}
\hline frequency & $\mathbf{W T} \boldsymbol{d}[\mathbf{m s}]$ & NRG1 $\boldsymbol{d}[\mathrm{ms}]$ & $\mathbf{t}(\mathbf{d f})$ & $\mathbf{p}$ \\
\hline $\mathbf{1 ~ H z}$ & $180.85 \pm 7.81$ & $196.05 \pm 4.99$ & $-1.6(20)$ & 0.117 \\
$\mathbf{3 ~ H z}$ & $47.74 \pm 3.27$ & $56.11 \pm 2.59$ & $-2.0(20)$ & 0.059 \\
$\mathbf{5 ~ H z}$ & $26.37 \pm 1.47$ & $32.34 \pm 0.93$ & $-3.4(20)$ & $\mathbf{0 . 0 0 3}$ \\
$\mathbf{8 ~ H z}$ & $9.54 \pm 1.07$ & $19.30 \pm 0.60$ & $-7.9(20)$ & $<\mathbf{0 . 0 0 0 1}$ \\
$\mathbf{1 0 ~ H z}$ & $11.15 \pm 1.03$ & $17.77 \pm 0.45$ & $-5.9(20)$ & $<\mathbf{0 . 0 0 0 1}$ \\
$\mathbf{1 2 ~ H z}$ & $12.19 \pm 0.67$ & $15.63 \pm 0.35$ & $-4.6(20)$ & $<\mathbf{0 . 0 0 1}$ \\
$\mathbf{1 5 ~ H z}$ & $10.58 \pm 0.40$ & $13.01 \pm 0.30$ & $-4.9(20)$ & $<\mathbf{0 . 0 0 0 1}$ \\
\hline
\end{tabular}

During the late time window, 2-3 s after stimulus onset, phase locking (Fig. 7A) and temporal dispersion (Fig. 7B) were differently modulated by frequency compared to the early time window. Maximal phase locking occurred at $3 \mathrm{~Hz}$ in WT mice and at 3-5 Hz in NRG1 mice. In this frequency range, NRG1 responses showed lower vector strength than WT responses ( $t$ tests, $p \leq 0.007$; Table 8), and higher temporal dispersion (t tests, $p \leq 0.005$; Table 9). In addition, decreased phase locking and increased temporal dispersion of NRG1 responses was also found in the $12 \mathrm{~Hz}$ condition. Of note, the MFR was generally lower during the 2-3 s window, and some WT MUAs did not accumulate a sufficient number of spikes in their phase histograms, particularly in the low frequency conditions that naturally had a lower number of stimulus cycles (see Methods, Section 3 and Chapter II). In 
these instances, vector strength and temporal dispersion values were excluded from the analysis, as indicated in Table 8 and $\mathbf{9 .}$

In summary, the analyses revealed that the $8 \mathrm{~Hz}$ resonance effect, as described at the level of firing rates, was also present at the level of temporal precision, but only during the early time window. In NRG1 mice, neuronal responses were less precisely timed than in WT mice, and the greatest deficits occurred around $8 \mathrm{~Hz}$.

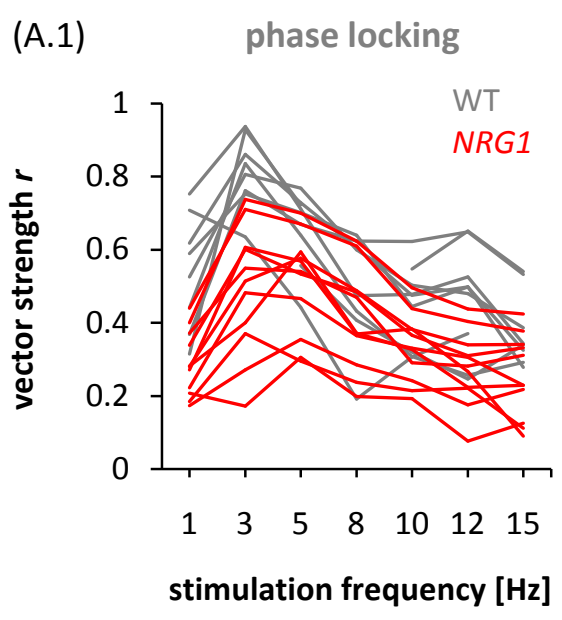

(A.2)

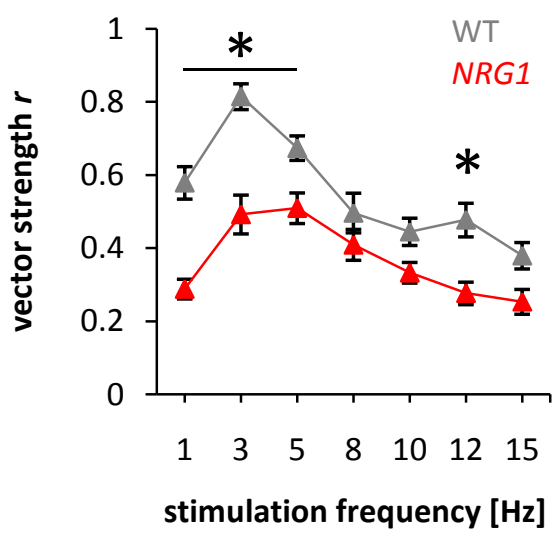

(B.1) temporal dispersion

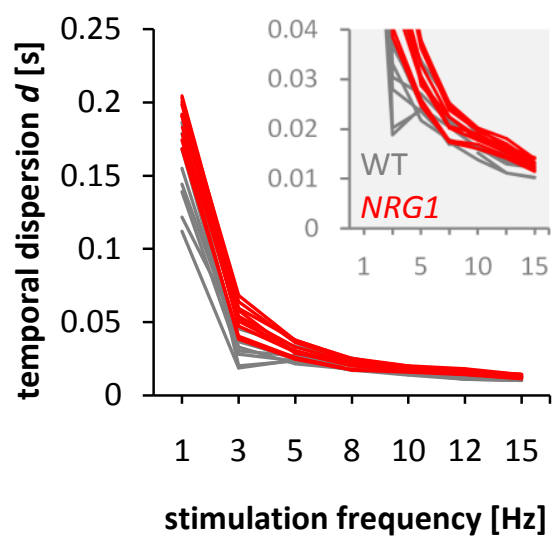

(B.2)

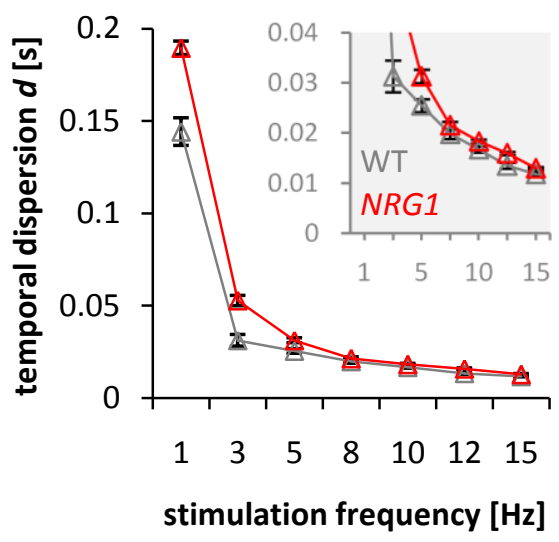

FIGURE 7. Temporal precision of firing rates 2-3 s post stimulus onset. Phase locking (vector strength; left column) and temporal dispersion (right column) were assessed for WT (gray traces) and NRG1 MUAs (red traces; same as in Fig. 6). A. Vector strength for each MUA (A1) and for the population (A2) across stimulation conditions (WT: $\mathrm{n}=11 ; N R G 1: \mathrm{n}=11$ MUAs). Vector strength in $N R G 1$ animals was reduced compared to WT mice in several conditions, with the largest reduction at $1 \mathrm{~Hz}$ (see Table 8 for details). B. Temporal dispersion for each MUA (B1) and the population (B2) in each stimulation condition (WT: $\mathrm{n}=8-11 ; N R G 1: \mathrm{n}=11$ MUAs). Insets show same data at a different scale. Temporal dispersion was increased in NRG1 mutants relative to WT animals, especially at $1 \mathrm{~Hz}$ and $3 \mathrm{~Hz}$ (see Table 9 for details and further information on the number of MUAs included in the comparison). * Significant between-group differences. 
TABLE 8. Between-group comparisons of vector strength measured 2-3 s post stimulus onset. Group differences were evaluated per condition with unpaired t-tests. The mean vector strength $r \pm \mathrm{SE}$ of WT and NRG1 responses are shown as well as the number of MUAs (n), the $t$ statistic, the degrees of freedom (df) and the corresponding $p$ value (in bold for significant differences). Of note, up to 3 WT MUAs were excluded from the analysis since their phase histograms did not have the required number of spikes for statistical analysis (see Methods). Bonferroni-corrected significance level: $p=$ 0.007 .

\begin{tabular}{ccccccc}
\hline frequency & $\mathbf{W T} \boldsymbol{r}$ & $\mathbf{N R G 1} \boldsymbol{r}$ & $\mathbf{W T} \mathbf{n}$ & $\mathbf{N R G 1} \mathbf{n}$ & $\mathbf{t}(\mathbf{d f})$ & $\mathbf{p}$ \\
\hline $\mathbf{1 ~ H z}$ & $0.58 \pm 0.04$ & $0.29 \pm 0.03$ & 11 & 11 & $5.6(20)$ & $<\mathbf{0 . 0 0 0 1}$ \\
$\mathbf{3 ~ H z}$ & $0.81 \pm 0.04$ & $0.49 \pm 0.05$ & 8 & 11 & $4.6(17)$ & $<\mathbf{0 . 0 0 1}$ \\
$\mathbf{5 ~ H z}$ & $0.67 \pm 0.03$ & $0.51 \pm 0.04$ & 10 & 11 & $1.3(19)$ & $\mathbf{0 . 0 0 7}$ \\
$\mathbf{8} \mathbf{~ H z}$ & $0.50 \pm 0.05$ & $0.41 \pm 0.04$ & 8 & 11 & $1.3(17)$ & 0.216 \\
$\mathbf{1 0 ~ H z}$ & $0.45 \pm 0.04$ & $0.33 \pm 0.03$ & 9 & 11 & $2.4(18)$ & 0.026 \\
$\mathbf{1 2} \mathbf{~ H z}$ & $0.48 \pm 0.05$ & $0.28 \pm 0.03$ & 10 & 11 & $3.7(19)$ & $\mathbf{0 . 0 0 2}$ \\
$\mathbf{1 5 ~ H z}$ & $0.38 \pm 0.04$ & $0.25 \pm 0.03$ & 8 & 11 & $2.5(17)$ & 0.023 \\
\hline
\end{tabular}

TABLE 9. Between-group differences in temporal dispersion 2-3 s following stimulus onset. Temporal dispersion $d$ of WT $(n=8-11)$ and NRG1 $(n=11)$ responses were compared per condition in each group using unpaired t-tests. Shown are the mean temporal dispersion $d \pm$ SE for WT and NRG1 responses, the number of MUAs, the t-statistic, degrees of freedom (df) and the corresponding $p$ value (in bold to indicate significance). Of note, some WT MUAs were excluded from the analysis since their phase histograms lacked the required number of spikes for statistical analysis (see Methods). Bonferroni-corrected significance level: $p=0.007$.

\begin{tabular}{ccccccc}
\hline frequency & $\mathbf{W T} \boldsymbol{d}[\mathrm{ms}]$ & $\mathbf{N R G 1} \boldsymbol{d}[\mathrm{ms}]$ & $\mathbf{W T} \mathbf{n}$ & $\mathbf{N R G 1} \mathbf{n}$ & $\mathbf{t}(\mathbf{d f})$ & $\mathbf{p}$ \\
\hline $\mathbf{1 ~ H z}$ & $144.18 \pm 7.48$ & $189.55 \pm 3.64$ & 11 & 11 & $-5.5(20)$ & $<\mathbf{0 . 0 0 0 1}$ \\
$\mathbf{3 ~ H z}$ & $31.23 \pm 3.16$ & $52.73 \pm 2.81$ & 8 & 11 & $-5.1(17)$ & $<\mathbf{0 . 0 0 0 1}$ \\
$\mathbf{5 ~ H z}$ & $25.44 \pm 1.25$ & $31.25 \pm 1.33$ & 10 & 11 & $-3.2(19)$ & $\mathbf{0 . 0 0 5}$ \\
$\mathbf{8 ~ H z}$ & $19.78 \pm 1.03$ & $21.48 \pm 0.79$ & 8 & 11 & $-1.3(17)$ & 0.20 \\
$\mathbf{1 0 ~ H z}$ & $16.70 \pm 0.57$ & $18.34 \pm 0.39$ & 9 & 11 & $-2.5(18)$ & 0.025 \\
$\mathbf{1 2 ~ H z}$ & $13.45 \pm 0.59$ & $15.92 \pm 0.34$ & 10 & 11 & $-3.7(19)$ & $\mathbf{0 . 0 0 1}$ \\
$\mathbf{1 5} \mathbf{~ H z}$ & $11.78 \pm 0.36$ & $12.93 \pm 0.30$ & 8 & 11 & $-2.5(17)$ & 0.023 \\
\hline
\end{tabular}

\subsection{NRG1 mice show normal barrel cortex patterning}

Since NRG1 is a gene that regulates thalamocortical axon guidance and neuronal migration during development (Mei and Xiong, 2008), we wanted to assure that gross anatomical features of the barrel cortex were comparable between NRG1 mutants and control mice. Barrels consist of a barrel 'wall' and a barrel center, or 'hollow'. The wall is made of densely packed neurons that project to the barrel center, while the hollow mainly contains axon bundles from the thalamus (Inan and Crair, 2007). We performed cytochrome oxidase stainings to visualize barrel hollows, as previously 
described (Golshani et al., 2005; Land and Simons, 1985). Tangential sections through layer IV of the postero-medial barrel subfield were cut to expose the barrel pattern in mutants $(n=2)$ and WT mice $(n=2)$. Visual inspection of the barrel arrays revealed no abnormal morphological characteristics in NRG1 mutants (Fig. 8).

WT

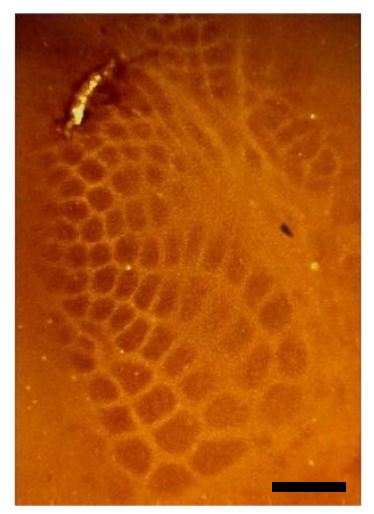

WT

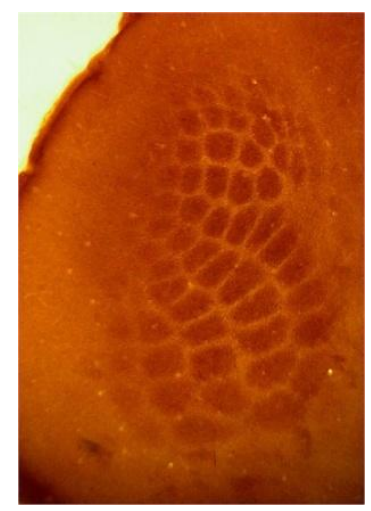

NRG1

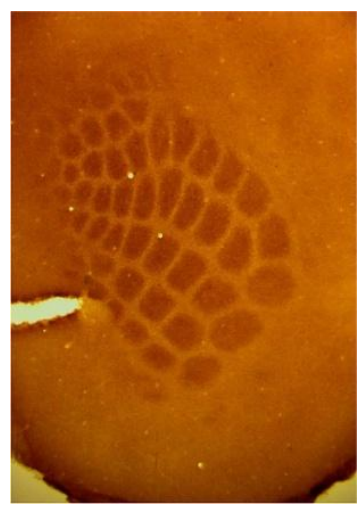

NRG1

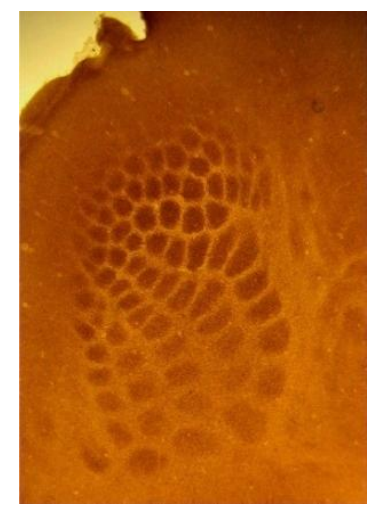

FIGURE 8. Barrel cortex gross morphology. Cytochrome oxidase staining of tangential slices from two WT (left) and two NRG1 animals (right). Mutant barrel anatomy resembles the WT morphology. Scale bar: $0.5 \mathrm{~mm}$.

\section{Discussion}

In the present study, we characterized sustained whisker-evoked responses in the NRG1 mouse model of schizophrenia to investigate potential disturbances of somatosensory resonance properties and their cellular correlates. Whiskers were stimulated repetitively with air puffs applied at 1-15 Hz, which corresponds to the typical whisking frequency range in mice (Kiryakova et al., 2010; Mitchinson et al., 2011; Söhnchen et al., 2010; Wesson et al., 2008). We presented four main results. First, NRG1 mutants showed increased stimulus-evoked and baseline firing rates, which led us to normalize evoked firing to spontaneous firing and thus express neuronal activity in terms of an SNR. We found that NRG1 onset responses (0-0.05 s) were significantly reduced in SNR across all conditions, and sustained responses (0.05-3 s) showed reduced SNR at 1, 3 and $8 \mathrm{~Hz}$ stimulation. Second, we found that firing rates in NRG1 mice displayed altered adaptation patterns, particularly in response to $8 \mathrm{~Hz}$. These patterns differed during the first part of the response $(0-1 \mathrm{~s})$ and the last part of the response (2-3 s). Third, we measured temporal fidelity (vector strength and temporal dispersion) of neuronal responses during the first and last part of the response. During the first time window (0.05-1 s), WT responses showed the highest temporal precision at $8 \mathrm{~Hz}$, while $N R G 1$ responses showed reduced precision in the $5-15 \mathrm{~Hz}$ range. During the second time window (2-3 s), 
WT responses were most precise at 1-3 Hz, while $N R G 1$ responses showed significantly reduced temporal fidelity in this range. Finally, our preliminary results suggest that aberrant responses in NRG1 mice cannot be explained by differences in gross anatomical features.

The findings can be interpreted in the context of whisking-related behaviors in mice and in the context of neuronal circuit abnormalities reminiscent of schizophrenia. We argue that (1) WT responses are tuned to behaviorally relevant frequency ranges, (2) NRG1 responses are less tuned and may thus impair optimal somatosensory stimulus processing, and (3) NRG1 response abnormalities are consistent with an imbalance in excitatory-inhibitory circuitry, possibly reflecting schizophrenia-related disease mechanisms.

\subsection{Whisking behavior and frequency tuning of barrel cortex responses}

Rodents whisk preferentially at frequencies between 8 and $10 \mathrm{~Hz}$ during exploration and around 3 $\mathrm{Hz}$ during rest (Cao et al., 2012; Harvey, 2001; Moore et al., 1999; Söhnchen et al., 2010). The frequencies of whisker motion during active and quiet behavioral states might serve optimal stimulus discrimination and detection, respectively (Moore et al., 1999; Moore, 2004; Nicolelis and Fanselow, 2002). Evidence from rat studies indicates that barrel cortex responses might be specifically tuned to these frequency ranges. Responses to low frequency stimulation (1-3 Hz) display no or little adaptation (Garabedian et al., 2003; Khatri et al., 2004) and are wide-spread in the cortex (Sheth et al., 1998), thus favoring stimulus detection. In contrast, high frequency $(5-10 \mathrm{~Hz})$ stimulation results in robust response adaptation (Ahissar et al., 2001; Chung et al., 2002; Khatri et al., 2004; Simons, 1978), which facilitates stimulus discrimination (Maravall et al., 2007). In addition, high frequency stimulation limits the spread of the cortical response (Sheth et al., 1998), decreases receptive field size (Katz et al., 2006), and sharpens angular tuning (Khatri and Simons, 2007). Thus, maximal contrast between input from the principal whisker and input from adjacent whiskers is achieved (Moore et al., 1999). Moreover, barrel cortex responses show augmentation in firing rate and phase locking at 5-10 Hz stimulation (Garabedian et al., 2003; Melzer et al., 2006; see also Chapter III), indicating cellular band-pass characteristics in this behaviorally relevant frequency range.

Several aspects of our data suggest that, similar to rat, WT barrel cortex responses also show specific tuning to low $(1-3 \mathrm{~Hz})$ and high $(8 \mathrm{~Hz})$ frequencies. First, in response to 1-15 Hz stimulation, WT MUAs displayed the highest (sustained) spike rates at $8 \mathrm{~Hz}$ (Fig. 2A, right panel, inset). When responses were normalized to baseline firing to calculate the SNR, they also showed the highest values at $8 \mathrm{~Hz}$ stimulation (Fig. 2C, right panel). We further demonstrated that the increase in firing rate was related to the response facilitation mainly during the first 600 ms after stimulus onset (Fig. 3B and 4A). During the last part of the response (2-3 s), this frequency-specific modulation in firing 
rate was not observed (Fig. 4A). Previous studies (Garabedian et al., 2003) reported elevated firing rates in response to $8-10 \mathrm{~Hz}$ during the last part of the response (1-5 s), but did not analyze the first second. Differences in response dynamics between previous reports and our results might stem from differences in the anesthetic regimen, which may influence the cortical state and thus alter adaptation (Castro-Alamancos, 2004). Despite these differences, our results show a preferential processing of $8 \mathrm{~Hz}$ stimuli, which is in agreement with earlier findings in rats (Garabedian et al., 2003) and BL6 mice (Chapter III), and supports the idea that barrel cortex neurons are tuned to exploratory whisking frequencies.

Second, WT mice exhibited no adaptation at $1 \mathrm{~Hz}$ and an increasing degree of adaptation with increasing stimulus frequencies (Fig. 3A,B). Even during $8 \mathrm{~Hz}$ stimulation, robust adaptation was observed after the first $600 \mathrm{~ms}$. Differences in adaptation at low and high frequencies have been previously shown in rats (Ahissar et al., 2001; Chung et al., 2002; Garabedian et al., 2003; Khatri et al., 2004; Simons, 1978). Sensory adaptation has been suggested to increase the efficiency of the neural code (Fairhall et al., 2001; Maravall et al., 2007; Wark et al., 2007), and to enhance performance to detect and discriminate stimuli (Kohn and Whitsel, 2002; Maravall et al., 2007; Moore et al., 1999).

Third, WT responses displayed modulations in their vector strength and temporal dispersion that were contingent on the stimulation frequency and the response window. During the first time window, 0.05-1 s after stimulus onset, WT MUAs displayed the highest vector strength values and thus the strongest phase locking in response to $8 \mathrm{~Hz}$ stimulation (Fig. 6A). During the second time window, 2-3 s after stimulus onset, phase locking was strongest at 3-5 $\mathrm{Hz}$ stimulation (Fig. 7A). Studies in rats demonstrated high temporal precision at $8-10 \mathrm{~Hz}$ during the last part of the response (1-5 s), but the first second was not analyzed (Garabedian et al., 2003). One possible explanation for this discrepancy might be differences in species and anesthesia, which may affect response dynamics. Our data in BL6 mice (Chapter III), obtained under the same anesthesia regimen, show similar phase locking dynamics as observed in WT mice. Another possibility is the choice of the time window across which the phase histogram is calculated that may determine the frequency for which the highest vector strength is observed. In our data set, we found that calculating phase histograms across the entire stimulus duration (0.05-3 s, excluding response onset) still results in a peak in vector strength at $8 \mathrm{~Hz}$, but masks a second peak at $3 \mathrm{~Hz}$ (data not shown). Thus, the results described by Garabedian and colleagues do not necessarily argue against a peak in vector strength at $3 \mathrm{~Hz}$ in addition to a peak around $8 \mathrm{~Hz}$. In light of the behavioral importance of these frequency ranges (Moore et al., 1999; Nicolelis and Fanselow, 2002), our results indicate that the temporal precision of neuronal firing is dynamically modulated, and may optimize the system for stimulus 
discrimination during the first part of the response (0-1 s) and for stimulus detection during later parts of the response (2-3 s).

In contrast to WT responses, NRG1 responses lacked several features of frequency-specific tuning, indicating suboptimal stimulus processing in the whisking frequency range, and possibly deficits in stimulus detection and discrimination. First, NRG1 sustained responses increased in MFR and SNR with increasing stimulus frequency, but did not show an $8 \mathrm{~Hz}$-specific augmentation (Fig. $2 A, C$ right panel). Instead, responses seemed to plateau at 8-15 Hz stimulation. Thus, the tuning of $N R G 1$ activity to the exploratory whisking frequency range was, if present, much broader and more subtle than in WT mice.

Second, NRG1 responses showed different response and adaptation dynamics than WT responses. In particular, NRG1 activity did not show facilitation during the first $600 \mathrm{~ms}$ in the $8 \mathrm{~Hz}$ condition (Fig. 3E and 4B), but an augmented state of adaptation (2-3 s post stimulus onset) in the 8$15 \mathrm{~Hz}$ conditions (Fig. 3F and 4B). Our data do not allow any conclusions about the implications of the lack of $8 \mathrm{~Hz}$ facilitation. However, in the context of the other findings (MFR and SNR), the data may be interpreted as a diminished amplification of signals in the exploratory whisking range. With regard to adaptation, research suggests that it reflects an effective coding of stimulus features by scaling neuronal output to stimulus features (Diaz-Quesada and Maravall, 2008; Maravall et al., 2007). Adaptation may thus enhance the detection of small changes in stimulus characteristics (Kohn and Whitsel, 2002; Wark et al., 2007) and facilitate texture discrimination (Arabzadeh et al., 2003). Hence, a reduced level of adaptation in NRG1 mice might indicate impaired coding and altered somatosensory representations.

Third, NRG1 responses were characterized by reduced temporal precision. During the first time window (0.05-1 s), NRG1 MUAs showed lower vector strength values than WT mice in the 5-15 $\mathrm{Hz}$ conditions, with the largest impairments seen in response to 8-10 Hz stimulation (Fig. 6A). During the second time window (2-3 s), NRG1 vector strength was reduced in the 1-5 Hz and $12 \mathrm{~Hz}$ conditions, with the largest reduction in the $1-3 \mathrm{~Hz}$ range (Fig. 7A). In line with these findings, NRG1 responses were more temporally dispersed in the 5-15 Hz range during the first time window (Fig. 6B). During the second time window, NRG1 responses were more temporally dispersed at 1-5 $\mathrm{Hz}$ and $12 \mathrm{~Hz}$ stimulation, with the largest dispersion occurring at $1 \mathrm{~Hz}$ and $3 \mathrm{~Hz}$ (Fig. 7B). Neuronal firing with high temporal precision has been associated with coding of vibrotactile information in rats (Arabzadeh et al., 2005; Deschênes et al., 2003; Ewert et al., 2008; Jones et al., 2004; Khatri et al., 2004; Melzer et al., 2006) and may serve to enhance tactile detection and discrimination (Arabzadeh et al., 2005; Panzeri and Diamond, 2010). Thus, the decreased temporal fidelity of NRG1 activity may reflect impaired temporal coding, which may result in poor stimulus detection and discrimination. 
Taken together, our findings demonstrate weaker vibrotactile coding in NRG1 mice with attenuated band-pass characteristics in frequency ranges relevant to stimulus detection and discrimination. This is the first report of impaired neuronal coding of frequency-modulated somatosensory information after manipulation of a schizophrenia risk gene, raising the possibility that similar mechanisms might contribute to deficits in somatosensory stimulus processing in schizophrenic patients and their relatives (Chang and Lenzenweger, 2001, 2004, 2005; Huang et al., 2010; Peled et al., 2003; Rosenbaum et al., 1965). Further research is needed to investigate how the neuronal deficits in the mutants affect their behavior, e.g. in somatosensory-based tasks.

\subsection{Neuronal circuit abnormalities in schizophrenia and in the NRG1 mouse model}

An imbalance in excitatory-inhibitory circuitry has been suggested as a cellular mechanism to account for predominantly cognitive dysfunctions in schizophrenia (Lewis et al., 2005; Lisman, 2012; Wang, 2006). This hypothesis is based on the observation in schizophrenic patients of changes in neuronal morphology and density (Beasley and Reynolds, 1997; Benes et al., 1991; Daviss and Lewis, 1995; Kalus et al., 1999), gene expression (Akbarian et al., 1995; Eastwood et al., 1995; Harrison et al., 1991; Hashimoto et al., 2003; Humphries et al., 1996; Volk et al., 2000; Volk et al., 2001) and neurotransmission (Bartha et al., 1997; Hahn et al., 2006; Kegeles et al., 2012; Marsman et al., 2013; Perry et al., 1979; Sherman et al., 1991) that impact excitatory and inhibitory signaling. Most of these changes were noted in the prefrontal cortex, which is important for cognitive functioning, including attention, memory, and social behavior. Based on modeling studies (Brunel and Wang, 2001; Durstewitz et al., 2000), it has been suggested that a direct consequence of altered excitatoryinhibitory circuitry is a diminished ratio of evoked to spontaneous activity, or SNR, in schizophrenia (Rolls et al., 2008; Winterer and Weinberger, 2004). In support of this idea, schizophrenic patients were shown to have a reduced SNR in an auditory task, which was accompanied by alterations in phase coherence (Winterer et al., 2000). In addition, increased noise power in prefrontal cortex was shown to correlate with cognitive performance during an auditory task (Winterer et al., 2004) and with prefrontal cortex activation levels during a visual task (Winterer et al., 2006). Animal studies have further corroborated the hypothesis that manipulating excitatory and/or inhibitory signaling has various downstream effects such as impairments in SNR (Gandal et al., 2012b; Saunders et al., 2012) and phase locking (Sivarao et al., 2013), which may ultimately contribute to cognitive and behavioral deficits (Gandal et al., 2012b; Yizhar et al., 2011).

Our results in the NRG1 mouse model of schizophrenia suggest that similar mechanisms might be at play in the somatosensory cortex. First, accumulating evidence indicates that the excitatory-inhibitory balance might be perturbed in NRG1 mutant mice (Marín, 2012; Mei and Xiong, 2008). Specifically, studies show that signaling of NRG1 and its receptor ErbB4 are required for the 
formation of excitatory synapses onto inhibitory cells (Ting et al., 2011) and the formation of inhibitory synapses onto excitatory cells (Fazzari et al., 2010). Furthermore, NRG1 plays a role in the inhibition of pyramidal neurons by stimulating gamma-aminobutyric acid (GABA) release from interneurons (Wen et al., 2010). Based on these findings, it may be hypothesized that NRG1 mutant mice suffer both from reduced inhibition due to a lack of excitatory drive to inhibitory cells and from increased levels of excitation due to a lack of inhibitory input to excitatory cells.

Another deficit in NRG1 mutants that parallels findings in schizophrenic subjects is the reduction in SNR. Mutants displayed a decreased ratio of evoked-to-spontaneous activity both during the onset response and the sustained response (Fig. 2C). In addition, we observed a significant elevation in spontaneous activity in mutants (Fig. 1B and 2B) compared to WT mice, indicating an increased level of noise. Our experimental findings in NRG1 mice are in close agreement with the modeling study by Vogels and Abbott who simulated the response of a hyperexcitable neuronal network with weakened inhibition to an incoming signal (Vogels and Abbott, 2007). The authors showed that firing rates were increased in baseline conditions in the absence of stimulation. Intriguingly, firing rates were also abnormally elevated in the presence of the signal. This finding matches our data showing increased MFR in NRG1 animals. Although the neuronal network model was intended to represent prefrontal cortex dysfunction, it is possible that similar disease mechanisms are present in the somatosensory cortex due to the similar architecture of both cortices and the pervasiveness of excitatory-inhibitory deregulation in schizophrenia.

Furthermore, our data indicate that deficits in adaptation could be another consequence of an excitatory-inhibitory imbalance and thus a potential mechanism for abnormal responses in schizophrenia. In particular, deficient adaptation in NRG1 mutants was characterized by altered adaptation dynamics (Fig. 4) as well as augmented steady-state responses in the 8-15 Hz conditions (Fig. 3F). Previous research demonstrated that adaptation depends on the balanced interplay of excitation and inhibition (Heiss et al., 2008; Higley and Contreras, 2006), and that perturbing the balance leads to elevated steady-state responses (Garabedian et al., 2003). Moreover, adaptation has been shown to increase the efficiency of neuronal encoding of somatosensory stimuli (Adibi et al., 2013; Davies et al., 2012; Diaz-Quesada and Maravall, 2008; Maravall et al., 2007).

To the best of our knowledge, no direct evidence exists yet about adaptation dynamics in schizophrenia. Nevertheless, two lines of evidence might be interpreted to suggest possible adaptation abnormalities in schizophrenic subjects. First, both the pre-pulse inhibition (PPI) of the startle response and the reduction of the P50 auditory-evoked response associated with it are reportedly decreased schizophrenic patients (Adler, 1982; Braff et al., 1978; Braff et al., 1992; Freedman et al., 1991; Light and Braff, 1999). Typically, when the interval between the first, weaker 
stimulus and the second, high intensity stimulus was $8.3 \mathrm{~Hz}$ or $16.7 \mathrm{~Hz}$, most studies observed PPI deficits in schizophrenic patients (Lang, 2005; pp 98-104) and in healthy subjects carrying certain variants of the NRG1 gene (Hong et al., 2008; Roussos et al., 2011). Despite these results, the PPI paradigm may not be best suited to study adaptation because it employs only two stimuli instead of a stimulus train, the stimuli have different intensities, and they are presented at a limited range of frequencies. In addition, PPI is mediated by brain-stem circuits (Fendt et al., 2001) and may therefore not be directly related to cortical adaptation.

In a second line of evidence indicating potential adaptation deficits in patients, researchers did employ stimulus trains at various frequencies and fixed intensities to measure oscillatory steadystate responses in different sensory domains (Brenner et al., 2009; Vialatte et al., 2010). However, responses were analyzed mainly in the frequency domain and expressed as signal power, which renders an analysis of adaptation dynamics challenging. Studies employing this paradigm showed steady-state response abnormalities with electroencephalography (EEG) at $40 \mathrm{~Hz}$ auditory stimulation (Krishnan et al., 2009; Light et al., 2006) and with magnetoencephalography (MEG) at 25 $\mathrm{Hz}$ somatosensory stimulation (Teale et al., 2013). In the visual system, where cortical responses are tuned to $8 \mathrm{~Hz}$ stimuli in normal subjects (Emir et al., 2008), schizophrenia patients showed reduced EEG responses in the 8-12 Hz range (Jin et al., 2000; Rice et al., 1989), and also at higher frequencies (Krishnan et al., 2005). The exact relationship between amplitude measures employed in EEG or MEG and neural (spiking) activity is, however, open to debate: A smaller amplitude of the visual steady-state response reported in patients may correspond to increased blood flow as described in studies using positron emission tomography (Taylor et al., 1997) and functional magnetic resonance imaging (Renshaw et al., 1994). Thus, further research is necessary to characterize potential adaptation deficits and their functional consequences in schizophrenia using different methodologies.

Finally, our data suggest that deficits in the temporal precision of neuronal firing may be another result of disturbed excitatory-inhibitory circuitry and thus a candidate mechanism for explaining somatosensory deficits in schizophrenia. Spiking precision has been shown to depend on the interaction of excitation and inhibition in rat barrel cortex (Higley and Contreras, 2006), and is reduced in NRG1 mutants, both with regard to phase locking (Fig. 6A, 7A) and temporal dispersion (Fig. 6B, 7B). Aberrant phase relationships of EEG oscillations have been commonly described in schizophrenic patients in response to auditory (Brockhaus-Dumke et al., 2008; Krishnan et al., 2009; Winterer et al., 2000) and visual stimulation (Spencer et al., 2003; Spencer et al., 2008), and have recently been reported with MEG in the somatosensory cortex as well (Teale et al., 2013). 
The NRG1 response abnormalities in firing rate, adaptation and phase locking may result from an excitatory-inhibitory imbalance, as described above. However, the question remains whether reduced frequency tuning or resonance may also be related to such an imbalance. A modeling study by Garabedian and colleagues suggested that GABA receptors, specifically the Gprotein coupled $\mathrm{GABA}_{\mathrm{B}}$ receptors, play a crucial role in neuronal adaptation and barrel cortex specific band-pass effects related to spike rate and vector strength (Garabedian et al., 2003). The authors used a model consisting of an inhibitory and excitatory neuron coupled via fast excitation (involving $\alpha$-amino-3-hydroxy-5-methyl-4-isoxazole propionic acid [AMPA] receptors) and fast and slow inhibition (involving $\mathrm{GABA}_{A}$ and $\mathrm{GABA}_{B}$ receptors, respectively). Both neurons received adapting depolarizing input from the thalamus and additional noisy excitatory input. The model accounted for increasing adaptation at increasing stimulation frequencies $(1-30 \mathrm{~Hz})$ as well as the peak in firing rate and vector strength around $10 \mathrm{~Hz}$. Removing thalamocortical adaptation from the model resulted in the abolishment of adaptation, a monotonic increase in firing rate with increasing stimulation frequency, but a normal distribution of vector strength with a peak at $10 \mathrm{~Hz}$. Removing the effect of slow inhibition $\left(G A B A_{B}\right)$ from the model resulted in a reduced degree of adaptation (but did not abolish it), an increase in average spike rate by almost 2 orders of magnitude, a reduction in average vector strength by approximately factor 5 , and the abolishment of typical band-pass characteristics with respect to firing rate and vector strength. These findings suggest that the pattern of results observed in NRG1 mice are largely due to an impairment of $\mathrm{GABA}_{B}$ inhibition of excitatory cells at the cortical level. The role of $\mathrm{GABA}_{B}$ in somatosensory deficits of schizophrenic subjects is hitherto unknown, but some general effects of $\mathrm{GABA}_{B}$ agonists on alleviating positive symptoms in schizophrenia have been noted (Kantrowitz et al., 2009). In addition, in an NMDA receptorhypofunction model of schizophrenia, $G_{A B A_{B}}$ agonists were found to improve the excitatoryinhibitory balance in hippocampus, the SNR of the cortical EEG response, and behavioral deficits (Gandal et al., 2012b).

\section{REFERENCES}

Adibi, M., McDonald, J.S., Clifford, C.W., and Arabzadeh, E. (2013). Adaptation improves neural coding efficiency despite increasing correlations in variability. J Neurosci 33, 2108-2120.

Adler, L.E. (1982). Neurophysiological evidence for a defect in neuronal mechanisms involved in sensory gating in schizophrenia. Biol Psychiatry 17, 639-54.

Agim, Z.S., Esendal, M., Briollais, L., Uyan, O., Meschian, M., Martinez, L.A., Ding, Y., Basak, A.N., and Ozcelik, H. (2013). Discovery, validation and characterization of Erbb4 and Nrg1 haplotypes using data from three genome-wide association studies of schizophrenia. PLoS One 8, 3.

Ahissar, E., Sosnik, R., Bagdasarian, K., and Haidarliu, S. (2001). Temporal frequency of whisker movement. II. Laminar organization of cortical representations. J Neurophysiol 86, 354-367. 
Akbarian, S., Kim, J.J., Potkin, S.G., Hagman, J.O., Tafazzoli, A., Bunney Jr, W.E., and Jones, E.G. (1995). Gene expression for glutamic acid decarboxylase is reduced without loss of neurons in prefrontal cortex of schizophrenics. Arch Gen Psychiatry 52, 258.

Alaerts, M., Ceulemans, S., Forero, D., Moens, L.N., De Zutter, S., Heyrman, L., Lenaerts, A.S., Norrback, K.F., De Rijk, P., Nilsson, L.G., et al. (2009). Support for NRG1 as a susceptibility factor for schizophrenia in a northern Swedish isolated population. Arch Gen Psychiatry 66, 828-837.

Arabzadeh, E., Petersen, R.S., and Diamond, M.E. (2003). Encoding of whisker vibration by rat barrel cortex neurons: implications for texture discrimination. J Neurosci 23, 9146-9154.

Arabzadeh, E., Zorzin, E., and Diamond, M.E. (2005). Neuronal encoding of texture in the whisker sensory pathway. PLoS Biol 3, e17.

Ashida, G., Wagner, H., and Carr, C.E. (2010). Processing of phase-locked spikes and periodic signals. In Analysis of parallel spike trains, S. Grün, and S. Rotter, eds. (Springer), 59-74.

Bartha, R., Williamson, P.C., Drost, D.J., Malla, A., Carr, T.J., Cortese, L., Canaran, G., Rylett, R.J., and Neufeld, R.W. (1997). Measurement of glutamate and glutamine in the medial prefrontal cortex of never-treated schizophrenic patients and healthy controls by proton magnetic resonance spectroscopy. Arch Gen Psychiatry 54, 959-965.

Beasley, C.L., and Reynolds, G.P. (1997). Parvalbumin-immunoreactive neurons are reduced in the prefrontal cortex of schizophrenics. Schizophr Res 24, 349-355.

Benes, F.M., McSparren, J., Bird, E.D., SanGiovanni, J.P., and Vincent, S.L. (1991). Deficits in small interneurons in prefrontal and cingulate cortices of schizophrenic and schizoaffective patients. Arch Gen Psychiatry 48, 996.

Bousman, C.A., Yung, A.R., Pantelis, C., Ellis, J.A., Chavez, R.A., Nelson, B., Lin, A., Wood, S.J., Amminger, G.P., Velakoulis, D., et al. (2013). Effects of NRG1 and DAOA genetic variation on transition to psychosis in individuals at ultra-high risk for psychosis. Transl Psychiatry 30, 23.

Braff, D., Stone, C., Callaway, E., Geyer, M., Glick, I., and Bali, L. (1978). Prestimulus effects on human startle reflex in normals and schizophrenics. Psychophysiology 15, 339-343.

Braff, D.L., Grillon, C., and Geyer, M.A. (1992). Gating and habituation of the startle reflex in schizophrenic patients. Arch Gen Psychiatry 49, 206.

Brenner, C.A., Krishnan, G.P., Vohs, J.L., Ahn, W.-Y., Hetrick, W.P., Morzorati, S.L., and O'Donnell, B.F. (2009). Steady state responses: electrophysiological assessment of sensory function in schizophrenia. Schizophr Bull 35, 1065-1077.

Brockhaus-Dumke, A., Mueller, R., Faigle, U., and Klosterkoetter, J. (2008). Sensory gating revisited: relation between brain oscillations and auditory evoked potentials in schizophrenia. Schizophr Res 99, 238-249.

Brunel, N., and Wang, X.-J. (2001). Effects of neuromodulation in a cortical network model of object working memory dominated by recurrent inhibition. J Comput Neurosci 11, 63-85.

Butler, P.D., Silverstein, S.M., and Dakin, S.C. (2008). Visual perception and its impairment in schizophrenia. Biol Psychiatry 64, 40.

Butler, P.D., Zemon, V., Schechter, I., Saperstein, A.M., Hoptman, M.J., Lim, K.O., Revheim, N., Silipo, G., and Javitt, D.C. (2005). Early-stage visual processing and cortical amplification deficits in schizophrenia. Arch Gen Psychiatry 62, 495.

Cao, Y., Roy, S., Sachdev, R.N., and Heck, D.H. (2012). Dynamic correlation between whisking and breathing rhythms in mice. J Neurosci 32, 1653-1659.

Carvell, G., and Simons, D. (1990). Biometric analyses of vibrissal tactile discrimination in the rat. J Neurosci 10, 2638-2648.

Castro-Alamancos, M.A. (2004). Dynamics of sensory thalamocortical synaptic networks during information processing states. Prog Neurobiol 74, 213-247.

Chang, B.P., and Lenzenweger, M.F. (2001). Somatosensory processing in the biological relatives of schizophrenia patients: a signal detection analysis of two-point discrimination. J Abnorm Psychol 110, 433. 
Chang, B.P., and Lenzenweger, M.F. (2004). Investigating graphesthesia task performance in the biological relatives of schizophrenia patients. Schizophr Bull 30, 327-334.

Chang, B.P., and Lenzenweger, M.F. (2005). Somatosensory processing and schizophrenia liability: proprioception, exteroceptive sensitivity, and graphesthesia performance in the biological relatives of schizophrenia patients. J Abnorm Psychol 114, 85.

Chen, Y.J., Johnson, M.A., Lieberman, M.D., Goodchild, R.E., Schobel, S., Lewandowski, N., Rosoklija, G., Liu, R.C., Gingrich, J.A., Small, S., et al. (2008). Type III neuregulin-1 is required for normal sensorimotor gating, memory-related behaviors, and corticostriatal circuit components. J Neurosci 28, 6872-6883.

Chung, S., Li, X., and Nelson, S.B. (2002). Short-term depression at thalamocortical synapses contributes to rapid adaptation of cortical sensory responses in vivo. Neuron 34, 437-446.

Davies, L.A., Garcia-Lazaro, J.A., Schnupp, J.W., Wennekers, T., and Denham, S.L. (2012). Tell me something interesting: context dependent adaptation in somatosensory cortex. J Neurosci Methods 210, 35-48.

Daviss, S.R., and Lewis, D.A. (1995). Local circuit neurons of the prefrontal cortex in schizophrenia: selective increase in the density of calbindin-immunoreactive neurons. Psychiatry Res 59, 81-96.

Deakin, I.H., Nissen, W., Law, A.J., Lane, T., Kanso, R., Schwab, M.H., Nave, K.A., Lamsa, K.P., Paulsen, O., Bannerman, D.M., et al. (2012). Transgenic overexpression of the type I isoform of neuregulin 1 affects working memory and hippocampal oscillations but not long-term potentiation. Cereb Cortex 22, 1520-1529.

Deschênes, M., Timofeeva, E., and Lavallée, P. (2003). The relay of high-frequency sensory signals in the whisker-to-barreloid pathway. J Neurosci 23, 6778-6787.

Diaz-Quesada, M., and Maravall, M. (2008). Intrinsic mechanisms for adaptive gain rescaling in barrel cortex. J Neurosci 28, 696-710.

Duffy, L., Cappas, E., Scimone, A., Schofield, P.R., and Karl, T. (2008). Behavioral profile of a heterozygous mutant mouse model for EGF-like domain neuregulin 1. Behav Neurosci 122, 748759.

Durstewitz, D., Seamans, J.K., and Sejnowski, T.J. (2000). Neurocomputational models of working memory. Nat Neurosci 3, 1184-1191.

Eastwood, S.L., McDonald, B., Burnet, P.W., Beckwith, J.P., Kerwin, R.W., and Harrison, P.J. (1995). Decreased expression of mRNAs encoding non-NMDA glutamate receptors GluRI and GluR2 in medial temporal lobe neurons in schizophrenia. Brain Res Mol Brain Res 29, 211-223.

Ehrlichman, R.S., Luminais, S.N., White, S.L., Rudnick, N.D., Ma, N., Dow, H.C., Kreibich, A.S., Abel, T., Brodkin, E.S., Hahn, C.G., et al. (2009). Neuregulin 1 transgenic mice display reduced mismatch negativity, contextual fear conditioning and social interactions. Brain Res 1294, 116-127.

Emir, U.E., Bayraktaroglu, Z., Ozturk, C., Ademoglu, A., and Demiralp, T. (2008). Changes in BOLD transients with visual stimuli across 1-44Hz. Neurosci Lett 436, 185-188.

Ewert, T.A., Vahle-Hinz, C., and Engel, A.K. (2008). High-frequency whisker vibration is encoded by phase-locked responses of neurons in the rat's barrel cortex. J Neurosci 28, 5359-5368.

Fairhall, A.L., Lewen, G.D., Bialek, W., and van Steveninck, R.R. (2001). Efficiency and ambiguity in an adaptive neural code. Nature 412, 787-792.

Fazzari, P., Paternain, A.V., Valiente, M., Pla, R., Luján, R., Lloyd, K., Lerma, J., Marín, O., and Rico, B. (2010). Control of cortical GABA circuitry development by Nrg1 and ErbB4 signalling. Nature 464, 1376-1380.

Fendt, M., Li, L., and Yeomans, J.S. (2001). Brain stem circuits mediating prepulse inhibition of the startle reflex. Psychopharmacology (Berl) 156, 216-224.

Freedman, R., Waldo, M., Bickford-Wimer, P., and Nagamoto, H. (1991). Elementary neuronal dysfunctions in schizophrenia. Schizophr Res 4, 233-243.

Fukui, N., Muratake, T., Kaneko, N., Amagane, H., and Someya, T. (2006). Supportive evidence for neuregulin 1 as a susceptibility gene for schizophrenia in a Japanese population. Neurosci Lett 396, 117-120. 
Gainetdinov, R.R., Mohn, A.R., and Caron, M.G. (2001). Genetic animal models: focus on schizophrenia. Trends Neurosci 24, 527-533.

Gandal, M.J., Edgar, J.C., Klook, K., and Siegel, S.J. (2012a). Gamma synchrony: towards a translational biomarker for the treatment-resistant symptoms of schizophrenia. Neuropharmacology 62, 1504-1518.

Gandal, M.J., Sisti, J., Klook, K., Ortinski, P.I., Leitman, V., Liang, Y., Thieu, T., Anderson, R., Pierce, R.C., Jonak, G., et al. (2012b). GABAB-mediated rescue of altered excitatory-inhibitory balance, gamma synchrony and behavioral deficits following constitutive NMDAR-hypofunction. Transl Psychiatry 17, 69.

Garabedian, C.E., Jones, S.R., Merzenich, M.M., Dale, A., and Moore, C.I. (2003). Band-pass response properties of rat SI neurons. J Neurophysiol 90, 1379-1391.

Geddes, A.E., Huang, X.-F., and Newell, K.A. (2011). Reciprocal signalling between NR2 subunits of the NMDA receptor and neuregulin1 and their role in schizophrenia. Prog Neuropsychopharmacol Biol Psychiatry 35, 896-904.

Georgieva, L., Dimitrova, A., Ivanov, D., Nikolov, I., Williams, N.M., Grozeva, D., Zaharieva, I., Toncheva, D., Owen, M.J., Kirov, G., et al. (2008). Support for neuregulin 1 as a susceptibility gene for bipolar disorder and schizophrenia. Biol Psychiatry 64, 419-427.

Golshani, P., Hutnick, L., Schweizer, F., and Fan, G. (2005). Conditional Dnmt1 deletion in dorsal forebrain disrupts development of somatosensory barrel cortex and thalamocortical long-term potentiation. Thalamus Relat Syst 3, 227-233.

Greenwood, T.A., Lazzeroni, L.C., Murray, S.S., Cadenhead, K.S., Calkins, M.E., Dobie, D.J., Green, M.F., Gur, R.E., Gur, R.C., Hardiman, G., et al. (2011). Analysis of 94 candidate genes and 12 endophenotypes for schizophrenia from the Consortium on the Genetics of Schizophrenia. Am J Psychiatry 168, 930-946.

Greenwood, T.A., Light, G.A., Swerdlow, N.R., Radant, A.D., and Braff, D.L. (2012). Association analysis of 94 candidate genes and schizophrenia-related endophenotypes. PLoS One 7, 13.

Hahn, C.-G., Wang, H.-Y., Cho, D.-S., Talbot, K., Gur, R.E., Berrettini, W.H., Bakshi, K., Kamins, J., Borgmann-Winter, K.E., and Siegel, S.J. (2006). Altered neuregulin 1-erbB4 signaling contributes to NMDA receptor hypofunction in schizophrenia. Nat Med 12, 824-828.

Harrison, P., McLaughlin, D., and Kerwin, R. (1991). Decreased hippocampal expression of a glutamate receptor gene in schizophrenia. Lancet 337, 450-452.

Harvey, M.A., Bermejo, R., Zeigler, H.P. (2001). Discriminative whisking in the head-fixed rat: optoelectronic monitoring during tactile detection and discrimination tasks. Somatosens Mot Res $18,211-222$.

Hashimoto, T., Volk, D.W., Eggan, S.M., Mirnics, K., Pierri, J.N., Sun, Z., Sampson, A.R., and Lewis, D.A. (2003). Gene expression deficits in a subclass of GABA neurons in the prefrontal cortex of subjects with schizophrenia. J Neurosci 23, 6315-6326.

Heiss, J.E., Katz, Y., Ganmor, E., and Lampl, I. (2008). Shift in the balance between excitation and inhibition during sensory adaptation of S1 neurons. J Neurosci 28, 13320-13330.

Higley, M.J., and Contreras, D. (2006). Balanced excitation and inhibition determine spike timing during frequency adaptation. J Neurosci 26, 448-457.

Higley, M.J., and Contreras, D. (2007). Frequency adaptation modulates spatial integration of sensory responses in the rat whisker system. J Neurophysiol 97, 3819-3824.

Hong, L.E., Wonodi, I., Stine, O.C., Mitchell, B.D., and Thaker, G.K. (2008). Evidence of missense mutations on the neuregulin 1 gene affecting function of prepulse inhibition. Biol Psychiatry 63, 17-23.

Huang, M.-X., Lee, R., Gaa, K., Song, T., Harrington, D., Loh, C., Theilmann, R., Edgar, J.C., Miller, G., Canive, J., et al. (2010). Somatosensory system deficits in schizophrenia revealed by MEG during a median-nerve oddball task. Brain Topogr 23, 82-104. 
Huertas-Vazquez, A., Teodorescu, C., Reinier, K., Uy-Evanado, A., Chugh, H., Jerger, K., Ayala, J., Gunson, K., Jui, J., Newton-Cheh, C., et al. (2013). A common missense variant in the neuregulin 1 gene is associated with both schizophrenia and sudden cardiac death. Heart Rhythm 10, 994-998.

Humphries, C., Mortimer, A., Hirsch, S., and de Belleroche, J. (1996). NMDA receptor mRNA correlation with antemortem cognitive impairment in schizophrenia. Neuroreport 7, 2051-2055.

Inan, M., and Crair, M.C. (2007). Development of cortical maps: perspectives from the barrel cortex. Neuroscientist 13, 49-61.

Jenkins, G., and Röhricht, F. (2007). From cenesthesias to cenesthopathic schizophrenia: a historical and phenomenological review. Psychopathology 40, 361-368.

Jiang, L., Emmetsberger, J., Talmage, D.A., and Role, L.W. (2013). Type III neuregulin 1 is required for multiple forms of excitatory synaptic plasticity of mouse cortico-amygdala circuits. J Neurosci 33, 9655-9666.

Jin, Y., Castellanos Jr, A., Solis Jr, E., and Potkin, S. (2000). EEG resonant responses in schizophrenia: a photic driving study with improved harmonic resolution. Schizophr Res 44, 213-220.

Jin, Y., Sandman, C.A., Wu, J.C., Bernat, J., and Potkin, S.G. (1995). Topographic analysis of EEG photic driving in normal and schizophrenic subjects. Clin Electroencephalogr 26, 102-107.

Jones, L.M., Depireux, D.A., Simons, D.J., and Keller, A. (2004). Robust temporal coding in the trigeminal system. Science 304, 1986-1989.

Kalus, P., Senitz, D., and Beckmann, H. (1999). Disturbances of corticogenesis in schizophrenia: morphological findings provide new evidence for the maldevelopmental hypothesis. Neuropsychobiology 40, 1-13.

Kantrowitz, J., Citrome, L., and Javitt, D. (2009). GABA(B) receptors, schizophrenia and sleep dysfunction: a review of the relationship and its potential clinical and therapeutic implications. CNS Drugs 23, 681-691.

Katz, Y., Heiss, J.E., and Lampl, I. (2006). Cross-whisker adaptation of neurons in the rat barrel cortex. J Neurosci 26, 13363-13372.

Kegeles, L.S., Mao, X., Stanford, A.D., Girgis, R., Ojeil, N., Xu, X., Gil, R., Slifstein, M., Abi-Dargham, A., Lisanby, S.H., et al. (2012). Elevated prefrontal cortex gamma-aminobutyric acid and glutamateglutamine levels in schizophrenia measured in vivo with proton magnetic resonance spectroscopy. Arch Gen Psychiatry 69, 449-459.

Khatri, V., Hartings, J.A., and Simons, D.J. (2004). Adaptation in thalamic barreloid and cortical barrel neurons to periodic whisker deflections varying in frequency and velocity. J Neurophysiol 92, 3244-3254.

Khatri, V., and Simons, D.J. (2007). Angularly nonspecific response suppression in rat barrel cortex. Cereb Cortex 17, 599-609.

Kiryakova, S., Söhnchen, J., Grosheva, M., Schuetz, U., Marinova, T., Dzhupanova, R., Sinis, N., Hübbers, C., Skouras, E., and Ankerne, J. (2010). Recovery of whisking function promoted by manual stimulation of the vibrissal muscles after facial nerve injury requires insulin-like growth factor 1 (IGF-1). Exp Neurol 222, 226-234.

Kohn, A., and Whitsel, B.L. (2002). Sensory cortical dynamics. Behav Brain Res 135, 119-126.

Krishnan, G., Hetrick, W., Brenner, C., Shekhar, A., Steffen, A., and O'Donnell, B. (2009). Steady state and induced auditory gamma deficits in schizophrenia. Neuroimage 47, 1711.

Krishnan, G.P., Vohs, J.L., Hetrick, W.P., Carroll, C.A., Shekhar, A., Bockbrader, M.A., and O'Donnell, B.F. (2005). Steady state visual evoked potential abnormalities in schizophrenia. Clin Neurophysiol 116, 614-624.

Kukshal, P., Bhatia, T., Bhagwat, A.M., Gur, R.E., Gur, R.C., Deshpande, S.N., Nimgaonkar, V.L., and Thelma, B.K. (2013). Association study of Neuregulin-1 gene polymorphisms in a north Indian schizophrenia sample. Schizophr Res 144, 24-30.

Land, P.W., and Simons, D.J. (1985). Cytochrome oxidase staining in the rat Sml barrel cortex. J Comp Neurol 238, 225-235.

Lang, M.V. (2005). Trends in schizophrenia research (Nova Publishers). 
Lewis, D.A., Hashimoto, T., and Volk, D.W. (2005). Cortical inhibitory neurons and schizophrenia. Nature Reviews Neuroscience 6, 312-324.

Li, D., Collier, D.A., and He, L. (2006). Meta-analysis shows strong positive association of the neuregulin 1 (NRG1) gene with schizophrenia. Hum Mol Genet 15, 1995-2002.

Li, T., Stefansson, H., Gudfinnsson, E., Cai, G., Liu, X., Murray, R.M., Steinthorsdottir, V., Januel, D., Gudnadottir, V.G., Petursson, H., et al. (2004). Identification of a novel neuregulin 1 at-risk haplotype in Han schizophrenia Chinese patients, but no association with the Icelandic/Scottish risk haplotype. Mol Psychiatry 9, 698-704.

Light, G.A., and Braff, D.L. (1999). Human and animal studies of schizophrenia-related gating deficits. Curr Psychiatry Rep 1, 31-40.

Light, G.A., Hsu, J.L., Hsieh, M.H., Meyer-Gomes, K., Sprock, J., Swerdlow, N.R., and Braff, D.L. (2006). Gamma band oscillations reveal neural network cortical coherence dysfunction in schizophrenia patients. Biol Psychiatry 60, 1231-1240.

Lipska, B.K., and Gogos, J.A. (2011). Animal models of schizophrenia. In Schizophrenia, D.R. Weinberger, and P.J. Harrison, eds. Third Edition (Wiley-Blackwell), 462-481.

Lisman, J. (2012). Excitation, inhibition, local oscillations, or large-scale loops: what causes the symptoms of schizophrenia? Curr Opin Neurobiol 22, 537-544.

Maravall, M., Petersen, R., Fairhall, A., Arabzadeh, E., and Diamond, M. (2007). Shifts in coding properties and maintenance of information transmission during adaptation in barrel cortex. PLoS Biol 5, e19.

Marín, O. (2012). Interneuron dysfunction in psychiatric disorders. Nat Rev Neurosci 13, 107-120.

Marsman, A., van den Heuvel, M.P., Klomp, D.W., Kahn, R.S., Luijten, P.R., and Hulshoff Pol, H.E. (2013). Glutamate in schizophrenia: a focused review and meta-analysis of (1)H-MRS studies. Schizophr Bull 39, 120-129.

Mei, L., and Xiong, W.C. (2008). Neuregulin 1 in neural development, synaptic plasticity and schizophrenia. Nat Rev Neurosci 9, 437-452.

Melzer, P., Champney, G.C., Maguire, M.J., and Ebner, F.F. (2006). Rate code and temporal code for frequency of whisker stimulation in rat primary and secondary somatic sensory cortex. Exp Brain Res 172, 370-386.

Meyer, D., and Birchmeier, C. (1995). Multiple essential functions of neuregulin in development. Nature 378, 386-390.

Mitchinson, B., Grant, R.A., Arkley, K., Rankov, V., Perkon, I., and Prescott, T.J. (2011). Active vibrissal sensing in rodents and marsupials. Philos Trans R Soc Lond B Biol Sci 366, 3037-3048.

Moberg, P.J., Agrin, R., Gur, R.E., Gur, R.C., Turetsky, B.I., and Doty, R.L. (1999). Olfactory dysfunction in schizophrenia: a qualitative and quantitative review. Neuropsychopharmacology 21, 325-340.

Mohamad Shariati, S.A., Behmanesh, M., and Galehdari, H. (2011). A study of the association between SNP8NRG241930 in the $5^{\prime}$ end of neuroglin 1 gene with schizophrenia in a group of Iranian patients. Cell J 13, 91-96.

Moore, C., Nelson, S., and Sur, M. (1999). Dynamics of neuronal processing in rat somatosensory cortex. Trends Neurosci 22, 513-520.

Moore, C.I. (2004). Frequency-dependent processing in the vibrissa sensory system. J Neurophysiol 91, 2390-2399.

Munafo, M.R., Thiselton, D.L., Clark, T.G., and Flint, J. (2006). Association of the NRG1 gene and schizophrenia: a meta-analysis. Mol Psychiatry 11, 539-546.

Näätänen, R., and Kähkönen, S. (2009). Central auditory dysfunction in schizophrenia as revealed by the mismatch negativity $(\mathrm{MMN})$ and its magnetic equivalent $\mathrm{MMNm}$ : a review. Int J Neuropsychopharmacol 12, 125-135.

Nason, M.W., Jr., Adhikari, A., Bozinoski, M., Gordon, J.A., and Role, L.W. (2011). Disrupted activity in the hippocampal-accumbens circuit of type III neuregulin 1 mutant mice. Neuropsychopharmacology 36, 488-496. 
Naz, M., Riaz, M., and Saleem, M. (2011). Potential role of Neuregulin 1 and TNF-alpha (-308) polymorphism in schizophrenia patients visiting hospitals in Lahore, Pakistan. Mol Biol Rep 38, 4709-4714.

Nicolelis, M.A., and Fanselow, E.E. (2002). Thalamocortical optimization of tactile processing according to behavioral state. Nat Neurosci 5, 517-523.

Panzeri, S., and Diamond, M.E. (2010). Information carried by population spike times in the whisker sensory cortex can be decoded without knowledge of stimulus time. Front Synaptic Neurosci 2.

Papaleo, F., Lipska, B.K., and Weinberger, D.R. (2012). Mouse models of genetic effects on cognition: relevance to schizophrenia. Neuropharmacology 62, 1204-1220.

Papiol, S., Begemann, M., Rosenberger, A., Friedrichs, H., Ribbe, K., Grube, S., Schwab, M.H., Jahn, H., Gunkel, S., Benseler, F., et al. (2011). A phenotype-based genetic association study reveals the contribution of neuregulin1 gene variants to age of onset and positive symptom severity in schizophrenia. Am J Med Genet B Neuropsychiatr Genet 3, 340-345.

Peled, A., Pressman, A., Geva, A.B., and Modai, I. (2003). Somatosensory evoked potentials during a rubber-hand illusion in schizophrenia. Schizophr Res 64, 157-163.

Perry, T., Buchanan, J., Kish, S., and Hansen, S. (1979). Y-Aminobutyric-acid deficiency in brain of schizophrenic patients. Lancet 313, 237-239.

Picton, T.W., John, M.S., Dimitrijevic, A., and Purcell, D. (2003). Human auditory steady-state responses. Int J Audiol 42, 177-219.

Renshaw, P.F., Yurgelun-Todd, D.A., and Cohen, B.M. (1994). Greater hemodynamic response to photic stimulation in schizophrenic patients: an echo planar MRI study. Am J Psychiatry 151, 1493-1495.

Rice, D.M., Potkin, S.G., Jin, Y., Isenhart, R., Heh, C.W.C., Sramek, J., Costa, J., and Sandman, C.A. (1989). EEG alpha photic driving abnormalities in chronic schizophrenia. Psychiatry Res 30, 313324.

Rolls, E.T., Loh, M., Deco, G., and Winterer, G. (2008). Computational models of schizophrenia and dopamine modulation in the prefrontal cortex. Nat Rev Neurosci 9, 696-709.

Rosenbaum, G., Flenning, F., and Rosen, H. (1965). Effects of weight intensity on discrimination thresholds of normals and schizophrenics. J Abnorm Psychol 70, 446.

Roussos, P., Giakoumaki, S.G., Adamaki, E., and Bitsios, P. (2011). The influence of schizophreniarelated neuregulin-1 polymorphisms on sensorimotor gating in healthy males. Biol Psychiatry 69, 479-486.

Saunders, J.A., Gandal, M.J., and Siegel, S.J. (2012). NMDA antagonists recreate signal-to-noise ratio and timing perturbations present in schizophrenia. Neurobiol Dis 46, 93-100.

Sherman, A.D., Davidson, A.T., Baruah, S., Hegwood, T.S., and Waziri, R. (1991). Evidence of glutamatergic deficiency in schizophrenia. Neurosci Lett 121, 77-80.

Sheth, B.R., Moore, C.I., and Sur, M. (1998). Temporal modulation of spatial borders in rat barrel cortex. J Neurophysiol 79, 464-470.

Simons, D.J. (1978). Response properties of vibrissa units in rat SI somatosensory neocortex. J Neurophysiol 41, 798-820.

Simpson, M., Slater, P., Deakin, J., Royston, M., and Skan, W. (1989). Reduced GABA uptake sites in the temporal lobe in schizophrenia. Neurosci Lett 107, 211-215.

Sivarao, D.V., Frenkel, M., Chen, P., Healy, F.L., Lodge, N.J., and Zaczek, R. (2013). MK-801 disrupts and nicotine augments $40 \mathrm{~Hz}$ auditory steady state responses in the auditory cortex of the urethane-anesthetized rat. Neuropharmacology 73, 1-9.

Söhnchen, J., Grosheva, M., Kiryakova, S., Hübbers, C.U., Sinis, N., Skouras, E., Ankerne, J., Kaidoglou, K., Fries, J.W.U., Irintchev, A., et al. (2010). Recovery of whisking function after manual stimulation of denervated vibrissal muscles requires brain-derived neurotrophic factor and its receptor tyrosine kinase B. Neuroscience 170, 372-380.

Spencer, K.M., Nestor, P.G., Niznikiewicz, M.A., Salisbury, D.F., Shenton, M.E., and McCarley, R.W. (2003). Abnormal neural synchrony in schizophrenia. J Neurosci 23, 7407-7411. 
Spencer, K.M., Niznikiewicz, M.A., Shenton, M.E., and McCarley, R.W. (2008). Sensory-evoked gamma oscillations in chronic schizophrenia. Biol Psychiatry 63, 744-747.

Stefansson, H., Sarginson, J., Kong, A., Yates, P., Steinthorsdottir, V., Gudfinnsson, E., Gunnarsdottir, S., Walker, N., Petursson, H., Crombie, C., et al. (2003a). Association of neuregulin 1 with schizophrenia confirmed in a Scottish population. Am J Hum Genet 72, 83-87.

Stefansson, H., Thorgeirsson, T.E., Gulcher, J.R., and Stefansson, K. (2003b). Neuregulin 1 in schizophrenia: out of Iceland. Mol Psychiatry 8, 639-640.

Tan, H.R., Lana, L., and Uhlhaas, P.J. (2013). High-frequency neural oscillations and visual processing deficits in schizophrenia. Front Psychol 4, 621.

Taylor, S.F., Tandon, R., and Koeppe, R.A. (1997). PET study of greater visual activation in schizophrenia. AJ Psychiatry 154, 1296-1298.

Teale, P., Pasko, B., Collins, D., Rojas, D., and Reite, M. (2013). Somatosensory timing deficits in schizophrenia. Psychiatry Res 212, 73-78.

Thomson, P.A., Christoforou, A., Morris, S.W., Adie, E., Pickard, B.S., Porteous, D.J., Muir, W.J., Blackwood, D.H., and Evans, K.L. (2007). Association of Neuregulin 1 with schizophrenia and bipolar disorder in a second cohort from the Scottish population. Mol Psychiatry 12, 94-104.

Ting, A.K., Chen, Y., Wen, L., Yin, D.M., Shen, C., Tao, Y., Liu, X., Xiong, W.C., and Mei, L. (2011). Neuregulin 1 promotes excitatory synapse development and function in GABAergic interneurons. J Neurosci 31, 15-25.

Tsuchimoto, R., Kanba, S., Hirano, S., Oribe, N., Ueno, T., Hirano, Y., Nakamura, I., Oda, Y., Miura, T., and Onitsuka, T. (2011). Reduced high and low frequency gamma synchronization in patients with chronic schizophrenia. Schizophr Res 133, 99-105.

Venables, N.C., Bernat, E.M., and Sponheim, S.R. (2009). Genetic and disorder-specific aspects of resting state EEG abnormalities in schizophrenia. Schizophr Bull 35, 826-839.

Vialatte, F.-B., Maurice, M., Dauwels, J., and Cichocki, A. (2010). Steady-state visually evoked potentials: focus on essential paradigms and future perspectives. Prog Neurobiol 90, 418-438.

Vogels, T.P., and Abbott, L.F. (2007). Gating deficits in model networks: a path to schizophrenia? Pharmacopsychiatry 40, S73-77.

Volk, D.W., Austin, M.C., Pierri, J.N., Sampson, A.R., and Lewis, D.A. (2000). Decreased glutamic acid decarboxylase67 messenger RNA expression in a subset of prefrontal cortical gammaaminobutyric acid neurons in subjects with schizophrenia. Arch Gen Psychiatry 57, 237-245.

Volk, D.W., Austin, M.C., Pierri, J.N., Sampson, A.R., and Lewis, D.A. (2001). GABA transporter-1 mRNA in the prefrontal cortex in schizophrenia: decreased expression in a subset of neurons. Am J Psychiatry 158, 256-265.

Walker, R.M., Christoforou, A., Thomson, P.A., McGhee, K.A., Maclean, A., Muhleisen, T.W., Strohmaier, J., Nieratschker, V., Nothen, M.M., Rietschel, M., et al. (2010). Association analysis of Neuregulin 1 candidate regions in schizophrenia and bipolar disorder. Neurosci Lett 478, 9-13.

Wang, X.-J. (2006). Toward a prefrontal microcircuit model for cognitive deficits in schizophrenia. Pharmacopsychiatry $39,80-87$.

Wark, B., Lundstrom, B.N., and Fairhall, A. (2007). Sensory adaptation. Curr Opin Neurobiol 17, 423429.

Wen, L., Lu, Y.S., Zhu, X.H., Li, X.M., Woo, R.S., Chen, Y.J., Yin, D.M., Lai, C., Terry, A.V., Jr., Vazdarjanova, A., et al. (2010). Neuregulin 1 regulates pyramidal neuron activity via ErbB4 in parvalbumin-positive interneurons. Proc Natl Acad Sci U S A 107, 1211-1216.

Wesson, D.W., Donahou, T.N., Johnson, M.O., and Wachowiak, M. (2008). Sniffing behavior of mice during performance in odor-guided tasks. Chem Senses 33, 581-596.

Winterer, G., Coppola, R., Goldberg, T.E., Egan, M.F., Jones, D.W., Sanchez, C.E., and Weinberger, D.R. (2004). Prefrontal broadband noise, working memory, and genetic risk for schizophrenia. Am J Psychiatry 161, 490-500. 
Winterer, G., Musso, F., Beckmann, C., Mattay, V., Egan, M., Jones, D., Callicott, J., Coppola, R., and Weinberger, D. (2006). Instability of prefrontal signal processing in schizophrenia. Am J Psychiatry 163, 1960-1968.

Winterer, G., and Weinberger, D.R. (2004). Genes, dopamine and cortical signal-to-noise ratio in schizophrenia. Trends Neurosci 27, 683-690.

Winterer, G., Ziller, M., Dorn, H., Frick, K., Mulert, C., Wuebben, Y., Herrmann, W.M., and Coppola, R. (2000). Schizophrenia: reduced signal-to-noise ratio and impaired phase-locking during information processing. Clin Neurophysiol 111, 837-849.

Woo, R.S., Li, X.M., Tao, Y., Carpenter-Hyland, E., Huang, Y.Z., Weber, J., Neiswender, H., Dong, X.P., Wu, J., Gassmann, M., et al. (2007). Neuregulin-1 enhances depolarization-induced GABA release. Neuron 54, 599-610.

Woolsey, T.A., and Van der Loos, H. (1970). The structural organization of layer IV in the somatosensory region (SI) of mouse cerebral cortex. The description of a cortical field composed of discrete cytoarchitectonic units. Brain Res 17, 205-242.

Yang, S.A. (2012). Association between a missense polymorphism (rs3924999, Arg253Gln) of neuregulin 1 and schizophrenia in Korean population. Exp Neurobiol 21, 158-163.

Yizhar, O., Fenno, L.E., Prigge, M., Schneider, F., Davidson, T.J., O’Shea, D.J., Sohal, V.S., Goshen, I., Finkelstein, J., and Paz, J.T. (2011). Neocortical excitation/inhibition balance in information processing and social dysfunction. Nature 477, 171-178.

Yokley, J.L., Prasad, K.M., Chowdari, K.V., Talkowski, M.E., Wood, J., Gur, R.C., Gur, R.E., Almasy, L., Nimgaonkar, V.L., and Pogue-Geile, M.F. (2012). Genetic associations between neuregulin-1 SNPs and neurocognitive function in multigenerational, multiplex schizophrenia families. Psychiatr Genet 22, 70-81.

Young, J.W., Zhou, X., and Geyer, M.A. (2010). Animal models of schizophrenia. In Behavioral Neurobiology of Schizophrenia and Its Treatment (Springer), 391-433. 


\section{Chapter V}

\section{Neural deficits during somatosensory stimulation at gamma frequencies in NRG1-deficient mice}

\section{Abstract}

Deficits in somatosensory processing in schizophrenia have been linked to alterations in the amplitude and temporal precision of the electroencephalographic response. In addition, sustained auditory and visual stimulation at $20-40 \mathrm{~Hz}$ evokes less gamma power in patients than in controls. Aberrant neural responses in patients may be due to increased background or noisy neural activity, as evidenced by enhanced spontaneous gamma oscillations in schizophrenic subjects. To investigate the cellular basis of these response alterations, we recorded oscillatory and spiking activity in the primary somatosensory cortex in the Neuregulin 1 mouse model of schizophrenia during sustained 20-70 Hz whisker stimulation. The mutants displayed elevated spike rates and gamma oscillations during baseline conditions, a smaller increase in sensory-evoked spiking and gamma activity relative to baseline, and reduced temporal precision (phase locking) of 20-40 Hz spiking activity. The findings suggest a link between genetic and electrophysiological endophenotypes of schizophrenia.

\section{Introduction}

The neuropathophysiological mechanisms underlying perceptual deficits in schizophrenia have been a subject of intense research during the past decades. Three major findings have emerged from studies using electroencephalography (EEG) or magnetoencephalography (MEG) to measure visually and acoustically evoked neuronal activity in patients: Altered stimulus response amplitudes, decreased and delayed phase locking of the response, and altered gamma oscillations (20-80 Hz; Brenner et al., 2009; Tan et al., 2013; Uhlhaas and Singer, 2010). Various types of gamma oscillations were found to be reduced during sensory stimulation in patients: Steady-state gamma oscillations during sustained auditory and visual stimulation at 20-40 Hz (Edgar et al., 2013; Krishnan et al., 2005; Kwon et al., 1999; Light et al., 2006; Mulert et al., 2011; Spencer et al., 2008b; Tsuchimoto et al., 2011); evoked gamma oscillations after presenting a transient auditory (Gallinat et al., 2004; Hall et al., 2011; Leicht et al., 2011; Leicht et al., 2010; Lenz et al., 2011) or visual stimulus (Grutzner et al., 2013; Spencer et al., 2003; Spencer et al., 2008a; Sun et al., 2013); and induced gamma oscillations in response to visual Gestalt stimuli (Grutzner et al., 2013; Sun et al., 2013; Uhlhaas et al., 2006) or auditory stimulation (Basar-Eroglu et al., 2009; Krishnan et al., 2009). While steady-state and evoked 
gamma oscillations are locked to the stimulus onset, induced gamma oscillations are not stimuluslocked (Tan et al., 2013). These findings suggest broad deficits in gamma power associated with sensory processing in schizophrenia. In addition, spontaneous gamma oscillations recorded during rest or before presenting a stimulus have been found to be increased in the $20-40 \mathrm{~Hz}$ range in schizophrenic patients (Itil et al., 1972; Spencer, 2012; Venables et al., 2009). Increased gamma power in the absence of stimulation is thought to reflect elevated cortical noise (Gandal et al., 2012a), and may be related to sensory hallucinations (Baldeweg et al., 1998). However, some studies observed decreased baseline gamma $(30-80 \mathrm{~Hz})$ power (Rutter et al., 2009), or no differences at all in the $20-30 \mathrm{~Hz}$ band (Miyauchi et al., 1990). Differences in baseline power are important considering that most studies apply baseline corrections to assess differences in gamma power and eventrelated potentials (Gandal et al., 2012a; Urbach and Kutas, 2006).

While sensory processing deficits in schizophrenia patients have mainly been studied in the auditory and visual domains, somatosensory impairments and their neuronal underpinnings are less well understood. Preliminary evidence suggests that similar mechanisms might be at work as in the auditory and visual domains. Studies revealed abnormal amplitudes of the somatosensory evoked potential in schizophrenic subjects (Ikuta et al., 2007; White et al., 2010) and aberrant activation patterns during a median-nerve oddball task (Huang et al., 2010). Furthermore, somatosensoryevoked and steady-state gamma oscillations appear to be perturbed in schizophrenia. One study revealed reduced $25 \mathrm{~Hz}$ power and decreased intertrial phase coherence in response to sustained stimulation using a $25 \mathrm{~Hz}$ vibratory stimulus applied to the patients' index finger (Teale et al., 2013). In a similar study, application of a $100 \mathrm{~Hz}$ vibratory stimulus revealed reduced stimulus-locked 25-45 $\mathrm{Hz}$ power in schizophrenic subjects (White et al., 2010). Another study found that a sudden change in weight of a hand-held load was accompanied by decreased evoked power at $21 \mathrm{~Hz}$ and $32 \mathrm{~Hz}$ of the EEG-recorded proprioceptive potential in patients (Arnfred et al., 2011). The authors speculated that the reduction in power might reflect a deficit in sensorimotor integration required for sensing the stimulus weight and preparing a correct motor response (Arnfred et al., 2011; Lalo et al., 2007).

A recent study investigated the neuronal basis of somatosensory processing deficits at the cellular level in the Neuregulin 1 (NRG1) mouse model of schizophrenia (Chapter IV). NRG1 is a schizophrenia risk gene ( $\mathrm{Li}$ et al., 2004; Stefansson et al., 2003) and a regulator of excitatoryinhibitory connectivity (Fazzari et al., 2010; Ting et al., 2011). As presented in Chapter IV, mice heterozygous for NRG1 showed abnormally elevated multi-unit spike discharge during baseline conditions and a reduced signal-to-noise ratio (SNR; or stimulation-to-baseline ratio) of spike responses during sustained 1-15 Hz somatosensory (whisker) stimulation. In addition, the temporal precision of neuronal firing, as measured by phase locking and temporal dispersion, was impaired in 
the $5-15 \mathrm{~Hz}$ range. These findings are consistent with alterations in the excitatory-inhibitory connectivity of the neuronal circuitry (Garabedian et al., 2003; Vogels and Abbott, 2007). Responses to higher stimulus frequencies were, however, not investigated.

Previous studies in the somatosensory (barrel) cortex of anesthetized rodents have shed light on normal response properties to high frequency whisker stimulation. The findings suggest that mean firing rates increase monotonically with increasing stimulation frequencies both in rats (Ahissar et al., 2001; Arabzadeh et al., 2005; Khatri et al., 2004) and BL6 mice (Chapter III), with smaller increases at higher (> $100 \mathrm{~Hz}$ ) frequencies (Kleinfeld et al., 2006). In addition, phase locking of whisker-evoked responses occurred over a wide range of frequencies (Garabedian et al., 2003; Khatri et al., 2004; Melzer et al., 2006), up to several hundred hertz (Ewert et al., 2008). Together, these results suggest that stimulation frequency is coded by spike rate as well as the temporal patterning of spikes. Furthermore, whisker-evoked responses to stimuli applied at $70 \mathrm{~Hz}$ and higher frequencies were found to be accompanied by induced gamma oscillations in the $20-40 \mathrm{~Hz}$ band in BL6 mice (Chapter III) and in the $30-70 \mathrm{~Hz}$ band in rats (Ewert et al., 2008). In the awake animal, gamma oscillations have been linked to stimulus exploration (Hamada et al., 1999) and may be required for coherent stimulus representation (Jones and Barth, 1997). Gamma oscillations depend on an intact network of inhibitory cells that can synchronously inhibit excitatory cells and thus create oscillatory activity (Cardin et al., 2009; Traub et al., 1996; Whittington et al., 2000). Evidence from slice studies suggests a link between NRG1 and gamma oscillations, since studies showed that bath application of NRG1 increases kainate-induced gamma activity in mouse and rat hippocampus (Andersson et al., 2012; Fisahn et al., 2009).

The present study set out to investigate the neuronal basis of perceptual impairments in the somatosensory domain commonly observed in schizophrenia. To this end, primary somatosensory responses to sustained $20-70 \mathrm{~Hz}$ whisker stimulation were characterized in the NRG1 mouse model of schizophrenia at the level of single unit activity (SUA), multi unit activity (MUA), and local field potentials (LFPs). Possible response aberrations in NRG1 mutants were evaluated with respect to (1) firing rate, (2) temporal precision, (3) induced gamma oscillations $(20-40 \mathrm{~Hz})$ during high frequency stimulation, and (4) steady-state gamma oscillations during $20-40 \mathrm{~Hz}$ stimulation. Spiking and oscillatory activity during stimulation was related to activity during pre-stimulus baseline to reveal possible deficits in the SNR of the neural responses.

\section{Methods}

Methods have been described previously (Chapter II). Briefly, tetrode recordings were performed in lightly anesthetized wildtype (WT; NRG1+/+) and NRG1 mutant mice (NRG1+/-). Whiskers were 
stimulated repetitively in trains of $1 \mathrm{~s}$ at frequencies between $10-70 \mathrm{~Hz}$ (10 Hz steps). The analysis focused on responses to $20-70 \mathrm{~Hz}$, as a detailed analysis of $10 \mathrm{~Hz}$ responses is provided in Chapter IV.

MUA and SUA were analyzed in terms of their mean firing rates (MFR) during baseline and during stimulation. Baseline responses were quantified $950 \mathrm{~ms}$ before stimulus onset across all trials. Sustained, stimulus-evoked responses were quantified 0.05-1 s following stimulus onset in each stimulation condition (onset responses omitted). In addition, the ratio of stimulus-evoked activity and baseline activity was calculated to obtain spike SNR. Gain modulation of MFRs and spike SNR was assessed based on the population response (least square fit). SUAs were included in the MFR and SNR analyses if they were modulated by stimulation frequency, as shown by increased spiking during $70 \mathrm{~Hz}$ stimulation as compared to $20 \mathrm{~Hz}$ stimulation.

The temporal fidelity of sustained spiking activity (0.05-1 s after stimulus onset, without onset responses) was assessed in terms of phase locking and temporal dispersion. First, phase histograms were constructed by counting the number of spikes per stimulus cycle and plotting them on a $0-360^{\circ}$ scale that represents the inter-stimulus interval. Subsequently, the spike distribution and the degree of phase locking were evaluated by using vector strength analysis. Temporal dispersion of spikes is measured based on the vector strength, but takes into account the inter-stimulus interval. Higher values of vector strength $r$ denote better phase locking (perfect locking at $r=1$ ), while lower values of temporal dispersion $d[\mathrm{~ms}]$ indicate higher temporal precision. Values of vector strength and temporal dispersion were included in the population analysis if phase histograms contained $>45$ spikes and $p<0.001$. Since SUAs did not meet these criteria due to low spike rates, the phase histograms of the single units were combined by summing the spikes in each time bin. Vector strength analysis and statistical assessment were then performed on one histogram for each stimulation condition.

LFPs were analyzed in terms of their power spectra during sustained responses (0.15-1 s post stimulus onset, omitting the onset response). The analysis focused on two types of gamma oscillations $(20-40 \mathrm{~Hz})$ : induced oscillations during high-frequency $(50-70 \mathrm{~Hz})$ stimulation, and steady-state gamma oscillations evoked by stimuli in the gamma range. Gamma oscillations were analyzed by quantifying $20-40 \mathrm{~Hz}$ power (8192 point Hanning window) during each trial of high (50$70 \mathrm{~Hz}$ ) or low $(20-40 \mathrm{~Hz})$ frequency stimulation, and subsequent averaging. Absolute gamma power was divided by the total power spectrum $(5-100 \mathrm{~Hz})$ to obtain the relative gamma power. Dividing relative gamma power during stimulation by relative gamma power during baseline yielded a measure of gamma SNR. Per recording session, 4 out of 16 LFPs that showed maximal relative gamma values were included in the power analysis. 
Correlations between spike SNR and induced gamma SNR were assessed using Spearman's rank order correlation. The analysis included LFPs with the highest gamma SNRs in response to 50-70 $\mathrm{Hz}$, as well as the spike SNRs of MUAs measured in response to $50-70 \mathrm{~Hz}$ at the corresponding tetrode. All data in the text and figures are presented as mean $\pm \mathrm{SE}$, and error bars indicate SE.

\section{Results}

To characterize the influence of the NRG1 mutation on cortical sensory evoked responses, we recorded neural activity in the barrel cortex of WT and NRG1 mice during 20-70 Hz whisker stimulation. The analysis omitted onset activity and focused on the sustained part of spiking and LFP responses in order to reveal stimulation frequency-specific changes in the magnitude and temporal precision of neuronal firing, and in gamma power.

WT

(A)

(B)

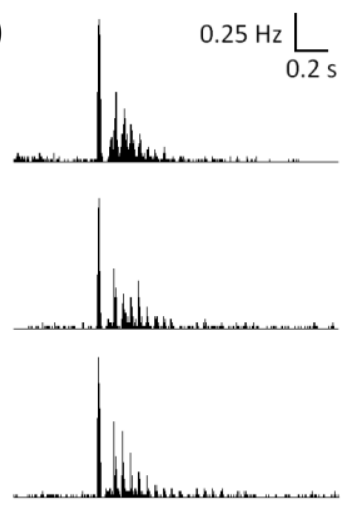

(C)
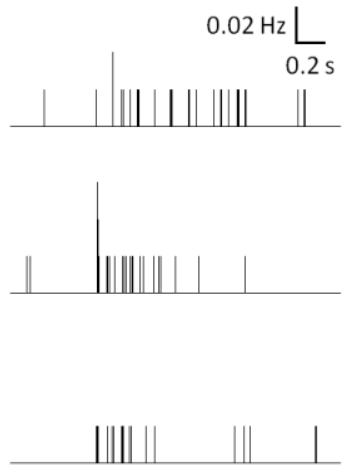
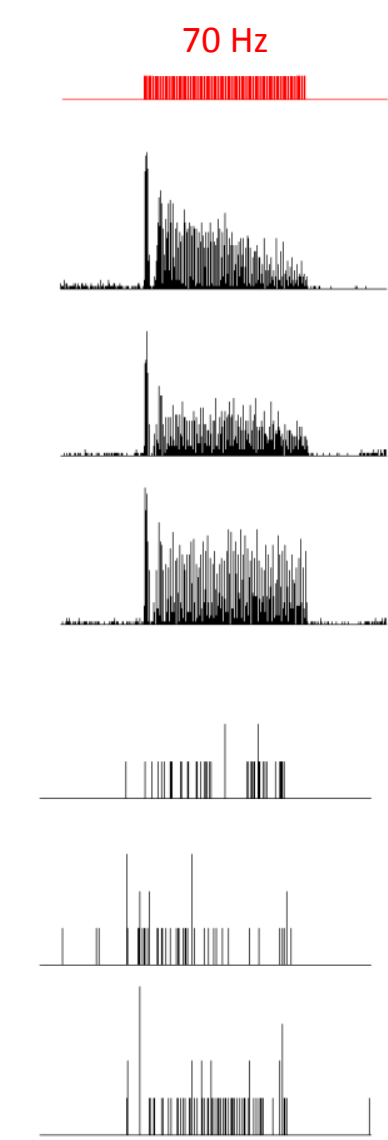

NRG1

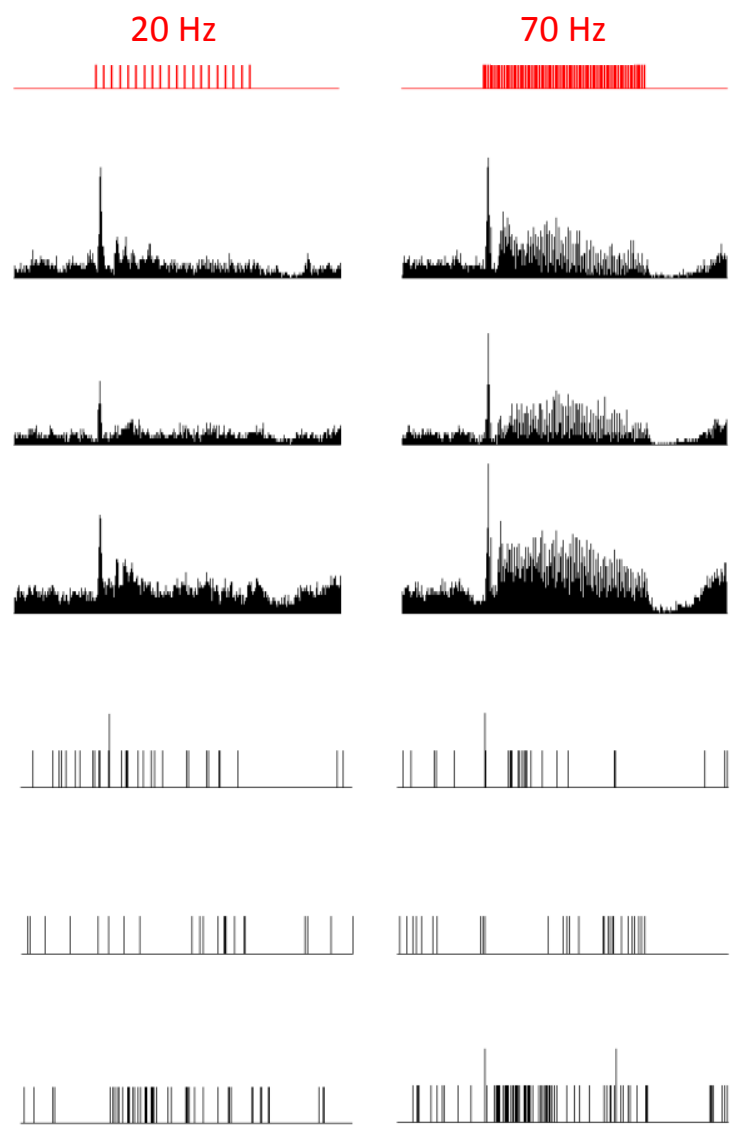

FIGURE 1. Stimulus-evoked activity during $20 \mathrm{~Hz}$ and $70 \mathrm{~Hz}$ whisker stimulation. Shown are representative responses from WT (left panel) and NRG1 mice (right panel). A. Stimuli were applied in trains of $1 \mathrm{~s}$ at frequencies ranging from 20 to $70 \mathrm{~Hz}$. Two example stimuli are displayed. B. PSTHs of three MUA examples (top to bottom) are displayed for WT and NRG1 mice. PSTHs (bin size: $1 \mathrm{ms)}$ were calculated as average responses [in $\mathrm{Hz}$ ] across 50 trials. Responses were modulated by frequency in both groups. In addition, NRG1 mice showed higher levels of baseline activity than WT mice. C. PSTHs of three SUA examples per group (same conventions as in $B$ ). 
(A.1)

MUA BL

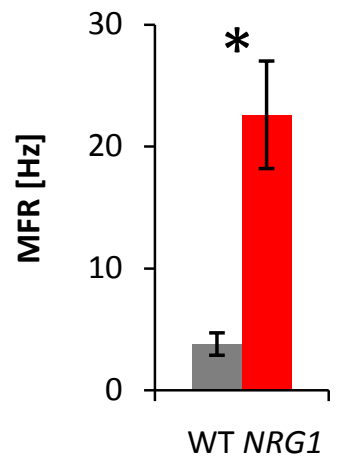

baseline

(B.1)

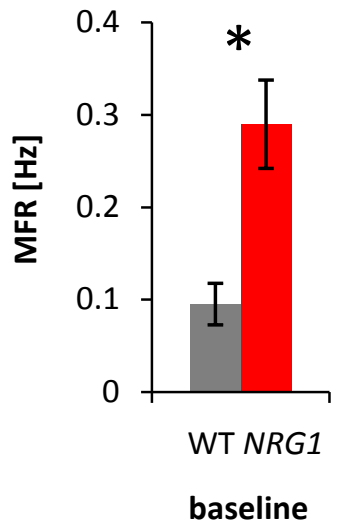

(A.2) MUA STIM

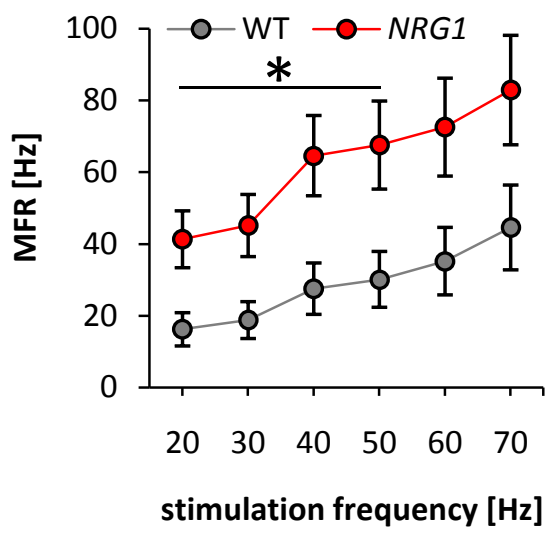

(B.2)

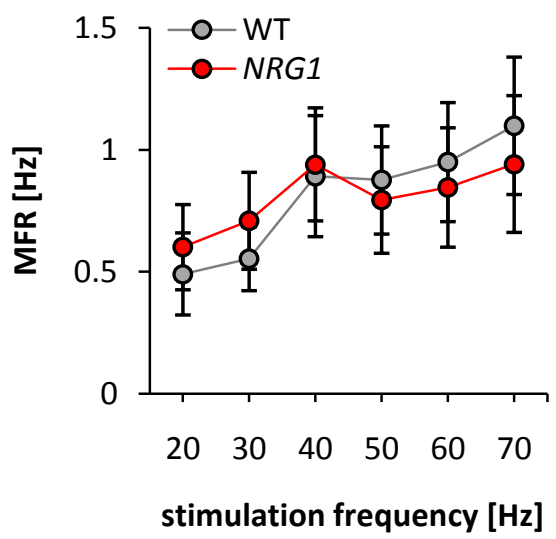

FIGURE 2. Spontaneous and stimulus-evoked firing rates. $A$. Spiking activity of $28 \mathrm{WT}$ and $25 N R G 1$ MUAs during baseline (BL) conditions (A.1) and stimulation (STIM) conditions (A.2). Compared to WT MUAs, NRG1 MUAs showed enhanced spontaneous MFR (Mann-Whitney, $U=131, p<0.0001$ ), and increased sustained responses for all stimulation frequencies below $60 \mathrm{~Hz}$ (see Table 1). B. MFR of 10 WT and 22 NRG1 SUAs during baseline (B.1) and stimulation conditions (B.2). Baseline activity was elevated in NRG1 SUAs (Mann-Whitney, $U=43, p<0.01$ ) compared to WT SUAs. Sustained responses in WT and NRG1 mice were similar in magnitude. * Significant between-group differences.

\subsection{Abnormal firing patterns during stimulation and baseline conditions in NRG1 mutants}

Quantitative data were derived from 28 WT and 25 NRG1 MUAs, as well as 10 WT SUAs and 22 NRG1 SUAs (Fig. 1). MUAs showed distinct onset responses (0-50 ms following stimulus onset) and sustained responses (0.05-1 s after stimulus onset). The distinction was less clear in SUAs due to low firing rates. Since low spike counts affect the robustness of the results derived from SUA analyses, SUA results should be interpreted with caution and in the context of the MUA results.

First, we quantified MFRs in baseline and sustained stimulation conditions for MUAs and SUAs (Fig. 2). Compared to WT MUAs, NRG1 MUAs showed a 6-fold increase in firing rates during 
baseline conditions (Mann-Whitney, $\mathrm{p}<0.0001$; Fig. 2A.1). In addition, NRG1 MUAs also displayed augmented firing rates of sustained responses during 20-50 Hz stimulation (Mann-Whitney, $\mathrm{p}<$ 0.007; Fig. 2A.2, Table 1). MUA MFR increased monotonically at higher frequencies in both groups. On average, WT responses gained 5.54 spikes per $10 \mathrm{~Hz}$ increase in stimulus frequency $\left(R^{2}=0.97\right)$, while NRG1 responses increased by 8.37 spikes per $10 \mathrm{~Hz}$ increase $\left(R^{2}=0.95\right)$.

At the level of SUAs, baseline activity was augmented by factor 3 in NRG1 animals compared to WT mice (Mann-Whitney, $p=0.005$, Fig. 2B.1). During stimulation conditions, no differences were detected in stimulus-evoked sustained responses (Mann-Whitney, $p>0.05$, Fig. 2B.2). Spiking activity increased monotonically in both groups, but more steeply in WT mice compared to NRG1 mutants (WT: $y=0.012$ spikes per $10 \mathrm{~Hz}$ increase; $\mathrm{R}^{2}=0.90 ; N R G 1$ : 0.006 spikes per $10 \mathrm{~Hz}$ increase; $\left.R^{2}=0.62\right)$.

TABLE 1. Between-group comparison of MUA MFR. The MFR \pm SE of WT $(n=28)$ and NRG1 $(n=25)$ MUAs are shown as well as the Mann-Whitney $U$ and the corresponding $p$ value (printed in bold if significant). Bonferroni-corrected significance level $=0.008$.

\begin{tabular}{ccccc}
\hline frequency & WT MFR [Hz] & NRG1 MFR [Hz] & U & p \\
\hline $\mathbf{2 0 ~ H z}$ & $16.20 \pm 4.63$ & $41.28 \pm 7.92$ & 192 & $\mathbf{0 . 0 0 4}$ \\
$\mathbf{3 0 ~ H z}$ & $18.77 \pm 5.13$ & $45.11 \pm 8.66$ & 199 & $\mathbf{0 . 0 0 7}$ \\
$\mathbf{4 0 ~ H z}$ & $27.52 \pm 7.16$ & $64.58 \pm 11.18$ & 183 & $\mathbf{0 . 0 0 3}$ \\
$\mathbf{5 0 ~ H z}$ & $30.11 \pm 7.78$ & $67.52 \pm 12.27$ & 190 & $\mathbf{0 . 0 0 4}$ \\
$\mathbf{6 0 ~ H z}$ & $35.19 \pm 9.40$ & $72.52 \pm 13.64$ & 204 & 0.009 \\
$\mathbf{7 0 ~ H z}$ & $44.58 \pm 11.82$ & $82.84 \pm 15.25$ & 215 & 0.016 \\
\hline
\end{tabular}

\subsection{Reduced signal-to-noise ratio and gain in NRG1 mutant mice}

Since NRG1 MUAs exhibited higher firing rates both during spontaneous and stimulation conditions compared to WT animals, we calculated the spike SNR of sustained responses for the two strains (Fig. 3). SNR was quantified by dividing the MFR during stimulation (measured per condition) by the spontaneous activity (measured across all trials). The comparison between 28 WT and 25 NRG1 MUAs revealed a significant reduction in spike SNR across all frequencies (Mann-Whitney, $p<0.001$;

Fig. 3A.1 and B.1, Table 2). In both groups, SNR increased monotonically with increasing stimulation frequency. On average, the gain in SNR was 3.6 times larger in WT MUAs (2.63 points per $10 \mathrm{~Hz}$ increase in stimulation frequency; $\left.R^{2}=0.96\right)$ compared to NRG1 MUAs $\left(0.74\right.$ per $10 \mathrm{~Hz}$ increase; $\mathrm{R}^{2}=$ 0.91 ). 
Spike SNR of sustained responses was also assessed in SUAs. In agreement with the MUA results, NRG1 SUAs showed a reduced SNR compared to WT mice across all stimulation frequencies (Fig. 3A.2 and B.2). However, after correction for multiple comparisons, a statistically significant change was only observed in the $60 \mathrm{~Hz}$ and $70 \mathrm{~Hz}$ conditions (Mann-Whitney, $\mathrm{p} \leq 0.003$; Table 3). The gain in SNR per $10 \mathrm{~Hz}$ increase in stimulation frequency was 8.6 times larger in WT SUAs (2.68; $\left.\mathrm{R}^{2}=0.84\right)$ compared to NRG1 SUAs $\left(0.31 ; \mathrm{R}^{2}=0.80\right)$.

(A.1)

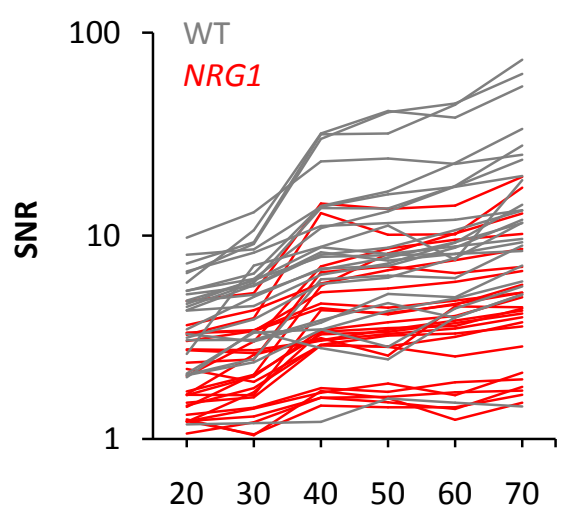

stimulation frequency $[\mathrm{Hz}]$

(B.1)

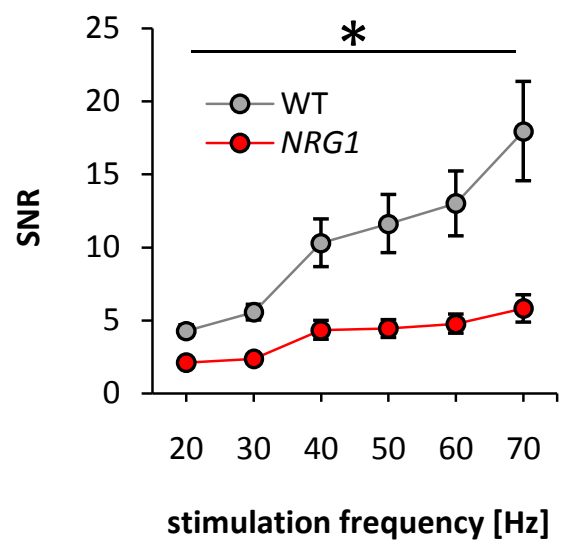

(A.2)

SUA SNR

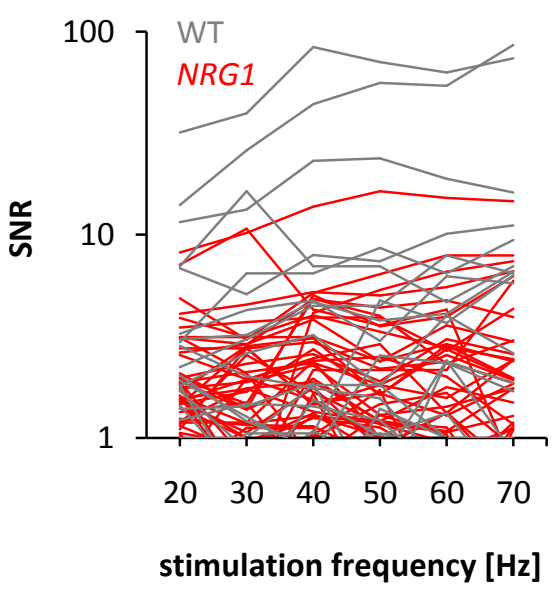

(B.2)

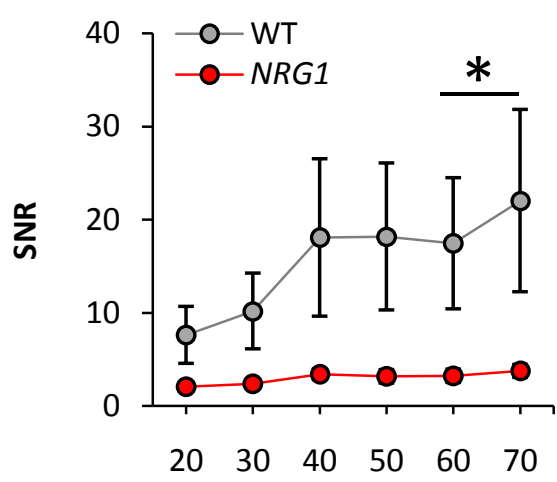

stimulation frequency $[\mathrm{Hz}]$

FIGURE 3. Spike SNR of sustained responses in MUA and SUA. SNR was defined as ratio between stimulus-evoked and baseline firing rate. SNR was determined in 28 WT and 25 NRG1 MUAs (left column), as well as in $10 \mathrm{WT}$ and 22 NRG1 SUAs (right column). A. SNR per MUA (A.1) and SUA (A.2) in WT (gray traces) and NRG1 mice (red traces). B. SNR population averages in MUAs (B.1) and SUAs (B.2). SNR was reduced in NRG1 animals compared to WT mice at the level of MUAs (20-70 Hz; see Table 2 for details) and SUAs (60-70 Hz; see Table 3). * Significant between-group differences. 
TABLE 2. Between-group comparison of MUA SNR. The SNR of WT $(n=28)$ and NRG1 $(n=25)$ MUA responses was compared per condition (Mann-Whitney). Displayed are the mean \pm SE of WT and NRG1 responses, the Mann-Whitney $U$ and the corresponding $\mathrm{p}$ value (highlighted in bold if significant). Bonferroni-corrected significance level: $p=0.008$.

\begin{tabular}{ccccc}
\hline frequency & WT MUA SNR & NRG1 MUA SNR & U & p \\
\hline $\mathbf{2 0 ~ H z}$ & $4.30 \pm 0.40$ & $2.12 \pm 0.20$ & 576 & $<\mathbf{0 . 0 0 0 1}$ \\
$\mathbf{3 0 ~ H z}$ & $5.57 \pm 0.54$ & $2.37 \pm 0.22$ & 604 & $<\mathbf{0 . 0 0 0 1}$ \\
$\mathbf{4 0 ~ H z}$ & $10.31 \pm 1.63$ & $4.35 \pm 0.64$ & 552 & $<\mathbf{0 . 0 0 1}$ \\
$\mathbf{5 0 ~ H z}$ & $11.63 \pm 1.99$ & $4.44 \pm 0.61$ & 553 & $<\mathbf{0 . 0 0 1}$ \\
$\mathbf{6 0 ~ H z}$ & $13.01 \pm 2.22$ & $4.78 \pm 0.66$ & 567 & $<\mathbf{0 . 0 0 0 1}$ \\
$\mathbf{7 0 ~ H z}$ & $17.96 \pm 3.40$ & $5.82 \pm 0.94$ & 571 & $<\mathbf{0 . 0 0 0 1}$ \\
\hline
\end{tabular}

TABLE 3. Between-group differences in SUA SNR. SNRs were compared per condition in WT $(n=10)$ and NRG1 $(\mathrm{n}=22)$ SUAs using a Mann-Whitney test. The mean SNR $\pm \mathrm{SE}$, the Mann-Whitney $U$ and the corresponding $\mathrm{p}$ value (highlighted in bold if significant) are shown. Bonferroni-corrected significance level: $p=0.008$.

\begin{tabular}{ccccc}
\hline frequency & WT SUA SNR & NRG1 SUA SNR & U & p \\
\hline $\mathbf{2 0 ~ H z}$ & $7.62 \pm 3.06$ & $2.06 \pm 0.38$ & 163 & 0.033 \\
$\mathbf{3 0 ~ H z}$ & $10.19 \pm 4.06$ & $2.37 \pm 0.44$ & 171 & 0.012 \\
$\mathbf{4 0 ~ H z}$ & $18.07 \pm 8.44$ & $3.40 \pm 0.58$ & 161 & 0.039 \\
$\mathbf{5 0 ~ H z}$ & $18.18 \pm 7.88$ & $3.18 \pm 0.72$ & 170 & 0.014 \\
$\mathbf{6 0 ~ H z}$ & $17.45 \pm 7.04$ & $3.24 \pm 0.71$ & 187 & $\mathbf{0 . 0 0 1}$ \\
$\mathbf{7 0 ~ H z}$ & $22.03 \pm 9.78$ & $3.76 \pm 0.70$ & 182 & $\mathbf{0 . 0 0 3}$ \\
\hline
\end{tabular}

\subsection{Temporal fidelity of neuronal firing}

Since precise spike timing might have important implications for the representation of sensory stimuli in primary cortical areas, we assessed whether the reduction in the spike SNR observed in NRG1 animals was associated with a decrease in the temporal precision of the sensory-evoked responses. Thus, we calculated the phase locking of MUA and SUA to the stimulus cycles for each stimulation frequency. The degree to which responses were phase-locked to the stimuli was quantified using vector strength analysis (see Methods, Section 3), where higher values of vector strength $r$ denote better phase locking (a vector strength value of 1 indicates perfect phase locking to the stimulus, whereas a vector strength of 0 indicates absence of a consistent phase relationship of the spikes to the stimulus cycles). Since the length of stimulus cycles changes as a function of the stimulation frequency, an additional measure of temporal precision was used to assess the temporal 
dispersion $d$ of MUA and SUA responses (see Methods, Section 3). Lower values of temporal dispersion $d[\mathrm{~ms}]$ indicate higher temporal precision.

(A)

WT MUA

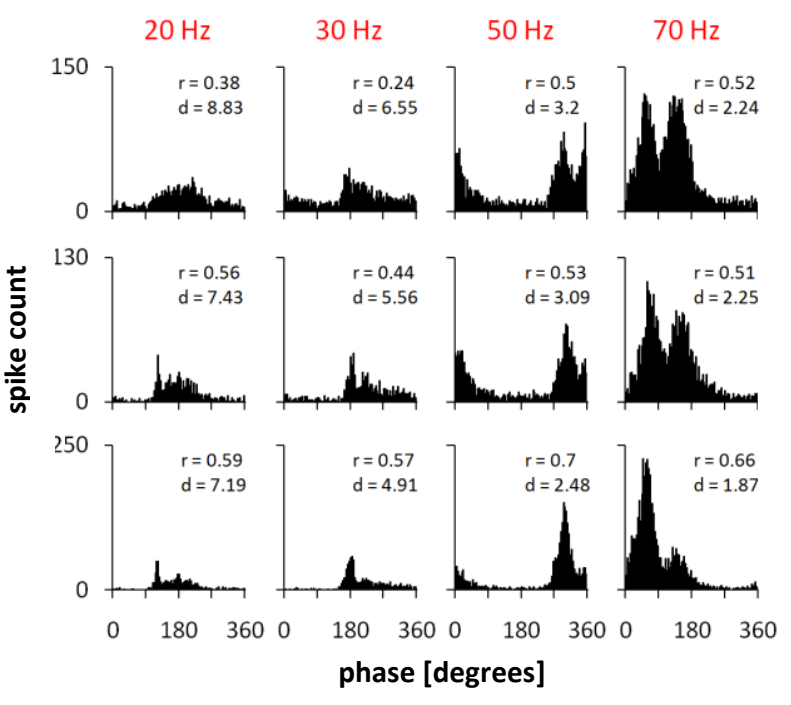

(B)
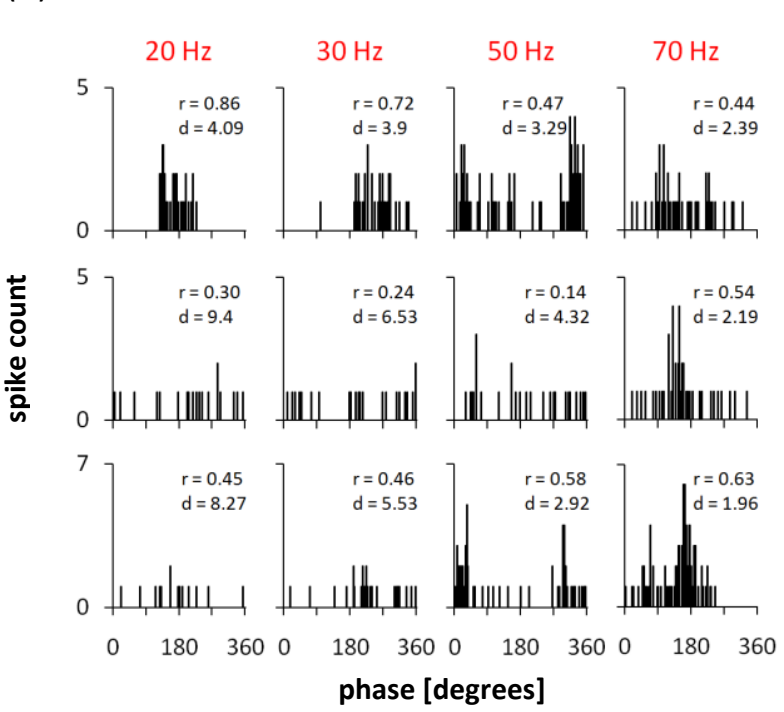

NRG1 MUA

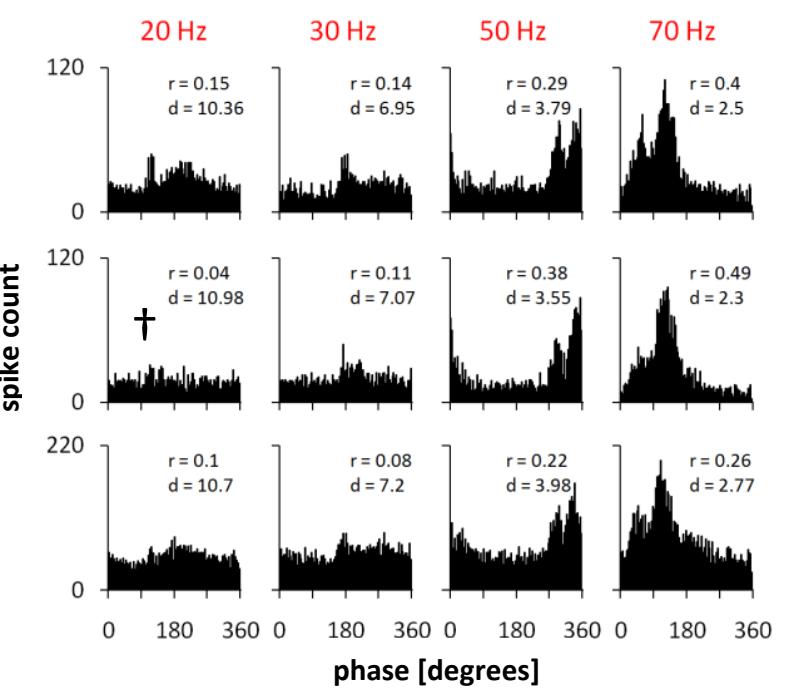

NRG1 SUA
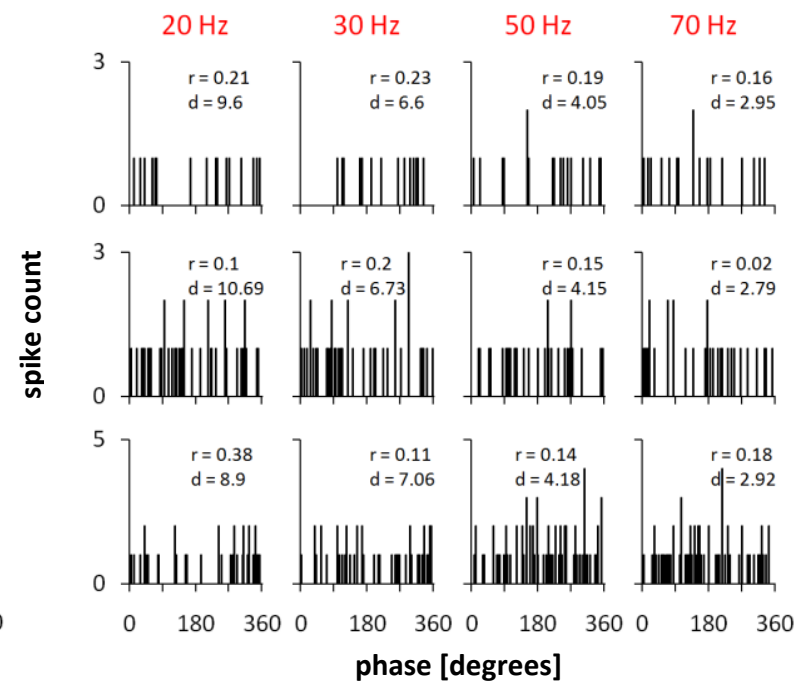

FIGURE 4. Phase histograms of MUA and SUA responses. Vector strength $r$ and temporal dispersion $d$ [ms] are displayed for each histogram. Higher values of vector strength indicate good phase locking, while lower values of temporal dispersion indicate high temporal precision. A. MUA phase histograms. Top-to-bottom: Histograms of three representative units (same MUAs as described in Figure 1B). Left-to-right: Phase locking during four stimulation conditions in WT (left panel) and NRG1 MUAs (right panel). MUAs not meeting the significance criterion $(p>0.001)$ are marked by $\dagger$. B. SUA phase histograms. Top-to-bottom: Histograms of three representative units (same SUAs as described in Figure 1C). Left-to-right: Phase locking during four stimulation conditions in WT (left panel) and NRG1 SUAs (right panel). Due to low spike counts, vector strength values of SUAs could not be assessed statistically. 
For all stimulation conditions, WT MUAs $(\mathrm{n}=28)$ and NRG1 MUAs $(\mathrm{n}=25)$ displayed significant phase locking to the stimulus cycles (Fig. 4A). In WT mice, the frequency of the stimulation did not substantially affect the phase locking of the MUA responses (Fig. 5A.1 and B.1). In NRG1 mice, MUAs showed a reduction in their phase locking to the stimulus cycles only for frequencies below $50 \mathrm{~Hz}$ (t-tests; Table 4). Moreover, NRG1 mutants showed increased temporal dispersion at $20 \mathrm{~Hz}$ and $40 \mathrm{~Hz}$ stimulation frequencies (Mann-Whitney, $\mathrm{p} \leq 0.004$; Fig. 5A.2 and B.2, Table 5). Thus, when the sensory evoked MUA firing rate is low, the decrease in the spike SNR observed in NRG1 mice is associated with a decrease in temporal precision.

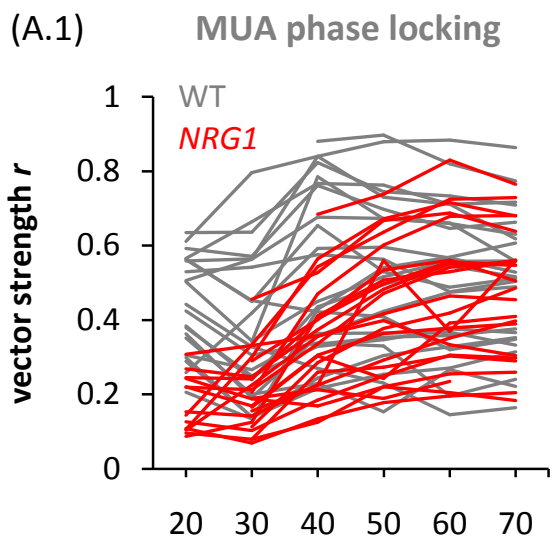

stimulation frequency $[\mathrm{Hz}]$

(B.1)

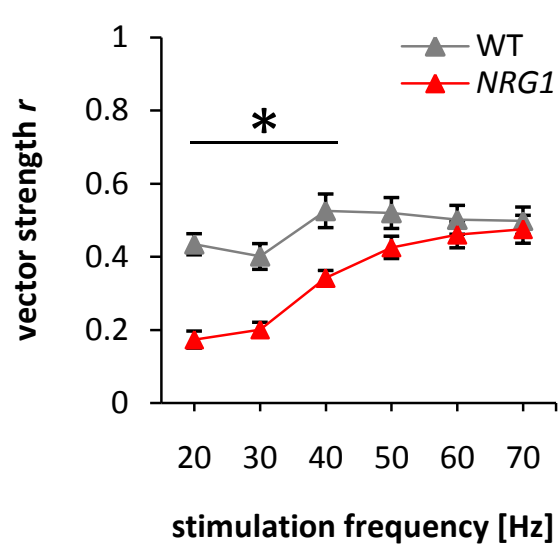

(A.2) MUA temporal dispersion

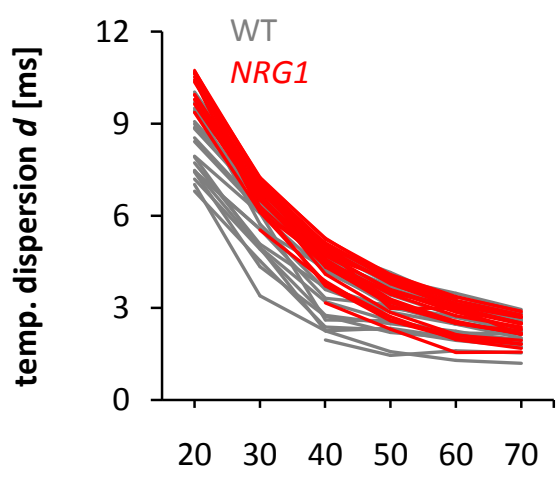

stimulation frequency $[\mathrm{Hz}]$

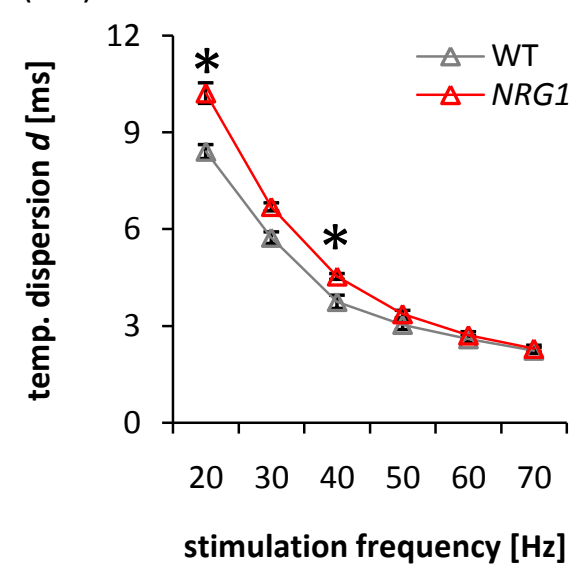

FIGURE 5. Temporal precision of MUA responses during 20-70 Hz stimulation. Temporal precision was assessed in terms of vector strength (left column) and temporal dispersion (right column) in 28 WT MUAs (gray traces) and 23 NRG1 MUAs (red traces). A. For individual MUAs, values of vector strength (A.1) and temporal dispersion (A.2) are displayed across stimulation conditions. B. MUA population averages of vector strength (B.1) and temporal dispersion (B.2) across stimulation conditions. Phase-locking was reduced in NRG1 mutants in the $20-40 \mathrm{~Hz}$ range (see Table 4 for details), while temporal dispersion was increased in NRG1 mutants in response to $20 \mathrm{~Hz}$ and $40 \mathrm{~Hz}$ stimulation (see Table 5 for details). * Significant between-group differences. 
With regard to SUAs, many units had a low spike rate that precludes a proper statistical analysis of the vector strength values. Therefore, the phase histograms of the single units (WT: $n=$ 10; NRG1: $\mathrm{n}=22$ ) were combined by summing the spikes in each time bin. Vector strength and temporal dispersion analyses were then performed on one histogram per group in each stimulation condition. The results revealed that WT responses were significantly phase-locked at all stimulation frequencies, while $N R G 1$ responses were locked to all frequencies but $30 \mathrm{~Hz}$ (Fig. 6A). When results were collapsed across conditions, NRG1 SUAs displayed a 3.8-fold reduction in vector strength relative to WT SUAs (t-test, $\mathrm{t}(10)=11.3, \mathrm{p}<0.0001$ ). In line with these findings, temporal dispersion was higher in NRG1 SUAs than in WT SUAs (Fig. 6B). Temporal dispersion values were not compared statistically between groups since values showed an exponential distribution that did not allow collapsing values across conditions.

TABLE 4. Between-group differences in MUA vector strength. Group differences were assessed per condition using unpaired t-tests. The mean vector strength $r \pm \mathrm{SE}$ of WT and NRG1 responses are shown as well as the number of MUAs ( $n$ ), the $t$ statistic, the degrees of freedom (df) and the corresponding $p$ value (in bold if significant). Bonferroni-corrected significance level: $p=0.008$.

\begin{tabular}{ccccccc}
\hline frequency & WT $\boldsymbol{r}$ & NRG1 $\boldsymbol{r}$ & WT $\mathbf{n}$ & $\mathbf{N R G 1} \mathbf{n}$ & $\mathbf{t}(\mathbf{d f})$ & $\mathbf{p}$ \\
\hline $\mathbf{2 0} \mathbf{~ H z}$ & $0.43 \pm 0.03$ & $0.17 \pm 0.02$ & 22 & 14 & $6.6(34)$ & $<\mathbf{0 . 0 0 0 1}$ \\
$\mathbf{3 0 ~ H z}$ & $0.40 \pm 0.04$ & $0.18 \pm 0.03$ & 26 & 22 & $4.9(46)$ & $<\mathbf{0 . 0 0 0 1}$ \\
$\mathbf{4 0 ~ H z}$ & $0.53 \pm 0.05$ & $0.34 \pm 0.03$ & 24 & 23 & $3.3(45)$ & $\mathbf{0 . 0 0 2}$ \\
$\mathbf{5 0 ~ H z}$ & $0.52 \pm 0.04$ & $0.43 \pm 0.04$ & 24 & 23 & $1.7(45)$ & 0.098 \\
$\mathbf{6 0 ~ H z}$ & $0.50 \pm 0.04$ & $0.46 \pm 0.04$ & 25 & 23 & $0.7(46)$ & 0.463 \\
$\mathbf{7 0 ~ H z}$ & $0.50 \pm 0.04$ & $0.36 \pm 0.05$ & 24 & 22 & $2.2(44)$ & 0.037 \\
\hline
\end{tabular}

TABLE 5. Between-group comparison of MUA temporal dispersion. The Mann-Whitney test was applied for comparing temporal dispersion values of WT and NRG1 MUAs per condition. Shown are the mean temporal dispersion $d \pm$ SE for WT and NRG1 responses, the number of MUAs $(n)$, the Mann-Whitney $U$ and the $p$ value (in bold to indicate significance). Bonferroni-corrected significance level: $p=0.008$.

\begin{tabular}{ccccccc}
\hline frequency & WT $\boldsymbol{d}[\mathrm{ms}]$ & $\mathbf{N R G 1} \boldsymbol{d}[\mathrm{ms}]$ & $\mathbf{W T} \mathbf{n}$ & $\mathbf{N R G 1} \mathbf{n}$ & $\mathbf{U}$ & $\mathbf{p}$ \\
\hline $\mathbf{2 0} \mathbf{~ H z}$ & $8.41 \pm 0.22$ & $8.75 \pm 1.0$ & 22 & 14 & 59 & $\mathbf{0 . 0 0 1}$ \\
$\mathbf{3 0 ~ H z}$ & $5.74 \pm 0.18$ & $5.76 \pm 0.51$ & 26 & 22 & 168 & 0.015 \\
$\mathbf{4 0 ~ H z}$ & $3.75 \pm 0.20$ & $4.54 \pm 0.11$ & 24 & 23 & 142 & $\mathbf{0 . 0 0 4}$ \\
$\mathbf{5 0 ~ H z}$ & $3.04 \pm 0.15$ & $3.37 \pm 0.11$ & 24 & 23 & 200 & 0.109 \\
$\mathbf{6 0 ~ H z}$ & $2.59 \pm 0.11$ & $2.71 \pm 0.10$ & 25 & 23 & 251 & 0.461 \\
$\mathbf{7 0 ~ H z}$ & $2.24 \pm 0.09$ & $1.79 \pm 0.22$ & 24 & 22 & 305 & 0.373 \\
\hline
\end{tabular}


(A)

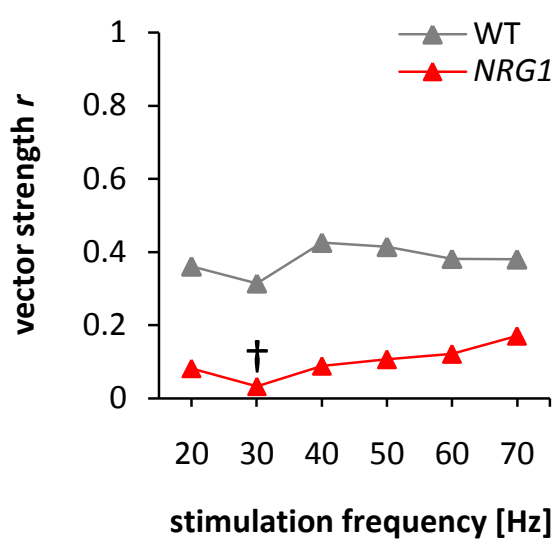

(B) SUA temporal dispersion

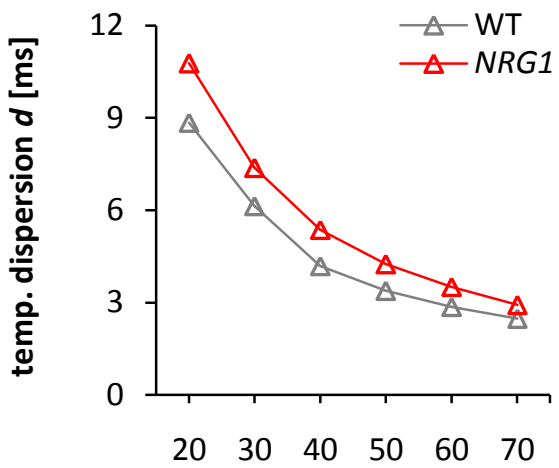

stimulation frequency $[\mathrm{Hz}]$

FIGURE 6. Temporal precision of SUA responses during 20-70 Hz stimulation. Vector strength and temporal dispersion were measured in WT SUAs $(n=25)$ and NRG1 SUAs $(n=51)$. Due to the low spike count of the SUAs, the phase histograms of the individual units were combined in one phase histogram per group. A. Vector strength in WT SUAs (gray traces) and NRG1 SUAs (red traces). Values not meeting the significance criterion $(p>0.05)$ are marked by $\dagger$. $B$. Temporal dispersion of SUA responses in WT SUAs (gray) and NRG1 SUAs (red) across frequencies.

\subsection{Reduced gamma oscillations in NRG1 mutants}

To test the ability of the NRG1 circuitry to sustain $20-40 \mathrm{~Hz}$ oscillations, two types of gamma oscillations have been investigated here. The first are gamma oscillations induced by high-frequency $(50-70 \mathrm{~Hz})$ stimulation. The second type are steady-state gamma oscillations evoked by stimuli in the gamma range $(20-40 \mathrm{~Hz})$. While induced oscillations are not locked to the stimulus onset, steadystate oscillations do show stimulus locking. We focused our analysis on sustained LFP responses (0.15-1 s post stimulus onset, omitting the onset response) to assess changes in power as a function of changes in stimulation frequency. We performed planned comparisons on selected conditions, hence a multiple comparison correction was not applied.

\subsubsection{Induced gamma during high frequency $(50-70 \mathrm{~Hz})$ stimulation}

In barrel cortex, gamma oscillations are more easily induced with high frequency stimulation than with low frequency stimulation (Ewert et al., 2008). In our study, we were limited to $70 \mathrm{~Hz}$ as the maximal stimulation frequency for technical reasons. Previously, we observed increasing gamma power in the $50-70 \mathrm{~Hz}$ range in BL6 mice, with gamma close to baseline levels at $50 \mathrm{~Hz}$ and the strongest gamma response at $70 \mathrm{~Hz}$ (Chapter III). We therefore hypothesized that if gamma deficits were present in NRG1 mutants, we would most likely detect them at the highest $(70 \mathrm{~Hz})$ stimulation frequency. 
Power analysis was performed for 36 WT LFPs and 32 NRG1 LFPs. Performing power analysis on single trial responses during $50-70 \mathrm{~Hz}$ stimulation revealed gamma oscillations (20-40 Hz) in WT mice that were not locked to the stimulus onset (i.e. induced; Fig. 7A,B). In NRG1 mice, induced gamma activity was less pronounced. In addition, power analysis on the average of single trial responses was performed to reveal stimulus-locked (evoked) components. No gamma activity was seen under these conditions in either WT or NRG1 animals (Fig. 7C,D). Therefore, subsequent analyses focused on changes in induced power.

To quantify changes in induced gamma power, we first measured total power in stimulation and baseline conditions (Fig. 8A). Total power during baseline and stimulation did not differ between the groups (Mann-Whitney, $p>0.05$ ). Next, we measured absolute gamma power during stimulation and baseline conditions (Fig. 8B). The analysis revealed no significant differences between groups in the level of absolute gamma during baseline and stimulation (Mann-Whitney, $p>0.05$ ). Additional analyses demonstrated that WT and NRG1 animals did not differ with respect to the peak frequency of the absolute gamma response at $70 \mathrm{~Hz}$ (WT: $23.8 \pm 0.8$; NRG1: $23.7 \pm 0.8$; Mann-Whitney, $\mathrm{p}$ > 0.05). However, the power of the measured gamma peak during $70 \mathrm{~Hz}$ stimulation was larger in WT $\left(1.54 \mathrm{E}-10 \pm 8.78 \mathrm{E}-12 \mathrm{~V}^{2}\right)$ than NRG1 mice $\left(1.16 \mathrm{E}-10 \pm 1.38 \mathrm{E}-11 \mathrm{~V}^{2}\right.$; Mann-Whitney, $\left.\mathrm{p}=0.041\right)$. The results show that absolute gamma measured in the $20-40 \mathrm{~Hz}$ range did not reveal differences between WT and NRG1 mice, but narrowing the analysis to the peak frequency did reveal differences.

To account for changes in the total power spectrum that may affect absolute gamma power, we also calculated changes in relative gamma (absolute gamma power divided by the total power spectrum) during stimulation and baseline (Fig. 8C). In baseline conditions, no between-group differences in relative gamma were found (Mann-Whitney, $p>0.05$ ). During stimulation, relative gamma levels did not differ at $50 \mathrm{~Hz}$ and $60 \mathrm{~Hz}$ (Mann-Whitney, $p>0.05$ ), but were reduced in NRG1 compared to WT mice at $70 \mathrm{~Hz}$ (Mann-Whitney, $\mathrm{p}=0.047$ ).

Finally, we sought to determine whether reductions in spike SNR in NRG1 MUAs were paralleled by a decrease in gamma SNR during high-frequency stimulation. Gamma SNR was quantified as relative gamma during stimulation divided by relative gamma during baseline. NRG1 responses to $70 \mathrm{~Hz}$ showed reduced gamma SNR compared to WT mice (Mann-Whitney, $p=0.037$; Fig. 8D). Gamma SNRs did not differ at $50 \mathrm{~Hz}$ or $60 \mathrm{~Hz}$ stimulation (Mann-Whitney, $p>0.05$ ). A correlation analysis between spike SNR and gamma SNR during 50-70 $\mathrm{Hz}$ stimulation revealed a positive association in WT mice (Spearman, $\mathrm{rs}=0.39, \mathrm{p}=0.0001$ ), but no association in NRG1 mice (Spearman, rs =-0.13, p > 0.05; Fig. 9). 
(A)

WT

NRG1

$50 \mathrm{~Hz}$

$60 \mathrm{~Hz}$

$70 \mathrm{~Hz}$

$50 \mathrm{~Hz}$

$60 \mathrm{~Hz}$

$70 \mathrm{~Hz}$
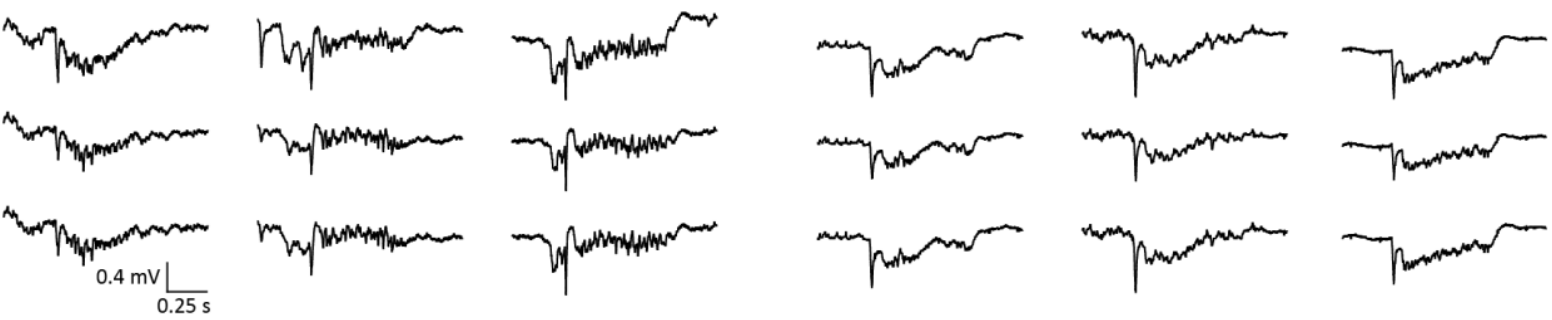

(B)
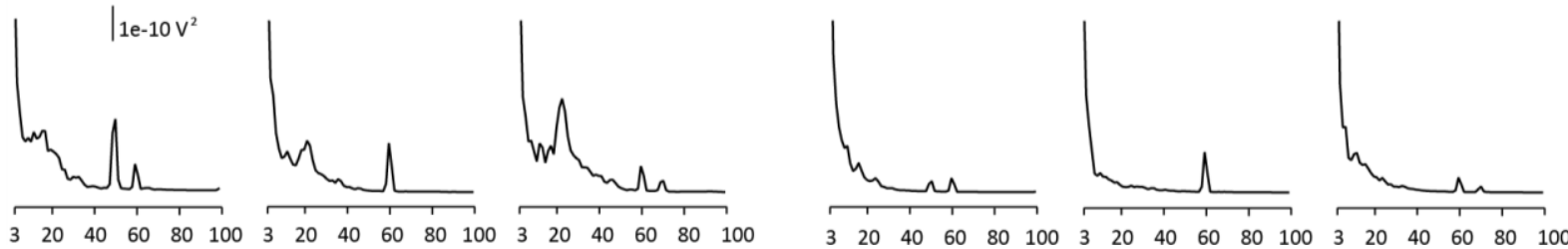

frequency $[\mathrm{Hz}]$

frequency $[\mathrm{Hz}]$

(C)

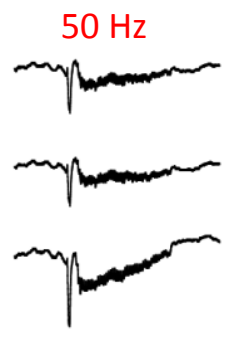

WT

NRG1

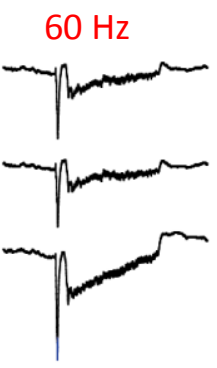

$70 \mathrm{~Hz}$
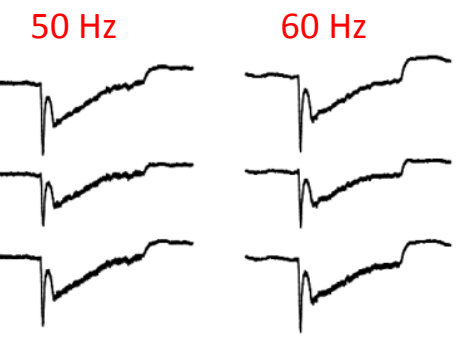

$70 \mathrm{~Hz}$

(D)
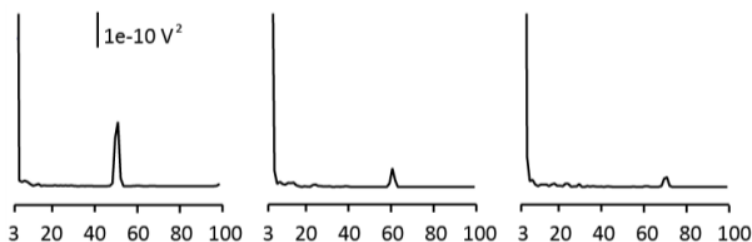

frequency $[\mathrm{Hz}]$
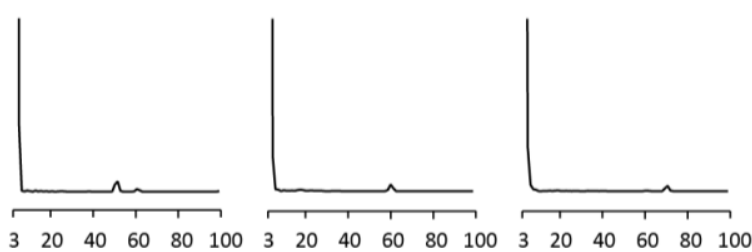

frequency $[\mathrm{Hz}]$

FIGURE 7. Gamma power during $50-70 \mathrm{~Hz}$ stimulation. Shown are traces and power spectra of induced $(A, B)$ and evoked $(C, D)$ responses in a WT mouse (left panel) and in an NRG1 mouse (right panel). $A$. Raw LFPs in response to $50-70 \mathrm{~Hz}$ stimulation. Shown are three single-trial traces (top to bottom) recorded at the same tetrode in a WT mouse (left) and in an NRG1 mutant (right). $B$. Average power spectra of single trials. Power was measured $0.15-1 \mathrm{~s}$ following response onset during each trial and averaged subsequently to reveal the components that are not stimulus-locked, i.e. induced. Unlike the NRG1 mutant, the WT mouse displayed a power peak at $23 \mathrm{~Hz}$ that increased at higher stimulus frequencies, reflecting stimulus-related gamma oscillations. In both WT and NRG1 mice, power peaked at the stimulation frequency $(50-70 \mathrm{~Hz})$ and at $60 \mathrm{~Hz}$. The former peak reflects stimulus-specific activity ('steady-state oscillations'), while the latter reflects electrical noise. $C$. Average LFPs in response to $50-70 \mathrm{~Hz}$ recorded at the same tetrode in a WT mouse (left panel) and in an NRG1 mutant (right panel; same as in A). D. Power spectra of the average LFP response. The graphs show the evoked oscillations that are locked to the stimulus onset. No peaks are detected in the gamma range. 


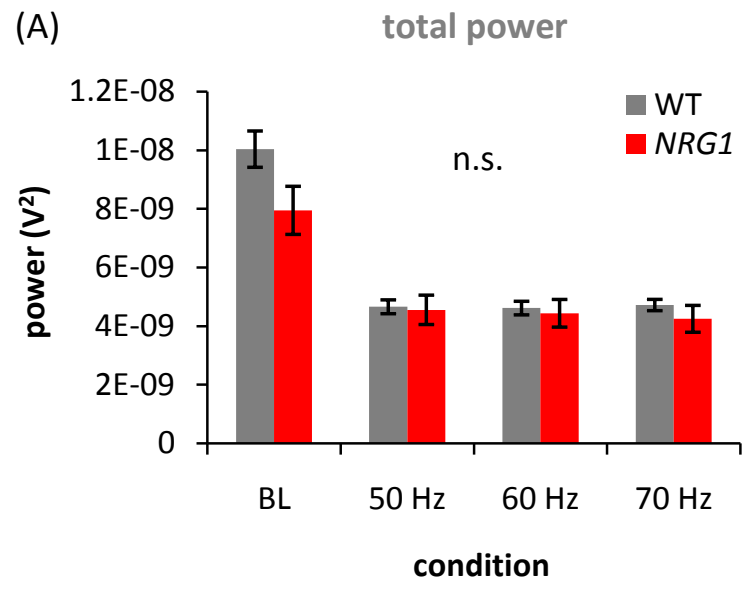

(C)

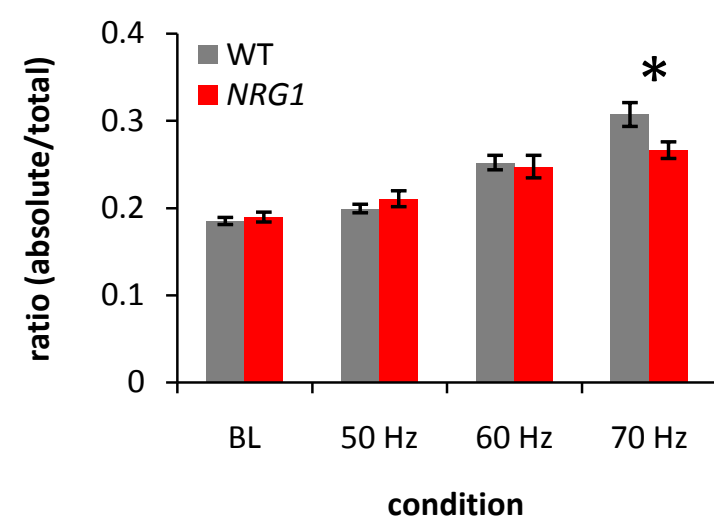

(B) absolute gamma

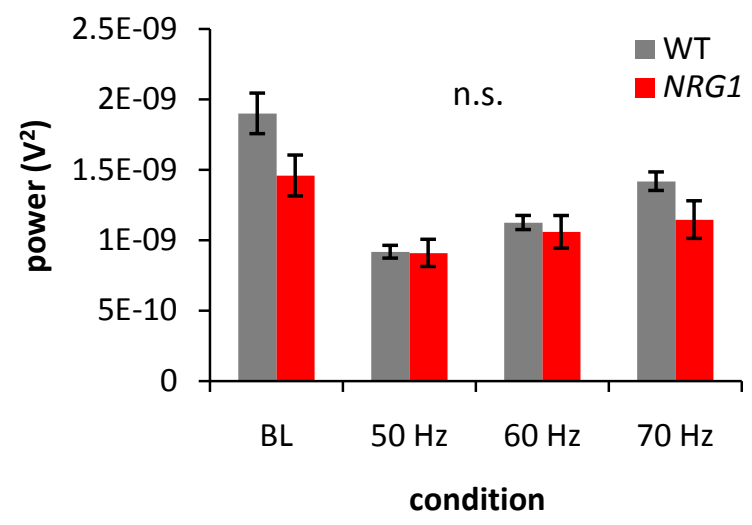

(D)

gamma SNR

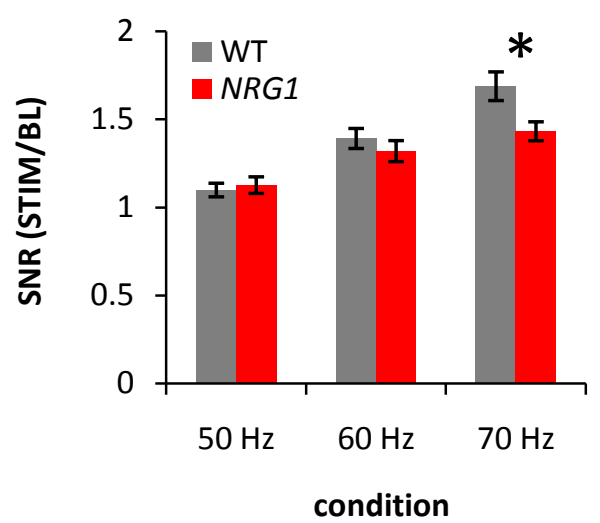

FIGURE 8. Induced gamma power during $50-70 \mathrm{~Hz}$ stimulation and baseline conditions. Power calculations are based on single-trial averages of power spectra derived from 36 WT LFPs and 32 NRG1 LFPs during baseline (BL) and stimulation (STIM; 50-70 Hz) conditions. A. Total power (5-100 $\mathrm{Hz}$ ) was comparable in magnitude between WT and NRG1 mice during $\mathrm{BL}$ (Mann-Whitney, $\mathrm{U}=728, \mathrm{p}$ $=0.062$ ) and STIM conditions (Mann-Whitney, $p>0.05)$. B. Absolute gamma power $(20-40 \mathrm{~Hz})$ did not differ between groups during BL and STIM conditions (Mann-Whitney, $p>0.05$ ). C. Relative gamma power, measured by dividing absolute gamma by total power, was reduced in NRG1 mice in response to $70 \mathrm{~Hz}$ (Mann-Whitney, $U=738, p=0.047$ ), but did not differ in other conditions or during $\mathrm{BL}$ (Mann-Whitney, $\mathrm{p}>0.05$ ). D. Gamma SNR during stimulation was significantly reduced in $N R G 1$ mutants in the $70 \mathrm{~Hz}$ condition (Mann-Whitney, $\mathrm{U}=746, \mathrm{p}=0.037$ ). Gamma SNR is the ratio between relative gamma during STIM and relative gamma during BL. * Significant between-group differences.

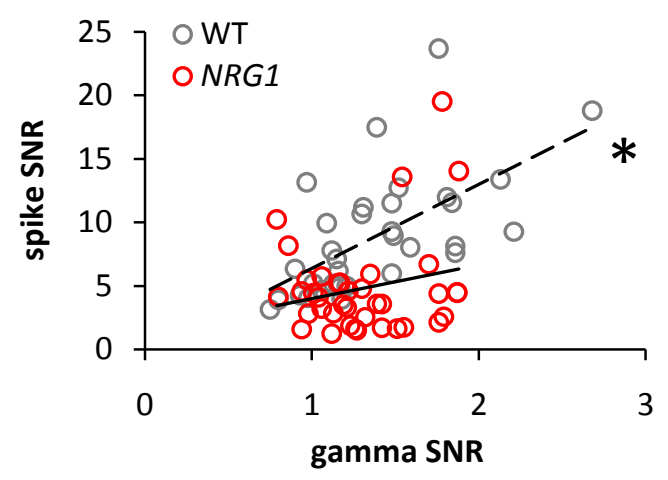

FIGURE 9. Correlation between gamma SNR and spike SNR. Trend lines are indicated for WT (dashed) and NRG1 responses (straight). Significant correlations are marked by *. Gamma SNR of the LFPs correlated moderately with spike SNR of the corresponding MUAs in WT mice (gray circles; $\mathrm{n}=33$; Spearman, $\mathrm{rs}(31)=0.39, \mathrm{p}=$ 0.0001 ), but not in NRG1 mice (red circles; $\mathrm{n}=38$; Spearman, $r s(37)=-0.13, p>0.05)$. 


\subsubsection{Steady-state gamma oscillations during $20-40 \mathrm{~Hz}$ stimulation}

In view of the finding that induced gamma SNR and induced relative gamma (20-40 Hz) were decreased during $70 \mathrm{~Hz}$ stimulation in NRG1 mutants, we wondered whether these impairments were related to specific processing deficits during high frequency stimulation, or whether the neuronal microcircuitry in NRG1 mice was generally less able to sustain oscillations in the $20-40 \mathrm{~Hz}$ range. We therefore measured gamma oscillations at 20,30 and $40 \mathrm{~Hz}$ in response to 20,30 , and 40 $\mathrm{Hz}$ stimulation (steady-state gamma). First, no differences were detected in total power during 20 , 30 and $40 \mathrm{~Hz}$ stimulation (Mann-Whitney, $\mathrm{p}>0.05$ ). Absolute $20-40 \mathrm{~Hz}$ power was slightly smaller in NRG1 mice than WT mice in the $20-40 \mathrm{~Hz}$ conditions, but differences were not significant (MannWhitney, $p>0.05)$.

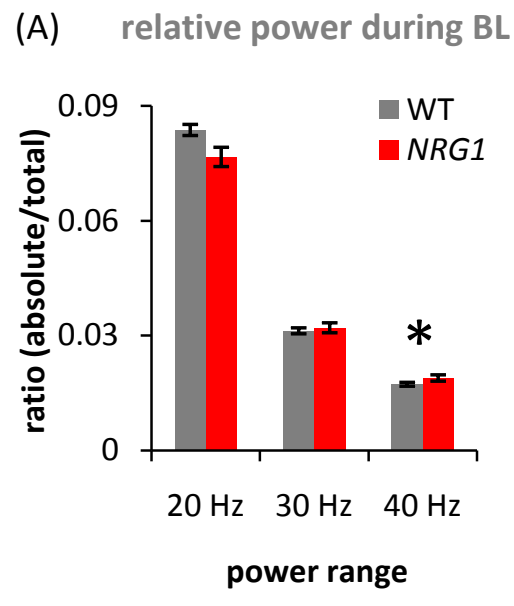

(B) relative power during STIM

(C) gamma SNR
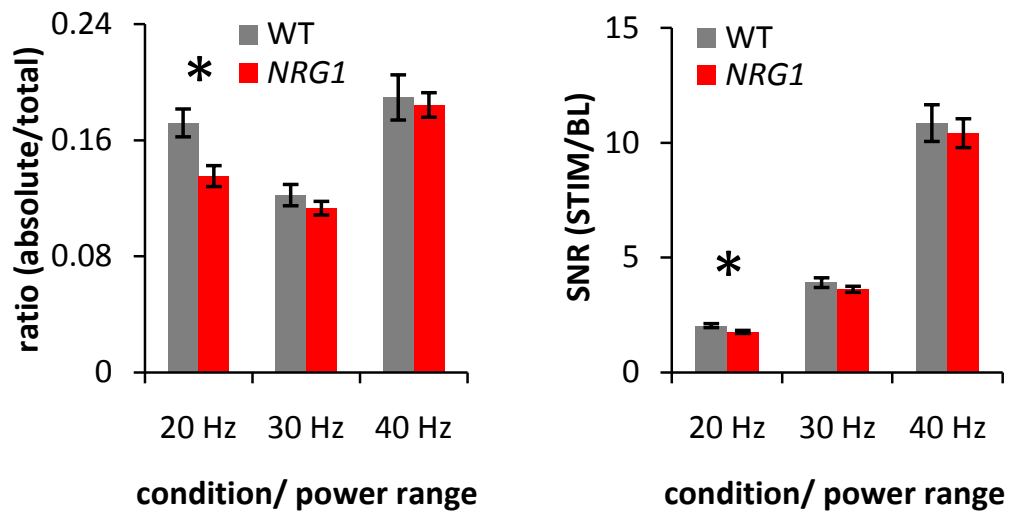

FIGURE 10. Steady-state gamma oscillations during $20-40 \mathrm{~Hz}$ stimulation. Power was measured at 20 , 30 or $40 \mathrm{~Hz}$ ('power range') during baseline, or during 20,30 or $40 \mathrm{~Hz}$ stimulation ('condition'). A. Relative power during baseline (BL) did not differ between WT and NRG1 mice in the 20-30 Hz range (Mann-Whitney, p > 0.05), but was significantly increased at $40 \mathrm{~Hz}$ in NRG1 mutants (Mann-Whitney, $\mathrm{U}=392, \mathrm{p}=0.023)$. B. Relative power during stimulation (STIM). Relative $20 \mathrm{~Hz}$ power in response to $20 \mathrm{~Hz}$ stimulation was lower in NRG1 mice than in WT mice (Mann-Whitney, $U=809, p=0.004$ ). $C$. SNR, defined as the ratio between relative power during STIM and relative power during BL. SNR during $20 \mathrm{~Hz}$ stimulation was significantly decreased in NRG1 mutants (Mann-Whitney, $\mathrm{U}=738, \mathrm{p}=$ 0.047), but normal during $30 \mathrm{~Hz}$ and $40 \mathrm{~Hz}$ stimulation (Mann-Whitney, $\mathrm{p}>0.05$ ). ${ }^{*}$ Significant between-group differences.

Moreover, relative gamma power was measured during baseline (Fig. 10A) and stimulation conditions (Fig. 10B). Relative baseline power did not differ between WT and NRG1 animals in the 20 $\mathrm{Hz}$ range (Mann-Whitney, $\mathrm{p}=0.08$ ) and $30 \mathrm{~Hz}$ range (Mann-Whitney, $\mathrm{p}>0.05$ ), but was significantly elevated in the $40 \mathrm{~Hz}$ band (Mann-Whitney, $p=0.023$; Fig. 10A). During stimulation, responses in 
NRG1 mice showed diminished relative gamma at $20 \mathrm{~Hz}$ (Mann-Whitney, $\mathrm{p}=0.004$ ), but normal power at $30 \mathrm{~Hz}$ and $40 \mathrm{~Hz}$ (Mann-Whitney, p > 0.05; Fig. 10B).

Finally, gamma SNR at $20 \mathrm{~Hz}$ was diminished in NRG1 mutants compared to WT mice (MannWhitney, $\mathrm{p}=0.047$; Fig. 10C). In contrast, no differences in gamma SNR were detected at $30 \mathrm{~Hz}$ or 40 $\mathrm{Hz}$ between the strains (Mann-Whitney; $\mathrm{p}>0.05$ ).

In summary, we demonstrated a reduction in non-locked, induced gamma during $70 \mathrm{~Hz}$ stimulation in NRG1 mutants, as shown by the impairments in absolute gamma ( $23 \mathrm{~Hz}$ peak), relative gamma $(20-40 \mathrm{~Hz})$, and gamma SNR $(20-40 \mathrm{~Hz})$. In addition, steady-state gamma oscillations at $20 \mathrm{~Hz}$ were diminished in NRG1 mice, as suggested by the decrease in relative power and gamma SNR during $20 \mathrm{~Hz}$ stimulation. While baseline power in the entire $20-40 \mathrm{~Hz}$ range did not differ between mutants and WT mice, a slight but significant increase in baseline gamma at $40 \mathrm{~Hz}$ was detected.

\section{Discussion}

To elucidate the neuronal basis of somatosensory processing abnormalities in schizophrenia, we applied repetitive $20-70 \mathrm{~Hz}$ whisker stimulation to mice heterozygous for the schizophrenia susceptibility gene NRG1 and measured unit and LFP responses at the level of the primary somatosensory cortex. We report (1) a reduction in spike SNR and an increase in baseline firing, (2) a decrease in temporal precision of neuronal responses to $20-40 \mathrm{~Hz}$ stimuli, (3) a reduction in induced and steady-state gamma, and (4) an increase in $40 \mathrm{~Hz}$ baseline gamma in NRG1 mutants compared to WT mice. The results were most robust in MUAs, and largely supported by the SUA data.

\subsection{Firing rates}

A previous study in NRG1 mutants showed abnormally elevated sustained MUA responses both during baseline and 1-15 $\mathrm{Hz}$ whisker stimulation, and a reduced spike SNR at 1, 3 and $8 \mathrm{~Hz}$ (Chapter IV). Following up on these findings, we now presented stimuli at $20-70 \mathrm{~Hz}$ and found a similar pattern of results at the level of MUAs, and to some degree also in SUAs: increased baseline spiking, elevated stimulus-evoked responses, and a decreased spike SNR of sustained responses (Fig. 2 and 3). In healthy mice (WT - this study, and BL6 - Chapter III) and rats (Ahissar et al., 2001; Arabzadeh et al., 2005; Khatri et al., 2004), neurons fire more at higher stimulation frequencies and thus achieve a large increase of stimulus-evoked spiking over baseline spiking (SNR). As a result, the SNR increases with increasing frequency in the $20-70 \mathrm{~Hz}$ range (Fig. 3). In NRG1 mice, in contrast, baseline spiking is elevated and thus the gain of the $20-70 \mathrm{~Hz}$ SNR is reduced at the level of MUAs and SUAs. The results are more variable for SUAs than for MUAs, possibly due to low spike counts in SUAs and a pooling of excitatory and inhibitory units. 
The finding of increased stimulus-evoked and baseline firing rates in the NRG1 mutant is in agreement with the role of the NRG1 gene in the excitatory-inhibitory tuning of the cortical network (Fazzari et al., 2010; Geddes et al., 2011; Hahn et al., 2006; Li et al., 2007; Marenco et al., 2011; Ting et al., 2011; Wen et al., 2010; Woo et al., 2007). Loss of NRG1 function, as reported in schizophrenic patients (Bousman et al., 2013; Dean et al., 2009; Fukui et al., 2006; Georgieva et al., 2008; Li et al., 2006), is associated with a reduction in inhibition (less excitatory drive to inhibitory cells; Ting et al., 2011) and an increase in excitation (less inhibitory drive to excitatory cells, i.e. disinhibition; Fazzari et al., 2010). Vogels and Abbott modeled the effects of hyperexcitability and weak inhibition on firing rates in two types of networks - with either equal or unequal inputs to excitatory and inhibitory neurons (Vogels and Abbott, 2007). When excitation was increased by $60 \%$ and inhibition was decreased by $60 \%$ in parallel, spontaneous as well as stimulus-evoked spiking activity was elevated in both network types. This augmentation in spiking was more pronounced in the network with unequal inputs compared to the network with equal inputs (Vogels and Abbott, 2007). Our results of a large increase in spike rate during baseline and stimulation conditions in NRG1 mice concur with the modeling results obtained in the network with unequal inputs. A network with unequal inputs may more closely resemble the barrel cortex circuitry during stimulation, since receptive field characteristics of barrel cortex neurons emerge from varying degrees of excitatory and inhibitory drive (Brumberg et al., 1996; Bruno and Simons, 2002; Ebner and Armstrong-James, 1990) and their relative timing (Wilent and Contreras, 2005).

Our results are further supported by experimental studies showing enhancements in the baseline firing rate in mouse mutants deficient for ErbB4 (Del Pino et al., 2013) and in mice lacking the N-methyl-D-aspartate (NMDA) receptor subunit NR1 (Belforte et al., 2010; Carlen et al., 2012). For example, Carlen and colleagues (2012) reported $0.49 \mathrm{~Hz}$ baseline MFRs of regular spiking cells in the barrel cortex of anesthetized NR1 mutants, as compared to $0.25 \mathrm{~Hz}$ in WT mice. These values are comparable to our measurements in SUAs in the barrel cortex of anesthetized NRG1 mice $(0.29 \mathrm{~Hz})$ and WT mice $(0.1 \mathrm{~Hz})$. Furthermore, mice and rats treated with NMDA receptor antagonists also showed enhanced baseline spike rates (Jackson et al., 2004; Wood et al., 2012; Zhang et al., 2012), and these changes were related to alterations in the excitatory-inhibitory balance (Homayoun and Moghaddam, 2007).

\subsection{Temporal precision of neuronal firing}

In line with previous studies in rats (Ewert et al., 2008; Garabedian et al., 2003; Khatri et al., 2004) and BL6 mice (Chapter III), WT mice showed phase-locked MUA and SUA responses up to $70 \mathrm{~Hz}$, indicating high levels of temporal fidelity of spiking. In comparison, NRG1 mice showed reduced phase locking and increased temporal dispersion in response to $20-40 \mathrm{~Hz}$ stimuli at the level of 
MUAs (Fig. 5), with similar trends in SUAs (Fig. 6). At higher stimulation frequencies, phase locking of NRG1 MUAs approached WT levels. Previously, we reported impaired phase locking and elevated temporal dispersion of NRG1 responses at 5-15 Hz stimulation (Chapter IV). Together, these findings show that the NRG1 mutation produces broad-band deficits in the temporal precision of spike timing in the $5-40 \mathrm{~Hz}$ range, with a peak around $8 \mathrm{~Hz}$ and gradually smaller deficits at higher frequencies.

A closer inspection of the phase histograms (Fig. 4) suggests that the reduction in NRG1 phase locking stems from an increase in noisy spikes, rather than from a generally lower level of accurately timed spikes. Thus, reduced spike precision in NRG1 mice may reflect decreased spike SNR as a result of elevated baseline firing (see Section 5.1). This result is consistent with the role of NRG1 in altering the excitatory-inhibitory microcircuitry, which increases network excitability and hence the level of noisy spikes. It has been proposed that phase-locked responses may constitute a code for time-varying stimulus features and may be relevant for texture discrimination (Ewert et al., 2008). As a result of increased baseline activity and impaired temporal coding of stimulus features, the processing of perceptual information may be diminished in NRG1 mice.

Deficits in the temporal precision of sensory responses have also been demonstrated in other models of schizophrenia. During auditory stimulation, reductions in the phase relationship between trials (intertrial coherence) have been described in rodents after NMDA antagonist treatment (Featherstone et al., 2013; Vohs et al., 2012), neonatal lesioning of the ventral hippocampus (Vohs et al., 2012), and in mice deficient for the schizophrenia risk gene Dysbindin-1, (Carlson et al., 2011). In addition, another study showed poorly phase-locked responses after optogenetic stimulation of the barrel cortex of NR1-deficient mice. However, frequency-specific effects were not investigated in this study (Carlen et al., 2012). Together, our results and previous studies suggest that altering excitatory-inhibitory signaling adversely affects the temporal precision of neuronal responses. In addition, our findings in NRG1 mice indicate that these effects might be dependent on the stimulation frequency.

\section{$\underline{5.3 \text { Gamma oscillations }}$}

NRG1 mutants displayed reductions (with respect to SNR and relative power) in induced gamma oscillations (20-40 Hz) during $70 \mathrm{~Hz}$ stimulation (Fig. 8), and in steady-state gamma oscillations (20 $\mathrm{Hz}$ ) during $20 \mathrm{~Hz}$ stimulation (Fig. 10). These findings suggest a generally decreased ability of the NRG1 barrel circuitry to support gamma oscillations, and confirm for the first time in vivo the previously suggested link between gamma and NRG1 (Buonanno, 2010; Fisahn et al., 2009).

An increase in induced gamma power has been reported in BL6 (Chapter III) and rat barrel cortex in response to high-frequency stimulation (Ewert et al., 2008) and may play a role in "linking activity distributed across different barrels" (Ewert et al., 2008). The idea behind this notion is that if 
two cortical areas (columns in this case) oscillate at the same frequency, communication between the neurons is more effective (Fries, 2005). Specifically, when LFPs are synchronized, the sending population is likely to fire action potentials the moment the receiving population has a more depolarized membrane potential and is thus more receptive to incoming signals (Fries, 2005). Consequently, information processed by disparate brain areas can be connected or "bound" together (Murthy and Fetz, 1992; Singer and Gray, 1995). Lower induced and steady-state gamma in NRG1 mutants suggests that this binding process might be disrupted.

In addition, it has been suggested that neural oscillations in the gamma range enhance neural responsiveness (Paik et al., 2009). Our data suggest a correlation between induced gamma SNR and spike SNR in the $50-70 \mathrm{~Hz}$ range in WT mice (Fig. 9). The lack of this association in NRG1 mice might indicate a deficit in cortical amplification of relevant signals, a possibility that warrants further investigation.

Evidence indicates that gamma oscillations depend on the action of fast-spiking interneurons (Cardin et al., 2009; Traub et al., 1996; Whittington et al., 2000) that are electrically coupled via gap junctions (Deans et al., 2001; Galarreta and Hestrin, 1999). These neurons can inhibit local excitatory neurons in a synchronous manner, thus generating oscillating LFPs (Hasenstaub et al., 2005; Wang and Buzsaki, 1996). It is conceivable that the disruption of gamma activity in NRG1 mutants results from impaired inhibitory synaptic contacts onto excitatory cells (Fazzari et al., 2010) and/or from dysfunctional excitatory synapses onto inhibitory cells (Ting et al., 2011).

Apart from changes in stimulus-related gamma oscillations, we also described elevations in $40 \mathrm{~Hz}$ power during baseline conditions in NRG1 mutants (Fig. 10). Our results are paralleled by a large number of studies showing enhanced baseline gamma in genetic (Carlen et al., 2012; Del Pino et al., 2013; Gandal et al., 2012b) and pharmacological models of schizophrenia (Hakami et al., 2009; Hunt et al., 2011; Kittelberger et al., 2012; Kocsis, 2012; Kulikova et al., 2012; Marquis et al., 1989; Nicolás et al., 2011; Palenicek et al., 2011; Pinault, 2008; Saunders et al., 2012). Our results of enhanced gamma oscillations and spiking activity during baseline conditions support the notion that neural deficits in the NRG1 model, similar to other schizophrenia models (Gandal et al., 2012a), are related to an abnormal elevation in noisy background activity.

\subsection{Relevance of findings in NRG1 mice to schizophrenia research in humans}

Schizophrenia is thought to emerge from an interaction of a genetic predisposition and environmental factors. Genetic deficit models can help isolate the contribution of a single gene to this complex disorder. It has been criticized, however, that "the degree of risk conferred by each gene seems to be small, and [...] the biological basis of the increased risk for illness remains unclear" (Lewis et al., 2005). Here we demonstrate that a heterozygous mutation in a single gene, NRG1, 
causes a wide range of neuronal response deficits, comprising reductions in spike gain and SNR, temporal precision and stimulus-related gamma oscillations. As we will argue subsequently, each of these deficits has been hypothesized as the biological basis for certain symptoms associated with schizophrenia.

Signal-to-noise ratio. Reductions in SNR have been previously identified with EEG in the prefrontal cortex of schizophrenia patients during an auditory reaction time paradigm (Winterer et al., 2000). The reduced SNR was attributed to increased levels of absolute noise power and a reduced response amplitude (Winterer et al., 2000). In a follow-up study, the authors found increased prefrontal noise power to be associated with a cognitive impairment in working memory function (Winterer et al., 2004). Reduced EEG responses and elevated noise levels have further been reported over occipital and frontal brain regions in patients during visual steady-state stimulation at various frequencies ranging from 4 to $40 \mathrm{~Hz}$, and were proposed to contribute to perceptual deficits in schizophrenia (Krishnan et al., 2005). Moreover, a reduction in gamma SNR (i.e. induced $40 \mathrm{~Hz}$ power normalized to baseline) has been found over auditory cortices in response to $40 \mathrm{~Hz}$ auditory steady-state stimulation (Wilson et al., 2008). Animal studies showed that reductions in cortical SNR can result from an altered excitatory-inhibitory balance (Gandal et al., 2012b; Saunders et al., 2012), which is also disturbed in schizophrenic patients (Benes et al., 1991; Humphries et al., 1996; Kegeles et al., 2012; Perry et al., 1979; Sherman et al., 1991; Volk et al., 2000; Volk et al., 2001). One may speculate that that prolonged states of imbalanced signaling account for perceptual and cognitive deficits as well as hallucinations and delusions (for a similar argument, see Winterer and Weinberger, 2004). So far, noise power has not been investigated with somatosensory stimuli in human subjects. However, an excitatory-inhibitory imbalance that is the likely cause of augmented levels of neuronal noise (Durstewitz et al., 2000; Vogels and Abbott, 2007) would presumably affect all cortical areas, including the somatosensory cortex. Our findings suggest that the NRG1 mutation increases baseline spiking activity in the somatosensory cortex and reduces the spike SNR during somatosensory stimulation. We therefore speculate that schizophrenic patients may also show nonspecific, noisy EEG activity in response to somatosensory stimuli.

Temporal precision. A delay or reduction in temporal precision of oscillatory responses has previously been observed with EEG and MEG in patients during auditory (Krishnan et al., 2009; Kwon et al., 1999; Light et al., 2006; Spencer et al., 2008b; Winterer et al., 2000), visual (Koychev et al., 2012) and somatosensory stimulation (Teale et al., 2013). In the auditory domain, temporal deficits occurred preferentially in response to stimuli presented at frequencies in the $30-40 \mathrm{~Hz}$ range (Brenner et al., 2009; Krishnan et al., 2009; Kwon et al., 1999; Light et al., 2006; Spencer et al., 2008b). In the somatosensory domain, only responses to $25 \mathrm{~Hz}$ have been tested, where reductions 
in intertrial coherence were identified (Teale et al., 2013). Our findings in the NRG1 mouse model of schizophrenia complement and extend reports in patients by showing that phase locking of spikes is reduced and temporal dispersion is increased in response to $20-40 \mathrm{~Hz}$ somatosensory stimulation. Based on these findings, we hypothesize that schizophrenic patients presented with a range of somatosensory stimuli may show deficits in stimulus-locked EEG oscillations in the $20-40 \mathrm{~Hz}$ band, and that a decreased degree of temporal fidelity of spikes may underlie these deficits.

Gamma oscillations. One of the leading theories in schizophrenia research is that the disruption of gamma oscillations hampers synchronization and thus information exchange between different brain regions, leading to disordered and incoherent percepts and thoughts (Spencer et al., 2003; Uhlhaas and Singer, 2010), and possibly hallucinations (Baldeweg et al., 1998). Gamma oscillations were reported to be reduced in patients when presenting visual or auditory stimuli at 20$40 \mathrm{~Hz}$ frequencies (Krishnan et al., 2009; Lee et al., 2010; Light et al., 2006; Spencer et al., 2008b), reflecting an inability of the cortical circuitry to sustain low-level, stimulus-related gamma oscillations. In addition, synchrony (i.e. phase coherence) in the $20-30 \mathrm{~Hz}$ range was reduced when patients viewed Gestalt stimuli (Spencer et al., 2003; Uhlhaas et al., 2006), suggesting a deficit in higher-level gamma possibly supporting the binding of perceptual information (Spencer, 2008; Uhlhaas and Singer, 2010). Furthermore, reductions in gamma (20-40 Hz) amplitudes have been found in schizophrenic patients during posture perturbation (Arnfred et al., 2011), while an increased amplitude of $40-450 \mathrm{~Hz}$ oscillations has been reported in response to $6 \mathrm{~Hz}$ somatosensory stimulation in patients relative to controls (Norra et al., 2004; Waberski et al., 2004). These results suggest that schizophrenia-related alterations in gamma oscillations might be common to all sensory domains. However, amplitude changes in gamma oscillations in response to somatosensory stimuli have not been tested for a large range of stimulation frequencies so far. Our results in NRG1 mice suggest that alterations in gamma in response to somatosensory stimuli might show frequencyspecific effects in patients. Moreover, our results indicate changes in steady-state as well as induced gamma power, which have not been examined yet in patients with a somatosensory paradigm.

In addition to stimulus-related alterations in gamma power, patients also exhibit enhanced baseline power in the $20-50 \mathrm{~Hz}$ range (Brockhaus-Dumke et al., 2008; Itil et al., 1972; Kikuchi et al., 2011; Spencer, 2012; Venables et al., 2009). Together with other preclinical studies in rodent models of schizophrenia (Gandal et al., 2012a), our results of increased $40 \mathrm{~Hz}$ power and augmented spontaneous firing rates support the view that altered baseline activity levels, reflecting enhanced excitability, may lead to altered stimulus processing in schizophrenia.

It is a well accepted fact that schizophrenia is a complex disease with diverse causes (Brown, 2011; Lisman, 2012; Rapoport et al., 2012; van Winkel et al., 2008; Yin et al., 2012). A mutation in 
the NRG1 gene is neither a necessary nor a sufficient condition for developing schizophrenia. Likewise, deficits in cortical SNR, phase locking and gamma power may not constitute unique biomarkers of schizophrenia. However, based on our findings it may be hypothesized that a link exists between the NRG1 mutation and a reduction in SNR, phase locking and gamma in schizophrenic patients. If this hypothesis can be validated, it may offer a diagnostic tool at least for a subset of schizophrenic patients as well as guidance in developing a targeted drug therapy.

\section{$\underline{5.5 \text { Possible anesthesia effects }}$}

One limitation of our study is that recordings were made under isoflurane/fentanyl anesthesia. While offering the advantage of controlling the state of arousal of the animals and avoiding an interference of the stimulus response by active whisking, anesthesia might change excitatory and inhibitory signaling pathways and thus affect the response properties. In addition, an interaction between the anesthesia regimen and the NRG1 mutation is possible.

Several studies in rats and humans examined the effects of isoflurane and fentanyl in the central and peripheral nervous system. In rats, high isoflurane levels (1-2 \%, end-tidal) suppressed thalamocortical responses to whisker stimulation and converted sustained into phasic responses (Detsch et al., 1999). This effect was likely due to enhanced GABAergic inhibition (Detsch et al., 2002a) and/or reduced glutamatergic excitation (Vahle-Hinz et al., 2007). Decreased network excitability has also been reported in rat neocortical brain slices at isoflurane concentrations of 0.1$0.3 \mathrm{mM}$ (Becker et al., 2012). Effects of isoflurane on dopamine levels have been found in rat striatum, but only at $2.5 \%$ concentration, not at $1 \%$ (Adachi et al., 2008). In humans, isoflurane decreased conduction velocities of somatosensory evoked potentials at a concentration of 1-2\%, but exerted no effect on spinal conduction velocity (Hume and Durkin, 1986). Furthermore, fentanyl has been found to increase GABA (Hirose et al., 1998) and dopamine concentrations in rat nucleus accumbens (Yoshida et al., 1999), and to alter GABA (Kouvaras et al., 2008) and acetylcholine levels (Horita et al., 1989) in rat hippocampus. Somatosensory evoked potentials after median nerve stimulation were not affected by fentanyl in humans (Hume and Durkin, 1986).

While we cannot fully rule out these confounding effects, we argue that their impact is probably small. First, the level of the isoflurane was kept at a minimum during the recordings (0.1$0.5 \%)$ - well below the concentration at which effects were detected in the aforementioned studies in both rats (Detsch et al., 2002a; Detsch et al., 1999; Vahle-Hinz et al., 2007) and humans (Hume and Durkin, 1986). Second, we observed sustained vibratory responses that were modulated by the stimulation frequency in both WT and NRG1 mice, indicating that the level of isoflurane used did not alter response properties in either group. Third, isoflurane should decrease network excitability (Becker et al., 2012; Detsch et al., 2002b; Vahle-Hinz et al., 2007), rather than enhance it, as seen in 
NRG1 mutants. Finally, fentanyl may have an impact on signal transmission in nucleus accumbens (Hirose et al., 1998; Yoshida et al., 1999) and hippocampus (Horita et al., 1989; Kouvaras et al., 2008); however the only study investigating somatosensory processing did not find an effect (Hume and Durkin, 1986).

Moreover, previous research suggests that the observed changes in neuronal activity in our mutants as well as other animal models of schizophrenia are at least to some extent independent of anesthetic conditions. For example, enhancements in baseline gamma oscillations have been observed in awake as well as anesthetized ErbB4-mutant mice (Del Pino et al., 2013), and in awake, sedated, lightly and deeply anesthetized rats treated with the NMDA inhibitor ketamine (Hakami et al., 2009; Kulikova et al., 2012). Other studies found that mice lacking the NMDA receptor subunit NR1 show augmented spontaneous firing rates both during active exploration (Belforte et al., 2010) and under anesthesia (Carlen et al., 2012). In addition to these baseline parameters, stimulationinduced changes in schizophrenia models have also been characterized in awake and anesthetized animals. Under both conditions, transient whisker-evoked gamma oscillations were shown to be impaired in ketamine-treated rats (Kulikova et al., 2012). In accordance with the role of NRG1 in ErbB4 signaling and NMDA receptor expression (Bjarnadottir et al., 2007; Mei and Xiong, 2008; Newell et al., 2013), interfering with either NRG1, ErbB4 or NMDA receptor signaling changes gamma power and spiking activity in a similar way. Thus, anesthesia-independent neuronal alterations in ErbB4 mutants and NMDA models of schizophrenia strongly suggest that similar findings in the NRG1 mice are not simply an artifact of the anesthesia use.

\section{REFERENCES}

Adachi, Y.U., Yamada, S., Satomoto, M., Higuchi, H., Watanabe, K., Kazama, T., Mimuro, S., and Sato, S. (2008). Isoflurane anesthesia inhibits clozapine- and risperidone-induced dopamine release and anesthesia-induced changes in dopamine metabolism was modified by fluoxetine in the rat striatum: an in vivo microdialysis study. Neurochem Int 52, 384-391.

Ahissar, E., Sosnik, R., Bagdasarian, K., and Haidarliu, S. (2001). Temporal frequency of whisker movement. II. Laminar organization of cortical representations. J Neurophysiol 86, 354-367.

Andersson, R.H., Johnston, A., Herman, P.A., Winzer-Serhan, U.H., Karavanova, I., Vullhorst, D., Fisahn, A., and Buonanno, A. (2012). Neuregulin and dopamine modulation of hippocampal gamma oscillations is dependent on dopamine D4 receptors. Proc Natl Acad Sci U S A 109, 1311813123.

Arabzadeh, E., Zorzin, E., and Diamond, M.E. (2005). Neuronal encoding of texture in the whisker sensory pathway. PLoS Biol 3, e17.

Arnfred, S.M., Morup, M., Thalbitzer, J., Jansson, L., and Parnas, J. (2011). Attenuation of beta and gamma oscillations in schizophrenia spectrum patients following hand posture perturbation. Psychiatry Res 185, 215-224.

Baldeweg, T., Spence, S., Hirsch, S.R., and Gruzelier, J. (1998). $\gamma$-band electroencephalographic oscillations in a patient with somatic hallucinations. Lancet 352, 620-621. 
Basar-Eroglu, C., Schmiedt-Fehr, C., Mathes, B., Zimmermann, J., and Brand, A. (2009). Are oscillatory brain responses generally reduced in schizophrenia during long sustained attentional processing? Int J Psychophysiol 71, 75-83.

Becker, K., Eder, M., Ranft, A., von Meyer, L., Zieglgansberger, W., Kochs, E., and Dodt, H.U. (2012). Low dose isoflurane exerts opposing effects on neuronal network excitability in neocortex and hippocampus. PLoS One 7, 18.

Belforte, J.E., Zsiros, V., Sklar, E.R., Jiang, Z., Yu, G., Li, Y., Quinlan, E.M., and Nakazawa, K. (2010). Postnatal NMDA receptor ablation in corticolimbic interneurons confers schizophrenia-like phenotypes. Nat Neurosci 13, 76-83.

Benes, F.M., McSparren, J., Bird, E.D., SanGiovanni, J.P., and Vincent, S.L. (1991). Deficits in small interneurons in prefrontal and cingulate cortices of schizophrenic and schizoaffective patients. Arch Gen Psychiatry 48, 996.

Bjarnadottir, M., Misner, D.L., Haverfield-Gross, S., Bruun, S., Helgason, V.G., Stefansson, H., Sigmundsson, A., Firth, D.R., Nielsen, B., Stefansdottir, R., et al. (2007). Neuregulin1 (NRG1) signaling through Fyn modulates NMDA receptor phosphorylation: differential synaptic function in NRG1+/- knock-outs compared with wild-type mice. J Neurosci 27, 4519-4529.

Bousman, C.A., Yung, A.R., Pantelis, C., Ellis, J.A., Chavez, R.A., Nelson, B., Lin, A., Wood, S.J., Amminger, G.P., Velakoulis, D., et al. (2013). Effects of NRG1 and DAOA genetic variation on transition to psychosis in individuals at ultra-high risk for psychosis. Transl Psychiatry 30, 23.

Brenner, C.A., Krishnan, G.P., Vohs, J.L., Ahn, W.-Y., Hetrick, W.P., Morzorati, S.L., and O'Donnell, B.F. (2009). Steady state responses: electrophysiological assessment of sensory function in schizophrenia. Schizophr Bull 35, 1065-1077.

Brown, A.S. (2011). The environment and susceptibility to schizophrenia. Prog Neurobiol 93, 23-58.

Brumberg, J.C., Pinto, D.J., and Simons, D.J. (1996). Spatial gradients and inhibitory summation in the rat whisker barrel system. J Neurophysiol 76, 130-140.

Bruno, R.M., and Simons, D.J. (2002). Feedforward mechanisms of excitatory and inhibitory cortical receptive fields. J Neurosci 22, 10966-10975.

Buonanno, A. (2010). The neuregulin signaling pathway and schizophrenia: from genes to synapses and neural circuits. Brain Res Bull 83, 122-131.

Cardin, J.A., Carlen, M., Meletis, K., Knoblich, U., Zhang, F., Deisseroth, K., Tsai, L.H., and Moore, C.I. (2009). Driving fast-spiking cells induces gamma rhythm and controls sensory responses. Nature 459, 663-667.

Carlen, M., Meletis, K., Siegle, J.H., Cardin, J.A., Futai, K., Vierling-Claassen, D., Ruhlmann, C., Jones, S.R., Deisseroth, K., Sheng, M., et al. (2012). A critical role for NMDA receptors in parvalbumin interneurons for gamma rhythm induction and behavior. Mol Psychiatry 17, 537-548.

Dean, B., Boer, S., Gibbons, A., Money, T., and Scarr, E. (2009). Recent advances in postmortem pathology and neurochemistry in schizophrenia. Curr Opin Psychiatry 22, 154-160.

Deans, M.R., Gibson, J.R., Sellitto, C., Connors, B.W., and Paul, D.L. (2001). Synchronous activity of inhibitory networks in neocortex requires electrical synapses containing connexin36. Neuron 31, 477-485.

Del Pino, I., Garcia-Frigola, C., Dehorter, N., Brotons-Mas, J.R., Alvarez-Salvado, E., Martinez de Lagran, M., Ciceri, G., Gabaldon, M.V., Moratal, D., Dierssen, M., et al. (2013). Erbb4 deletion from fast-spiking interneurons causes schizophrenia-like phenotypes. Neuron 79, 1152-1168.

Detsch, O., Kochs, E., Siemers, M., Bromm, B., and Vahle-Hinz, C. (2002a). Differential effects of isoflurane on excitatory and inhibitory synaptic inputs to thalamic neurones in vivo. $\mathrm{Br} J$ Anaesth 89, 294-300.

Detsch, O., Kochs, E., Siemers, M., Bromm, B., and Vahle-Hinz, C. (2002b). Increased responsiveness of cortical neurons in contrast to thalamic neurons during isoflurane-induced EEG bursts in rats. Neurosci Lett 317, 9-12.

Detsch, O., Vahle-Hinz, C., Kochs, E., Siemers, M., and Bromm, B. (1999). Isoflurane induces dosedependent changes of thalamic somatosensory information transfer. Brain Res 829, 77-89. 
Durstewitz, D., Seamans, J.K., and Sejnowski, T.J. (2000). Neurocomputational models of working memory. Nat Neurosci 3, 1184-1191.

Ebner, F.F., and Armstrong-James, M.A. (1990). Intracortical processes regulating the integration of sensory information. Prog Brain Res 86, 129-141.

Edgar, J.C., Chen, Y.H., Lanza, M., Howell, B., Chow, V.Y., Heiken, K., Liu, S., Wootton, C., Hunter, M.A., Huang, M., et al. (2013). Cortical thickness as a contributor to abnormal oscillations in schizophrenia? Neuroimage Clin 4, 122-129.

Ewert, T.A., Vahle-Hinz, C., and Engel, A.K. (2008). High-frequency whisker vibration is encoded by phase-locked responses of neurons in the rat's barrel cortex. J Neurosci 28, 5359-5368.

Fazzari, P., Paternain, A.V., Valiente, M., Pla, R., Luján, R., Lloyd, K., Lerma, J., Marín, O., and Rico, B. (2010). Control of cortical GABA circuitry development by Nrg1 and ErbB4 signalling. Nature 464, 1376-1380.

Featherstone, R.E., V, M.T.-L., Suh, J.D., Lin, R., Lucki, I., and Siegel, S.J. (2013). Electrophysiological and behavioral responses to ketamine in mice with reduced Akt1 expression. Psychopharmacology (Berl) 227, 639-649.

Fisahn, A., Neddens, J., Yan, L., and Buonanno, A. (2009). Neuregulin-1 modulates hippocampal gamma oscillations: implications for schizophrenia. Cereb Cortex 19, 612-618.

Fries, P. (2005). A mechanism for cognitive dynamics: neuronal communication through neuronal coherence. Trends Cogn Sci 9, 474-480.

Fukui, N., Muratake, T., Kaneko, N., Amagane, H., and Someya, T. (2006). Supportive evidence for neuregulin 1 as a susceptibility gene for schizophrenia in a Japanese population. Neurosci Lett 396, 117-120.

Galarreta, M., and Hestrin, S. (1999). A network of fast-spiking cells in the neocortex connected by electrical synapses. Nature 402, 72-75.

Gallinat, J., Winterer, G., Herrmann, C.S., and Senkowski, D. (2004). Reduced oscillatory gamma-band responses in unmedicated schizophrenic patients indicate impaired frontal network processing. Clin Neurophysiol 115, 1863-1874.

Gandal, M.J., Edgar, J.C., Klook, K., and Siegel, S.J. (2012a). Gamma synchrony: towards a translational biomarker for the treatment-resistant symptoms of schizophrenia. Neuropharmacology 62, 1504-1518.

Gandal, M.J., Sisti, J., Klook, K., Ortinski, P.I., Leitman, V., Liang, Y., Thieu, T., Anderson, R., Pierce, R.C., Jonak, G., et al. (2012b). GABAB-mediated rescue of altered excitatory-inhibitory balance, gamma synchrony and behavioral deficits following constitutive NMDAR-hypofunction. Transl Psychiatry 17, 69.

Garabedian, C.E., Jones, S.R., Merzenich, M.M., Dale, A., and Moore, C.I. (2003). Band-pass response properties of rat SI neurons. J Neurophysiol 90, 1379-1391.

Geddes, A.E., Huang, X.F., and Newell, K.A. (2011). Reciprocal signalling between NR2 subunits of the NMDA receptor and neuregulin 1 and their role in schizophrenia. Prog Neuropsychopharmacol Biol Psychiatry 35, 896-904.

Georgieva, L., Dimitrova, A., Ivanov, D., Nikolov, I., Williams, N.M., Grozeva, D., Zaharieva, I., Toncheva, D., Owen, M.J., Kirov, G., et al. (2008). Support for neuregulin 1 as a susceptibility gene for bipolar disorder and schizophrenia. Biol Psychiatry 64, 419-427.

Grutzner, C., Wibral, M., Sun, L., Rivolta, D., Singer, W., Maurer, K., and Uhlhaas, P.J. (2013). Deficits in high- $(>60 \mathrm{~Hz})$ gamma-band oscillations during visual processing in schizophrenia. Front Hum Neurosci 7.

Hahn, C.-G., Wang, H.-Y., Cho, D.-S., Talbot, K., Gur, R.E., Berrettini, W.H., Bakshi, K., Kamins, J., Borgmann-Winter, K.E., and Siegel, S.J. (2006). Altered neuregulin 1-erbB4 signaling contributes to NMDA receptor hypofunction in schizophrenia. Nat Med 12, 824-828.

Hakami, T., Jones, N.C., Tolmacheva, E.A., Gaudias, J., Chaumont, J., Salzberg, M., O'Brien, T.J., and Pinault, D. (2009). NMDA receptor hypofunction leads to generalized and persistent aberrant 
gamma oscillations independent of hyperlocomotion and the state of consciousness. PLoS One 4, 0006755.

Hall, M.H., Taylor, G., Salisbury, D.F., and Levy, D.L. (2011). Sensory gating event-related potentials and oscillations in schizophrenia patients and their unaffected relatives. Schizophr Bull 37, 11871199.

Hamada, Y., Miyashita, E., and Tanaka, H. (1999). Gamma-band oscillations in the "barrel cortex" precede rat's exploratory whisking. Neuroscience 88, 667-671.

Hasenstaub, A., Shu, Y., Haider, B., Kraushaar, U., Duque, A., and McCormick, D.A. (2005). Inhibitory postsynaptic potentials carry synchronized frequency information in active cortical networks. Neuron 47, 423-435.

Hirose, N., Yoshida, Y., Koide, S., Takada, K., Saigusa, T., and Koshikawa, N. (1998). Effects of propofol and fentanyl on extracellular levels of gamma-aminobutyric acid in the rat nucleus accumbens: an in vivo microdialysis study. J Oral Sci 40, 165-170.

Homayoun, H., and Moghaddam, B. (2007). NMDA receptor hypofunction produces opposite effects on prefrontal cortex interneurons and pyramidal neurons. J Neurosci 27, 11496-11500.

Horita, A., Carino, M.A., and Chinn, C. (1989). Fentanyl produces cholinergically-mediated analeptic and EEG arousal effects in rats. Neuropharmacology 28, 481-486.

Huang, M.-X., Lee, R., Gaa, K., Song, T., Harrington, D., Loh, C., Theilmann, R., Edgar, J.C., Miller, G., Canive, J., et al. (2010). Somatosensory system deficits in schizophrenia revealed by MEG during a median-nerve oddball Task. Brain Topogr 23, 82-104.

Hume, A.L., and Durkin, M.A. (1986). Central and spinal somatosensory conduction times during hypothermic cardiopulmonary bypass and some observations on the effects of fentanyl and isoflurane anesthesia. Electroencephalogr Clin Neurophysiol 65, 46-58.

Humphries, C., Mortimer, A., Hirsch, S., and de Belleroche, J. (1996). NMDA receptor mRNA correlation with antemortem cognitive impairment in schizophrenia. Neuroreport 7, 2051-2055.

Hunt, M.J., Falinska, M., Leski, S., Wojcik, D.K., and Kasicki, S. (2011). Differential effects produced by ketamine on oscillatory activity recorded in the rat hippocampus, dorsal striatum and nucleus accumbens. J Psychopharmacol 25, 808-821.

Ikuta, T., Furuta, N., Kihara, S., Okura, M., Nagamine, I., Nakayama, H., Ishimoto, Y., Kaneda, Y., Tomotake, M., Izaki, Y., et al. (2007). Differences in waveforms of cerebral evoked potentials among healthy subjects, schizophrenics, manic-depressives and epileptics. J Med Invest 54, 303315.

Itil, T.M., Saletu, B., and Davis, S. (1972). EEG findings in chronic schizophrenics based on digital computer period analysis and analog power spectra. Biol Psychiatry 5, 1-13.

Jackson, M.E., Homayoun, H., and Moghaddam, B. (2004). NMDA receptor hypofunction produces concomitant firing rate potentiation and burst activity reduction in the prefrontal cortex. Proc Natl Acad Sci U S A 101, 8467-8472.

Jones, M.S., and Barth, D.S. (1997). Sensory-evoked high-frequency ( $\gamma$-band) oscillating potentials in somatosensory cortex of the unanesthetized rat. Brain Res 768, 167-176.

Kegeles, L.S., Mao, X., Stanford, A.D., Girgis, R., Ojeil, N., Xu, X., Gil, R., Slifstein, M., Abi-Dargham, A., Lisanby, S.H., et al. (2012). Elevated prefrontal cortex gamma-aminobutyric acid and glutamateglutamine levels in schizophrenia measured in vivo with proton magnetic resonance spectroscopy. Arch Gen Psychiatry 69, 449-459.

Khatri, V., Hartings, J.A., and Simons, D.J. (2004). Adaptation in thalamic barreloid and cortical barrel neurons to periodic whisker deflections varying in frequency and velocity. J Neurophysiol 92, 3244-3254.

Kittelberger, K., Hur, E.E., Sazegar, S., Keshavan, V., and Kocsis, B. (2012). Comparison of the effects of acute and chronic administration of ketamine on hippocampal oscillations: relevance for the NMDA receptor hypofunction model of schizophrenia. Brain Struct Funct 217, 395-409.

Kleinfeld, D., Ahissar, E., and Diamond, M.E. (2006). Active sensation: insights from the rodent vibrissa sensorimotor system. Curr Opin Neurobiol 16, 435-444. 
Kocsis, B. (2012). Differential role of NR2A and NR2B subunits in N-Methyl-D-Aspartate receptor antagonist-induced aberrant cortical gamma oscillations. Biol Psychiatry 71, 987-995.

Kouvaras, E., Asprodini, E.K., Asouchidou, I., Vasilaki, A., Kilindris, T., Michaloudis, D., Koukoutianou, I., Papatheodoropoulos, C., and Kostopoulos, G. (2008). Fentanyl treatment reduces GABAergic inhibition in the CA1 area of the hippocampus $24 \mathrm{~h}$ after acute exposure to the drug. Neuropharmacology 55, 1172-1182.

Koychev, I., El-Deredy, W., Mukherjee, T., Haenschel, C., and Deakin, J.F. (2012). Core dysfunction in schizophrenia: electrophysiology trait biomarkers. Acta Psychiatr Scand 126, 59-71.

Krishnan, G., Hetrick, W., Brenner, C., Shekhar, A., Steffen, A., and O'Donnell, B. (2009). Steady state and induced auditory gamma deficits in schizophrenia. Neuroimage 47, 1711.

Krishnan, G.P., Vohs, J.L., Hetrick, W.P., Carroll, C.A., Shekhar, A., Bockbrader, M.A., and O'Donnell, B.F. (2005). Steady state visual evoked potential abnormalities in schizophrenia. Clin Neurophysiol 116, 614-624.

Kulikova, S.P., Tolmacheva, E.A., Anderson, P., Gaudias, J., Adams, B.E., Zheng, T., and Pinault, D. (2012). Opposite effects of ketamine and deep brain stimulation on rat thalamocortical information processing. Eur J Neurosci 36, 3407-3419.

Kwon, J.S., O'Donnell, B.F., Wallenstein, G.V., Greene, R.W., Hirayasu, Y., Nestor, P.G., Hasselmo, M.E., Potts, G.F., Shenton, M.E., and McCarley, R.W. (1999). Gamma frequency-range abnormalities to auditory stimulation in schizophrenia. Arch Gen Psychiatry 56, 1001-1005.

Lalo, E., Gilbertson, T., Doyle, L., Di Lazzaro, V., Cioni, B., and Brown, P. (2007). Phasic increases in cortical beta activity are associated with alterations in sensory processing in the human. Exp Brain Res 177, 137-145.

Lee, S.H., Kim, D.W., Kim, E.Y., Kim, S., and Im, C.H. (2010). Dysfunctional gamma-band activity during face structural processing in schizophrenia patients. Schizophr Res 119, 191-197.

Leicht, G., Karch, S., Karamatskos, E., Giegling, I., Moller, H.J., Hegerl, U., Pogarell, O., Rujescu, D., and Mulert, C. (2011). Alterations of the early auditory evoked gamma-band response in firstdegree relatives of patients with schizophrenia: hints to a new intermediate phenotype. J Psychiatr Res 45, 699-705.

Leicht, G., Kirsch, V., Giegling, I., Karch, S., Hantschk, I., Moller, H.J., Pogarell, O., Hegerl, U., Rujescu, D., and Mulert, C. (2010). Reduced early auditory evoked gamma-band response in patients with schizophrenia. Biol Psychiatry 67, 224-231.

Lenz, D., Fischer, S., Schadow, J., Bogerts, B., and Herrmann, C.S. (2011). Altered evoked gammaband responses as a neurophysiological marker of schizophrenia? Int J Psychophysiol 79, 25-31.

Lewis, D.A., Hashimoto, T., and Volk, D.W. (2005). Cortical inhibitory neurons and schizophrenia. Nat Rev Neurosci 6, 312-324.

Li, B., Woo, R.-S., Mei, L., and Malinow, R. (2007). The neuregulin-1 receptor erbB4 controls glutamatergic synapse maturation and plasticity. Neuron 54, 583-597.

Li, D., Collier, D.A., and He, L. (2006). Meta-analysis shows strong positive association of the neuregulin 1 (NRG1) gene with schizophrenia. Hum Mol Genet 15, 1995-2002.

Li, T., Stefansson, H., Gudfinnsson, E., Cai, G., Liu, X., Murray, R.M., Steinthorsdottir, V., Januel, D., Gudnadottir, V.G., Petursson, H., et al. (2004). Identification of a novel neuregulin 1 at-risk haplotype in Han schizophrenia Chinese patients, but no association with the Icelandic/Scottish risk haplotype. Mol Psychiatry 9, 698-704.

Light, G.A., Hsu, J.L., Hsieh, M.H., Meyer-Gomes, K., Sprock, J., Swerdlow, N.R., and Braff, D.L. (2006). Gamma band oscillations reveal neural network cortical coherence dysfunction in schizophrenia patients. Biol Psychiatry 60, 1231-1240.

Lisman, J. (2012). Excitation, inhibition, local oscillations, or large-scale loops: what causes the symptoms of schizophrenia? Curr Opin Neurobiol 22, 537-544.

Marenco, S., Geramita, M., van der Veen, J.W., Barnett, A.S., Kolachana, B., Shen, J., Weinberger, D.R., and Law, A.J. (2011). Genetic association of ErbB4 and human cortical GABA levels in vivo. J Neurosci 31, 11628-11632. 
Marquis, K.L., Paquette, N.C., Gussio, R.P., and Moreton, J.E. (1989). Comparative electroencephalographic and behavioral effects of phencyclidine, (+)-SKF-10,047 and MK-801 in rats. J Pharmacol Exp Ther 251, 1104-1112.

Mei, L., and Xiong, W.C. (2008). Neuregulin 1 in neural development, synaptic plasticity and schizophrenia. Nat Rev Neurosci 9, 437-452.

Melzer, P., Champney, G.C., Maguire, M.J., and Ebner, F.F. (2006). Rate code and temporal code for frequency of whisker stimulation in rat primary and secondary somatic sensory cortex. Exp Brain Res 172, 370-386.

Miyauchi, T., Tanaka, K., Hagimoto, H., Miura, T., Kishimoto, H., and Matsushita, M. (1990). Computerized EEG in schizophrenic patients. Biol Psychiatry 28, 488-494.

Mulert, C., Kirsch, V., Pascual-Marqui, R., McCarley, R.W., and Spencer, K.M. (2011). Long-range synchrony of gamma oscillations and auditory hallucination symptoms in schizophrenia. Int $J$ Psychophysiol 79, 55-63.

Murthy, V.N., and Fetz, E.E. (1992). Coherent 25-to 35-Hz oscillations in the sensorimotor cortex of awake behaving monkeys. Proc Natl Acad Sci 89, 5670-5674.

Newell, K.A., Karl, T., and Huang, X.F. (2013). A neuregulin 1 transmembrane domain mutation causes imbalanced glutamatergic and dopaminergic receptor expression in mice. Neuroscience $248,670-680$.

Nicolás, M.J., López-Azcárate, J., Valencia, M., Alegre, M., Pérez-Alcázar, M., Iriarte, J., and Artieda, J. (2011). Ketamine-induced oscillations in the motor circuit of the rat basal ganglia. PLoS One 6, e21814.

Paik, S.B., Kumar, T., and Glaser, D.A. (2009). Spontaneous local gamma oscillation selectively enhances neural network responsiveness. PLoS Comput Biol 5, 3.

Palenicek, T., Fujakova, M., Brunovsky, M., Balikova, M., Horacek, J., Gorman, I., Tyls, F., Tislerova, B., Sos, P., Bubenikova-Valesova, V., et al. (2011). Electroencephalographic spectral and coherence analysis of ketamine in rats: correlation with behavioral effects and pharmacokinetics. Neuropsychobiology 63, 202-218.

Perry, T., Buchanan, J., Kish, S., and Hansen, S. (1979). -Aminobutyric-acid deficiency in brain of schizophrenic patients. Lancet 313, 237-239.

Pinault, D. (2008). N-methyl d-aspartate receptor antagonists ketamine and MK-801 induce wakerelated aberrant gamma oscillations in the rat neocortex. Biol Psychiatry 63, 730-735.

Rapoport, J.L., Giedd, J.N., and Gogtay, N. (2012). Neurodevelopmental model of schizophrenia: update 2012. Mol Psychiatry 17, 1228-1238.

Rutter, L., Carver, F.W., Holroyd, T., Nadar, S.R., Mitchell-Francis, J., Apud, J., Weinberger, D.R., and Coppola, R. (2009). Magnetoencephalographic gamma power reduction in patients with schizophrenia during resting condition. Hum Brain Mapp 30, 3254-3264.

Saunders, J.A., Gandal, M.J., and Siegel, S.J. (2012). NMDA antagonists recreate signal-to-noise ratio and timing perturbations present in schizophrenia. Neurobiol Dis 46, 93-100.

Sherman, A.D., Davidson, A.T., Baruah, S., Hegwood, T.S., and Waziri, R. (1991). Evidence of glutamatergic deficiency in schizophrenia. Neurosci Lett 121, 77-80.

Singer, W., and Gray, C.M. (1995). Visual feature integration and the temporal correlation hypothesis. Annu Rev Neurosci 18, 555-586.

Spencer, K.M. (2008). Visual gamma oscillations in schizophrenia: implications for understanding neural circuitry abnormalities. Clinical EEG and neuroscience 39, 65-68.

Spencer, K.M. (2012). Baseline gamma power during auditory steady-state stimulation in schizophrenia. Front Hum Neurosci 5.

Spencer, K.M., Nestor, P.G., Niznikiewicz, M.A., Salisbury, D.F., Shenton, M.E., and McCarley, R.W. (2003). Abnormal neural synchrony in schizophrenia. J Neurosci 23, 7407-7411.

Spencer, K.M., Niznikiewicz, M.A., Shenton, M.E., and McCarley, R.W. (2008a). Sensory-evoked gamma oscillations in chronic schizophrenia. Biol Psychiatry 63, 744-747. 
Spencer, K.M., Salisbury, D.F., Shenton, M.E., and McCarley, R.W. (2008b). Gamma-band auditory steady-state responses are impaired in first episode psychosis. Biol Psychiatry 64, 369-375.

Stefansson, H., Sarginson, J., Kong, A., Yates, P., Steinthorsdottir, V., Gudfinnsson, E., Gunnarsdottir, S., Walker, N., Petursson, H., Crombie, C., et al. (2003). Association of neuregulin 1 with schizophrenia confirmed in a Scottish population. Am J Hum Genet 72, 83-87.

Sun, L., Castellanos, N., Grutzner, C., Koethe, D., Rivolta, D., Wibral, M., Kranaster, L., Singer, W., Leweke, M.F., and Uhlhaas, P.J. (2013). Evidence for dysregulated high-frequency oscillations during sensory processing in medication-naive, first episode schizophrenia. Schizophr Res 150, 519-525.

Tan, H.R., Lana, L., and Uhlhaas, P.J. (2013). High-frequency neural oscillations and visual processing deficits in schizophrenia. Front Psychol 4, 621.

Teale, P., Pasko, B., Collins, D., Rojas, D., and Reite, M. (2013). Somatosensory timing deficits in schizophrenia. Psychiatry Res 212, 73-78.

Ting, A.K., Chen, Y., Wen, L., Yin, D.M., Shen, C., Tao, Y., Liu, X., Xiong, W.C., and Mei, L. (2011). Neuregulin 1 promotes excitatory synapse development and function in GABAergic interneurons. J Neurosci 31, 15-25.

Traub, R.D., Whittington, M.A., Stanford, I.M., and Jefferys, J.G. (1996). A mechanism for generation of long-range synchronous fast oscillations in the cortex. Nature 383, 621-624.

Tsuchimoto, R., Kanba, S., Hirano, S., Oribe, N., Ueno, T., Hirano, Y., Nakamura, I., Oda, Y., Miura, T., and Onitsuka, T. (2011). Reduced high and low frequency gamma synchronization in patients with chronic schizophrenia. Schizophr Res 133, 99-105.

Uhlhaas, P.J., Linden, D.E., Singer, W., Haenschel, C., Lindner, M., Maurer, K., and Rodriguez, E. (2006). Dysfunctional long-range coordination of neural activity during Gestalt perception in schizophrenia. J Neurosci 26, 8168-8175.

Uhlhaas, P.J., and Singer, W. (2010). Abnormal neural oscillations and synchrony in schizophrenia. Nat Rev Neurosci 11, 100-113.

Urbach, T.P., and Kutas, M. (2006). Interpreting event-related brain potential (ERP) distributions: implications of baseline potentials and variability with application to amplitude normalization by vector scaling. Biol Psychol 72, 333-343.

Vahle-Hinz, C., Detsch, O., Siemers, M., and Kochs, E. (2007). Contributions of GABAergic and glutamatergic mechanisms to isoflurane-induced suppression of thalamic somatosensory information transfer. Exp Brain Res 176, 159-172.

van Winkel, R., Stefanis, N.C., and Myin-Germeys, I. (2008). Psychosocial stress and psychosis. A review of the neurobiological mechanisms and the evidence for gene-stress interaction. Schizophr Bull 34, 1095-1105.

Venables, N.C., Bernat, E.M., and Sponheim, S.R. (2009). Genetic and disorder-specific aspects of resting state EEG abnormalities in schizophrenia. Schizophr Bull 35, 826-839.

Vogels, T.P., and Abbott, L.F. (2007). Gating deficits in model networks: a path to schizophrenia? Pharmacopsychiatry 40, S73-77.

Vohs, J.L., Chambers, R.A., O'Donnell, B.F., Krishnan, G.P., and Morzorati, S.L. (2012). Auditory steady state responses in a schizophrenia rat model probed by excitatory/inhibitory receptor manipulation. Int J Psychophysiol 86, 136-142.

Volk, D.W., Austin, M.C., Pierri, J.N., Sampson, A.R., and Lewis, D.A. (2000). Decreased glutamic acid decarboxylase67 messenger RNA expression in a subset of prefrontal cortical gammaaminobutyric acid neurons in subjects with schizophrenia. Arch Gen Psychiatry 57, 237-245.

Volk, D.W., Austin, M.C., Pierri, J.N., Sampson, A.R., and Lewis, D.A. (2001). GABA transporter-1 mRNA in the prefrontal cortex in schizophrenia: decreased expression in a subset of neurons. Am J Psychiatry 158, 256-265.

Wang, X.J., and Buzsaki, G. (1996). Gamma oscillation by synaptic inhibition in a hippocampal interneuronal network model. J Neurosci 16, 6402-6413. 
Wen, L., Lu, Y.S., Zhu, X.H., Li, X.M., Woo, R.S., Chen, Y.J., Yin, D.M., Lai, C., Terry, A.V., Jr., Vazdarjanova, A., et al. (2010). Neuregulin 1 regulates pyramidal neuron activity via ErbB4 in parvalbumin-positive interneurons. Proc Natl Acad Sci U S A 107, 1211-1216.

White, T.P., Joseph, V., O'Regan, E., Head, K.E., Francis, S.T., and Liddle, P.F. (2010). Alpha-gamma interactions are disturbed in schizophrenia: a fusion of electroencephalography and functional magnetic resonance imaging. Clin Neurophysiol 121, 1427-1437.

Whittington, M.A., Faulkner, H.J., Doheny, H.C., and Traub, R.D. (2000). Neuronal fast oscillations as a target site for psychoactive drugs. Pharmacol Ther 86, 171-190.

Wilent, W.B., and Contreras, D. (2005). Dynamics of excitation and inhibition underlying stimulus selectivity in rat somatosensory cortex. Nat Neurosci 8, 1364-1370.

Wilson, T.W., Hernandez, O.O., Asherin, R.M., Teale, P.D., Reite, M.L., and Rojas, D.C. (2008). Cortical gamma generators suggest abnormal auditory circuitry in early-onset psychosis. Cereb Cortex 18, 371-378.

Winterer, G., Coppola, R., Goldberg, T.E., Egan, M.F., Jones, D.W., Sanchez, C.E., and Weinberger, D.R. (2004). Prefrontal broadband noise, working memory, and genetic risk for schizophrenia. Am J Psychiatry 161, 490-500.

Winterer, G., Ziller, M., Dorn, H., Frick, K., Mulert, C., Wuebben, Y., Herrmann, W.M., and Coppola, R. (2000). Schizophrenia: reduced signal-to-noise ratio and impaired phase-locking during information processing. Clin Neurophysiol 111, 837-849.

Woo, R.S., Li, X.M., Tao, Y., Carpenter-Hyland, E., Huang, Y.Z., Weber, J., Neiswender, H., Dong, X.P., Wu, J., Gassmann, M., et al. (2007). Neuregulin-1 enhances depolarization-induced GABA release. Neuron 54, 599-610.

Wood, J., Kim, Y., and Moghaddam, B. (2012). Disruption of prefrontal cortex large scale neuronal activity by different classes of psychotomimetic drugs. J Neurosci 32, 3022-3031.

Yin, D.M., Chen, Y.J., Sathyamurthy, A., Xiong, W.C., and Mei, L. (2012). Synaptic dysfunction in schizophrenia. Adv Exp Med Biol 970, 493-516.

Yoshida, Y., Koide, S., Hirose, N., Takada, K., Tomiyama, K., Koshikawa, N., and Cools, A.R. (1999). Fentanyl increases dopamine release in rat nucleus accumbens: involvement of mesolimbic muand delta-2-opioid receptors. Neuroscience 92, 1357-1365.

Zhang, Y., Yoshida, T., Katz, D.B., and Lisman, J.E. (2012). NMDAR antagonist action in thalamus imposes delta oscillations on the hippocampus. J Neurophysiol 107, 3181-3189. 


\section{Chapter VI}

\section{Discussion and future directions}

\section{Microcircuit abnormalities and their effects on sensory processing in NRG1 mutant mice}

The main finding of the present work is that mice heterozygous for the schizophrenia risk gene NRG1 show several cellular response aberrancies to frequency-modulated somatosensory stimulation that parallel sensory response deficits in schizophrenic patients. Response deficits in mutants include elevated firing rates during baseline and stimulation, reduced frequency-dependent phase locking, and reduced gamma oscillations. In this section, a model is suggested to explain the findings in the context of the circuitry of the barrel column, the NRG1 expression pattern and the signaling pathways regulated by NRG1.

\subsection{Columnar connectivity in the barrel cortex}

The connectivity of the cortical column in the rodent primary somatosensory cortex has been widely investigated (for review, see Diamond and Arabzadeh, 2013; Feldmeyer et al., 2013; Fox, 2008; Lubke and Feldmeyer, 2007). Whisker-derived thalamocortical signals are transmitted to barrel cortex layer IV, or granular layer, which is the main input layer of the cortex. As detailed in Figure 1 (left panel), thalamocortical afferents target excitatory neurons in layer IV, in particular spiny stellate and star pyramid cells. In addition, inhibitory neurons also receive thalamic input. From layer IV, signals are passed on to the supragranular layers II/III (and to a smaller extent also to layer V). Layer II/III pyramidal neurons then send information to the infragranular layers $\mathrm{V} / \mathrm{VI}$, where signals are integrated and relayed to other cortical areas and subcortical regions including the thalamus. Excitatory cells are the only source of corticothalamic projections, and the main source of crosslaminar projections. Intra-laminar projections are characterized by reciprocal coupling among and between excitatory and inhibitory neurons. Importantly, signaling among inhibitory interneurons can also occur via gap junctions, allowing the cells to synchronize their activity. This synchronization occurs in the gamma range and gates the activity of excitatory cells (Bartos et al., 2007). Of note, the present model of columnar organization includes only a subset of inhibitory neurons - the fastspiking chandelier and basket cells - because they are the main expression sites of the NRG1 receptor ErbB4 (see Section 1.2). 
barrel cortex circuitry

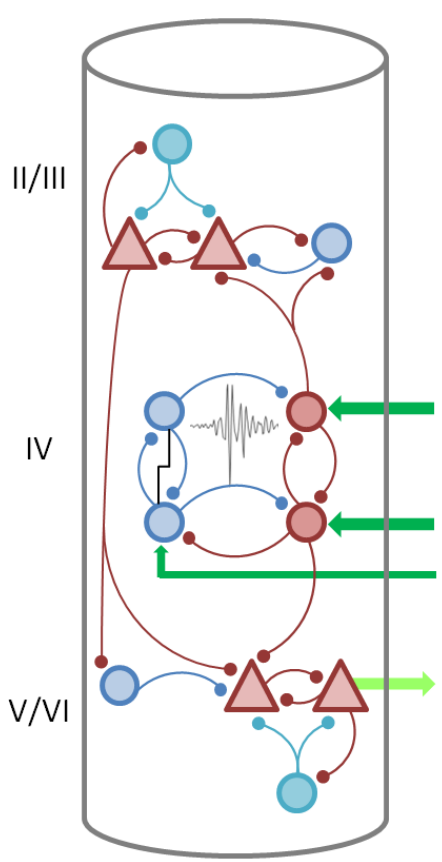

NRG1/ErbB4 expression

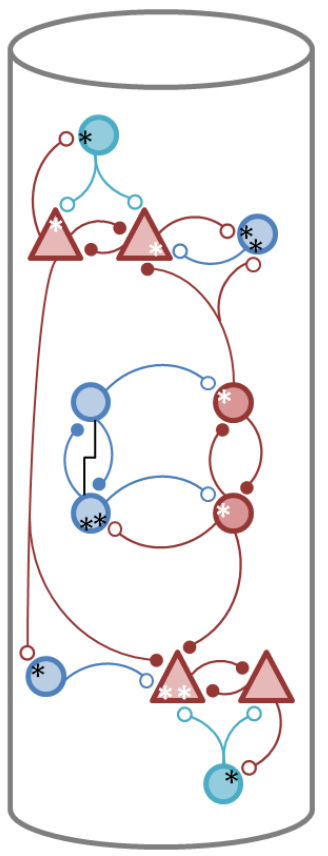

changes in mutants

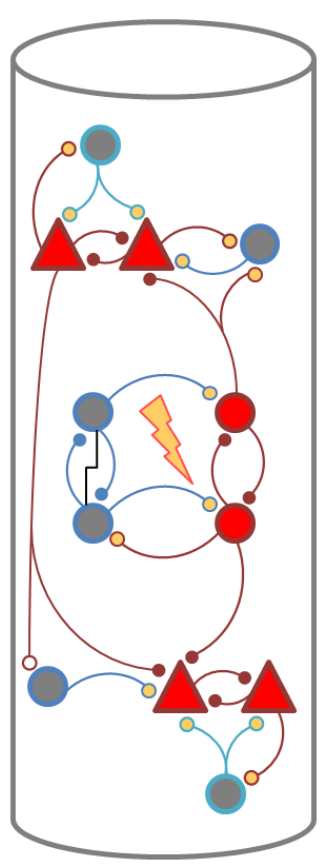

Legend

circuitry

chandelier cell

basket cell

o spiny stellate cell

$\Delta$ pyramidal cell

- excitatory synapse

- inhibitory synapses

$\checkmark$ gapjunction

W gamma oscillations

- thalamocortical afferents

$\Rightarrow$ efferent projections

expression

- presynaptic NRG1

○० presynaptic ErbB4

(3) postsynaptic NRG1

* * postsynaptic ErbB4

mutants

- reduced excitatory synaptic transmission

oo reduced inhibitory synaptic transmission

increased firing

reduced firing

altered gamma

FIGURE 1. Hypothesized effects of deficient NRG1-ErbB4 signaling on neural activity in the cortical column of the mouse primary somatosensory cortex. Left panel. Normal connectivity pattern of excitatory and inhibitory neurons in the barrel column (Fox, 2008). Thalamocortical afferents primarily project to layer IV (dark green arrows), and to a lesser extent to layer V/VI (not shown here). Layers $\mathrm{V} / \mathrm{VI}$ are the main output layers, sending projections to other cortical and subcortical areas (light green arrow). Intracortical projections occur within layers and between layers (IV $\rightarrow$ II/III $\rightarrow \mathrm{V} / \mathrm{VI}$ ). Synaptic connections are depicted in a simplified manner without implying dendritic, axonal or somatic target specificity. Note that only so-called fast-spiking, parvalbumin-positive inhibitory interneuron types are shown here. Middle panel. Putative expression sites of NRG1 and ErbB4 that are assumed to be affected by the NRG1 mutation. Right panel. Expected cellular changes in NRG1 mutants. The mutation likely leads to increased activity of excitatory cells, decreased activity of inhibitory interneurons, and alterations in gamma oscillations.

\subsection{Putative NRG1-ErbB4 expression sites in the barrel column}

NRG1 and ErbB4 are expressed in cortical layers II-VI in humans and rodents (Abe et al., 2011; Law et al., 2004; Mei and Xiong, 2008). Furthermore, it has been shown that cortical ErbB4 expression is largely restricted to inhibitory chandelier and basket cells, where it is found in axon terminals contacting excitatory neurons, and in postsynaptic densities of inhibitory cells receiving excitatory projections (Fazzari et al., 2010). In contrast, NRG1 (type III) has been found to be expressed at the soma, axon and dendrites of pyramidal cells in the cortex, and in pyramidal cells of the amygdala and cingulate cortex (Chen et al., 2010 and Yachi Chen, personal communication; Jiang et al., 2013). This data provides the basis for NRG1 and ErbB4 expression sites indicated in Figure 1 (middle panel), with the caveat that the expression patterns have hitherto not been specifically verified in the barrel 
cortex. The present model assumes that ErbB4 expression is limited to inhibitory interneurons, and that NRG1 expression is limited to excitatory cells. Since NRG1 and ErbB4 can serve as both ligands and receptors for each other, it is further assumed that NRG1 is expressed presynaptically where ErbB4 has been found in postsynaptic densities, and that NRG1 is expressed postsynaptically where ErbB4 is known to be located presynaptically at axon terminals.

\subsection{Effects of defective synaptic signaling on the excitatory-inhibitory balance in NRG1 mutants}

NRG1 has several roles in synaptic functioning, which are likely to be compromised in the NRG1 heterozygous mice. Several gain-of-function studies have investigated the effects of NRG1 application in vivo and ex vivo, and the effects of NRG1 overexpression. In slices of prefrontal cortex, acute application of NRG1 was found to reduce N-Methyl-D-aspartate (NMDA) receptor-mediated currents in pyramidal neurons, and to increase inhibitory transmission of $\gamma$-aminobutyric acid (GABA)-ergic cells (Woo et al., 2007). Moreover, juvenile mice that received repeated postnatal NRG1 injections showed increased inhibitory (but not excitatory) inputs to layer $V$ pyramidal neurons, and increased $\alpha$-amino-3-hydroxy-5-methyl-4-isoxazole propionic acid (AMPA)-mediated currents in cortical inhibitory interneurons receiving excitatory input (Abe et al., 2011). An increased frequency of excitatory currents in GABAergic interneurons has also been reported following NRG1 treatment of dissociated cortical neurons (Ting et al., 2011). Furthermore, mice overexpressing NRG1 were found to show increased GABA levels in prefrontal cortex (Kato et al., 2010). These results are complemented by loss-of-function experiments using different NRG1-deficient mouse lines. In the hippocampus, mice heterozygous for the NRG1 transmembrane domain show hypophosphorylation of the NR2B subunit of the NMDA receptor (Bjarnadottir et al., 2007). In pyramidal neurons of the amygdala, heterozygous NRG1 type III knockouts display a lower NMDA/AMPA ratio of the synaptic current, and larger AMPA current amplitudes (Jiang et al., 2013). Importantly, effects of the NRG1 mutation might differ across brain regions. In mice heterozygous for the NRG1 transmembrane domain, increased expression of NMDA receptors has been found in nucleus accumbens, cingulate cortex, sensory and motor cortices, but not in other areas of the brain (Newell et al., 2013). Together, the findings from gain-of-function and loss-of-function experiments indicate that NRG1 plays an important role in excitatory and inhibitory signal transmission, and that the precise mechanisms may differ across brain regions.

Based on the available data, it can be hypothesized that in the somatosensory cortex of our NRG1 mutants, inhibitory neurons would show decreased activity (due to reduced AMPA receptormediated inputs), and excitatory neurons would show increased activity (due to reduced input from inhibitory interneurons and increased NMDA- and AMPA-mediated inputs from excitatory neurons). The synaptic connections affected by the NRG1 mutation can be derived from the activation flow 
and connectivity pattern in the cortical column (Fig. 1, left panel) and the cortical expression pattern of NRG1 and ErbB4 (Fig. 1, middle panel). Given the dysfunctional transmission at excitatory $\rightarrow$ inhibitory and inhibitory $\rightarrow$ excitatory synapses in NRG1 mutants, the model of the microcircuitry suggests a reduced activation of inhibitory neurons and an enhanced activation of excitatory neurons (Figure 1, right panel). The degree to which each neuron shows activity reduction or enhancement will depend on its connections with other neurons. In this context, it is important to note that excitatory cells receive inputs from various kinds of inhibitory neurons, some of which may not express ErbB4 and may be functioning at a normal level despite the NRG1 mutation (not displayed here). For the proposed model of alterations in the barrel cortex of NRG1 mice, we assume no major changes in cellular morphology and connectivity in NRG1 mutants. The assumption is based on the finding of normal barrel gross morphology in NRG1 mutants (Chapter IV), and on a previous study showing that mice with a disruption of the NRG1-dependent ErbB2/ErbB4 signaling pathway show no alterations in brain morphology and no changes in the organization of cortical layers (Barros et al., 2009).

\subsection{Possible contribution of synaptic dysfunctions at the thalamic level}

NRG1 is expressed in the thalamus in both humans and rodents. More specifically, NRG1 has been found in the mediodorsal and lateral geniculate nuclei in humans (Law et al., 2004), and in the reticular nucleus and the medial habenula in rodents (Chen et al., 1994; Corfas et al., 1995; Woo et al., 2007). Moreover, mouse studies revealed that underexpression of NRG1 reduces NMDA receptor density in the thalamus (Newell et al., 2013). Thus, it is conceivable that thalamic information processing is compromised in NRG1 mice. In addition, transmission at thalamocortical and corticothalamic synapses may be affected by the mutation. Despite a possible contribution of thalamic deficits to the functional abnormalities reported in NRG1 mice, the proposed model suggests that deficits in the intracortical circuitry are sufficient to cause the observed abnormalities independent of a thalamic contribution. This would especially apply if the impairment in NRG1/ErbB4 signaling affects a large number of cells.

1.5 Consequences of altered excitatory-inhibitory signaling in NRG1 mutants, and relation with other $\underline{\text { schizophrenia models }}$

\subsubsection{Elevated baseline firing}

In our study, we observed increased baseline firing rates in the somatosensory cortex of NRG1 mutants. The finding is in agreement with several lines of research investigating how an excitatoryinhibitory imbalance affects neuronal spiking activity. One study showed that ErbB4 deletion 
enhances excitatory and inhibitory activity in hippocampal slices, as suggested by an increased number of EPSCs in both excitatory and inhibitory neurons, and increased spontaneous firing rates of inhibitory neurons (Del Pino et al., 2013). Moreover, postnatal deletion of the gene encoding the NMDA receptor subunit NR1 in cortical and hippocampal interneurons was shown to result in increased baseline spiking activity of pyramidal neurons in primary somatosensory cortex of actively exploring mice (Belforte et al., 2010). The mutants also displayed various schizophrenia-like deficits, including hyperlocomotion, anhedonia, anxiety, impaired social behaviors, disrupted working memory and deficient PPI. The electrophysiological and behavioral impairments were only apparent when the genetic manipulation occurred postnatally, but not in adult animals (Belforte et al., 2010). These findings were supported by another study examining the effects of the NR1 deletion in parvalbumin-positive interneurons that reported enhanced firing rates in regular spiking (excitatory) neurons in the primary somatosensory cortex in anesthetized mutants (Carlen et al., 2012).

Similar to these genetic manipulations, administering the NMDA blockers MK801 and ketamine also causes an augmentation in baseline activity. In awake rats, inhibiting NMDA receptors was reported to increase spontaneous firing rates in the orbitofrontal cortex and nucleus accumbens (Wood et al., 2012), and in the thalamus and hippocampus (Zhang et al., 2012). In addition, MK801treated rats were shown to have working memory deficits and elevated baseline firing rates in prefrontal pyramidal cells (Jackson et al., 2004). A follow-up study suggested that the increase in cortical excitation was primarily due to a decrease in activity of inhibitory neurons, which was followed by disinhibition (and elevated firing rates) of excitatory cells (Homayoun and Moghaddam, 2007). In line with this finding, modeling studies demonstrated that increased spontaneous cellular activity results from increased excitation and disinhibition in a cortical neuronal network (Murray et al., 2012; Vogels and Abbott, 2007). Together, the results obtained in genetic, pharmacological and computational studies indicate that enhanced spontaneous activity is a consequence of increased excitation and reduced inhibition, resulting in elevated cortical noise that interferes with schizophrenia-related cognitive functioning.

Our finding of increased baseline activity seems to be at variance with previous reports on NRG1-related effects, however. In hippocampal slices, studies found no changes in basal synaptic transmission in mice overexpressing NRG1 type I (Deakin et al., 2012) and in heterozygous NRG1 EGF-like domain knockout mice (Bjarnadottir et al., 2007). Similarly, several studies reported that NRG1 treatment of hippocampal slices was found to have no effects on basal synaptic transmission (Bjarnadottir et al., 2007; Huang et al., 2000; Kwon et al., 2005), although one study reported increased firing rates of inhibitory cells in hippocampal and cortical slices after NRG1 treatment (Li et al., 2011). Moreover, acute extracellular recordings of single cells and local field potentials (LFPs) in 
hippocampus and nucleus accumbens in urethane anesthetized NRG1 type III knockouts revealed no difference in mean firing rates between mutant and WT neurons (Nason et al., 2011). The contradictory findings may be explained by various differences between our study and previous reports, including recording methodology (in vitro versus in vivo), anesthesia levels, as well as the brain region and NRG1 isoform/ mutation under investigation. With regard to anesthesia, baseline firing rates are generally decreased under deep anesthesia as it is achieved with urethane, which may have occluded potential NRG1-related changes in firing rate in the nucleus accumbens (Nason et al., 2011). More generally, it is conceivable that NRG1-related effects on baseline firing rates are dependent on the precise excitatory-inhibitory tuning of the network, which might differ according to the type of NRG1 mutation or isoform, the connectivity in the brain region being studied, and the brain state (awake versus anesthetized). In support of this hypothesis, brain state-dependent effects have been shown after NMDA antagonist treatment, with decreased and increased baseline firing rates in urethane-anesthetized animals (Gratton et al., 1987) and awake animals (Jackson et al., 2004), respectively. In addition, modeling studies showed that increases in baseline firing rates depend on the functional connectivity of the network (i.e. responsiveness of sending and target neurons) and on the combination of hyperexcitability and disinhibition (Vogels and Abbott, 2007).

\subsubsection{Increased neuronal responsiveness to sensory stimulation}

We further demonstrated enhanced mean firing rates in response to low and high frequency whisker stimulation in NRG1 mice. To the best of our knowledge, this is the first report of changes in sensoryevoked neuronal firing rates in a schizophrenia model. Recent intracellular recordings in hippocampal slices of ErbB4 knockout mice revealed that the firing rate of inhibitory neurons is enhanced after ramp stimulation compared to firing rates in normal mice (Del Pino et al., 2013). In addition, hippocampal stimulation in anesthetized ErbB4 mutants was shown to facilitate hippocampal LFP responses (Del Pino et al., 2013). Similarly, enhanced firing rates were found during electrical stimulation of pyramidal neurons in hippocampal slices of mice deficient for the NR1 subunit of the NMDA receptor (Gandal et al., 2012b).

Modeling studies suggested that increased stimulus-evoked firing, as well as increased baseline firing, result from elevated levels of excitation and reduced inhibition in neuronal networks (Vogels and Abbott, 2007). In fact, evidence suggests that these two phenomena might be related. According to modeling and in vivo studies, the level of background activity or 'noise' can affect the integrative properties of the neuron (Destexhe and Pare, 1999) and its responsiveness to a stimulus, the 'gain' (Chance et al., 2002). In pyramidal cells, for example, increasing background synaptic activity results in a more depolarized membrane potential and larger fluctuations of the membrane potential (Destexhe and Pare, 1999). As a result of increased noise, pyramidal cells show an 
enhanced responsiveness, also to inputs that would normally be sub-threshold (Ho and Destexhe, 2000). In addition, elevated background activity leads to higher spike variability in response to a stimulus (Holt et al., 1996; Softky and Koch, 1993), which is thought to increase the bandwidth of signal transmission (Shadlen and Newsome, 1994). To prevent the firing rate of excitatory neurons from saturating, inhibitory neurons have to balance excitation in order to control the gain of neuronal signaling (Berman et al., 1992; Douglas and Martin, 1991; Shadlen and Newsome, 1994). In NRG1 mutants, the lack of inhibitory drive might interfere with the gain control mechanism, thus leading to higher response amplitudes.

\subsubsection{Reduced spiking signal-to-noise ratio and neuronal gain}

We introduced the measure of spike signal-to-noise ratio (SNR) to quantify the relation between firing rates during baseline and stimulation conditions in NRG1 mutants. We found that spike SNR is reduced during low and high frequency stimulation in mutants compared to WT mice. In addition, mutants showed a smaller increase (gain) in SNR than WT mice in response to $20-70 \mathrm{~Hz}$ stimulation. Since stimulus-evoked firing rates (not normalized to baseline firing) had similar gain functions in mutants and WT mice at $20-70 \mathrm{~Hz}$, we concluded that the decreased SNR gain in mutants is primarily due to enhanced baseline firing rates. The results suggest that elevated baseline firing rates significantly alter cortical processing of stimulus-related information. This mechanism provides a possible link between the previously reported increase in prefrontal and somatosensory firing rates in schizophrenia models based on NMDA receptor hypofunction, and the associated deficits in cognitive functioning (Belforte et al., 2010; Jackson et al., 2004).

\subsubsection{Impaired phase locking of spikes}

We further demonstrated reductions in sensory-evoked phase locking of firing rates over a wide range of frequencies $(5-40 \mathrm{~Hz})$ in NRG1 mutants. The deficits appear at lower frequencies where fewer stimulus-evoked spikes are generated and the difference with background activity is small. In contrast, phase locking was normal at higher frequencies $(50-70 \mathrm{~Hz})$ where enough spikes were evoked to produce a strong phase locking effect.

Previous research has investigated changes in phase relationships between oscillatory brain activity (i.e. LFPs) in various schizophrenia models, and revealed reduced phase locking between brain areas (phase coherence) and between trials (intertrial coherence). One study showed weak phase coherence between nucleus accumbens cells and hippocampal theta oscillations in NRG1 type III knockout mice (Nason et al., 2011). Moreover, decreased phase coherence between the prefrontal cortex and hippocampus has been observed in the theta range in $D f(16) A$ knockout mice, a model for the 22q11.2 deletion in humans that confers an increased risk for schizophrenia 
(Sigurdsson et al., 2010). Similar alterations of prefrontal-hippocampal coherence in the theta range have also been demonstrated in ErbB4 mutants (Del Pino et al., 2013). In awake rats treated with ketamine or MK801, phase coherence was reduced in the gamma range between the motor cortex and basal ganglia (Nicolás et al., 2011), unchanged in the gamma range between bilateral parietal cortices (Kulikova et al., 2012), and enhanced in the delta range between hippocampus and thalamus (Zhang et al., 2012). In addition, ketamine administration increased the degree to which firing rates of regular spiking neurons in the hippocampus and thalamus were modulated by the phase of delta oscillations (Zhang et al., 2012).

Furthermore, intertrial coherence has been shown to be reduced in the gamma band in response to auditory stimuli in mice treated with ketamine (Featherstone et al., 2013), and in mice deficient for Dysbindin-1, another schizophrenia risk gene (Carlson et al., 2011). Intertrial coherence during auditory stimulation was also reduced in two schizophrenia rat models using ketamine treatment or neonatal lesions of the ventral hippocampus, in particular in response to $50 \mathrm{~Hz}$ stimulation (Vohs et al., 2012). Additionally, rats treated with the $G_{A B A}$ agonist muscimol showed enhanced intertrial coherence during 30-40 Hz auditory stimulation (Vohs et al., 2012).

To the best of our knowledge, only one study has hitherto examined the reliability of stimulus-related spike timing in a schizophrenia model. Mice with an interneuron-specific deletion of the NR1 subunit of the NMDA receptor showed less precise responses to optogenetic activation of the somatosensory cortex under anesthesia (Carlen et al., 2012). However, frequency-specific effects were not investigated. Extending these results, our study provides the first evidence for frequencyspecific impairments in phase locking of spikes in response to a sensory stimulus in a schizophrenia model. Our findings indicate that enhanced neural noise reduces the temporal precision of neuronal firing to a somatosensory stimulus. Along with the decreased spike SNR, deficient phase locking may provide a mechanistic explanation for the adverse impact of increased baseline firing on cognition as previously reported (Belforte et al., 2010; Jackson et al., 2004).

\subsubsection{Decreased stimulus-related gamma oscillations}

Another novel finding of our study is the reduction in gamma oscillations $(20-40 \mathrm{~Hz})$ induced by high frequency $(70 \mathrm{~Hz})$ whisker stimulation in NRG1 mice. In addition, we found a decrease in $20 \mathrm{~Hz}$ oscillations in response to $20 \mathrm{~Hz}$ stimulation in the mutants. The reductions in both induced and steady-state oscillations were evident at the level of relative gamma power and gamma SNR, defined as the ratio of relative gamma during stimulation and during baseline. Together with the finding of impaired phase locking to $20-40 \mathrm{~Hz}$ stimulation, these results suggest deficits in the neuronal circuitry in NRG1 mutants to entrain both evoked and induced gamma oscillations. These results 
represent the first demonstration of deficits in sensory-evoked gamma oscillations during sustained, frequency-modulated whisker stimulation in a schizophrenia model.

Our findings concur with previous reports of gamma deficits in primary somatosensory cortex during transient whisker deflection in ketamine-treated rats, both under awake and lightly anesthetized conditions (Kulikova et al., 2012). Our findings also support results in mice with an interneuron-specific deletion of the NR1 subunit of the NMDA receptor. Upon optogenetic stimulation of the primary somatosensory cortex at frequencies ranging from $8 \mathrm{~Hz}$ to $200 \mathrm{~Hz}$, the gamma SNR $(30-60 \mathrm{~Hz})$ was reduced during $30-60 \mathrm{~Hz}$ stimulation in the anesthetized mutants (Carlen et al., 2012). Furthermore, our findings extend previous research on changes in auditory-evoked gamma power in different schizophrenia animal models. These studies recorded neural activity across the whole brain using two macroelectrodes, and found reductions in auditory-evoked gamma oscillations and gamma SNR in Dysbindin-1 knockouts (Carlson et al., 2011), in NR1 knockouts (Gandal et al., 2012b), and in mice treated with the NMDA antagonists MK801 or ketamine (Saunders et al., 2012). Changes in auditory-evoked responses have also been demonstrated in rats treated with ketamine or muscimol, both of which enhanced oscillatory power in response to 30-40 $\mathrm{Hz}$ stimulation (Vohs et al., 2012). In addition, reduced gamma oscillations in response to auditory stimuli have been reported in rats treated with methylazoxymethanol acetate (Lodge et al., 2009). Furthermore, our results support the role of NRG1 in regulating gamma oscillations, as previously demonstrated in hippocampal slices (Andersson et al., 2012; Deakin et al., 2012; Fisahn et al., 2009).

The generation of gamma oscillations depends on fast-spiking, parvalbumin-positive interneurons, in particular basket cells, which synchronize the activity of pyramidal cells (Bartos et al., 2007; Cardin et al., 2009; Sohal et al., 2009; Volman et al., 2011). The fact that the NRG1 receptor ErbB4 is primarily expressed by parvalbumin-positive chandelier and basket cells (Fazzari et al., 2010) suggests that NRG1-mediated effects on gamma rhythms are due to impaired inhibitory signaling. The exact mechanisms underlying such a deficit are currently not clear, however. According to previous research, impaired NRG1-ErbB4 signaling, as present in the NRG1 mutants, decreases GABA release (Wen et al., 2010; Woo et al., 2007). However, reduced GABA release has been associated with an increase in gamma oscillations, at least in baseline conditions in the absence of sensory stimulation (Gandal et al., 2012a). This account is at variance with an NRG1-induced increase in gamma power reported in hippocampal slices (Andersson et al., 2012; Fisahn et al., 2009) and with the gamma deficit reported in our NRG1-deficient mutants. An alternative mechanism may involve an NRG1-mediated deficit of NMDA receptor function in interneurons. In line with this view, NMDA receptor antagonists that produce increases in gamma oscillations are believed to act predominantly on inhibitory neurons expressing NMDA receptors (Gandal et al., 2012a). While the NRG1-ErbB4 
pathway has been shown to affect NMDA receptor-dependent signaling at excitatory cells (Garcia et al., 2000; Gu et al., 2005), the presumed influence of NRG1 on NMDA receptor function in inhibitory neurons awaits experimental validation.

\subsubsection{Baseline gamma oscillations}

We found no changes in baseline oscillations measured in the $20-40 \mathrm{~Hz}$ range, but we did detect a selective increase in baseline oscillatory power at $40 \mathrm{~Hz}$ in NRG1 mutants. Previous studies in genetic and pharmacological models of schizophrenia have demonstrated broad-band increases in baseline gamma oscillations in various cortical and subcortical regions (Gandal et al., 2012a; Hunt and Kasicki, 2013). In genetic models, enhanced gamma power in the $30-100 \mathrm{~Hz}$ range has been reported in the prefrontal cortex and hippocampus of ErbB4 mutant mice, using extracellular recordings in the awake animal and in the urethane- and ketamine-anesthetized animal (Del Pino et al., 2013). Moreover, enhanced baseline gamma power $(30-80 \mathrm{~Hz})$ has been found using cortical EEG recordings in awake mice lacking the NR1 subunit of the NMDA receptor (Gandal et al., 2012b). Another study examining the effects of the NR1 deletion in parvalbumin-positive interneurons reported enhanced baseline gamma $(36-44 \mathrm{~Hz})$ in the primary somatosensory cortex in anesthetized mutants, but not in the $30-80 \mathrm{~Hz}$ band in awake mutants (Carlen et al., 2012). In pharmacological models, enhanced broad-band gamma oscillations during awake baseline conditions have been observed after treating mice and rats with the NMDA antagonists phencyclidine, MK801 or ketamine. Augmented gamma oscillations have been noted in frontal, temporal, parietal and occipital cortices (Kocsis, 2012; Marquis et al., 1989; Palenicek et al., 2011; Pinault, 2008). More specifically, cortical subregions showing enhanced baseline gamma after NMDA blockade include the orbitofrontal/prefrontal cortex, the secondary auditory cortex, the somatosensory, visual and motor cortices (Hakami et al., 2009; Kulikova et al., 2012; Nicolás et al., 2011; Palenicek et al., 2011; Wood et al., 2012), and the hippocampus (Ehrlichman et al., 2009; Featherstone et al., 2013; Hunt et al., 2011; Kittelberger et al., 2012; Lazarewicz et al., 2010; Leung, 1985; Ma and Leung, 2000, 2007; Saunders et al., 2012; Zhang et al., 2012). In addition, subcortical areas displaying enhanced gamma comprise the thalamus, amygdala, striatum, nucleus accumbens and basal ganglia (Hakami et al., 2009; Hunt et al., 2010; Nicolás et al., 2011; Olszewski et al., 2013; Wood et al., 2012; Zhang et al., 2012). Notably, acute and chronic treatment with NMDA antagonists may have different effects on baseline gamma oscillations, as acute ketamine or MK801 administration has been shown to increase hippocampal gamma oscillations, while chronic administration decreased spontaneous gamma oscillations (Kittelberger et al., 2012).

Given the wealth of evidence of augmented baseline gamma in various pharmacological and genetic schizophrenia models, a large increase in baseline gamma oscillations might be expected in 
NRG1 mutants as well. However, our findings suggest more subtle changes in baseline gamma in the mutants, at least under the presently used recording conditions. One explanation for a smaller magnitude of gamma enhancement could be the use of anesthesia, although previous results in ErbB4-deficient mice (Del Pino et al., 2013) and ketamine-treated rats (Hakami et al., 2009; Kulikova et al., 2012) found gamma enhancements both in awake as well as anesthetized conditions. Another explanation could be that spontaneous gamma oscillations are altered to various extents in different cortical areas in the NRG1 mice, possibly due to differences in NMDA receptor expression across brain regions in NRG1 mutants (Newell et al., 2013). These chronic effects may also explain differences in NRG1 animals compared to acute pharmacological manipulations. For example, it is not known whether the enhancement in baseline gamma in primary somatosensory cortex after the administration of the NMDA antagonist (Hakami et al., 2009; Kulikova et al., 2012) would also be seen after chronic drug administration (compare Kittelberger et al., 2012). More generally, the magnitude of baseline gamma oscillations in our experiment is difficult to quantify robustly simply because there is little gamma activity. In contrast to the stimulation conditions, where a clear peak in the power spectrum is visible, no such peak can be observed under baseline conditions. Since the magnitude of gamma power depends on the power at lower frequencies, baseline gamma results should be interpreted with caution.

\subsection{Stimulation frequency-dependent deficits in NRG1 mice}

NRG1 mutants displayed response abnormalities that were particularly pronounced in the $8-10 \mathrm{~Hz}$ and $20-40 \mathrm{~Hz}$ ranges. One possible explanation for this pattern is that different neuronal cell populations contribute to the observed deficits in the different frequency ranges. It has previously been demonstrated that stimulating excitatory (regular spiking) neurons selectively enhances low frequency oscillations around $8 \mathrm{~Hz}$, while driving inhibitory (fast spiking) cells amplifies $40 \mathrm{~Hz}$ oscillations (Cardin et al., 2009). In light of these findings, it is possible that impaired signaling at excitatory synapses contributes mainly to the low-frequency deficits reported in the mutants, while impaired transmission at inhibitory synapses contributes more to the high-frequency deficits. In addition, changes in intrinsic excitability and membrane resonances of the neurons, as well as changes in active dendritic conductances and in synaptic connections (Castro-Alamancos and Connors, 1996; Llinas et al., 1991; Mahon and Charpier, 2012; Whittington et al., 1995) may contribute to frequency-specific deficits and alterations in baseline activity in the mutants.

Furthermore, previous research suggests that NRG1 signaling may depend on the stimulus frequency. In cultured neurons from the pontine nucleus and cerebellum, the cleavage and release of NRG1 was found to peak in response to $50 \mathrm{~Hz}$ electrical stimulation, while being smaller at 1,10 or $100 \mathrm{~Hz}$ stimulation frequencies (Ozaki et al., 2004). It is therefore conceivable that 
underexpression of NRG1 modulates the network function in a stimulation-dependent manner, in addition to more chronic effects on excitatory and inhibitory synaptic transmission. Such frequencydependent changes in NRG1 signaling might contribute to the impairments in the high-frequency range in NRG1 mice.

\subsection{Relevance to findings in schizophrenic patients}

Previous EEG and MEG studies revealed that in response to somatosensory stimulation, schizophrenic subjects display enhanced ERP amplitudes (Ikuta et al., 2007; Shagass, 1977), decreased phase locking (Teale et al., 2013), reduced phase coherence and decreased power in the 20-40 Hz band (Arnfred, 2012; Arnfred et al., 2006; Arnfred et al., 2011). Our findings in NRG1 mutants parallel these reports, suggesting that NRG1 mice display an electrophysiological endophenotype of schizophrenia linked to deficient somatosensory information processing. In addition, it is conceivable that the described endophenotype reflects more general schizophreniarelated deficits in sensory processing. In schizophrenia patients, many of the reported abnormalities in the somatosensory domain have also been found with auditory and visual stimuli in patients, including reductions in temporal precision and in 20-40 Hz power (Krishnan et al., 2005; Kwon et al., 1999; Light et al., 2006). However, some deficits may also be modality-specific, as ERP amplitudes have been found to be decreased in response to auditory and visual stimulation, as opposed to being increased during somatosensory stimulation (Ikuta et al., 2007; Shagass, 1977). Possible differences between visual, auditory and somatosensory processing have hitherto not been assessed in any type of NRG1 mutant, but they likely exist. Supporting this hypothesis, a recent study in NRG1 transmembrane-domain mutant mice revealed that NMDA receptor levels are specifically increased in somatosensory cortex but not in other sensory areas (Newell et al., 2013).

Furthermore, our results showed enhanced spiking activity and increased $40 \mathrm{~Hz}$ oscillations during baseline conditions in NRG1 mutants. These findings parallel previous reports of enhanced baseline 20-50 Hz power in schizophrenic patients (Brockhaus-Dumke et al., 2008; Itil et al., 1972; Kikuchi et al., 2011; Spencer, 2012; Venables et al., 2009), and increased 40-85 Hz power in healthy subjects after treatment with the NMDA inhibitor ketamine (Hong et al., 2010). Increased spiking activity and gamma oscillations in patients and animal models of schizophrenia have been interpreted to reflect abnormally elevated "cortical noise" that interferes with stimulus processing (Gandal et al., 2012a; Hakami et al., 2009). In support of this notion, our study described reductions in spike SNR and gamma SNR during somatosensory stimulation. In schizophrenic patients, reductions in SNR have previously been demonstrated during auditory stimulation and cognitive tasks (Krishnan et al., 2005; Winterer et al., 2000), and may be particularly pronounced in the gamma range (Gandal et al., 2012a). Deficits in SNR have been linked to sensory and cognitive 
processing deficits in schizophrenia patients (Winterer et al., 2004; Winterer and Weinberger, 2004; Winterer et al., 2000). Whether patients might display SNR reductions in the somatosensory domain, as suggested by our study, is open for future investigation.

Taken together, we suggest the following working hypothesis of NRG1 dysfunction in the somatosensory cortex (Fig. 2). By interfering with normal synapse formation of excitatory and inhibitory cells, the NRG1 mutation decreases the level of inhibition and increases the level of excitation in the neuronal network (Fig. 2, green boxes). As a result, the level of subthreshold, synaptic noise increases along with baseline firing rates and gamma oscillations. More noise, in turn, enhances neuronal responsiveness to subthreshold inputs, and the network becomes hyperexcitable. In addition, changes in the excitatory-inhibitory tuning of the network also lead to impaired stimulus-related gamma oscillations, and decreased spike SNR and spike gain (Fig. 2, orange boxes). As a consequence of altered neural processing in primary somatosensory cortex, several adverse effects on brain functioning with relevance to schizophrenia can be hypothesized (Fig. 2, blue boxes). One type of defect in the primary somatosensory cortex is the impaired encoding of sensory information in terms of timing and magnitude of the neural response, thus generating 'output errors' when the information is transmitted to target regions (see Chapter I, Section 4.1). As a consequence, downstream brain areas such as the thalamus, secondary sensory cortex or primary motor cortex, may show deficits in deciphering the neural code for certain stimulus properties coded by spike rate, e.g. stimulus frequency. In addition, incoming signals from other brain areas may be processed differentially in the somatosensory cortex due to enhanced baseline firing rates and a diminished capability to support gamma activity ('input processing deficits'). Moreover, neural deficits in somatosensory cortex may lead to inaccurate somatosensory representations and large 'prediction errors' about the sensory consequences of self-generated actions. Together, deficits in sensory input/output processing and error prediction may contribute to a range of cognitive impairments characteristic for schizophrenia, including perceptual alterations, hallucinations, and attentional deficits.

Since schizophrenia is a heterogeneous disease with multiple environmental and genetic determinants, the mechanisms underlying sensory and cognitive deficits are likely to differ among schizophrenia patients. Understanding these mechanisms and variations across the schizophrenia spectrum is instrumental in developing new therapeutic targets and treatments. In this respect, the NRG1 mouse model of schizophrenia can provide valuable insights since NRG1 polymorphisms have been particularly associated with the nondeficit type of schizophrenia (Bakker et al., 2004). The response aberrancies described in NRG1 mutants in our study might therefore be specifically related to neuronal deficits in patients falling in this category. Supporting this notion, the decrease in 
stimulus-induced $40 \mathrm{~Hz}$ power in NRG1 mutants concurs with findings from a patient study revealing reductions in $40 \mathrm{~Hz}$ induced power during auditory stimulation in non-deficit patients, while deficittype schizophrenia patients did not display these alterations (Bucci et al., 2007). Establishing a link between the NRG1 mutation, subtypes of schizophrenia and alterations in sensory, cognitive and electrophysiological measures will require further research in healthy and schizophrenic subjects carrying NRG1 mutations.

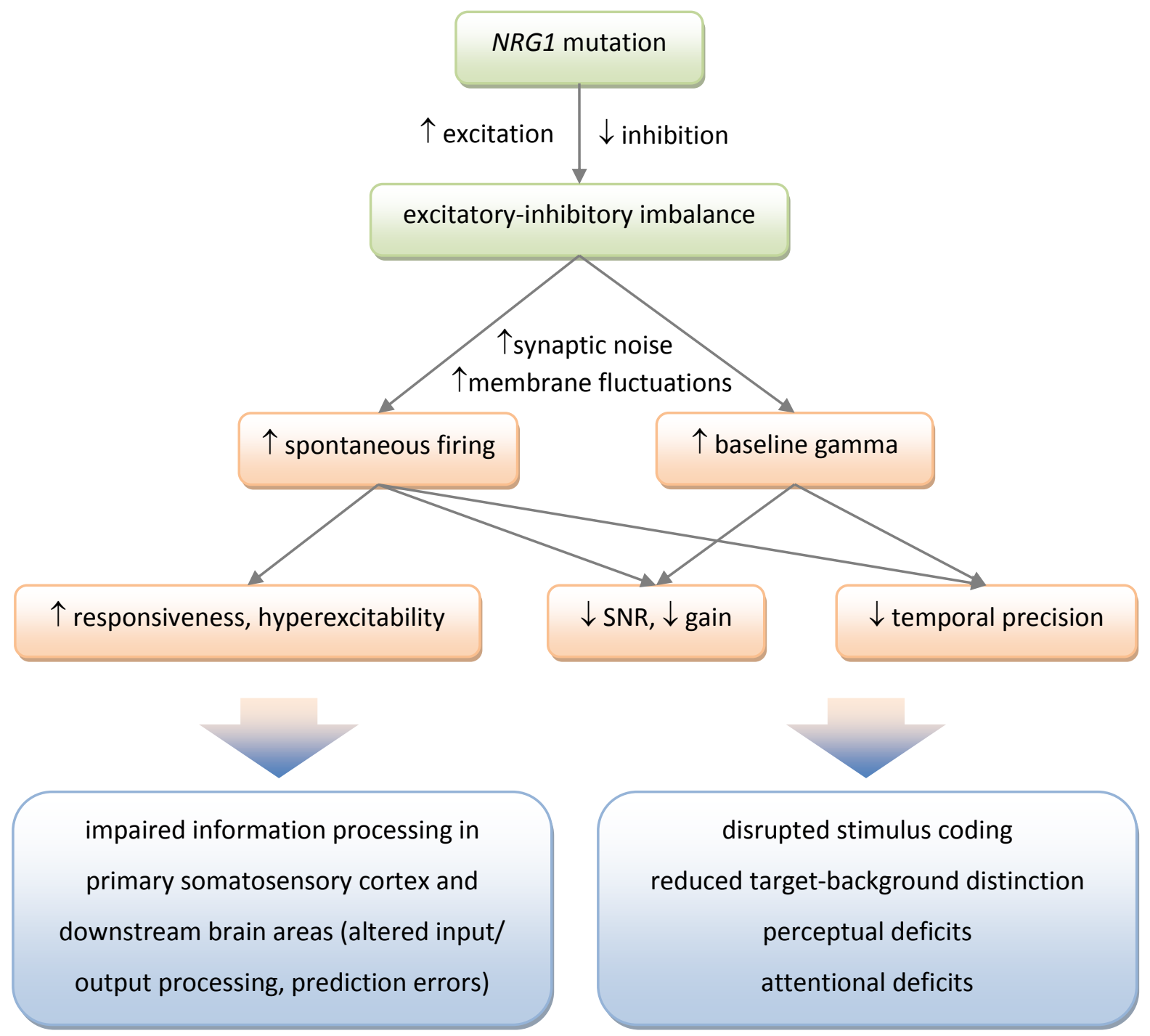

FIGURE 2. Effects of the NRG1 mutation and their relevance to schizophrenia. Green boxes summarize potential circuit mechanisms of NRG1 dysfunction suggested by previous studies, orange boxes outline findings of the present study, and blue boxes sketch out possible perceptual and cognitive implications relevant to schizophrenia. 


\section{Future research directions}

Previous studies in patients and animal models of schizophrenia have demonstrated the significance of sensory deficits in the schizophrenia pathology and started to reveal their neuronal underpinnings. However, several key questions have not been addressed so far. First, studies in patients and schizophrenia models have not established a direct link between morphological changes in primary sensory areas on the one hand, and functional deficits in sensory stimulus processing on the other hand. Furthermore, postmortem studies in patients have found morphological alterations in primary sensory cortex only in pyramidal cells (Sweet et al., 2007; Sweet et al., 2004; Sweet et al., 2009), while nothing is known about morphological changes in inhibitory interneurons that are critical in regulating pyramidal cell activity in primary sensory cortices (Bartos et al., 2007; Cardin et al., 2009; Glausier and Lewis, 2013). Moreover, deficits in excitatory and inhibitory neuronal morphology have not been investigated yet in primary sensory areas in animal models of schizophrenia. In addition to changes within primary sensory areas, recent evidence suggests that sensory information transfer between hemispheres is also disrupted in schizophrenia (Mulert et al., 2011). However, how exactly interhemispheric deficits contribute to impairments in sensory processing at the cellular level has not yet been studied either in patients or in animal models.

To answer these questions, it will be necessary to develop a better understanding of how neurons participate in intra- and interhemispheric sensory information processing, both in the healthy and in the diseased brain. To investigate these aspects, neuronal activation can be compared during unilateral and bilateral whisker stimulation in normal mice and in mouse models of schizophrenia. In addition, recent methodological advances allow researchers to correlate functional properties of neurons determined in vivo with morphological and synaptic properties determined in vitro (Lien and Scanziani, 2011). Combining theses experimental approaches will help elucidate whether morphological properties (e.g. axonal and dendritic arborization, intra-columnar versus cross-columnar innervation) and synaptic properties (e.g. excitatory versus inhibitory and facilitating versus depressing characteristics) of different cell types can explain their activity and firing pattern during sensory stimulation. In addition, the use of unilateral and bilateral whisker stimulation can reveal whether all cells or only subclasses of excitatory and inhibitory neurons participate in the integration of bilateral stimuli at the cortical level. The comparison between healthy mice and models of schizophrenia can elucidate which structural and functional changes in neurons of the somatosensory cortex contribute to deficient intra- and interhemispheric sensory processing. 


\section{REFERENCES}

Abe, Y., Namba, H., Kato, T., Iwakura, Y., and Nawa, H. (2011). Neuregulin-1 signals from the periphery regulate AMPA receptor sensitivity and expression in GABAergic interneurons in developing neocortex. J Neurosci 31, 5699-5709.

Andersson, R.H., Johnston, A., Herman, P.A., Winzer-Serhan, U.H., Karavanova, I., Vullhorst, D., Fisahn, A., and Buonanno, A. (2012). Neuregulin and dopamine modulation of hippocampal gamma oscillations is dependent on dopamine D4 receptors. Proc Natl Acad Sci U S A 109, 1311813123.

Arnfred, S.M. (2012). Proprioceptive information processing in schizophrenia. Dan Med J 59.

Arnfred, S.M., Hemmingsen, R.P., and Parnas, J. (2006). Delayed early proprioceptive information processing in schizophrenia. Br J Psychiatry 189, 558-559.

Arnfred, S.M., Morup, M., Thalbitzer, J., Jansson, L., and Parnas, J. (2011). Attenuation of beta and gamma oscillations in schizophrenia spectrum patients following hand posture perturbation. Psychiatry Res 185, 215-224.

Bakker, S.C., Hoogendoorn, M.L.C., Selten, J.P., Verduijn, W., Pearson, P.L., Sinke, R.J., and Kahn, R.S. (2004). Neuregulin 1: genetic support for schizophrenia subtypes. Mol Psychiatry 9, 1061-1063.

Barros, C.S., Calabrese, B., Chamero, P., Roberts, A.J., Korzus, E., Lloyd, K., Stowers, L., Mayford, M., Halpain, S., and Muller, U. (2009). Impaired maturation of dendritic spines without disorganization of cortical cell layers in mice lacking NRG1/ErbB signaling in the central nervous system. Proc Natl Acad Sci U S A 106, 4507-4512.

Bartos, M., Vida, I., and Jonas, P. (2007). Synaptic mechanisms of synchronized gamma oscillations in inhibitory interneuron networks. Nat Rev Neurosci 8, 45-56.

Belforte, J.E., Zsiros, V., Sklar, E.R., Jiang, Z., Yu, G., Li, Y., Quinlan, E.M., and Nakazawa, K. (2010). Postnatal NMDA receptor ablation in corticolimbic interneurons confers schizophrenia-like phenotypes. Nat Neurosci 13, 76-83.

Berman, N.J., Douglas, R.J., and Martin, K.A. (1992). GABA-mediated inhibition in the neural networks of visual cortex. Prog Brain Res 90, 443-476.

Bjarnadottir, M., Misner, D.L., Haverfield-Gross, S., Bruun, S., Helgason, V.G., Stefansson, H., Sigmundsson, A., Firth, D.R., Nielsen, B., Stefansdottir, R., et al. (2007). Neuregulin1 (NRG1) signaling through Fyn modulates NMDA receptor phosphorylation: differential synaptic function in NRG1+/- knock-outs compared with wild-type mice. J Neurosci 27, 4519-4529.

Brockhaus-Dumke, A., Mueller, R., Faigle, U., and Klosterkoetter, J. (2008). Sensory gating revisited: relation between brain oscillations and auditory evoked potentials in schizophrenia. Schizophr Res 99, 238-249.

Bucci, P., Mucci, A., Merlotti, E., Volpe, U., and Galderisi, S. (2007). Induced gamma activity and event-related coherence in schizophrenia. Clin EEG Neurosci 38, 96-104.

Cardin, J.A., Carlen, M., Meletis, K., Knoblich, U., Zhang, F., Deisseroth, K., Tsai, L.H., and Moore, C.I. (2009). Driving fast-spiking cells induces gamma rhythm and controls sensory responses. Nature 459, 663-667.

Carlen, M., Meletis, K., Siegle, J.H., Cardin, J.A., Futai, K., Vierling-Claassen, D., Ruhlmann, C., Jones, S.R., Deisseroth, K., Sheng, M., et al. (2012). A critical role for NMDA receptors in parvalbumin interneurons for gamma rhythm induction and behavior. Mol Psychiatry 17, 537-548.

Carlson, G.C., Talbot, K., Halene, T.B., Gandal, M.J., Kazi, H.A., Schlosser, L., Phung, Q.H., Gur, R.E., Arnold, S.E., and Siegel, S.J. (2011). Dysbindin-1 mutant mice implicate reduced fast-phasic inhibition as a final common disease mechanism in schizophrenia. Proc Natl Acad Sci U S A 108, 3.

Castro-Alamancos, M.A., and Connors, B.W. (1996). Cellular mechanisms of the augmenting response: short-term plasticity in a thalamocortical pathway. J Neurosci 16, 7742-7756.

Chance, F.S., Abbott, L., and Reyes, A.D. (2002). Gain modulation from background synaptic input. Neuron 35, 773-782. 
Chen, M.S., Bermingham-McDonogh, O., Danehy, F.T., Jr., Nolan, C., Scherer, S.S., Lucas, J., Gwynne, D., and Marchionni, M.A. (1994). Expression of multiple neuregulin transcripts in postnatal rat brains. J Comp Neurol 349, 389-400.

Chen, Y., Hancock, M.L., Role, L.W., and Talmage, D.A. (2010). Intramembranous valine linked to schizophrenia is required for neuregulin 1 regulation of the morphological development of cortical neurons. J Neurosci 30, 9199-9208.

Corfas, G., Rosen, K.M., Aratake, H., Krauss, R., and Fischbach, G.D. (1995). Differential expression of ARIA isoforms in the rat brain. Neuron 14, 103-115.

Deakin, I.H., Nissen, W., Law, A.J., Lane, T., Kanso, R., Schwab, M.H., Nave, K.A., Lamsa, K.P., Paulsen, O., Bannerman, D.M., et al. (2012). Transgenic overexpression of the type I isoform of neuregulin 1 affects working memory and hippocampal oscillations but not long-term potentiation. Cereb Cortex 22, 1520-1529.

Del Pino, I., Garcia-Frigola, C., Dehorter, N., Brotons-Mas, J.R., Alvarez-Salvado, E., Martinez de Lagran, M., Ciceri, G., Gabaldon, M.V., Moratal, D., Dierssen, M., et al. (2013). Erbb4 deletion from fast-spiking interneurons causes schizophrenia-like phenotypes. Neuron 79, 1152-1168.

Destexhe, A., and Pare, D. (1999). Impact of network activity on the integrative properties of neocortical pyramidal neurons in vivo. J Neurophysiol 81, 1531-1547.

Diamond, M.E., and Arabzadeh, E. (2013). Whisker sensory system - from receptor to decision. Prog Neurobiol 103, 28-40.

Douglas, R.J., and Martin, K.A. (1991). A functional microcircuit for cat visual cortex. J Physiol 440, 735-769.

Ehrlichman, R.S., Gandal, M.J., Maxwell, C.R., Lazarewicz, M.T., Finkel, L.H., Contreras, D., Turetsky, B.I., and Siegel, S.J. (2009). N-methyl-d-aspartic acid receptor antagonist-induced frequency oscillations in mice recreate pattern of electrophysiological deficits in schizophrenia. Neuroscience 158, 705-712.

Fazzari, P., Paternain, A.V., Valiente, M., Pla, R., Luján, R., Lloyd, K., Lerma, J., Marín, O., and Rico, B. (2010). Control of cortical GABA circuitry development by Nrg1 and ErbB4 signalling. Nature 464, 1376-1380.

Featherstone, R.E., V, M.T.-L., Suh, J.D., Lin, R., Lucki, I., and Siegel, S.J. (2013). Electrophysiological and behavioral responses to ketamine in mice with reduced Akt1 expression. Psychopharmacology (Berl) 227, 639-649.

Feldmeyer, D., Brecht, M., Helmchen, F., Petersen, C.C., Poulet, J.F., Staiger, J.F., Luhmann, H.J., and Schwarz, C. (2013). Barrel cortex function. Prog Neurobiol 103, 3-27.

Fisahn, A., Neddens, J., Yan, L., and Buonanno, A. (2009). Neuregulin-1 modulates hippocampal gamma oscillations: implications for schizophrenia. Cereb Cortex 19, 612-618.

Fox, K. (2008). Barrel cortex (Cambridge University Press).

Gandal, M.J., Edgar, J.C., Klook, K., and Siegel, S.J. (2012a). Gamma synchrony: towards a translational biomarker for the treatment-resistant symptoms of schizophrenia. Neuropharmacology 62, 1504-1518.

Gandal, M.J., Sisti, J., Klook, K., Ortinski, P.I., Leitman, V., Liang, Y., Thieu, T., Anderson, R., Pierce, R.C., Jonak, G., et al. (2012b). GABAB-mediated rescue of altered excitatory-inhibitory balance, gamma synchrony and behavioral deficits following constitutive NMDAR-hypofunction. Transl Psychiatry 17, 69.

Garcia, R.A., Vasudevan, K., and Buonanno, A. (2000). The neuregulin receptor ErbB-4 interacts with PDZ-containing proteins at neuronal synapses. Proc Natl Acad Sci U S A 97, 3596-3601.

Glausier, J.R., and Lewis, D.A. (2013). Dendritic spine pathology in schizophrenia. Neuroscience 251, 90-107.

Gratton, A., Hoffer, B.J., and Freedman, R. (1987). Electrophysiological effects of phencyclidine in the medial prefrontal cortex of the rat. Neuropharmacology 26, 1275-1283.

Gu, Z., Jiang, Q., Fu, A.K., Ip, N.Y., and Yan, Z. (2005). Regulation of NMDA receptors by neuregulin signaling in prefrontal cortex. J Neurosci 25, 4974-4984. 
Hakami, T., Jones, N.C., Tolmacheva, E.A., Gaudias, J., Chaumont, J., Salzberg, M., O'Brien, T.J., and Pinault, D. (2009). NMDA receptor hypofunction leads to generalized and persistent aberrant gamma oscillations independent of hyperlocomotion and the state of consciousness. PLoS One 4, e6755.

Ho, N., and Destexhe, A. (2000). Synaptic background activity enhances the responsiveness of neocortical pyramidal neurons. J Neurophysiol 84, 1488-1496.

Holt, G.R., Softky, W.R., Koch, C., and Douglas, R.J. (1996). Comparison of discharge variability in vitro and in vivo in cat visual cortex neurons. J Neurophysiol 75, 1806-1814.

Homayoun, H., and Moghaddam, B. (2007). NMDA receptor hypofunction produces opposite effects on prefrontal cortex interneurons and pyramidal neurons. J Neurosci 27, 11496-11500.

Hong, L.E., Summerfelt, A., Buchanan, R.W., O'Donnell, P., Thaker, G.K., Weiler, M.A., and Lahti, A.C. (2010). Gamma and delta neural oscillations and association with clinical symptoms under subanesthetic ketamine. Neuropsychopharmacology 35, 632-640.

Huang, Y.Z., Won, S., Ali, D.W., Wang, Q., Tanowitz, M., Du, Q.S., Pelkey, K.A., Yang, D.J., Xiong, W.C., Salter, M.W., et al. (2000). Regulation of neuregulin signaling by PSD-95 interacting with ErbB4 at CNS synapses. Neuron 26, 443-455.

Hunt, M.J., Falinska, M., and Kasicki, S. (2010). Local injection of MK801 modifies oscillatory activity in the nucleus accumbens in awake rats. J Psychopharmacol 24, 931-941.

Hunt, M.J., Falinska, M., Leski, S., Wojcik, D.K., and Kasicki, S. (2011). Differential effects produced by ketamine on oscillatory activity recorded in the rat hippocampus, dorsal striatum and nucleus accumbens. J Psychopharmacol 25, 808-821.

Hunt, M.J., and Kasicki, S. (2013). A systematic review of the effects of NMDA receptor antagonists on oscillatory activity recorded in vivo. J Psychopharmacol 27, 972-986.

Ikuta, T., Furuta, N., Kihara, S., Okura, M., Nagamine, I., Nakayama, H., Ishimoto, Y., Kaneda, Y., Tomotake, M., Izaki, Y., et al. (2007). Differences in waveforms of cerebral evoked potentials among healthy subjects, schizophrenics, manic-depressives and epileptics. J Med Invest 54, 303315.

Itil, T.M., Saletu, B., and Davis, S. (1972). EEG findings in chronic schizophrenics based on digital computer period analysis and analog power spectra. Biol Psychiatry 5, 1-13.

Jackson, M.E., Homayoun, H., and Moghaddam, B. (2004). NMDA receptor hypofunction produces concomitant firing rate potentiation and burst activity reduction in the prefrontal cortex. Proc Natl Acad Sci U S A 101, 8467-8472.

Jiang, L., Emmetsberger, J., Talmage, D.A., and Role, L.W. (2013). Type III neuregulin 1 is required for multiple forms of excitatory synaptic plasticity of mouse cortico-amygdala circuits. J Neurosci 33, 9655-9666.

Kato, T., Kasai, A., Mizuno, M., Fengyi, L., Shintani, N., Maeda, S., Yokoyama, M., Ozaki, M., and Nawa, H. (2010). Phenotypic characterization of transgenic mice overexpressing neuregulin-1. PLoS One 5, e14185.

Kikuchi, M., Hashimoto, T., Nagasawa, T., Hirosawa, T., Minabe, Y., Yoshimura, M., Strik, W., Dierks, T., and Koenig, T. (2011). Frontal areas contribute to reduced global coordination of resting-state gamma activities in drug-naive patients with schizophrenia. Schizophr Res 130, 187-194.

Kittelberger, K., Hur, E.E., Sazegar, S., Keshavan, V., and Kocsis, B. (2012). Comparison of the effects of acute and chronic administration of ketamine on hippocampal oscillations: relevance for the NMDA receptor hypofunction model of schizophrenia. Brain Struct Funct 217, 395-409.

Kocsis, B. (2012). Differential role of NR2A and NR2B subunits in N-Methyl-D-Aspartate receptor antagonist-induced aberrant cortical gamma oscillations. Biol Psychiatry 71, 987-995.

Krishnan, G.P., Vohs, J.L., Hetrick, W.P., Carroll, C.A., Shekhar, A., Bockbrader, M.A., and O'Donnell, B.F. (2005). Steady state visual evoked potential abnormalities in schizophrenia. Clin Neurophysiol 116, 614-624. 
Kulikova, S.P., Tolmacheva, E.A., Anderson, P., Gaudias, J., Adams, B.E., Zheng, T., and Pinault, D. (2012). Opposite effects of ketamine and deep brain stimulation on rat thalamocortical information processing. Eur J Neurosci 36, 3407-3419.

Kwon, J.S., O'Donnell, B.F., Wallenstein, G.V., Greene, R.W., Hirayasu, Y., Nestor, P.G., Hasselmo, M.E., Potts, G.F., Shenton, M.E., and McCarley, R.W. (1999). Gamma frequency-range abnormalities to auditory stimulation in schizophrenia. Arch Gen Psychiatry 56, 1001-1005.

Kwon, O.B., Longart, M., Vullhorst, D., Hoffman, D.A., and Buonanno, A. (2005). Neuregulin-1 reverses long-term potentiation at CA1 hippocampal synapses. J Neurosci 25, 9378-9383.

Law, A.J., Shannon Weickert, C., Hyde, T.M., Kleinman, J.E., and Harrison, P.J. (2004). Neuregulin-1 (NRG-1) mRNA and protein in the adult human brain. Neuroscience 127, 125-136.

Lazarewicz, M.T., Ehrlichman, R.S., Maxwell, C.R., Gandal, M.J., Finkel, L.H., and Siegel, S.J. (2010). Ketamine modulates theta and gamma oscillations. J Cogn Neurosci 22, 1452-1464.

Leung, L.W. (1985). Spectral analysis of hippocampal EEG in the freely moving rat: effects of centrally active drugs and relations to evoked potentials. Electroencephalogr Clin Neurophysiol 60, 65-77.

Li, K.X., Lu, Y.M., Xu, Z.H., Zhang, J., Zhu, J.M., Zhang, J.M., Cao, S.X., Chen, X.J., Chen, Z., Luo, J.H., et al. (2011). Neuregulin 1 regulates excitability of fast-spiking neurons through Kv1.1 and acts in epilepsy. Nat Neurosci 15, 267-273.

Lien, A.D., and Scanziani, M. (2011). In vivo labeling of constellations of functionally identified neurons for targeted in vitro recordings. Front Neural Circuits 5, 16.

Light, G.A., Hsu, J.L., Hsieh, M.H., Meyer-Gomes, K., Sprock, J., Swerdlow, N.R., and Braff, D.L. (2006). Gamma band oscillations reveal neural network cortical coherence dysfunction in schizophrenia patients. Biol Psychiatry 60, 1231-1240.

Llinas, R.R., Grace, A.A., and Yarom, Y. (1991). In vitro neurons in mammalian cortical layer 4 exhibit intrinsic oscillatory activity in the $10-$ to $50-\mathrm{Hz}$ frequency range. Proc Natl Acad Sci U S A 88, 897901.

Lodge, D.J., Behrens, M.M., and Grace, A.A. (2009). A loss of parvalbumin-containing interneurons is associated with diminished oscillatory activity in an animal model of schizophrenia. J Neurosci 29, 2344-2354.

Lubke, J., and Feldmeyer, D. (2007). Excitatory signal flow and connectivity in a cortical column: focus on barrel cortex. Brain Struct Funct 212, 3-17.

$\mathrm{Ma}$, J., and Leung, L.S. (2000). Relation between hippocampal gamma waves and behavioral disturbances induced by phencyclidine and methamphetamine. Behav Brain Res 111, 1-11.

Ma, J., and Leung, L.S. (2007). The supramammillo-septal-hippocampal pathway mediates sensorimotor gating impairment and hyperlocomotion induced by MK-801 and ketamine in rats. Psychopharmacology (Berl) 191, 961-974.

Mahon, S., and Charpier, S. (2012). Bidirectional plasticity of intrinsic excitability controls sensory inputs efficiency in layer 5 barrel cortex neurons in vivo. J Neurosci 32, 11377-11389.

Marquis, K.L., Paquette, N.C., Gussio, R.P., and Moreton, J.E. (1989). Comparative electroencephalographic and behavioral effects of phencyclidine, (+)-SKF-10,047 and MK-801 in rats. J Pharmacol Exp Ther 251, 1104-1112.

Mei, L., and Xiong, W.C. (2008). Neuregulin 1 in neural development, synaptic plasticity and schizophrenia. Nat Rev Neurosci 9, 437-452.

Mulert, C., Kirsch, V., Pascual-Marqui, R., McCarley, R.W., and Spencer, K.M. (2011). Long-range synchrony of gamma oscillations and auditory hallucination symptoms in schizophrenia. Int $J$ Psychophysiol 79, 55-63.

Murray, J.D., Anticevic, A., Gancsos, M., Ichinose, M., Corlett, P.R., Krystal, J.H., and Wang, X.J. (2012). Linking microcircuit dysfunction to cognitive impairment: effects of disinhibition associated with schizophrenia in a cortical working memory model. Cereb Cortex 29, 29.

Nason, M.W., Jr., Adhikari, A., Bozinoski, M., Gordon, J.A., and Role, L.W. (2011). Disrupted activity in the hippocampal-accumbens circuit of type III neuregulin 1 mutant mice. Neuropsychopharmacology 36, 488-496. 
Newell, K.A., Karl, T., and Huang, X.F. (2013). A neuregulin 1 transmembrane domain mutation causes imbalanced glutamatergic and dopaminergic receptor expression in mice. Neuroscience $248,670-680$.

Nicolás, M.J., López-Azcárate, J., Valencia, M., Alegre, M., Pérez-Alcázar, M., Iriarte, J., and Artieda, J. (2011). Ketamine-induced oscillations in the motor circuit of the rat basal ganglia. PLoS One 6, e21814.

Olszewski, M., Dolowa, W., Matulewicz, P., Kasicki, S., and Hunt, M.J. (2013). NMDA receptor antagonist-enhanced high frequency oscillations: are they generated broadly or regionally specific? Eur Neuropsychopharmacol 23, 1795-1805.

Ozaki, M., Itoh, K., Miyakawa, Y., Kishida, H., and Hashikawa, T. (2004). Protein processing and releases of neuregulin-1 are regulated in an activity-dependent manner. J Neurochem 91, 176188.

Palenicek, T., Fujakova, M., Brunovsky, M., Balikova, M., Horacek, J., Gorman, I., Tyls, F., Tislerova, B., Sos, P., Bubenikova-Valesova, V., et al. (2011). Electroencephalographic spectral and coherence analysis of ketamine in rats: correlation with behavioral effects and pharmacokinetics. Neuropsychobiology 63, 202-218.

Pinault, D. (2008). N-methyl d-aspartate receptor antagonists ketamine and MK-801 induce wakerelated aberrant gamma oscillations in the rat neocortex. Biol Psychiatry 63, 730-735.

Saunders, J.A., Gandal, M.J., and Siegel, S.J. (2012). NMDA antagonists recreate signal-to-noise ratio and timing perturbations present in schizophrenia. Neurobiol Dis 46, 93-100.

Shadlen, M.N., and Newsome, W.T. (1994). Noise, neural codes and cortical organization. Curr Opin Neurobiol 4, 569-579.

Shagass, C. (1977). Early evoked potentials. Schizophr Bull 3, 80-92.

Sigurdsson, T., Stark, K.L., Karayiorgou, M., Gogos, J.A., and Gordon, J.A. (2010). Impaired hippocampal-prefrontal synchrony in a genetic mouse model of schizophrenia. Nature 464, 763767.

Softky, W.R., and Koch, C. (1993). The highly irregular firing of cortical cells is inconsistent with temporal integration of random EPSPs. J Neurosci 13, 334-350.

Sohal, V.S., Zhang, F., Yizhar, O., and Deisseroth, K. (2009). Parvalbumin neurons and gamma rhythms enhance cortical circuit performance. Nature 459, 698-702.

Spencer, K.M. (2012). Baseline gamma power during auditory steady-state stimulation in schizophrenia. Front Hum Neurosci 5, 190.

Sweet, R.A., Bergen, S.E., Sun, Z., Marcsisin, M.J., Sampson, A.R., and Lewis, D.A. (2007). Anatomical evidence of impaired feedforward auditory processing in schizophrenia. Biol Psychiatry 61, 854864.

Sweet, R.A., Bergen, S.E., Sun, Z., Sampson, A.R., Pierri, J.N., and Lewis, D.A. (2004). Pyramidal cell size reduction in schizophrenia: evidence for involvement of auditory feedforward circuits. Biol Psychiatry 55, 1128-1137.

Sweet, R.A., Henteleff, R.A., Zhang, W., Sampson, A.R., and Lewis, D.A. (2009). Reduced dendritic spine density in auditory cortex of subjects with schizophrenia. Neuropsychopharmacology 34 , 374-389.

Teale, P., Pasko, B., Collins, D., Rojas, D., and Reite, M. (2013). Somatosensory timing deficits in schizophrenia. Psychiatry Res 212, 73-78.

Ting, A.K., Chen, Y., Wen, L., Yin, D.M., Shen, C., Tao, Y., Liu, X., Xiong, W.C., and Mei, L. (2011). Neuregulin 1 promotes excitatory synapse development and function in GABAergic interneurons. J Neurosci 31, 15-25.

Venables, N.C., Bernat, E.M., and Sponheim, S.R. (2009). Genetic and disorder-specific aspects of resting state EEG abnormalities in schizophrenia. Schizophr Bull 35, 826-839.

Vogels, T.P., and Abbott, L.F. (2007). Gating deficits in model networks: a path to schizophrenia? Pharmacopsychiatry 40, 573-77. 
Vohs, J.L., Chambers, R.A., O'Donnell, B.F., Krishnan, G.P., and Morzorati, S.L. (2012). Auditory steady state responses in a schizophrenia rat model probed by excitatory/inhibitory receptor manipulation. Int J Psychophysiol 86, 136-142.

Volman, V., Behrens, M.M., and Sejnowski, T.J. (2011). Downregulation of parvalbumin at cortical GABA synapses reduces network gamma oscillatory activity. J Neurosci 31, 18137-18148.

Wen, L., Lu, Y.-S., Zhu, X.-H., Li, X.-M., Woo, R.-S., Chen, Y.-J., Yin, D.-M., Lai, C., Terry, A.V., and Vazdarjanova, A. (2010). Neuregulin 1 regulates pyramidal neuron activity via ErbB4 in parvalbumin-positive interneurons. Proc Natl Acad Sci U S A 107, 1211-1216.

Whittington, M.A., Traub, R.D., and Jefferys, J.G. (1995). Synchronized oscillations in interneuron networks driven by metabotropic glutamate receptor activation. Nature 373, 612-615.

Winterer, G., Coppola, R., Goldberg, T.E., Egan, M.F., Jones, D.W., Sanchez, C.E., and Weinberger, D.R. (2004). Prefrontal broadband noise, working memory, and genetic risk for schizophrenia. Am J Psychiatry 161, 490-500.

Winterer, G., and Weinberger, D.R. (2004). Genes, dopamine and cortical signal-to-noise ratio in schizophrenia. Trends Neurosci 27, 683-690.

Winterer, G., Ziller, M., Dorn, H., Frick, K., Mulert, C., Wuebben, Y., Herrmann, W.M., and Coppola, R. (2000). Schizophrenia: reduced signal-to-noise ratio and impaired phase-locking during information processing. Clin Neurophysiol 111, 837-849.

Woo, R.S., Li, X.M., Tao, Y., Carpenter-Hyland, E., Huang, Y.Z., Weber, J., Neiswender, H., Dong, X.P., $\mathrm{Wu}, \mathrm{J.}$, Gassmann, M., et al. (2007). Neuregulin-1 enhances depolarization-induced GABA release. Neuron 54, 599-610.

Wood, J., Kim, Y., and Moghaddam, B. (2012). Disruption of prefrontal cortex large scale neuronal activity by different classes of psychotomimetic drugs. J Neurosci 32, 3022-3031.

Zhang, Y., Yoshida, T., Katz, D.B., and Lisman, J.E. (2012). NMDAR antagonist action in thalamus imposes delta oscillations on the hippocampus. J Neurophysiol 107, 3181-3189. 


\section{Samenvatting}

Schizofrenie is een psychiatrische stoornis die naar schatting 0.7-1 \% van de bevolking treft. Cognitieve symptomen zoals wanen, hallucinaties, lusteloosheid en het verlies van concentratie en geheugen zijn de hoofdkenmerken van deze ziekte. Steeds meer studies suggereren echter dat ook sensorische en perceptuele tekorten een belangrijke rol spelen. Neurowetenschappelijk onderzoek toonde al veranderingen in de hersenactiviteit van patiënten aan tijdens auditieve, visuele of tactiele stimulatie, met name wanneer de stimuli werden gepresenteerd met frequenties van 20-40 Hz. De bevindingen lieten verschillende effecten zien, met name veranderingen in gamma $(20-40 \mathrm{~Hz})$ hersengolven en in de temporele precisie en amplitude van de elektrische hersenactiviteit. Daarnaast bleek uit het onderzoek dat schizofrene patiënten een verhoogde gamma-activiteit tijdens de rust-metingen (zonder stimulatie) lieten zien.

Dit proefschrift tracht de kennis te vergroten over de neuronale mechanismen die ten grondslag liggen aan de verstoorde sensorische verwerking bij schizofrenie. Omdat cellulair onderzoek in patiënten niet mogelijk is, werd gebruik gemaakt van genetisch-gemanilpuleerde knock-out muizen. Heterozygote Neuregulin 1 (NRG1) knockout muizen zijn een geschikt model voor schizofrenie vanwege hun op schizofrenie gelijkend gedrag. Het is bekend dat veranderingen in het NRG1 gen bij de mens het risico op schizofrenie verhogen. Om sensorische informatieverwerking in muizen te onderzoeken is het tactiele (somatosensorische) systeem het meest geschikt, omdat muizen hun omgeving vooral met hun snorharen waarnemen. Snorharen worden actief naar voren en naar achteren bewogen met een frequentie van $5-20 \mathrm{~Hz}$ om bepaalde objecten te verkennen. Daarnaast vibreren de snorharen passief op 50-200 Hz tijdens contact met een object. Informatie van de snorharen wordt verwerkt in de primaire somatosensorische ('barrel') cortex. Eerdere studies met ratten suggereerden dat barrel-cortexactiviteit afhankelijk is van de frequenties waarmee snorharen worden gestimuleerd. Deze frequentie-specifieke stimulatie is een geschikt paradigma om somatosensorische hersenactiviteit in normale en knockout muizen te kunnen vergelijken.

Omdat deze frequentie-specifieke barrel-cortexactiviteit nog niet bekend is in muizen, was het eerste doel om deze activiteit in een pilotstudie met C57/BL6 (controle) muizen te karakteriseren (hoofdstuk 3). Muizen werden verdoofd met isofloran en fentanyl, en de cellulaire activiteit werd afgeleid via meetelektrodes in de lagen II-IV van de barrel-cortex. Snorharen werden gestimuleerd met constante luchtstootjes op frequenties van 1 tot $70 \mathrm{~Hz}$. Vervolgens werden de actiepotentialen ('spikes') en lokale oscillaties in de gamma band $(20-40 \mathrm{~Hz})$ in de barrel-cortex geanalyseerd. De cellulaire responsen vertoonden een verhoogd aantal spikes en een hoge temporele precisie van spikes tijdens de 8-10 $\mathrm{Hz}$ stimulatie ten opzichte van de andere stimulatie-frequenties. Deze 
bevindingen duiden op een neuronaal resonantie-effect voor frequenties die belangrijk zijn voor de tactiele exploratie van objecten. Bovendien toonden cellulaire responsen een sterkere adaptatie op hogere stimulatie frequenties. Op zeer hoge frequenties $(50-70 \mathrm{~Hz})$ werden gamma oscillaties geïnduceerd. Dit kan betekenen dat het gamma-ritme een belangrijke rol speelt bij het coderen van sensorische informatie in de barrel-cortex.

Het tweede doel was om resonantie-effecten in NRG1 muizen te bestuderen (hoofdstuk 4). Eerder onderzoek suggereerde verminderde resonantie-effecten tijdens $8 \mathrm{~Hz}$ en $40 \mathrm{~Hz}$ sensorische stimulatie bij schizofrene patiënten. Door gebruik te maken van het experimentele paradigma en de stimuli (1-15 Hz) van de pilotstudie, werden de volgende bevindingen in NRG1 muizen geconstateerd. De neuronale activiteit was zowel tijdens stimulatie, en in de baseline-condities zonder stimulatie, verhoogd. Dit leidde tot een reductie van de signaal-ruisverhouding in de mutanten vergeleken met de normale muizen. Ook de temporele precisie van spikes was verlaagd, en de responsen vertoonden minder adaptatie. Deze effecten waren het meest duidelijk in de $8 \mathrm{~Hz}$ conditie, wat als tekort in het resonantie-effect in mutanten opgevat kan worden. Bovendien werden veranderingen in de response-adaptatie geobserveerd.

De analyse van veranderingen in neuronale responsen op hoge frequenties $(20-70 \mathrm{~Hz})$ in NRG1 muizen was het derde doel van de onderzoek (hoofdstuk 5). De resultaten onthulden een verminderde toename van spikes als functie van frequentie in mutanten, wat kan wijzen op een verlies van codeerefficiëntie. Verder was de temporele precisie van spikes verlaagd in de $20-40 \mathrm{~Hz}-$ condities, en gamma-oscillaties waren verminderd in de $70 \mathrm{~Hz}$ conditie. Bovendien toonden de mutanten een verhoogde gamma-activiteit $(40 \mathrm{~Hz})$ tijdens de rust-metingen. Deze resultaten lijken op de bevindingen in schizofrenie patiënten en tonen een vergaande invloed van de NRG1 mutatie op de sensorische informatieverweking aan.

Samengevat laten de bevindingen van deze studies zien dat barrel-cortexactiviteit in muizen, net als in ratten, afhankelijk is van de stimulatie frequenties van de snorharen, en dat deze activiteit duidelijk veranderdt is in NRG1 muizen. De resultaten zijn in overeenstemming met de rol van NRG1 in het balanceren van stimulerende en remmende neuronaal activiteit. Deze bevindingen ondersteunen eerdere studies over neuronale veranderingen in schizofreniemodellen die gebaseerd zijn op de manipulatie van excitatorische of inhibitoire hersenactiviteit, en breiden deze verder uit. De gelijkenis van de sensorische activiteitsveranderingen in de NRG1 muizen en schizofrenie patiënten suggereert dat de mutanten een elektrofysiologische endofenotype voor deze stoornis laten zien. Het is mogelijk dat abnormale zintuiglijke waarnemingen van schizofreniepatiënten gepaard gaan met veranderingen in de cellulair activiteit, zowel tijdens rust als tijdens sensorische stimulatie. 


\section{List of abbreviations}

\begin{tabular}{|c|c|}
\hline AMPA & alpha-amino-3-hydroxy-5-methyl-4-isoxazole propionic acid \\
\hline ANOVA & analysis of variance \\
\hline$B L$ & baseline \\
\hline BOLD & blood-oxygen-level dependent \\
\hline CSD & cysteine-rich domain \\
\hline df & degrees of freedom \\
\hline DNA & deoxyribonucleic acid \\
\hline EEG & electroencephalography \\
\hline e.g. & for example (Latin: exempli gratia) \\
\hline EGF & epidermal growth factor \\
\hline EMG & electromyography \\
\hline ERK & extracellular signal-regulated kinase \\
\hline ERO & event-related oscillation \\
\hline ERP & event-related potential \\
\hline et al. & and others (Latin: et alii) \\
\hline Fig. & figure \\
\hline fMRI & functional magnetic resonance imaging \\
\hline GABA & gamma-aminobutyric acid \\
\hline G-G & Greenhouse-Geisser \\
\hline i.e. & that is (Latin: id est) \\
\hline $\lg$ & immunoglobulin \\
\hline i.p. & intraperitoneal \\
\hline IQ & intelligence quotient \\
\hline LFP & local field potential \\
\hline MEG & magnetoencephalography \\
\hline MEK & mitogen-activated protein kinase/ ERK kinase \\
\hline MFR & mean firing rate \\
\hline MMN & mismatch negativity \\
\hline MUA & multi unit activity \\
\hline $\mathrm{n}$ & number \\
\hline NMDA & $\mathrm{N}$-methyl-D-aspartate \\
\hline NRG1 & Neuregulin 1 \\
\hline
\end{tabular}




$\begin{array}{ll}\text { n.S. } & \text { not significant } \\ \text { PCR } & \text { polymerase chain reaction } \\ \text { PET } & \text { positron emission tomography } \\ \text { PI3K } & \text { phosphatidylinositol-4,5-bisphosphate 3-kinase } \\ \text { PMBS } & \text { postero-medial barrel subfield } \\ \text { PPI } & \text { prepulse inhibition } \\ \text { PSD95 } & \text { postsynaptic density protein 95 } \\ \text { PSTH } & \text { peri-stimulus time histograms } \\ \text { RM } & \text { repeated measures } \\ \text { SD } & \text { standard deviation } \\ \text { SE } & \text { standard error } \\ \text { SNR } & \text { signal-to-noise ratio } \\ \text { STIM } & \text { stimulation } \\ \text { SUA } & \text { single unit activity } \\ \text { TM } & \text { transmembrane } \\ \text { WT } & \text { wildtype }\end{array}$




\section{Acknowledgements}

I am grateful to my supervisors Dirk Feldmeyer, Ted Abel and Diego Contreras, who have supported me throughout my PhD with their scientific expertise and enthusiasm for research. You provided me with the resources and independence to follow my interests, to explore new techniques, to fail and to succeed. Without your faith in my abilities, this research would not have been possible. My special thanks also goes to Thomas Bessaih for sharing his ideas and skills with me, and for many inspiring discussions. Your significant contributions to the experimental design, anesthesia and recording setup as well as the data analysis are of fundamental importance to this work. I also thank Dirk, Ted, and Thomas for giving helpful feedback on the manuscript. Furthermore, I would like to thank Steve Siegel and Ted Brodkin for providing me with the Neuregulin 1 mice, and Charles Kenworthy from the Ted Abel lab for breeding them.

During my PhD, I was fortunate to work in several labs, each of which taught me a different set of skills and techniques. I therefore would like to thank the members of the Feldmeyer, Abel and Contreras labs for their support and patience in answering my many questions. In particular, I want to express my gratitude to Hannah Schoch from the Ted Abel lab for always offering help, ideas and a great deal of optimism - and even a hug if needed.

My stay abroad and the collaboration with the University of Pennsylvania have been made possible by the graduate school IRTG 1328 at RWTH Aachen. I am very thankful for this opportunity, and for the fruitful exchanges between clinical and fundamental researchers at the yearly winter school meetings.

Furthermore, I wish to thank Peter De Weerd and Bernadette Jansma for their guidance and support for the last important steps towards my graduation. I feel grateful to have benefited from the socially and scientifically rich environment in your department during the research master. Bernadette and Peter, both of you believed in me from day one we met, and without your faith in me I would probably have stayed in political science, rather than following my passion for neuroscience. In addition, I want to thank Peter for his comments on the thesis manuscript, and Judith Peters and Job van den Hurk for their feedback on the Dutch summary.

My greatest thanks go to my family. I am indebted to my parents for their unconditional love and trust in me. Even though my mom cannot witness this achievement anymore, she deserves most appreciation for planting the seeds for this success. Last, but certainly not least, I want to thank my husband for his love and care during the ups and downs of the past years. You have successfully endured long nights of experiments, salsa dancing and baby crying, for which you deserve a special honorary degree (with distinction, of course). 


\section{Curriculum vitae}

Claudia Barz (maiden name: Schreiner) was born in Rudolstadt, Thüringen on November 29, 1984. In 2003 she graduated from high school 'Gymnasium Fridericianum' in Rudolstadt. She received the Bachelor of Arts (cum laude) in European Studies at the Faculty of Arts and Social Sciences at Maastricht University in 2007. Subsequently, she enrolled for the Research Master in Cognitive Neuroscience at the Faculty of Psychology and Neuroscience at Maastricht University, where she attained the Master of Science degree (cum laude) in Cognitive Neuroscience, Neuropsychology and Psychopathology in 2009. From 2009 until 2013, Claudia was a stipend holder at the graduate school IRTG 1328 Schizophrenia and Autism at the RWTH Aachen. During her PhD, she performed in vitro patch clamp recordings in the lab of Dirk Feldmeyer (Research Centre Jülich, Germany), biochemical and molecular work in the lab of Ted Abel (University of Pennsylvania, USA), and in vivo mouse recordings in the lab of Diego Contreras (University of Pennsylvania, USA). The experimental work presented in this thesis was conducted during her stay as visiting scholar and associate at the University of Pennsylvania in 2010 and 2011. Her position as an IRTG stipend holder was followed by an appointment as a researcher in the lab of Dirk Feldmeyer at the Research Centre Jülich in September 2013, and the post-doc position in the labs of Florent Haiss and Dirk Feldmeyer at RWTH Aachen University in March 2014. 